\title{
3D seismic attribute-assisted analysis of microseismic events in the Marcellus Shale
}

Ariel Kelton Hart

Follow this and additional works at: https://researchrepository.wvu.edu/etd

\section{Recommended Citation}

Hart, Ariel Kelton, "3D seismic attribute-assisted analysis of microseismic events in the Marcellus Shale" (2015). Graduate Theses, Dissertations, and Problem Reports. 5774.

https://researchrepository.wvu.edu/etd/5774

This Thesis is protected by copyright and/or related rights. It has been brought to you by the The Research Repository @ WVU with permission from the rights-holder(s). You are free to use this Thesis in any way that is permitted by the copyright and related rights legislation that applies to your use. For other uses you must obtain permission from the rights-holder(s) directly, unless additional rights are indicated by a Creative Commons license in the record and/ or on the work itself. This Thesis has been accepted for inclusion in WVU Graduate Theses, Dissertations, and Problem Reports collection by an authorized administrator of The Research Repository @ WVU. For more information, please contact researchrepository@mail.wvu.edu. 


\title{
3D Seismic Attribute-Assisted Analysis of Microseismic Events in the Marcellus Shale
}

\author{
Ariel Kelton Hart \\ Thesis submitted to the \\ Eberly College of Arts and Sciences \\ At West Virginia University \\ In partial fulfillment of requirements \\ For the degree of \\ Master of Science \\ In \\ Geology \\ Thomas Wilson, Ph. D., Chair \\ Jaime Toro, Ph. D. \\ Peter Sullivan \\ Valerie Smith \\ Department of Geology and Geography \\ Morgantown, West Virginia \\ 2015
}

Keywords: Marcellus Shale, Utica Shale, Microseismic, Hydraulic

Fracturing

Copyright 2015 Ariel Hart 


\title{
Abstract \\ 3D Seismic Attribute-Assisted Analysis of Microseismic Events within the
}

\author{
Marcellus Shale
}

\begin{abstract}
Ariel K. Hart
Microseismic monitoring is often used during the process of oil and gas exploitation to monitor seismicity that may be triggered by hydraulic fracturing, a common practice in the Appalachian Basin. Anthropogenically-induced minor upward fracture growth is not uncommon in the Marcellus shale; however, in the area of study, significant microseismic activity was registered above the target zone. In order to ascertain whether out-of-zone growth might have been predictable and identify which areas are more likely to experience brittle failure first, 3D seismic and microseismic data were analyzed with a focus on better understanding variations in the acoustic properties associated with unconventional naturally fractured reservoirs.

Ant Tracking was used to identify areas of increased local seismic discontinuity, as these areas are generally more intensely deformed and may represent zones of increased fracture intensity. Ant Tracking results reveal discontinuities in the Marcellus are oriented approximately at N52E and N41W; discontinuities do not coincide with N25E trending folds apparent in the 3D seismic, but tend to follow deeper structural trends instead. These discontinuity orientations are interpreted to be a result of continued movement on deeper faults throughout the Paleozoic; these faults possibly acted as seed points for fractures further upsection and potentially led to the precipitation of the large N25E trending imbricate backthrusts seen in the 3D seismic.

The reservoir's response to hydraulic fracturing also provided insights into local stress anisotropy and into optimal well and stage spacing needed to maximize drainage area and locate additional wells during the field development phase. Microseismic, well, and pump data used to gauge the reservoir's response to a hydraulic fracture treatment indicated that the number of stages, lateral length, total proppant volume, and fracture energy heavily influence how a well produces. $\mathrm{S}_{\mathrm{Hmax}}$ in the area is oriented at $\sim \mathrm{N} 96 \mathrm{E}$ in the region and microseismic event swarms generally trend N56E. Microseismic activity which forms at acute angles to $S_{H \max }$ is interpreted to be a result of shearing on preexisting fractures. Ideally this study will fit into a larger framework of previous case studies that can be used to better understand shale gas reservoirs, and make hydrocarbon extraction safer, more efficient, and more predictable.
\end{abstract}




\section{Acknowledgements}

I would like to thank my committee chair Dr. Wilson for taking me on as a student; he has provided me with financial assistance and valuable advice. My future looks much brighter thanks to his generosity. I would also like to thank my other committee members Dr. Toro, Pete Sullivan, and Valerie Smith for their guidance and time.

I would also like to thank Energy Corporation of America for providing a host of excellent data (seismic, microseismic, well data, etc...).

Also a special thanks to West Virginia University and Schlumberger for providing software packages I could not have otherwise afforded myself.

Research is funded by the Houston Advanced Research Center's Environmentally Friendly Drilling Program through the Research Partnership to Secure Energy for America (RPSEA)

To my husband Adam - thank you for supporting me through school. Your love and encouragement are critical to my success.

Thanks be to God for seeing me through a demanding, yet wonderful time in my life. 


\section{Table of Contents}

Chapter

1

1.1 Previous Work

2

Geologic Setting

2.1 Structural Setting

2.2 Marcellus Shale

3 Data and Methodology

3.1 Data

3.1.1 3D Seismic Survey

3.1.2 Microseismic Survey

3.1.3 Well Logs

3.2 Methodology

3.2.1 Seismic Attributes

3.2.1.1 3D Curvature

3.2.1.2 Ant Tracking

3.2.1.3 Cosine of Instantaneous Phase

3.2.1.4 Variance

3.2.1.5 Chaos

3.2.2 Microseismic

4 Microseismic Analysis

4.1 Stress Analysis

4.2 Energy Release Analysis

5 Interpretations

5.1 Structural Interpretations

5.1.1 Fault Interpretations

5.1.2 Discontinuity Mapping Interpretations

5.2 Stratigraphic Interpretations

6

Conclusions \& Future Work

6.1 Anticipated Outcomes/Objectives

6.2 Conclusions

6.3 Future Work

6.3.1 Structural and Stratigraphic Analyses

6.3.2 Seismic Attributes

6.3.3 Microseismic Events

7

References

8
118

138

Page Number

1

8

16

42

78

140 


\section{Chapter 1: Introduction}

In this thesis a study is conducted of a gas field in Greene County, PA. Numerous wells have been drilled in the Marcellus shale, and the local structure is well-defined by well logs and 3D seismic data. Some microseismic events (Figure 1) produced during a hydraulic fracture treatment of wells at the site extend vertically out-of-zone greater than $2,000 \mathrm{ft}$. For this study it is beneficial to know where potential fault and fracture zones might be located, as these zones may be more easily ruptured and facilitate stress and strain transfer to shallower strata. Efforts to locate potential faults and fracture zones ahead of hydraulic fracturing are beneficial, as drilling fluids, time, and money - amongst many other resources - are wasted when an operation is unsuccessful; also, pinpointing these zones prior to hydraulic fracturing can help modify treatment on a stage-bystage basis.

\subsection{Previous Work}

The key to developing tight gas reservoirs is the use of hydraulic fracturing (Maxwell, 2012). Tight gas formations are very low permeability reservoirs, so hydraulic fracturing must be used to create permeability in order to exploit economically viable reserves of hydrocarbons. Hydraulic fracturing is constantly evolving as companies try to make the process more efficient and safe by using less hazardous chemicals, and by using 3D seismic to better design drilling trajectories (Figure 2). The design of hydraulic fracture treatments can be optimized through an advanced understanding of subsurface fracture geometry and the present-day stress field, and the effectiveness of the treatment can be 


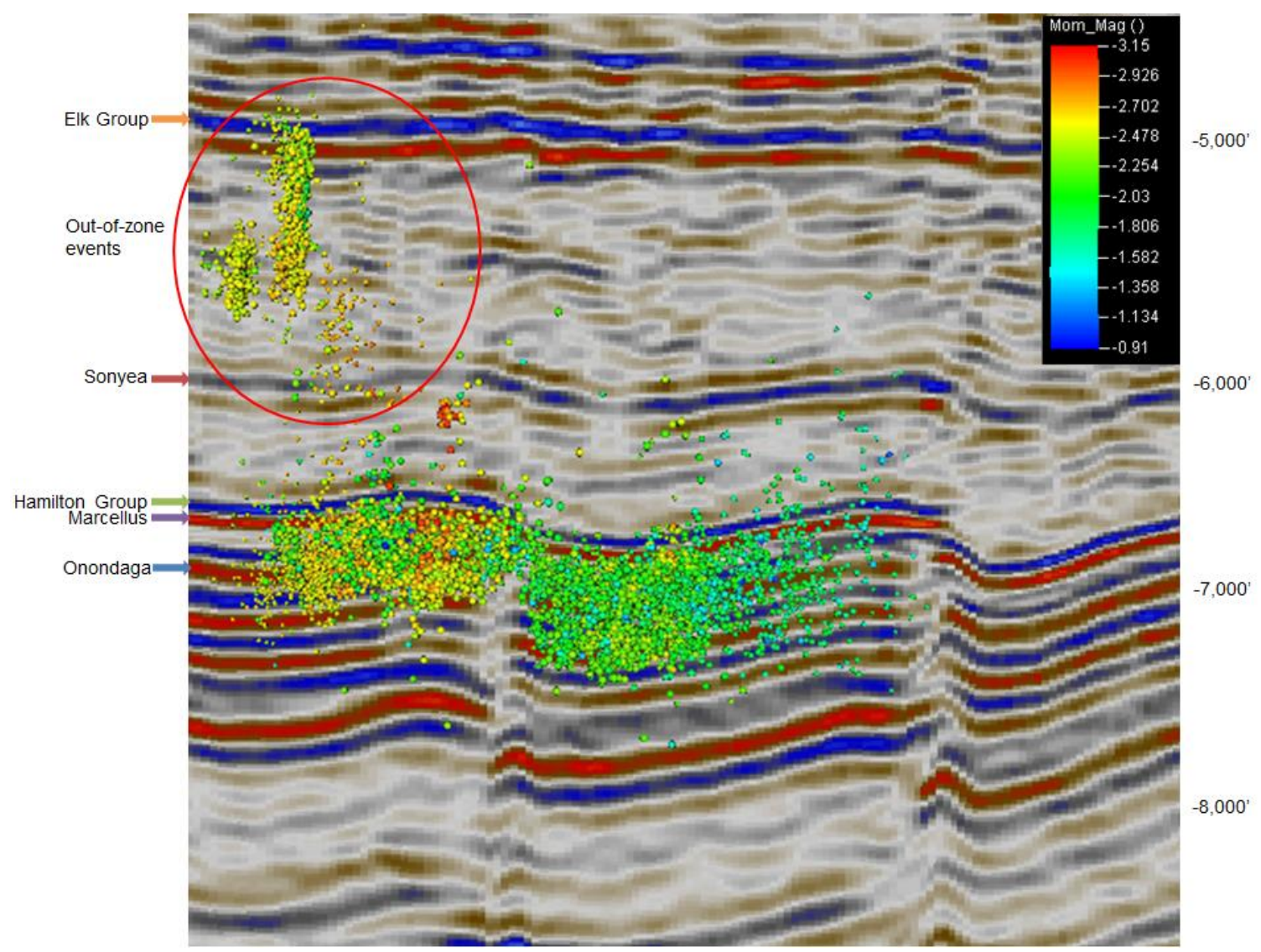

Figure 1: Microseismic events extending out-of-zone. The main reservoir and subreservoir events are located between depths of - 6,800' and -7,200', while the out-ofzone events are clustered between $\sim-4,900$ 'to -5,600'subsea. 


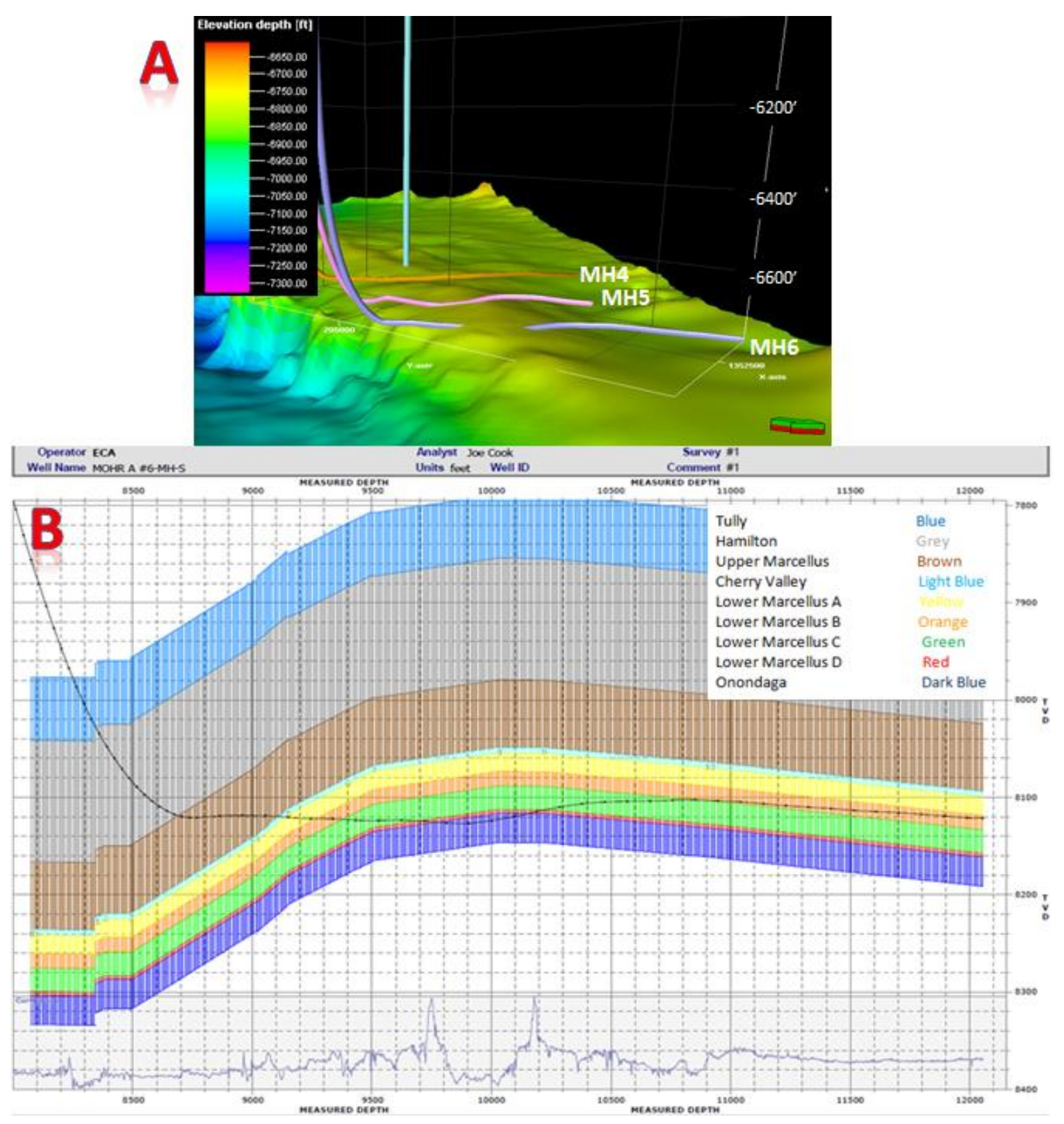

Figure 2: A) Onondaga Ls seismic surface and MH6 well path viewed from the northeast. B) The MohrA\#6 well path can be seen dipping into the Onondaga LS in both the 3D seismic and the Geosteering log. 3D seismic can be used alongside traditional Geosteering methods in order to execute a more accurate drilling trajectory. 
evaluated through microseismic monitoring. An understanding of reservoir fracture systems enables one to plot out more advantageous drilling trajectories, and horizontal drilling technology enables the wellbore to tap into a much greater volume of hydrocarbon reserves.

A major factor in hydraulic fracturing success is the induced fracture height (Maxwell, 2012). Induced fracture height is of great concern from both a production and environmental standpoint. Fractures that travel too far out of zone (target or reservoir interval) can lead to wasted frac energy and lackluster reservoir stimulation; also, other water-laden formations could be tapped (Miller, 2013). An important constraint on fracture growth is the orientation of the minimum present-day compressive stress direction, since induced tensile fractures tend to grow perpendicular to the minimum stress direction $\left(S_{h m i n}\right)$. Due to the depth at which most petroleum reservoirs are tapped, $S_{h m i n}$ is approximately horizontal which results in the propagation of vertical fractures (Maxwell, 2011).

Two major limiting factors to vertical fracture propagation are layer thickness and the fabric of the rock. Lithology changes and bedding laminations (such as those found in shale gas reservoirs) should theoretically limit vertical fracture-height growth for both natural and hydraulically created fractures. Controlling vertical growth of hydraulically induced fractures is a significant challenge in hydraulic fracture treatment design. Limited fracture-height growth may require additional wells to effectively produce the reservoir, which is both inefficient and very expensive; whereas out-of-zone growth may create "thief 
zones" which can sap hydraulic energy needed to effectively fracture the reservoir. Microseismic data provide valuable insights into the response of the reservoir and bounding strata to hydraulic fracture treatment as well as regulating height containment (Maxwell, 2012). Real time monitoring may reveal reduced or excessive fracture height that can be regulated by altering injection pressure, water volume, and proppant concentration. This is an important issue in the Marcellus shale, as hydraulic fracturing operations quite regularly register microseismic events at least a few hundred feet vertically out-of-zone (Warpinski, 2009). Perhaps just as important (or more important) is the horizontal extent to which microseismic events propagate; the lateral extent of these events influences future lateral spacing and drainage volume.

Microseismic monitoring has proven to be the most reliable technology for the measurement of hydraulic fracture growth away from the wellbore (Maxwell, 2012). The mapping of hypocenters reveals the extent of fracturing; this is especially useful for observing out-of-zone fracturing, detecting fault activation, and for determining optimal frac-stage spacing and well orientation for future wells (Maxwell, 2012). Another excellent use of microseismic data involves its integration with geological reservoir models (Figure 3). These reservoir models already provide clues about which geologic factors, such as local structure and visible faults, impact hydraulic fracture patterns, but one can also forward-model numerous scenarios such as estimated reservoir pressure decline and effective fracture volume (Warpinski, 2009, Maxwell, 2012, Ardoso, 2013).

Donahoe (2011) conducted a 3D seismic attribute assisted interpretation 


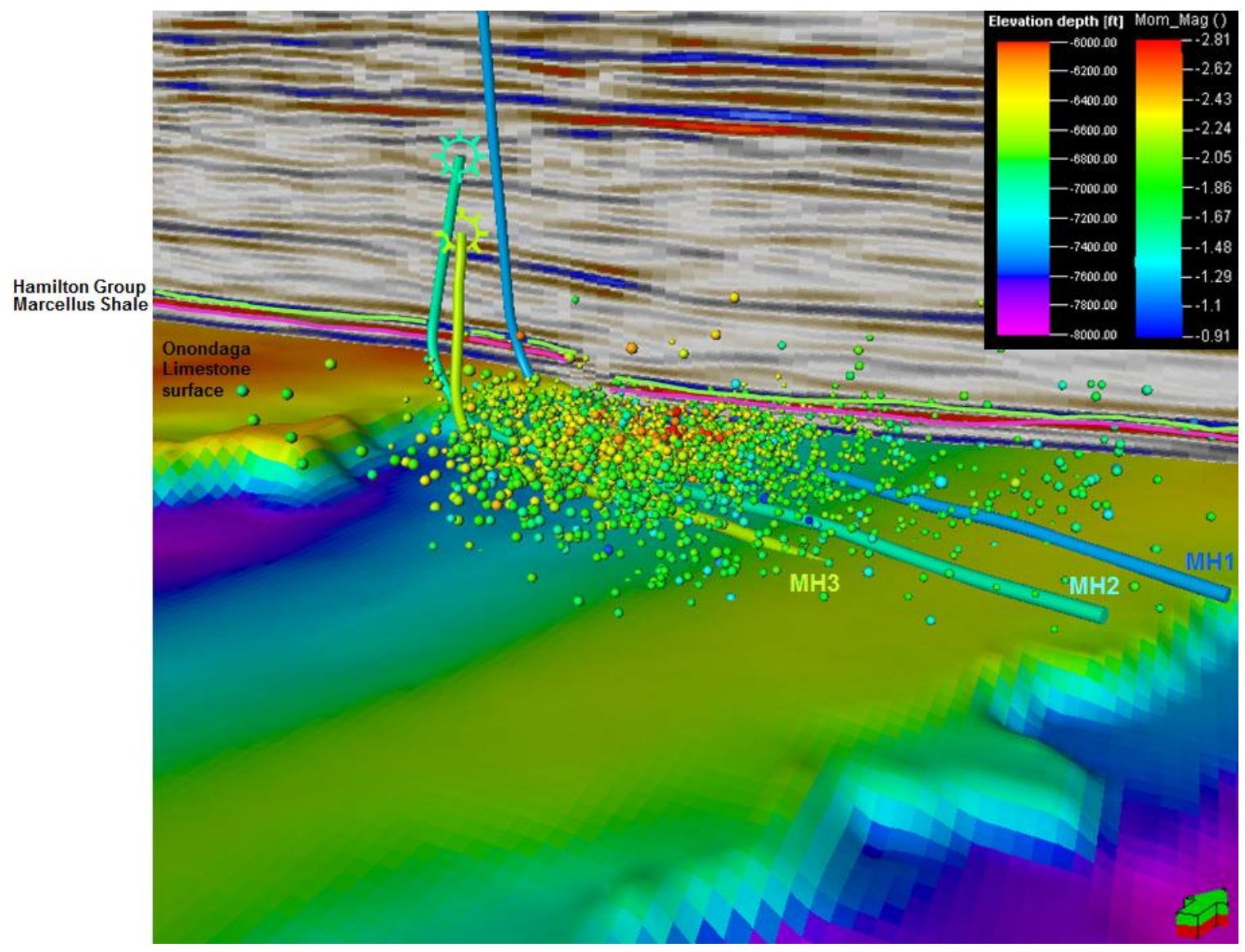

Figure 3: Onondaga Limestone seismic surface picked from 3D seismic with microseismic data integrated. Cooler colors represent microseismic events of greater magnitude; warmer colors represent smaller magnitude events. The majority of the induced microseismic activity is sandwiched between the Hamilton Group and the top of the Onondaga Limestone. The targeted area for drilling lies right above the Onondaga. 
of the same study area; his study presents an interpretation of the present day structural fabric development. Detachment intervals such as the Salina salt and additional shale intervals were interpreted and mapped through the area. Much of his interpretation was derived from interpretation of a waveform model regression volume version $(\mathrm{Gao}, 2004)$ of the 3D seismic volume. 3D seismic acquisition and interpretation are key tools used to characterize unconventional reservoirs, and provide valuable insights into reservoir structure and stratigraphic variability. Having a better model of the reservoir is likely to increase the chance of success (Alfaro et al., 2007). 


\section{Chapter 2: Geologic Setting}

\subsection{Structural Setting}

The Appalachian Orogen is primarily a compilation of 4 orogenic events Cambrian-Ordovician failed rifting along with the subsequent Taconic, Acadian, and Allegheny orogenies. The Cambrian-Ordovician extensional event produced numerous basement faults in the region (Shumaker and Wilson 1996) and has had significant bearing on the tectonic evolution of the pre-Appalachian and Appalachian foreland (Figure 4) (Gao et al., 2000). The basement faults were often reactivated during subsequent convergent tectonic events which began during the Late Ordovician and extended through the Pennsylvanian (Wilson, 2000).

Underlying highs created by Cambrian-Ordovician aged normal faults being reactivated in a reverse sense could have led to the precipitation of large backthrusts seen in the region, as the shallower backthrusts appear to be spawned from faults deeper in the section (see Figure 62). These steeply-dipping backthrusts are anomalous, but not rare; they also appear to chiefly affect the Upper Silurian through Middle Devonian section. It is likely that the mixture of competent and incompetent units within the Upper Silurian through Middle Devonian section was partially responsible for the extensive detachment folding that occurred during the Alleghanian Orogeny. Alternating mechanically stiff (such as the Onondaga Limestone) and weak (such as the Marcellus Shale) stratigraphic layers allowed for increased detachment in Upper Silurian through Middle Devonian strata, while the extensive packages of incompetent units seen 

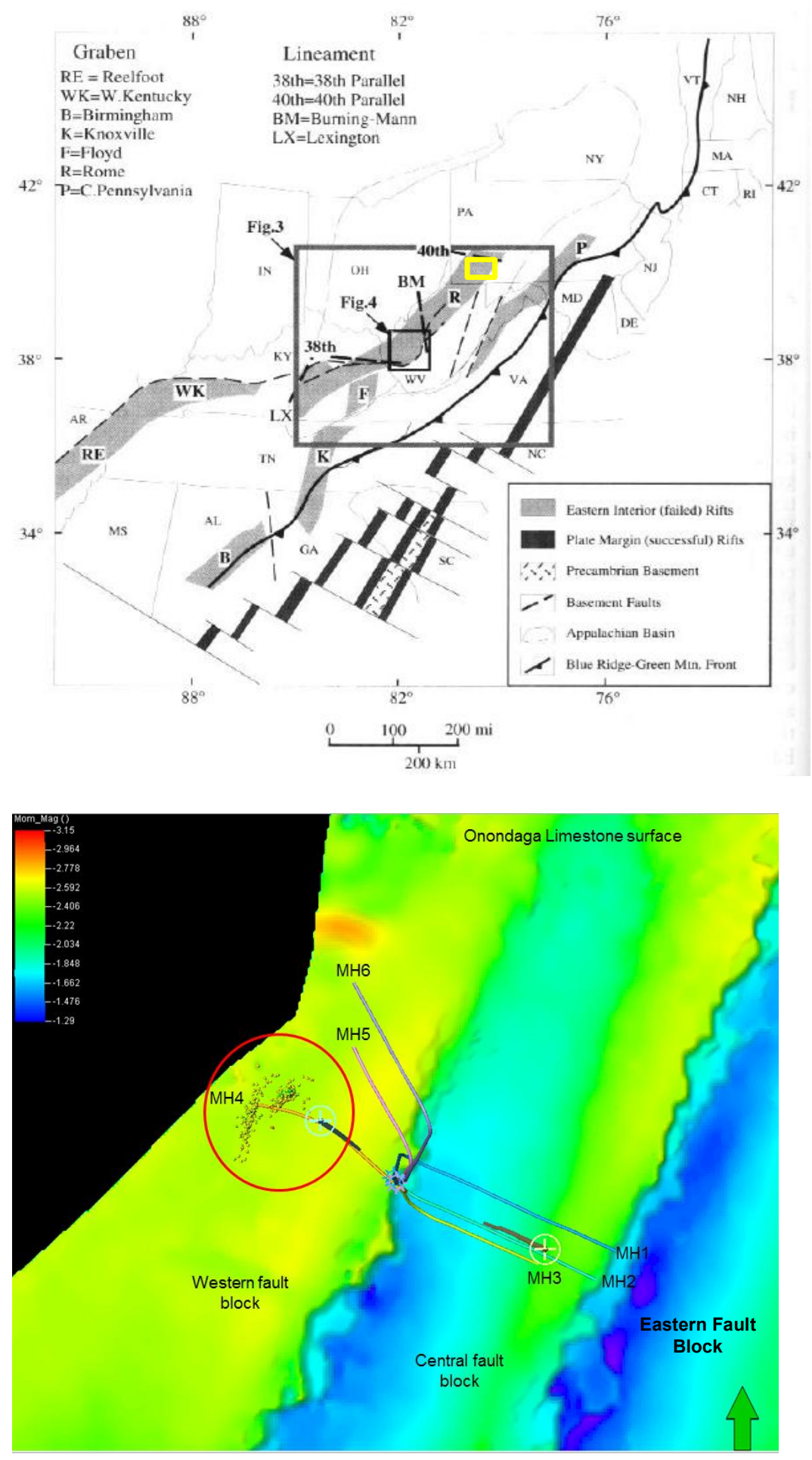

Figure 4: Above: The Rome Trough underlies the study area (yellow box) and has had a significant effect on the local geology (Gao et al., 2000). Below: 6 study wells shown on surface of Onondaga Limestone.

in the Ordovician (such as the Utica Shale, Queenston Shale, and 
Reedsville Shale) and Upper Devonian (Sonyea Group, Elk Group)

accommodated shortening chiefly through shale flowage leading to vertical fracturing.

There was also a Triassic-Jurassic rifting phase associated with the separation of Pangea; potential effects (if any) of this rifting phase will need to be further examined in other studies, as this rifting phase was focused mainly around the North Atlantic region of the United States (May, 1971).

\subsection{Marcellus Shale}

The Marcellus shale, a major component of the Middle Devonian black shale play, is the basal member of the Hamilton Group (Figure 5) and can be found beneath much of Ohio, West Virginia, Pennsylvania, and New York. The Hamilton Group is bounded above by the Middle Devonian Tully Limestone and below by the Lower Devonian Onondaga Limestone; depending on the presence of the Cherry Valley/Purcell Limestone, the Marcellus shale can be divided into lower and upper segments, with the Cherry Valley Limestone separating those segments (Figure 6). The Marcellus shale thins from the northeast part of the basin to the north, south, and west (Figure 7) (Zargoski et al., 2011, Wrightstone, 2009). High gamma ray, high density, high porosity, and high resistivities characterize the Marcellus shale in the study area, and the shale in southwestern Pennsylvania contains a higher concentration of organics on a per foot basis $(\sim 2-$ 15 weight percent) (Zagorski et al., 2011). This shale play includes natural gas production from thick units of carbonaceous, fractured, and high clay content marine shales deposited as distal facies of the Acadian clastic wedge (Figure 8) 


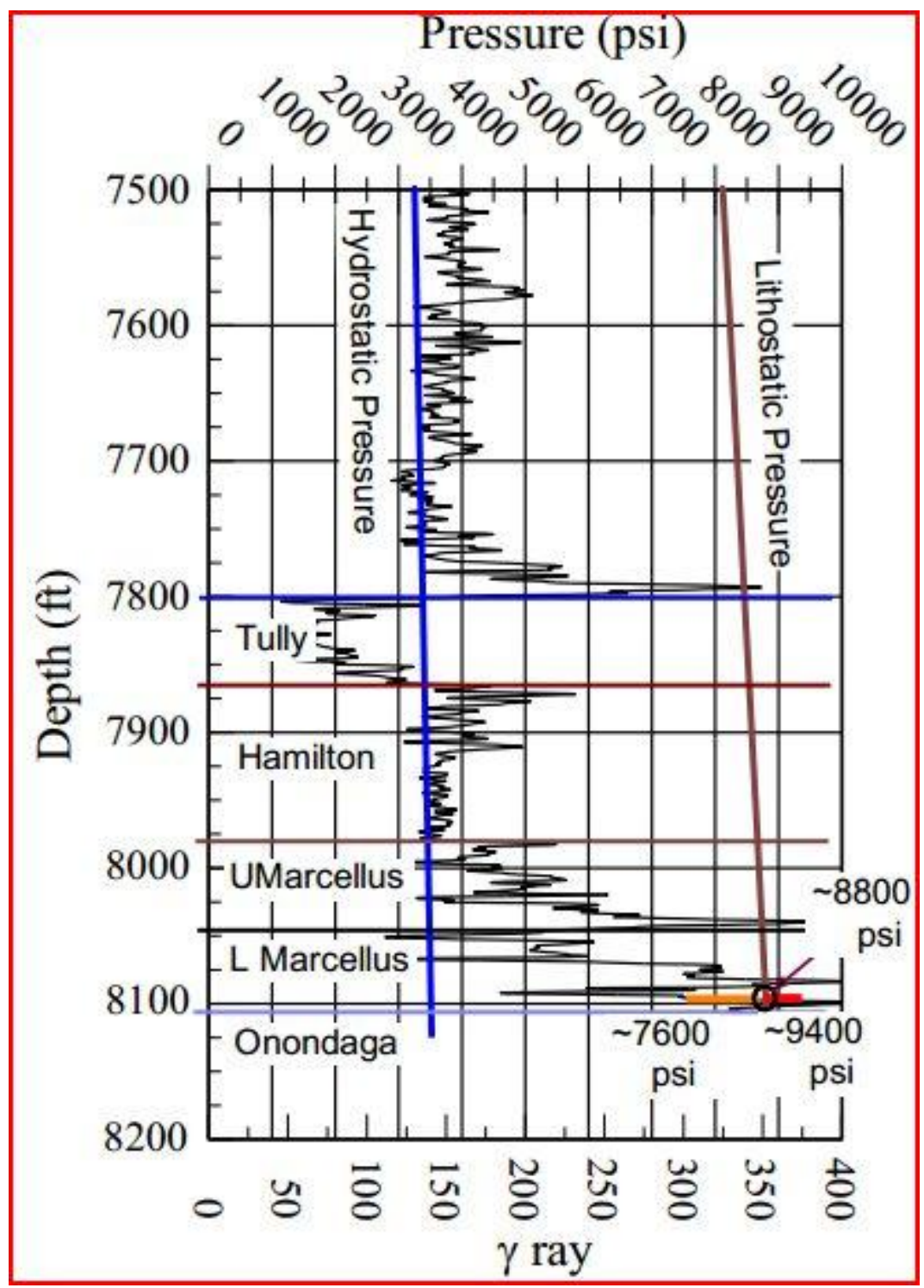

Figure 5: Type Section from the the Gribble 3MH well (API number: 3705925278) displaying various units (Wilson, written communication). 


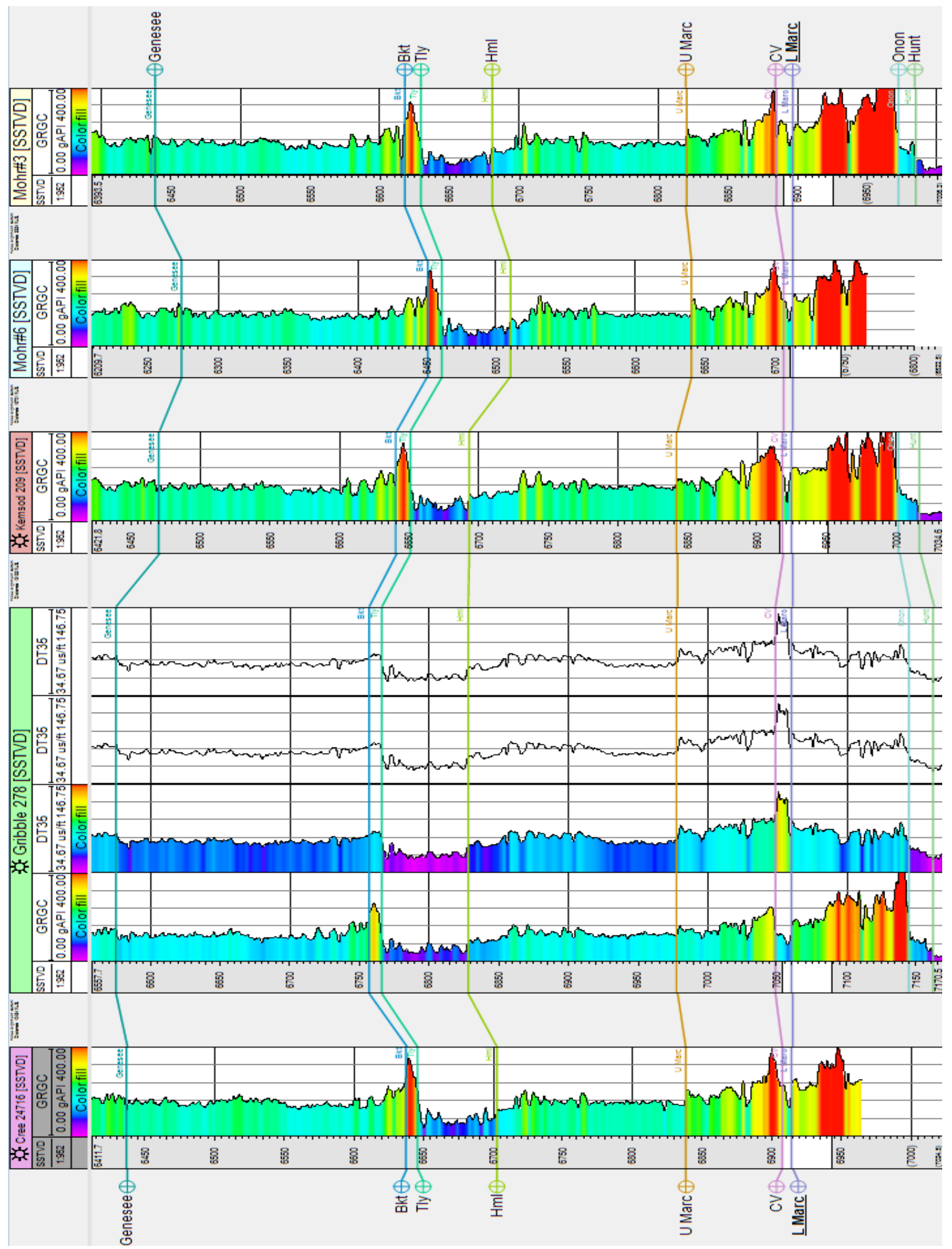

Figure 6: Well section illustrating typical gamma ray responses in the area. A sonic log is also shown for the Gribble 278 well. Abbreviations are as follows: the Upper Marcellus (U Marc), Cherry Valley LS (CV), Lower Marcellus (L Marc), and the Onondaga LS (Onon) 


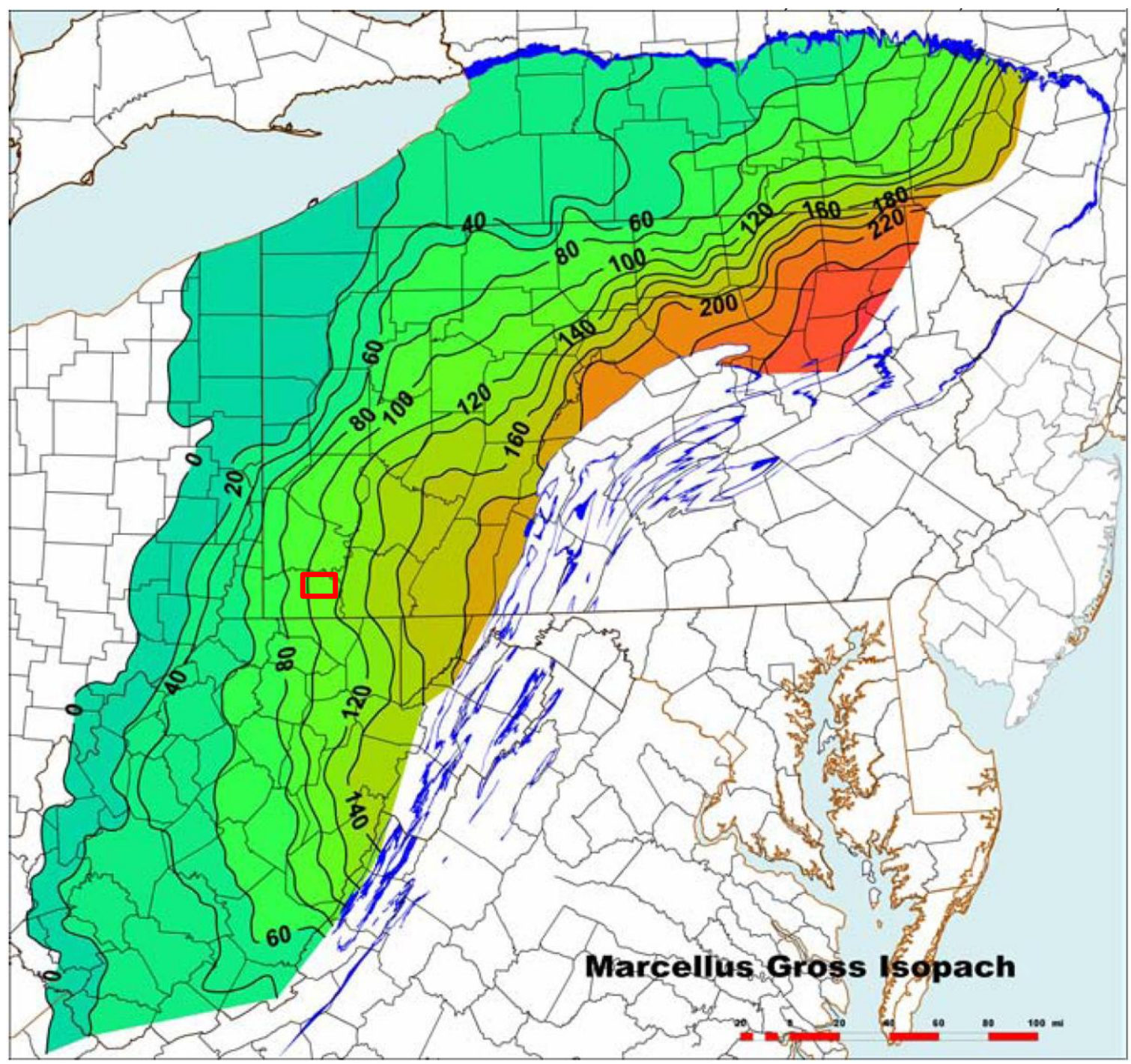

Figure 7: Marcellus shale gross isopach,(feet) taken from Wrightstone (2009). The study area lies within the red box. 


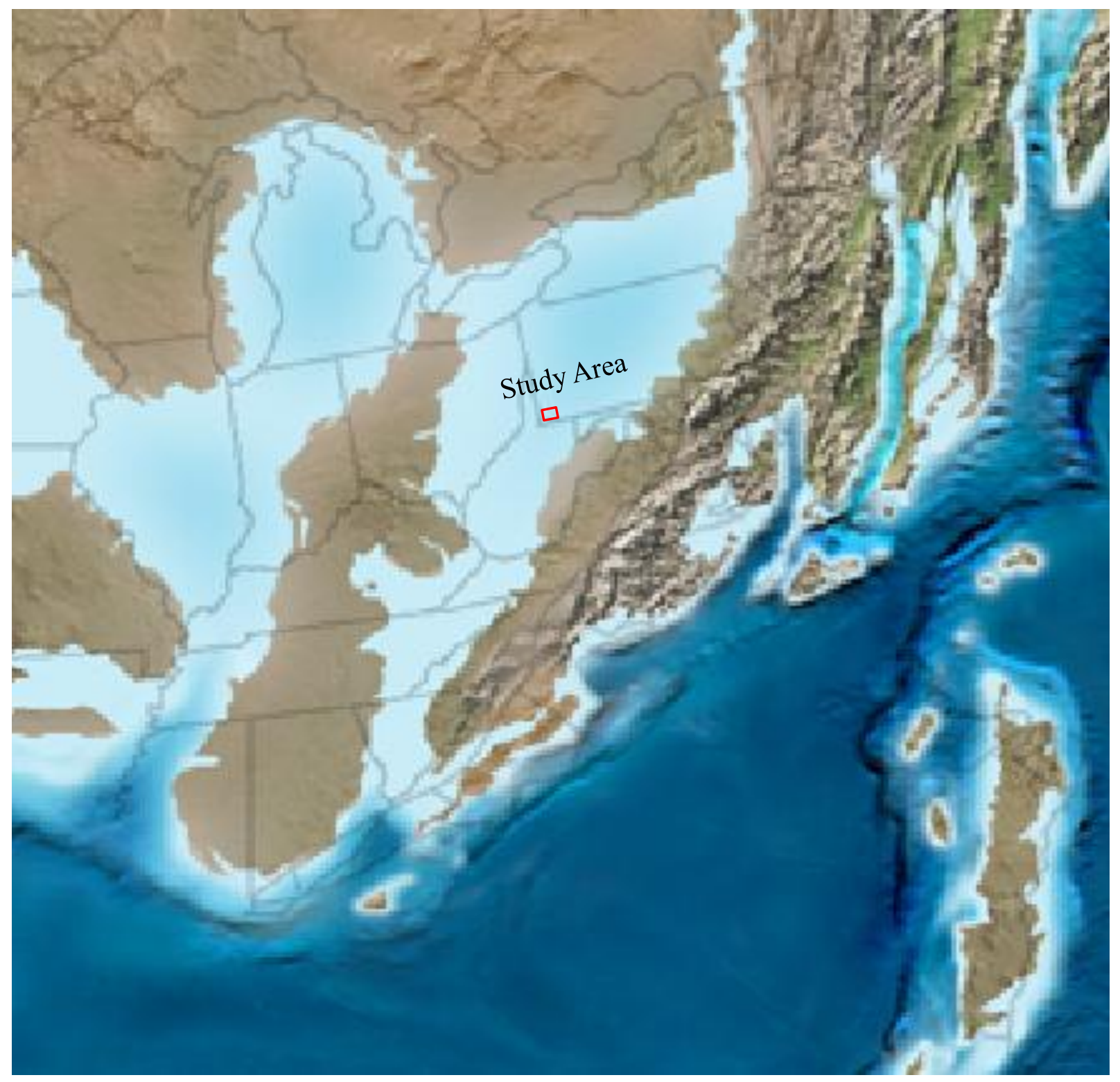

Figure 8: Paleogeographical map of the Appalachians in the Middle Devonian (385Ma). Location of study area indicated by red box (Blakey, 2008). 
(Boswell, 1996). As one moves eastward, individual black shale units grade into and intertongue with distal turbidites and other non-black shales of the Catskill delta complex (Milici, 1996). 


\section{Chapter 3: Data and Methodology}

\subsection{Data}

\subsubsection{D Seismic Survey}

The 3D seismic dataset covers approximately 25 square miles in eastern Greene County, Pennsylvania (Figure 9). The survey was conducted by Geokinetics USA Inc. for Energy Corporation of America (Donahoe, 2011). Both dynamite and vibroseis were used in data acquisition. Bill Wepfer of Echo Geophysical Corporation processed data using an 8-bit dynamic range in the time domain (Donahoe, 2011); a post-stack migration volume is used for this work.

The coordinate reference system for this project is the North American Datum of 1927 Pennsylvania State Planes, Southern Zone, with surface units in US feet. The seismic reference datum of the area is set at 1,200 feet. The stacking bin spacing is 110 feet and there are 332 inlines and 296 crosslines. The sample rate is 2 milliseconds. Inline rotation from North is set at $91.50^{\circ}$, so that inlines extend from west to east (seismic inline displays are oriented west to east).

\subsubsection{Microseismic Survey}

Weatherford International conducted a microseismic survey of 56 hydraulic fracturing stages for the wells Mohr $\mathrm{A} 1 \mathrm{MH}$ (14 stages), $2 \mathrm{MH}$ (14 stages), $3 \mathrm{MH}$ (10 stages), $4 \mathrm{MH}$ (10 stages), $5 \mathrm{MH}$ (7 stages), and $6 \mathrm{MH}$ (1 stage). Mohr \#3 was used to monitor wells $1 \mathrm{MH}, 2 \mathrm{MH}$, and $3 \mathrm{MH}$, and Mohr \#6 was used to monitor wells $4 \mathrm{MH}, 5 \mathrm{MH}$, and $6 \mathrm{MH}$ (Figure 10). An 8-level SlimWave tool 


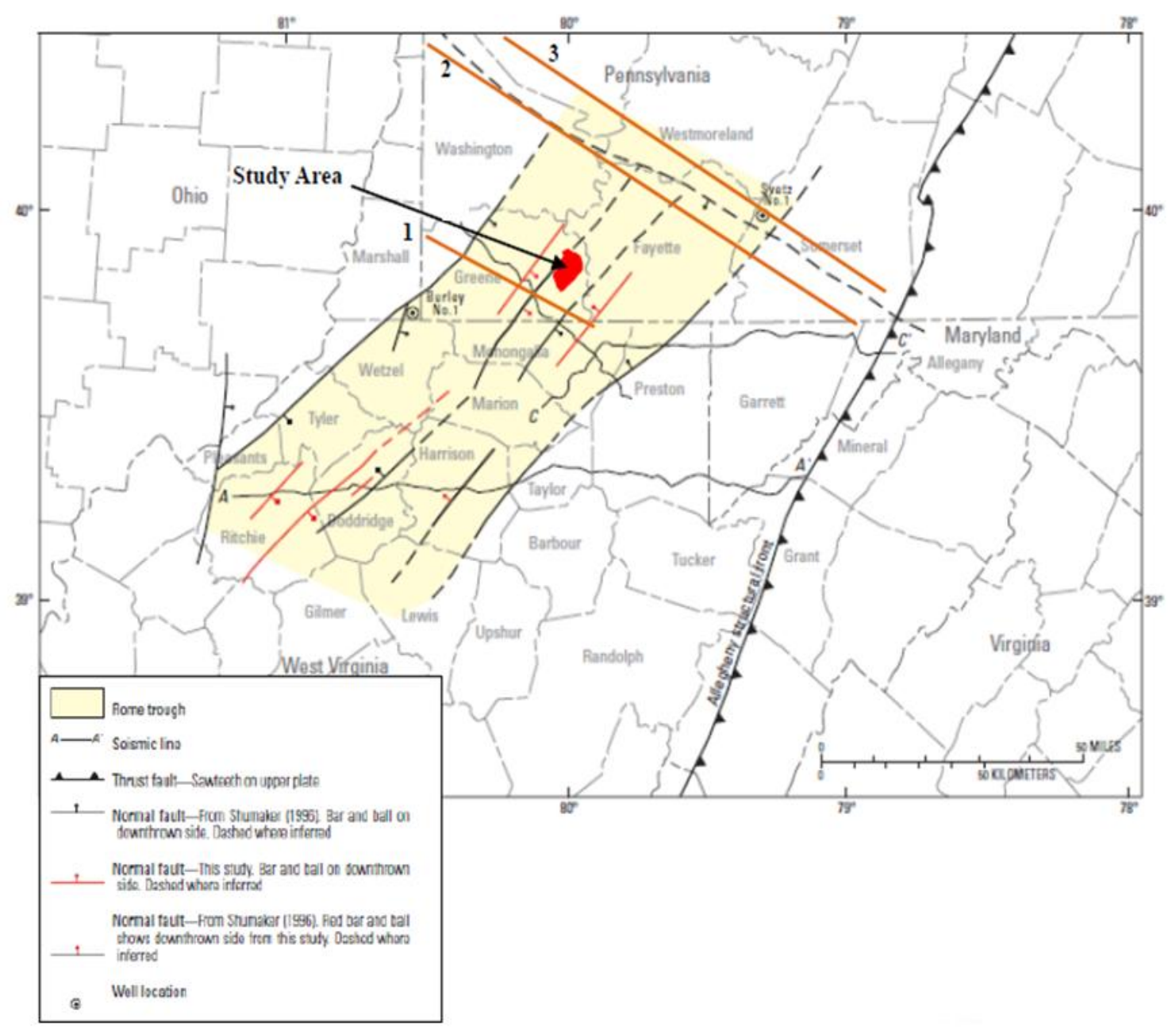

Figure 9: Above: detailed map showing the study area. Taken from Donahoe (2011). Originally seen in Kulander and Ryder (2005). 


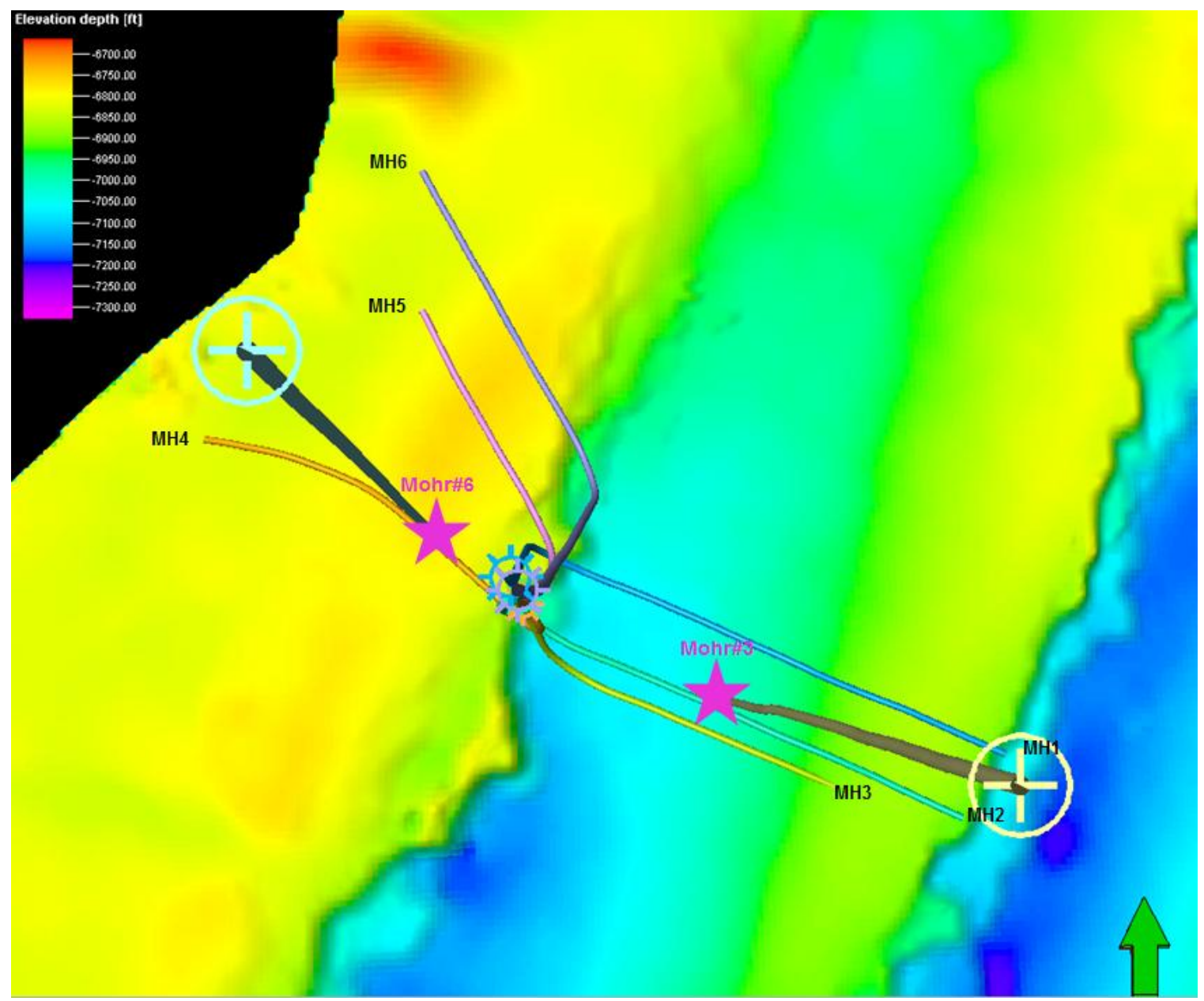

Figure 10: Treatment wells (black text) and monitoring wells (purple text) displayed on the surface of the Onondaga Limestone. The logs from the monitoring wells were used for a basic well log analysis. 
with sensors equally spaced 100 feet apart was used to monitor the entire treatment and was deployed vertically in both wells. A "zipper-frac" configuration was used to stimulate the wells (zippering for $4 \mathrm{MH}, 5 \mathrm{MH}, 6 \mathrm{MH}$ and $1 \mathrm{MH}, 2 \mathrm{MH}$, $3 \mathrm{MH}$ ), and perforations were positioned in a zero phase orientation (pointing straight down). A "zipper-frac" completion involves "fracturing adjacent wells in sequence, with one well holding frac pressure while the adjacent well is frac'ed (Halliburton, 2012)." The MH1, MH2, and MH3 wells were zippered in ascending numerical order until the $\mathrm{MH} 3$ ran out of stages; after that point the $\mathrm{MH} 1$ and MH2 wells were zippered. Figure 11 displays zipper frac order as well as how long the frac lasted for each stage. The company had intended to zipper between the MH4 and MH6 wells, but when stage one of the MH6 well spawned out-ofzone activity the company decided to zipper between the $\mathrm{MH} 4$ and $\mathrm{MH} 5$ wells. The MH6 well was completed at a later date.

\subsubsection{Well Logs}

Energy Corporation of America provided wells within the area covered by the 3D survey. Basic log analyses were conducted on 2 wells (Mohr\#3 and Mohr\#6) to determine whether there was any variation in the petrophysical properties between the hangingwall and footwall fault blocks (Figure 12). Well logs were mainly used to identify formation tops and portray structural features.

\subsection{Methodology}

Research conducted for this study focused on an integrated interpretation of 3D seismic and microseismic data from the Greene County, PA area. The initial structural analysis was undertaken using various 3D seismic attributes 

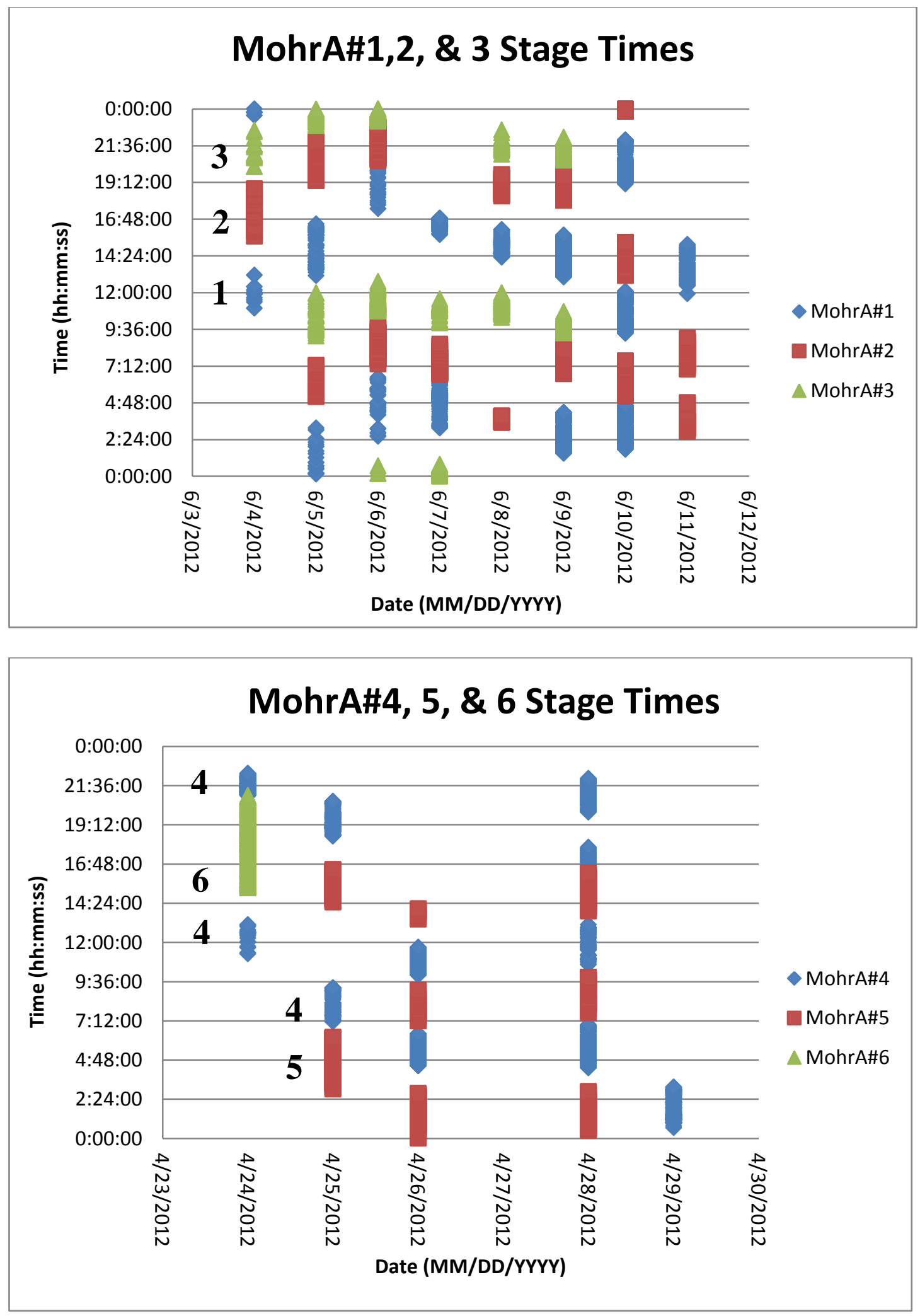

Figure 11:Graphs were made in MS Excel to confirm fracs were zippered. They all wereevents that appear to be overlapping are not, but are rather just very closely spaced. 


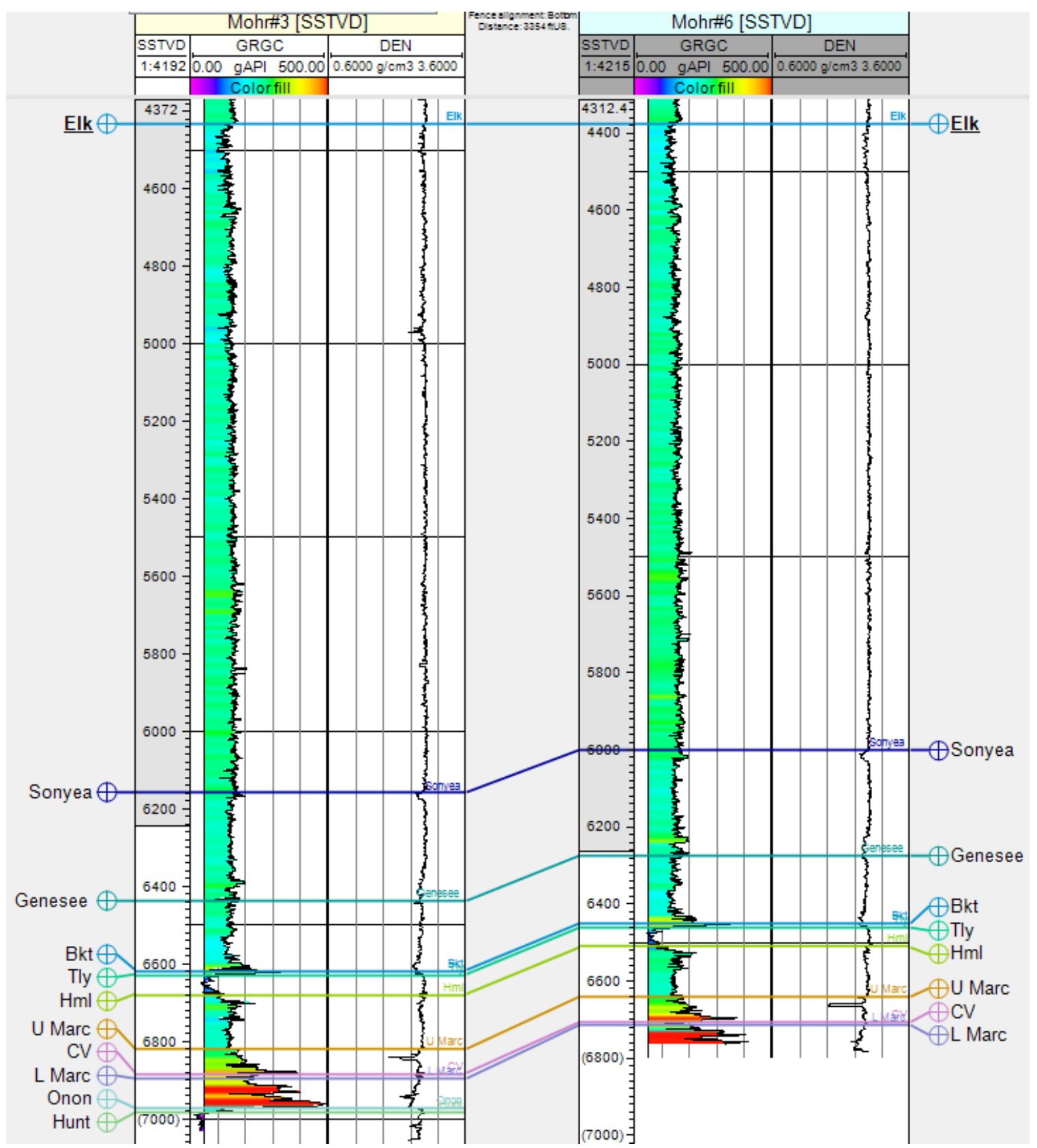

Figure 12: Gamma Ray and Density logs from the two observation wells reveal little variation in the petrophysical properties of each fault block. Mohr\#3 was used to monitor the treatment of the MH 1-3 wells, and the Mohr\#6 was used to monitor the treatment of the MH 4-6 wells. Seismic Reference Datum is 1,200'.Depth values are TVD sub sea. 
such as the absolute value of the first derivative (AFD), 3D curvature (Figure 13), variance (Figure 14), chaos (Figure 15), and ant tracking. Microseismic data were then compared against a backdrop of various seismic attributes in order to determine whether a correlation existed between the out-of-zone microseismic activity and any features present in the seismic data.

\subsubsection{Seismic Attributes}

For the purposes of this project, seismic attributes were used in an attempt to identify faults, potential fracture networks, zones of preexisting weakness, and the thickness and continuity of the Marcellus Shale. A seismic attribute is some measure of the seismic data that is used to visually enhance or quantify geologic features or reservoir properties that are of interest to the interpreter (Chopra and Marfurt, 2007). Seismic discontinuities are of interest to this study, as they may represent fracturing of the rock; fractures in the reservoir are important features as they could aid in transmitting hydrocarbons to the wellbore more efficiently. Potential fracture identification was also important to this study, as some fractures represent potential hazards and can negatively impact production.

Seismic attributes allow the interpreter to infer the structural and/or depositional nature of the subsurface area of interest; this is not always possible with raw seismic data. When attributes are calibrated against other well data such as core, well logs, microseismic the interpreter can gain physical insight into their interpretational target. Important targets to enhance in the study include features such as a hazardous area or a sweet spot. 


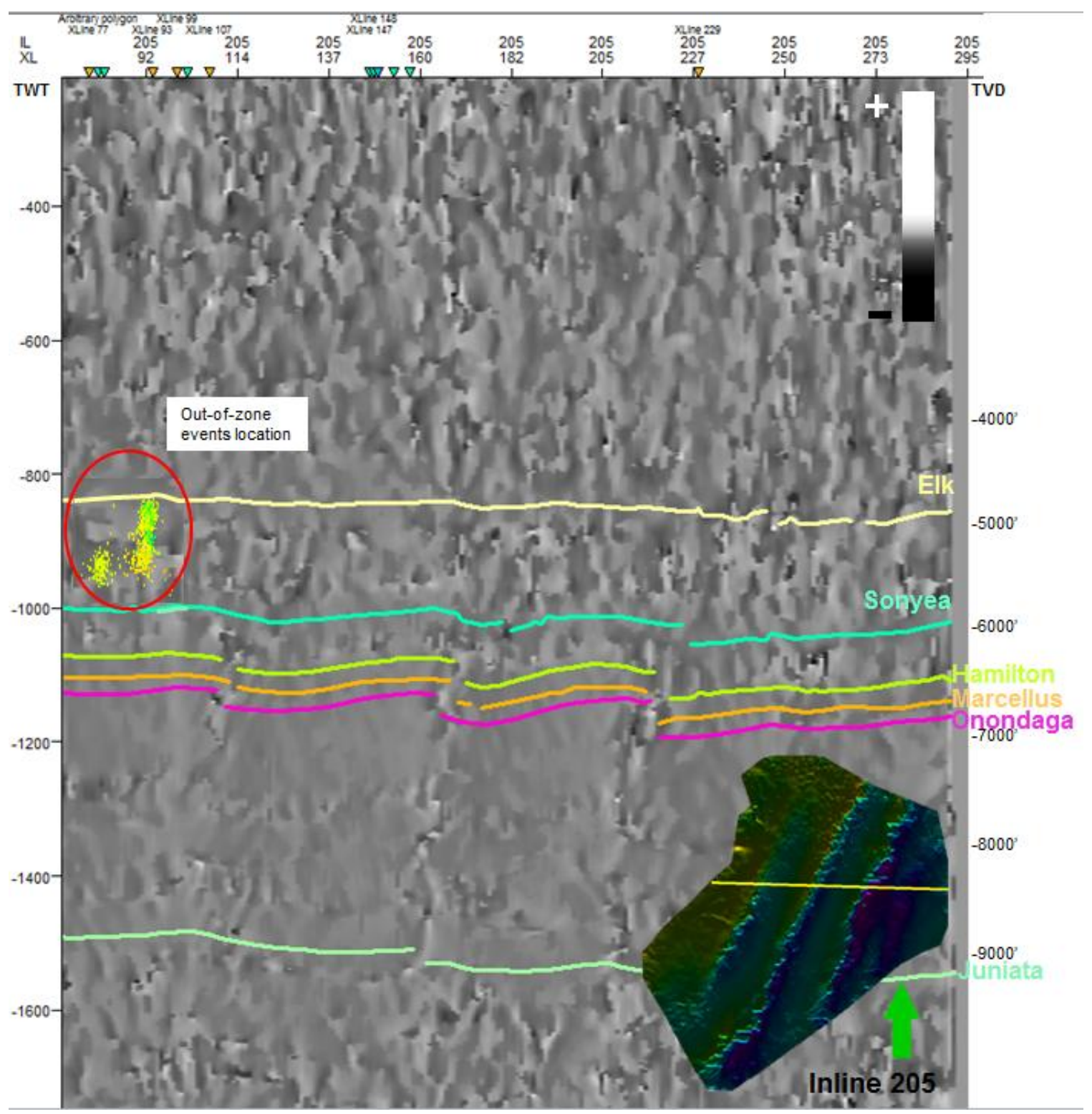

Figure 13: Most extreme curvature attribute computed on time volume in vicinity of outof-zone microseismic activity. Out-of-zone microseismic activity is highlighted by the red circle. Inset map of Onondaga Limestone surface shown on right. 


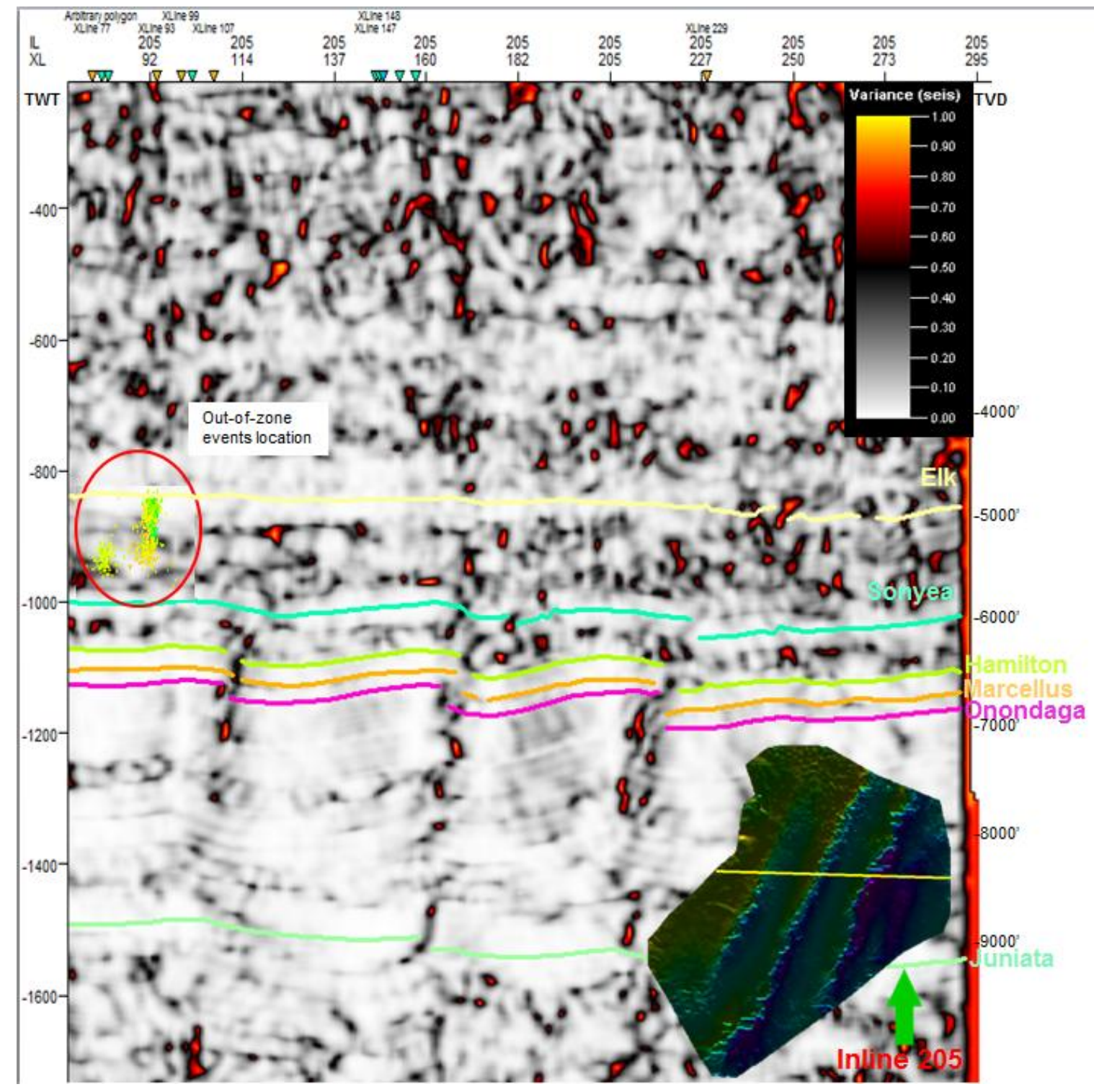

Figure 14: Variance attribute computed on time volume in vicinity of out-of-zone microseismic activity. Out-of-zone microseismic activity is highlighted by the red circle. Inset map of Onondaga Limestone surface shown on right. 


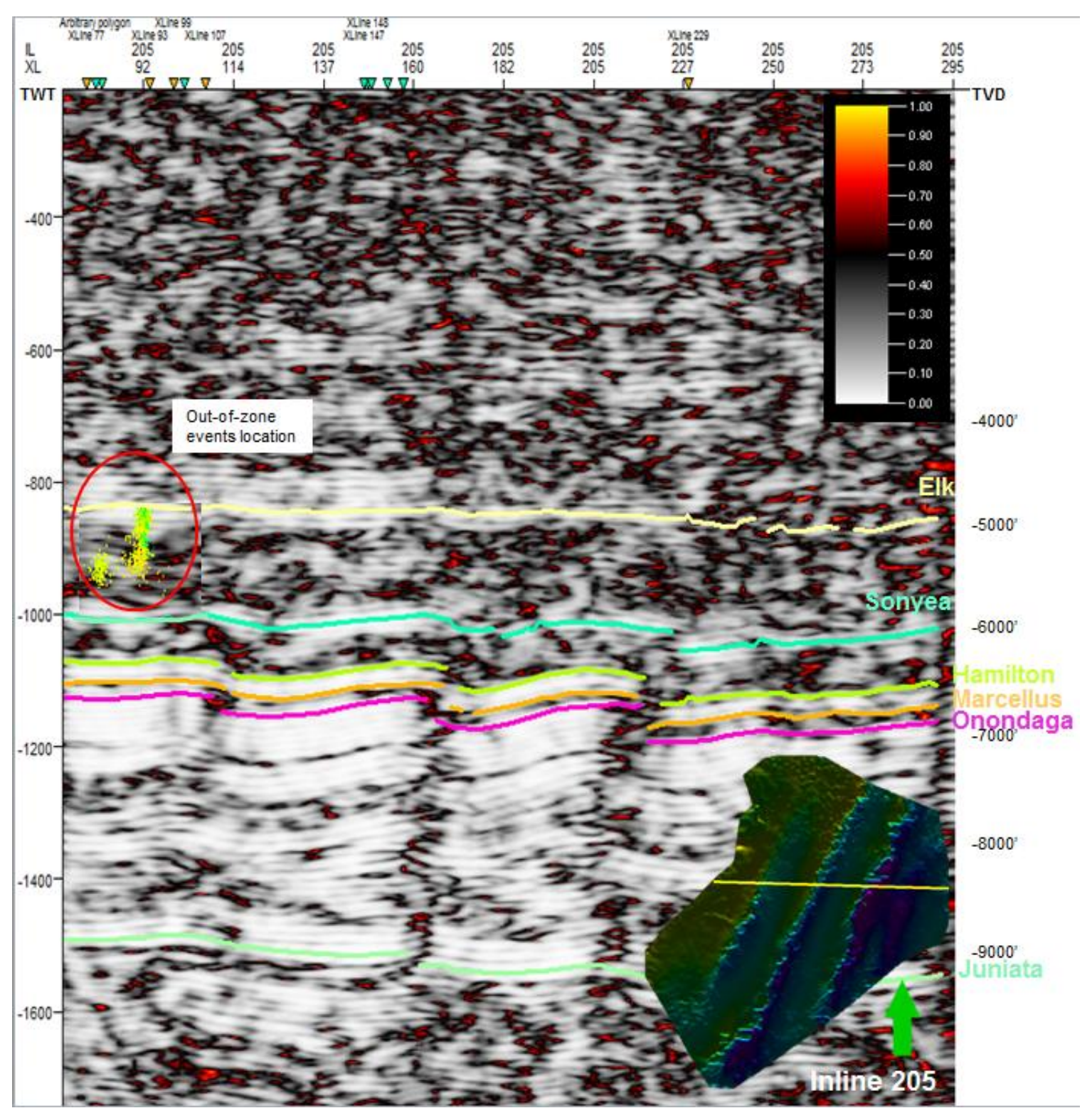

Figure 15: Chaos attribute computed on time volume in vicinity of out-of-zone microseismic activity. Out-of-zone microseismic activity is highlighted by the red circle. Inset map of Onondaga Limestone surface shown on right. 


\subsubsection{3D Curvature}

Curvature is a two-dimensional property of a line that describes how much it deviates from a straight line at a given point (Schlumberger, 2012). Curvature is a structural attribute that identifies changes of shape (focuses on features caused by folding and faulting) rather than changes in seismic amplitude. The curvature attribute uses vectors to determine whether curvature is positive or negative, and to what extent a surface curves (Figure 16). For example, curvature is defined as positive where vectors diverge over the crest of an anticline; but curvature is defined as negative where vectors converge in the nadir of a syncline. In Petrel there are 13 different types of curvature that can be calculated, but only a few were calculated and compared: most extreme curvature, most positive curvature, and most negative curvature.

The 3D curvature attribute is useful for highlighting structural discontinuities and stratigraphic features not readily apparent in the seismic data; curvature attributes are especially helpful when conducting risk analyses on an area, these attributes aid in fault/hazard identification. Knowing the location of high curvature areas within our data set is beneficial, as high curvature areas may be more prone to brittle failure.

\subsubsection{Ant tracking}

Ant tracking is a complex seismic attribute that mimics the swarm intelligence utilized by ants for finding food and building colonies; it is an iterative scheme that progressively attempts connecting adjacent zones of low coherence that have been filtered to eliminate horizontal features associated with 


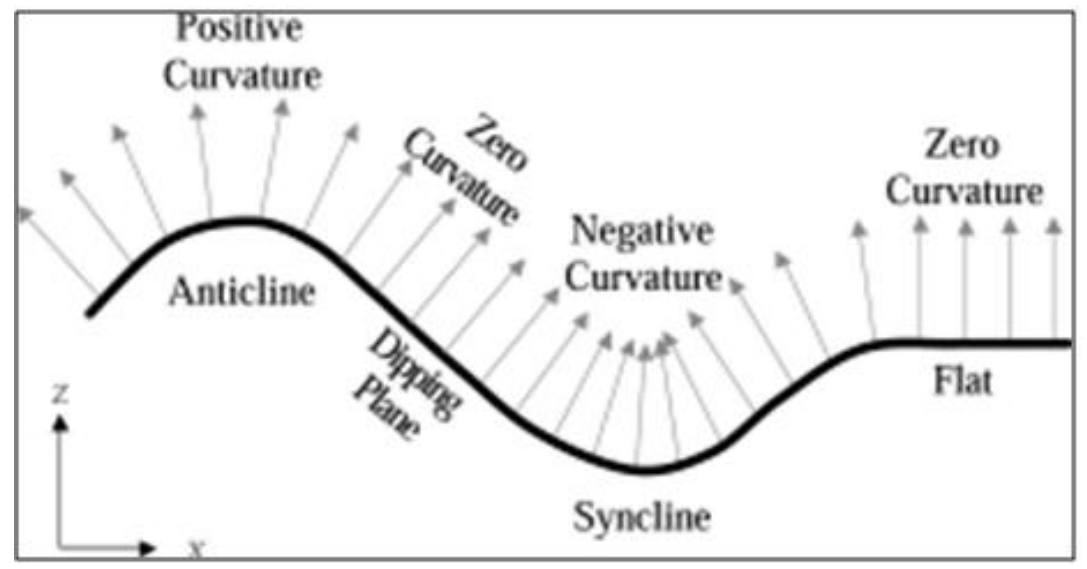

Figure 16: A figure from Schlumberger's Petrel user manual displaying varying curvature vectors 
stratigraphy (Chopra and Marfurt, 2007). Ants use a chemical substance called a pheromone (a secreted or excreted chemical factor that triggers a social response in members of the same species [MedicineNet Inc., 2012]) to direct other colony members down the most efficient path from the nest to food. Ants may branch out in different directions, but the most efficient path to food will contain the strongest pheromone trail. The ant tracking attribute draws from this biological process and uses computer agents coded to follow discontinuities for identifying, tracking, and/or sharpening faults (Pedersen et al, 2005). Once mapped, the orientations of fault surfaces and the values of attribute strength are stored as surface measurements; the fault surface orientations and attribute strengths are then used to extract fault surfaces (Chopra and Marfurt, 2007). Extracted fault surfaces can also be further filtered using the stereonet function; fault surfaces can be omitted based on dip and azimuth. For example, one could filter out extracted discontinuities that run parallel to bedding planes or those extracted discontinuities that may be a result of acquisition footprint.

There are 6 Ant Tracking parameters (initial ant boundary, ant track deviation, ant step size, illegal steps allowed, legal steps required, and stop criteria) that control how ant agents operate within the seismic volume. Parameterization is extremely important when using the ant tracking process, as not understanding parameterization can lead to misinterpretation of the seismic volume. Initial ant boundary controls how far apart ant agents are spaced within the volume. The distance is measured in terms of voxels; the greater this number, the more passive the ant tracking (Schlumberger, 2012). The ant track 
deviation parameter controls how many voxels an ant can deviate from its tracking path. A larger number means the ant agent will make more connections, and the ant tracking process will become more aggressive. The ant step size is the measure of how far an ant agent can advance at each point in its search; the larger this value, the more connections the ant will make. The illegal steps allowed parameter controls how far an ant can search beyond its current location without detecting an edge (Schlumberger, 2012). An increase in this parameter's value will result in a more aggressive approach. The legal steps required parameter controls how far an ant may advance after making an illegal step; the higher the value, the more restrictive the action. The stop criteria parameter is used to terminate an ant's path when too many illegal steps have been taken (Schlumberger, 2012).

For this project ant tracking was used to identify faults; however, it was also utilized to map fracture zones throughout the study area and infer the paleo maximum horizontal stress direction associated with local reservoir deformation. From a risk-assessment standpoint ant tracking is a highly valuable attribute, as it can detect locations in the area of data coverage where substantial frac energy could be lost, faults could be activated, or structural deformation could be unfavorable for the containment of hydrocarbons.

\subsubsection{Cosine of Instantaneous Phase}

The cosine of the instantaneous phase helps enhance structural features in areas where features may be difficult to see in the seismic data alone. For this attribute the recorded trace amplitude is divided by the reflection strength 
(Landmark, 2009); reflections are enhanced and data do not exhibit the discontinuous wrapping that instantaneous phase data experience. The trace values for the cosine of phase range from -1 to +1 in this data set.

\subsubsection{Variance}

The variance attribute estimates the local variance in the signal and is defined as:

$$
\sigma_{t}=\frac{\sum_{j=t-L / 2}^{j=t+L / 2} w_{j-t} \sum_{i=1}^{l}\left(x_{i j}-\bar{x}_{j}\right)^{2}}{\sum_{j=t-L / 2}^{j=t+L / 2} w_{j-t} \sum_{i=1}^{l}\left(x_{i j}\right)^{2}}
$$

where $x_{i j}$ is the sample value at the horizontal position, $x_{j}$ the vertical sample, $w_{j-t}$ is the vertical smoothing term, $L$ is vertical window length and $I$ is horizontal window length - the sum being symmetrical about the sample point $t$. Dip guided variance can be used to accentuate faults; when used without dip guidance it can highlight depositional features such as channels and reefs (Schlumberger, 2012). For this project, dip guided variance was used to detect faults. The stratigraphy of the region is not too complicated, as the study area is located in one of the deeper more quiescent parts of the basin, so variance was not used to seek out stratigraphic anomalies in this study.

\subsubsection{Chaos}

The chaos attribute is a measure of the lack of organization in the dip and azimuth estimation method. The mathematics behind the chaos attribute are proprietary (therefore, not known to the author), but the attribute yields similar 
results as variance; chaos tends to extract significantly more discontinuities than the variance attribute (Figure 17). This attribute can be used to highlight discontinuities in the seismic data; these discontinuities can then be related to geologic features such as faults, joints, gas migration paths, and many other features.

\subsubsection{Microseismic}

Microseismic data were analyzed in Excel and Petrel to gain a better understanding of event timing and quality, event relationships to areas of disrupted seismic response, and microseismic response to variable pumping rates and fluid volumes. Proper event placement is critical to this study. Hypocenter locations may vary greatly between $-4,900$ ' and $-5,600$ ', as the outof-zone events were detected above the tool string (Figure 18). These events were still factored into the following interpretation.

Viewing limits were set for each well (Figure 19); the purpose of setting a viewing limit is to determine what the smallest magnitude event that can be detected reliably for all stages is - this is independent of SNR (signal-to-noise ratio) calculations. A viewing limit was not set for the MH6 well since it had only one stage. Magnitudes vs. time were plotted to ascertain when larger events occurred during the frac as well as where potential faults could have been activated (Figure 20). Fault activation can cause an increase in magnitudes, an increase in the number of microseismic events, and a change in the location of microseismic activity (Maxwell, 2014). Depths vs. magnitudes were also plotted to see at what depths the greatest magnitudes were located (Figure 21). Depths 


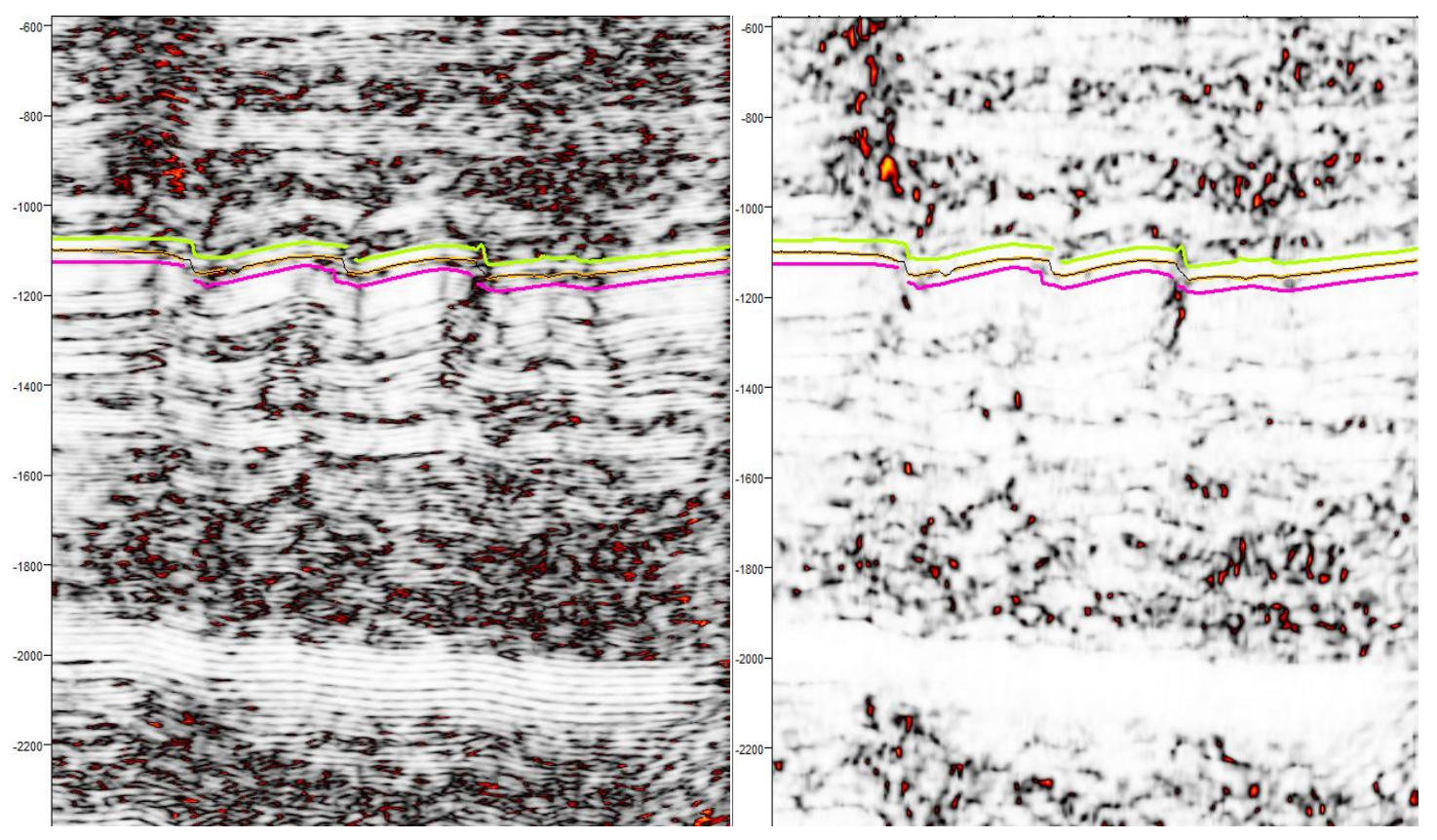

Figure 17: Chaos (left) vs. Dip-guided Variance (right). The chaos attribute highlights many more discontinuities in the seismic data than variance does. 


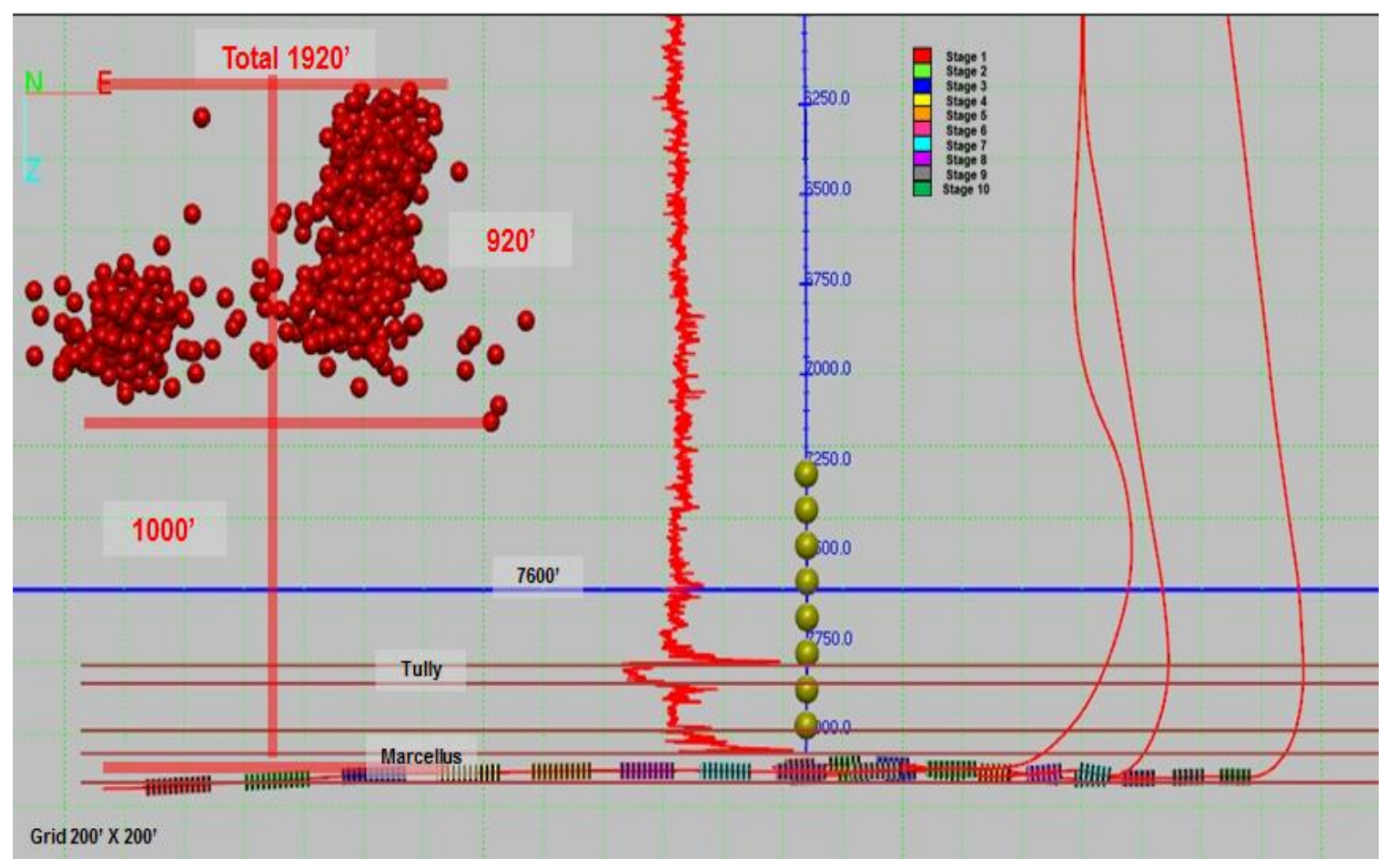

Figure 18: Out-of-zone microseismic events from the MH 6 well were detected above the tool string, and 200'above the uppermost geophone (tool string for Mohr\#6 shown). Image courtesy of Weatherford. 

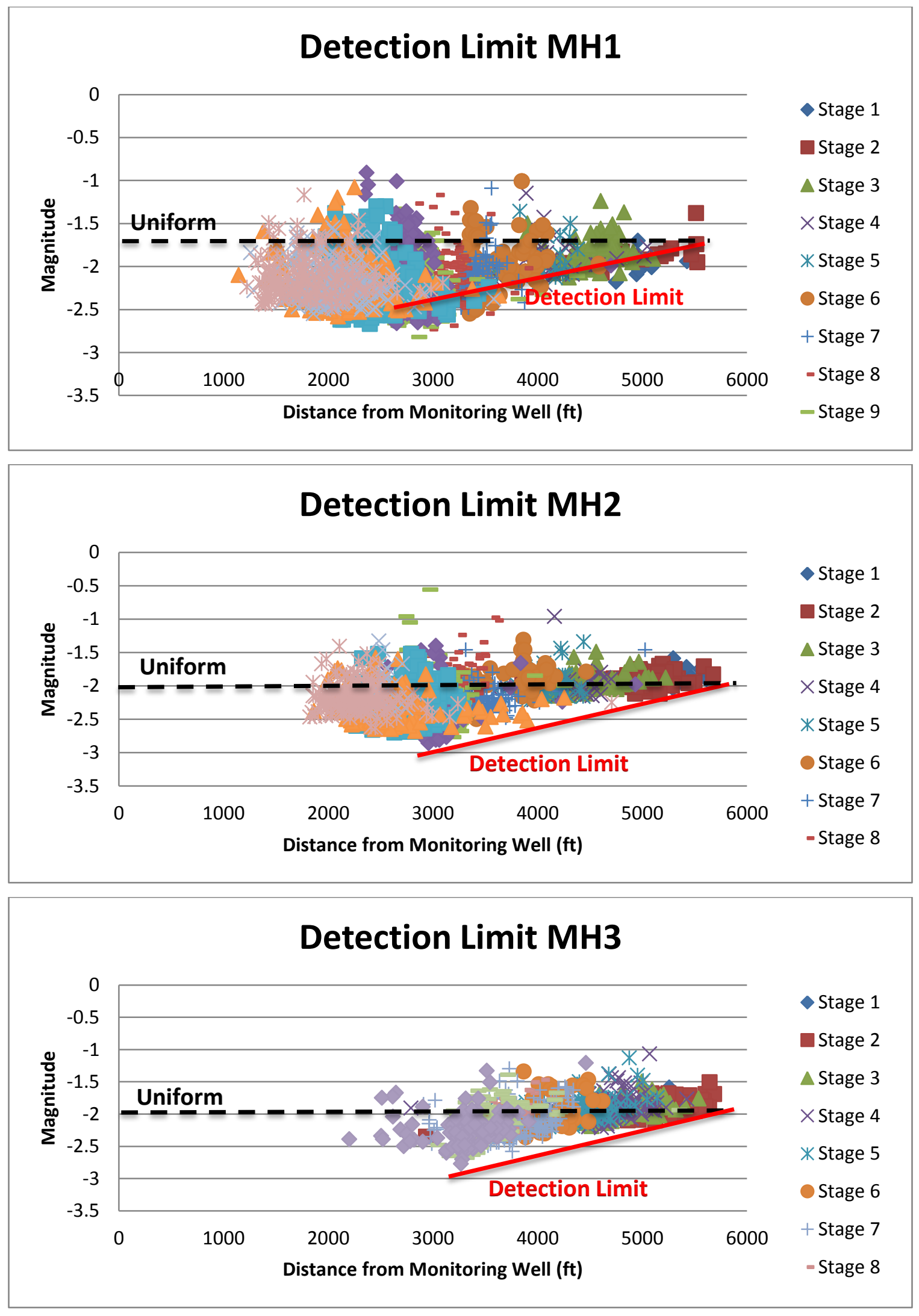

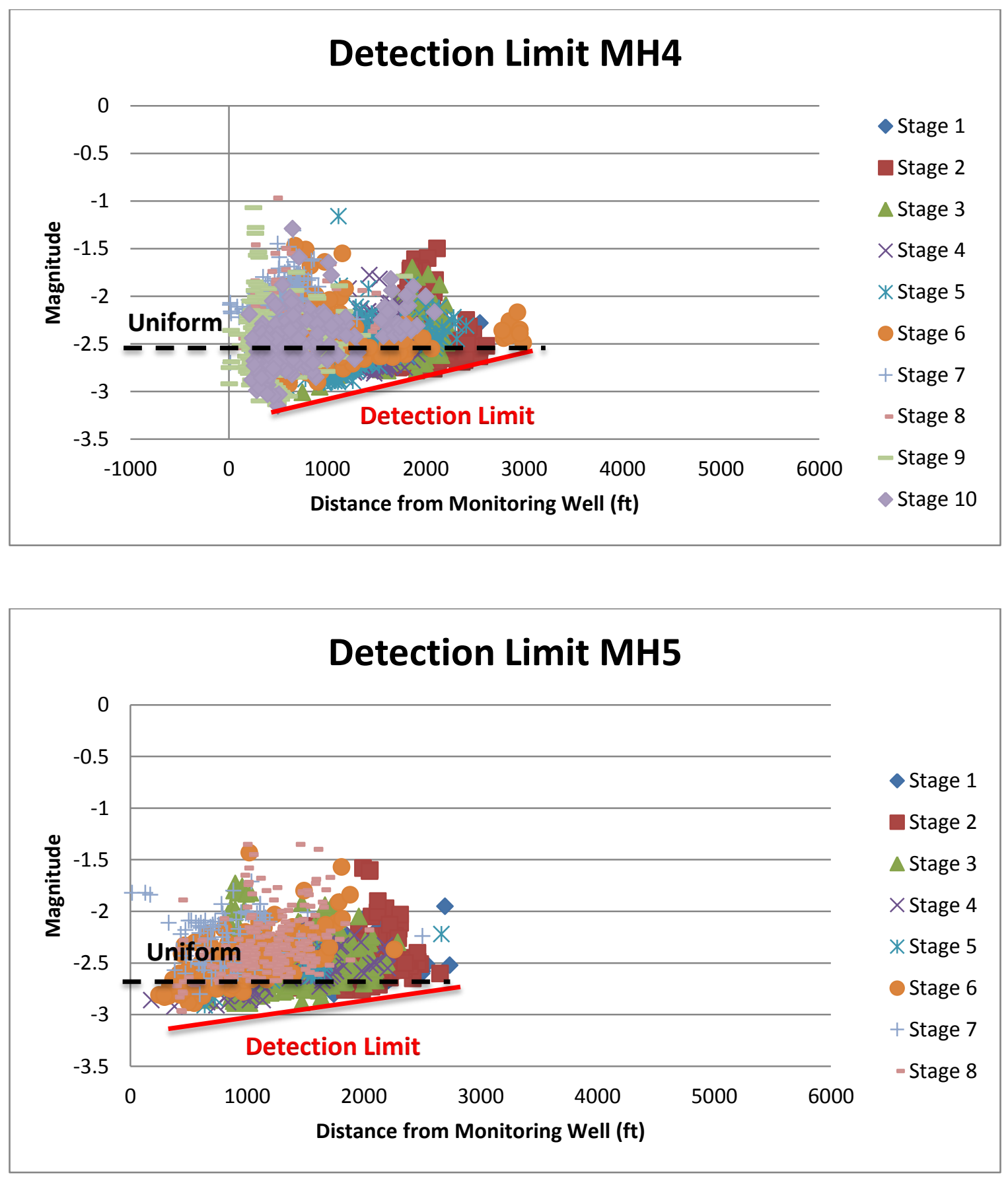

Figure 19: Viewing limits for each lateral well. Footwall wells seem to have an overall detectable magnitude of -2 , and hangingwall wells seem to have an overall detectable magnitude of -2.5 . 

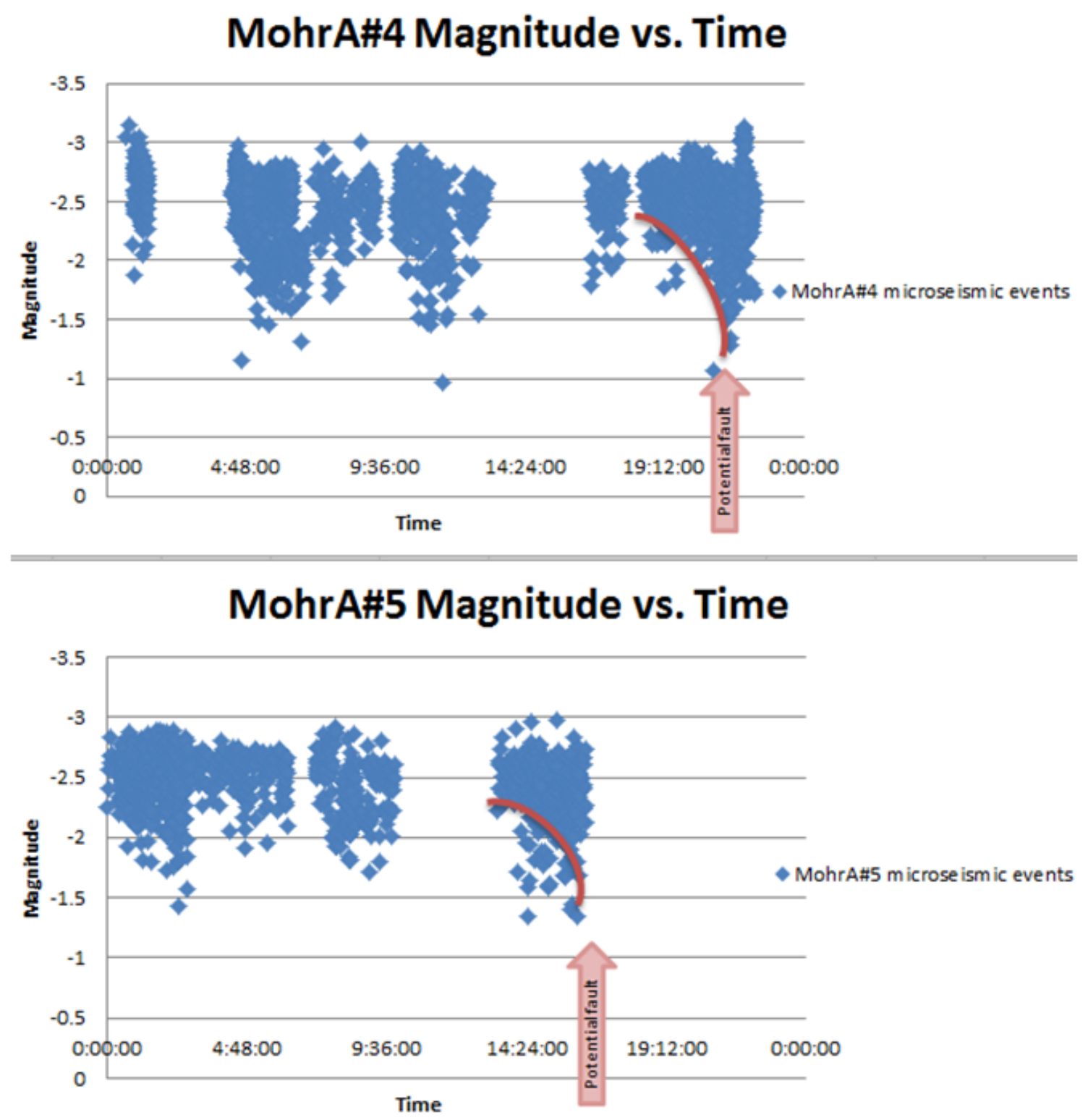

Figure 20: Magnitude vs. time graphs were made to determine whether there were any sharp rises in microseismic activity and magnitudes (which could be indicative of fault slip). 


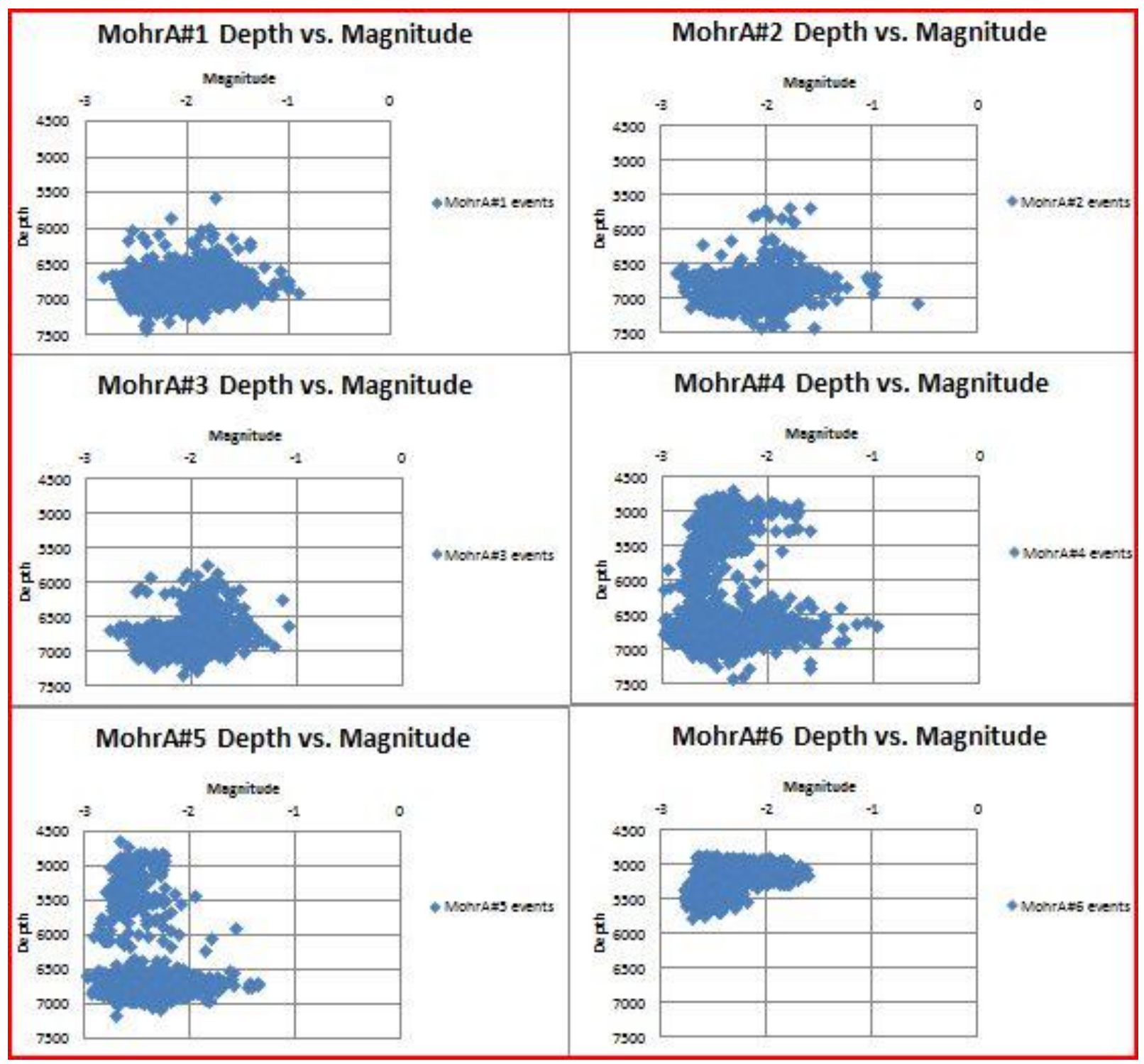

Figure 21: Depth vs. magnitude graphs were made to ascertain at what depths the greatest magnitudes existed. 
vs. time were graphed in order to determine when out-of- zone rupture first occurred and which depths experienced reactivation throughout the frac (Figure 22). Event spreads were also plotted to examine microseismic events scattering with respect to monitoring well locations (Figure 23). Events were also examined in Schlumberger's Petrel for the purpose of making visual correlations with any seismic attributes that may help explain why there was such extensive out-ofzone activity. Treatment curves, microseismic events colored by stage, and vertical distribution of microseismic events for the MH6 well (the well that generated extensive out-of-zone microseismic activity) can be seen in Appendix A. 


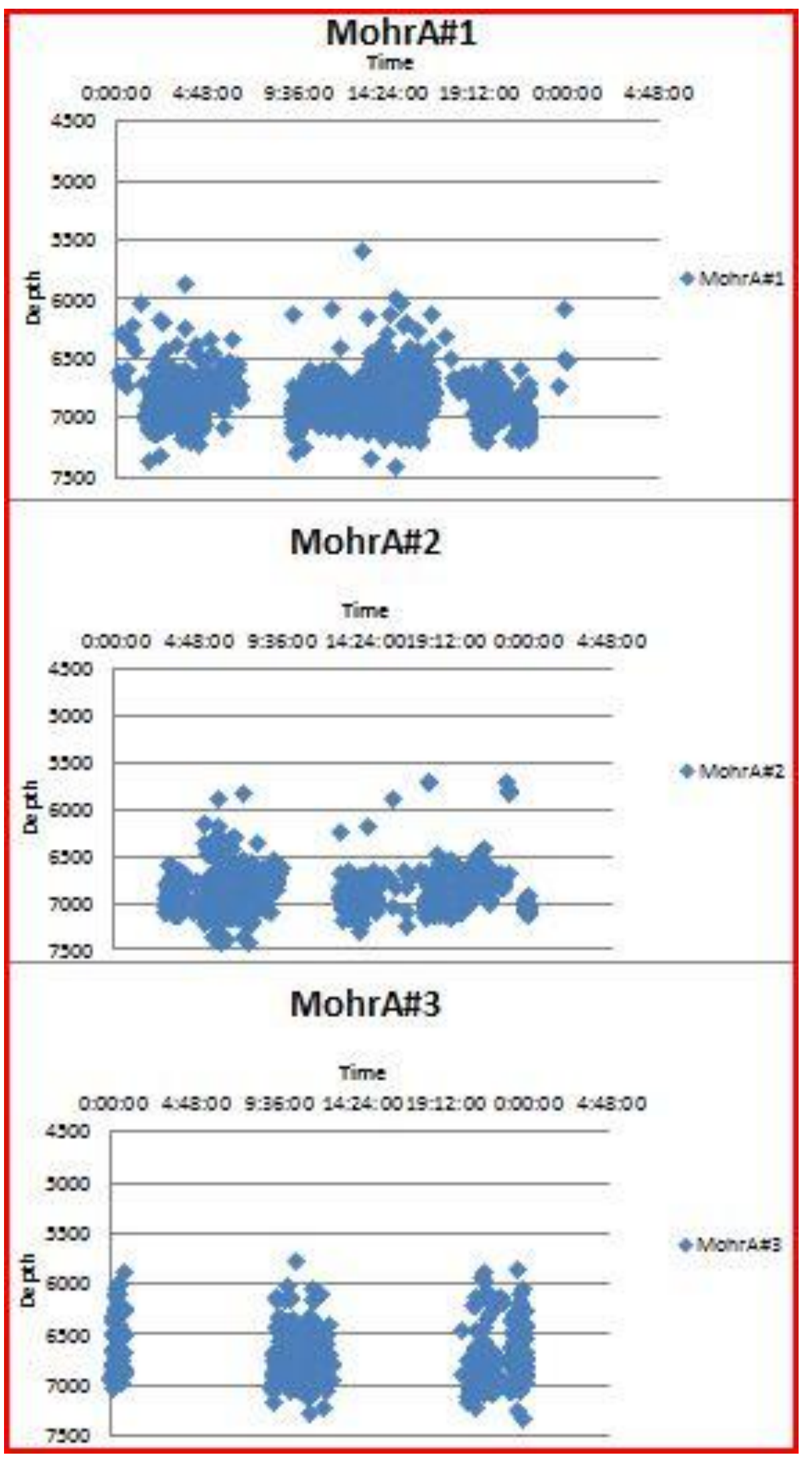




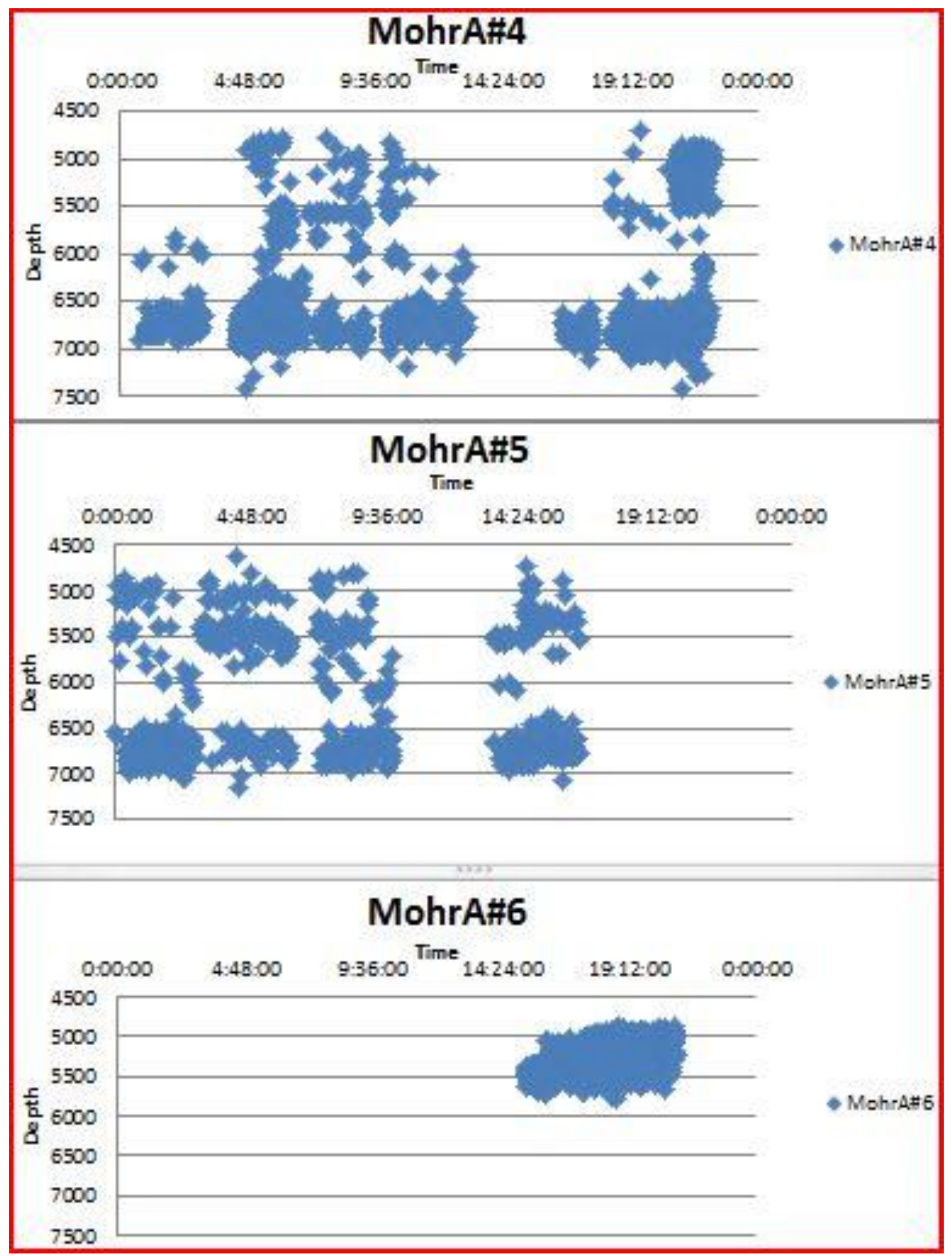

Figure 22: Depth vs. magnitude graphs were made to see what depths were continually activated throughout the frac. 


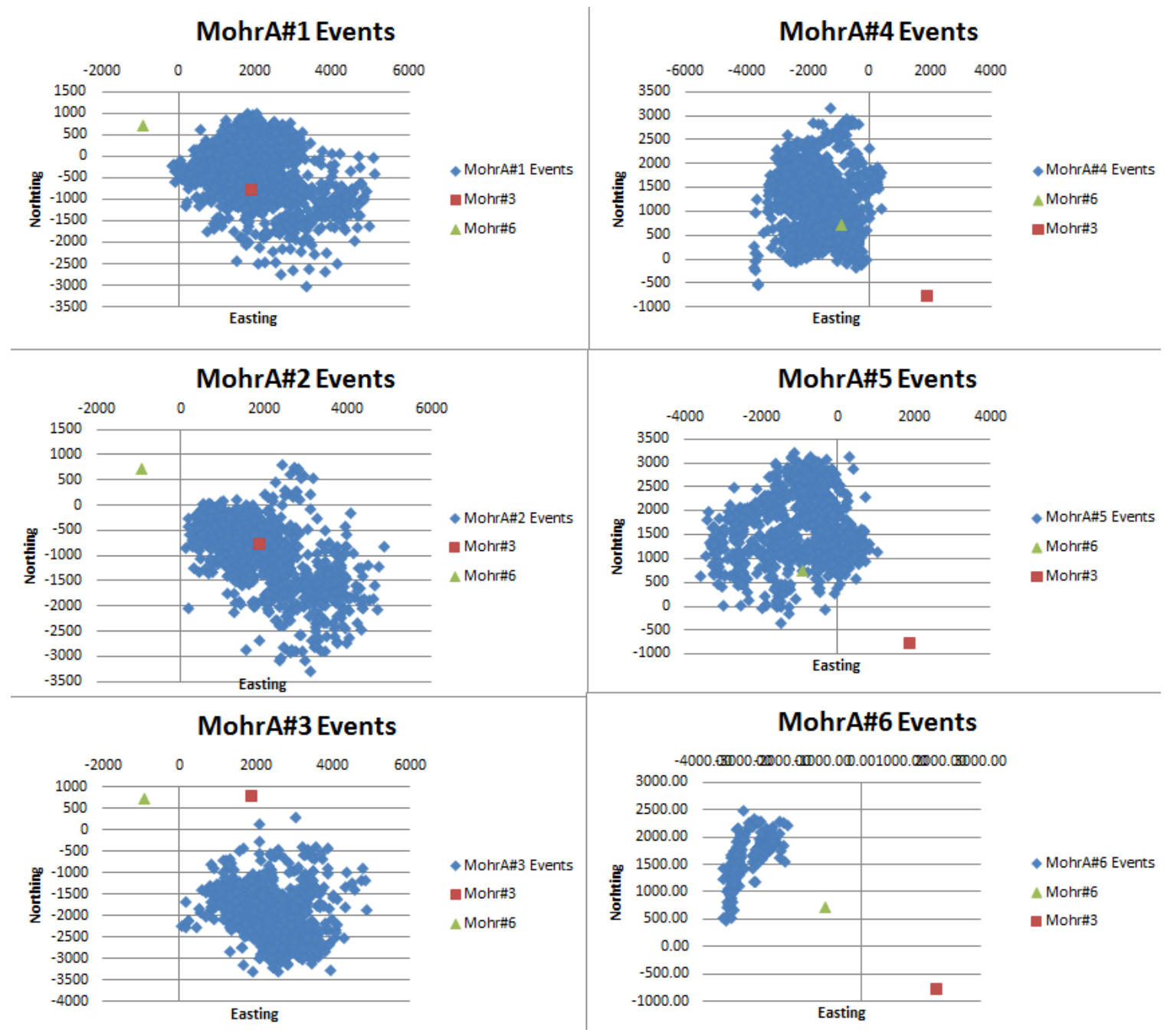

Figure 23: Events are plotted in mapview to see how much event spreading is occurring. Usually more event spreading will occur the farther one moves from the monitoring well. 


\section{Chapter 4: Microseismic Analysis}

Many studies have shown microseismic data to be an excellent tool for improving production strategies (Maxwell, 2014). For this study microseismic data have been used to infer how present day stresses may have influenced paleo-fracture systems activated during the frac, how much radiated seismic energy was released on a per stage basis, and what strata were affected by the hydraulic fracture treatments. These data may be used to improve drilling trajectories to better exploit pre-existing natural fracture networks, facilitate realtime adjustment of hydraulic fracture treatment design, or avoid non-beneficial fractures such as large faults.

\subsection{Microseismic Event Trend Analysis}

For this study microseismic event swarm orientations were examined on a stage-by-stage basis (Table 1); this allowed the author to infer which orientation wells in the area should be drilled. $\mathrm{S}_{\mathrm{Hmax}}$ was assumed to be about N96E based off of A level (high quality) thrust regime world stress map data (Heidbach et al., 2008), and this data originates from hydraulic fracture treatments of 4 well localities several $\mathrm{km}$ apart. Most of the microseismic clusters form within $30-40$ degrees of this trend (Wilson et al., 2014a); this offset of event clusters from $\mathrm{S}_{\mathrm{Hmax}}$ indicates events could have occurred along pre-existing natural fractures, and the orientations in which they occurred are suitable for shear motion (Yang and Zoback, 2014).

As part of the event trend analysis, microseismic event swarm orientations and vertical extents of event swarms were measured. Primary event cloud 
Table 1: Author's interpretation of microseismic event swarm orientations

\begin{tabular}{|c|c|c|c|c|c|c|c|c|}
\hline MH1 & primary & secondary & MH2 & primary & secondary & МH3 & primary & secondary \\
\hline stage 1 & 36 & & stage 1 & 54 & & stage 1 & 69 & \\
\hline stage 2 & 26 & & stage 2 & 48 & & stage 2 & 68 & \\
\hline stage 3 & 50 & & stage 3 & 62 & 6 & stage 3 & 61 & \\
\hline stage 4 & 65 & 20 & stage 4 & 46 & & stage 4 & 56 & \\
\hline stage 5 & 74 & 43 & stage 5 & 56 & & stage 5 & 52 & \\
\hline stage 6 & 80 & 62 & stage 6 & 58 & 68 & stage 6 & 60 & \\
\hline stage 7 & 56 & & stage 7 & 51 & & stage 7 & 52 & \\
\hline stage 8 & 63 & & stage 8 & 59 & & stage 8 & 48 & \\
\hline stage 9 & 57 & & stage 9 & 57 & & stage 9 & 57 & \\
\hline stage 10 & 57 & & stage 10 & 70 & & stage 10 & 62 & \\
\hline stage 11 & 63 & 15 & stage 11 & 70 & & & & \\
\hline stage 12 & 52 & & stage 12 & 65 & 1 & & & \\
\hline stage 13 & 55 & & stage 13 & 20 & & & & \\
\hline stage 14 & 53 & & stage 14 & 44 & & & & \\
\hline MH4 & primary & secondary & MH5 & primary & secondary & MH6 & primary & secondary \\
\hline stage 1 & 51 & & stage 1 & 62 & & stage 1 & 60 & 18 \\
\hline stage 2 & 48 & 36 & stage 2 & 60 & & & & \\
\hline stage 3 & 35 & 68 & stage 3 & 56 & 77 & & & \\
\hline stage 4 & 50 & & stage 4 & 62 & & & & \\
\hline stage 5 & 58 & 85 & stage 5 & 66 & & & & \\
\hline stage 6 & 55 & & stage 6 & 71 & & & & \\
\hline stage 7 & 46 & & stage 7 & 60 & & & & \\
\hline stage 8 & 56 & & & & & & & \\
\hline stage 9 & 61 & & & & & & & \\
\hline stage 10 & 54 & 8 & & & & & & \\
\hline
\end{tabular}

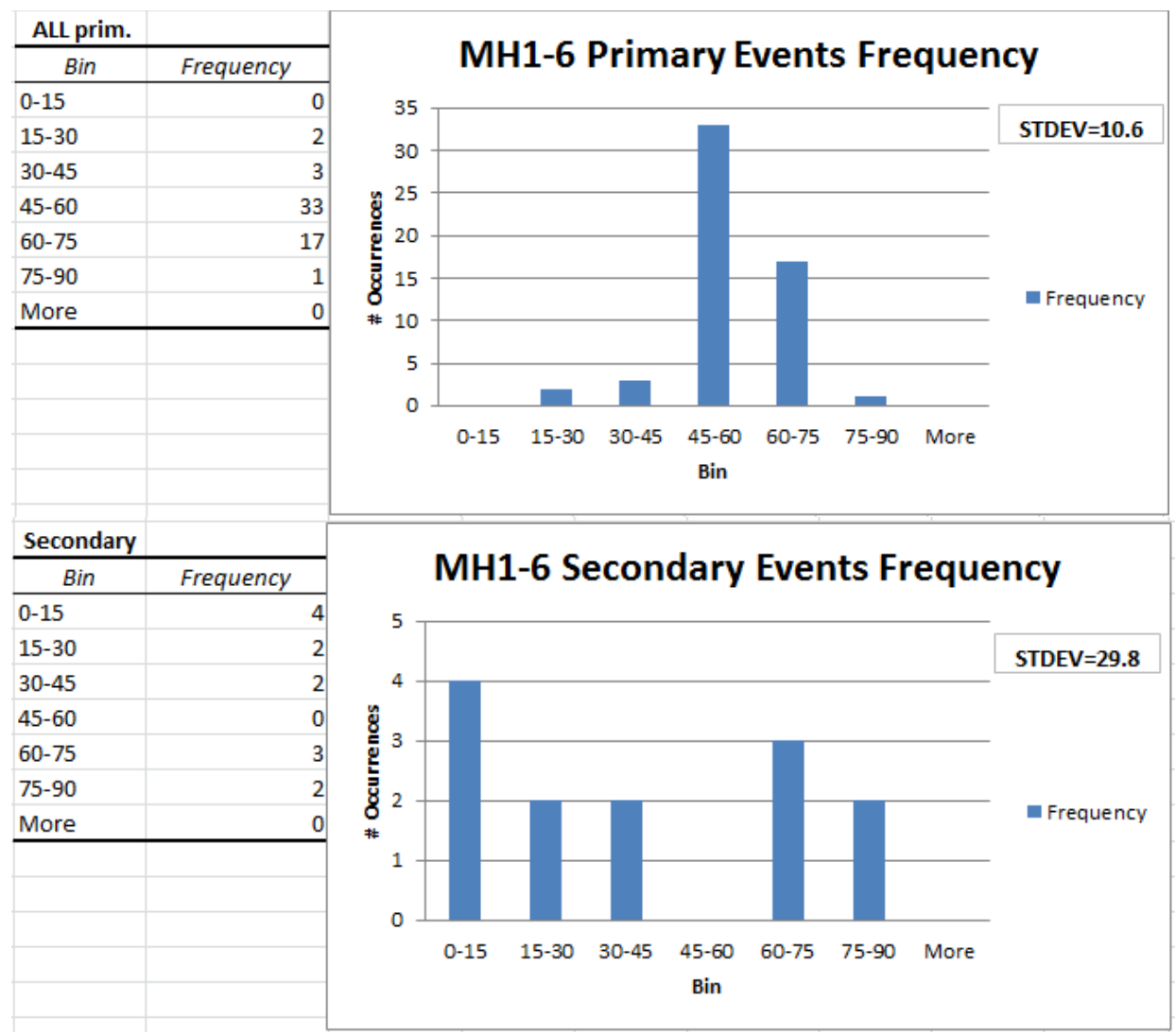


orientations are identified as those with the most events in-reservoir, and secondary event cloud orientations are other event cloud trends that differ from the primary event cloud (Figure 24). Overall primary event cloud azimuths are oriented at acute angles to $\mathrm{S}_{\mathrm{Hmax}}$ that are likely associated with shear failure. Although focal mechanisms derived from research conducted by Microseismic Inc., and Hulsey et al. (2010) have shown strike-slip activation to be common in the Marcellus Shale, the relative magnitudes of $S_{H \max }$ and $S_{v}$ are unknown in the study area. However, the relative orientations of event clouds to $S_{H \max }$ help support the idea that during hydraulic stimulation shearing is occurring on preexisting natural fractures (Yang and Zoback, 2014). Preferential upward growth of microseismic activity is common in the Marcellus Shale (Warpinski, 2009 and Maxwell, 2011) (Figure 25); this occurrence suggests that $S_{v}$ is greater than $\mathrm{S}_{\text {Hmax. }}$ The TVTAS (time variant trace amplitude slicing) seismic volume shows a complex system of small faults and fracture zones in the Upper Devonian section; the residual stress on some of these small faults and fracture zones from earlier tectonic events probably left generated fractures in the out-of-zone area critically stressed and close to their frictional limit. Small changes in pore pressure produced by hydraulic fracture treatments may produce failure without direct interactions with injected fluids (Wilson et al., 2014a). It is likely that out-ofzone microseismicity is controlled by pre-existing faults and fracture zones (Wilson et al., 2014a).

Event swarm orientations were more difficult to determine towards the toes of each well, as many events were probably out of the monitoring well's 


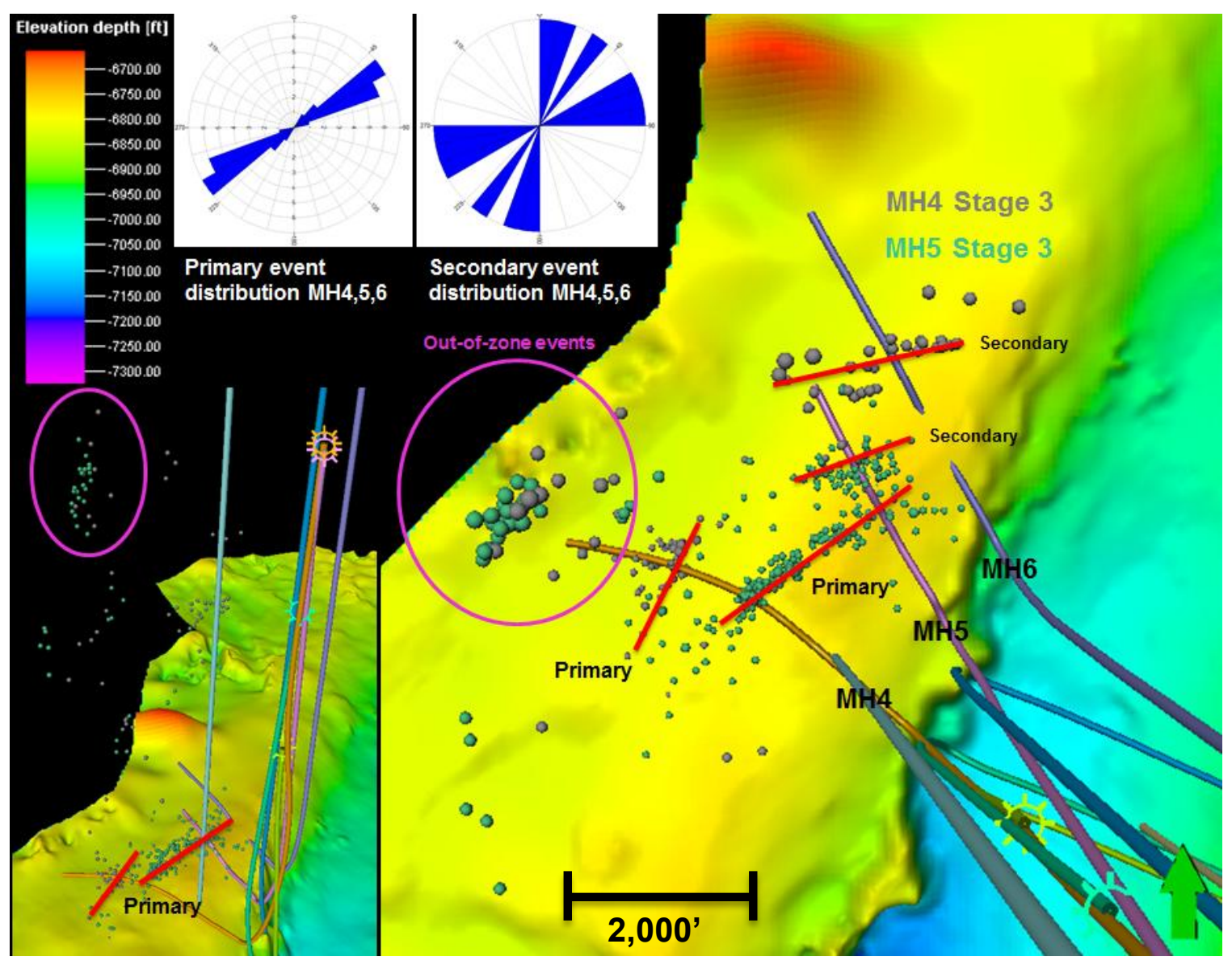

Figure 24: Primary event cloud vs. secondary event cloud orientations shown on surface of Onondaga Limestone. Note on inset view that primary event clouds remain inreservoir. 


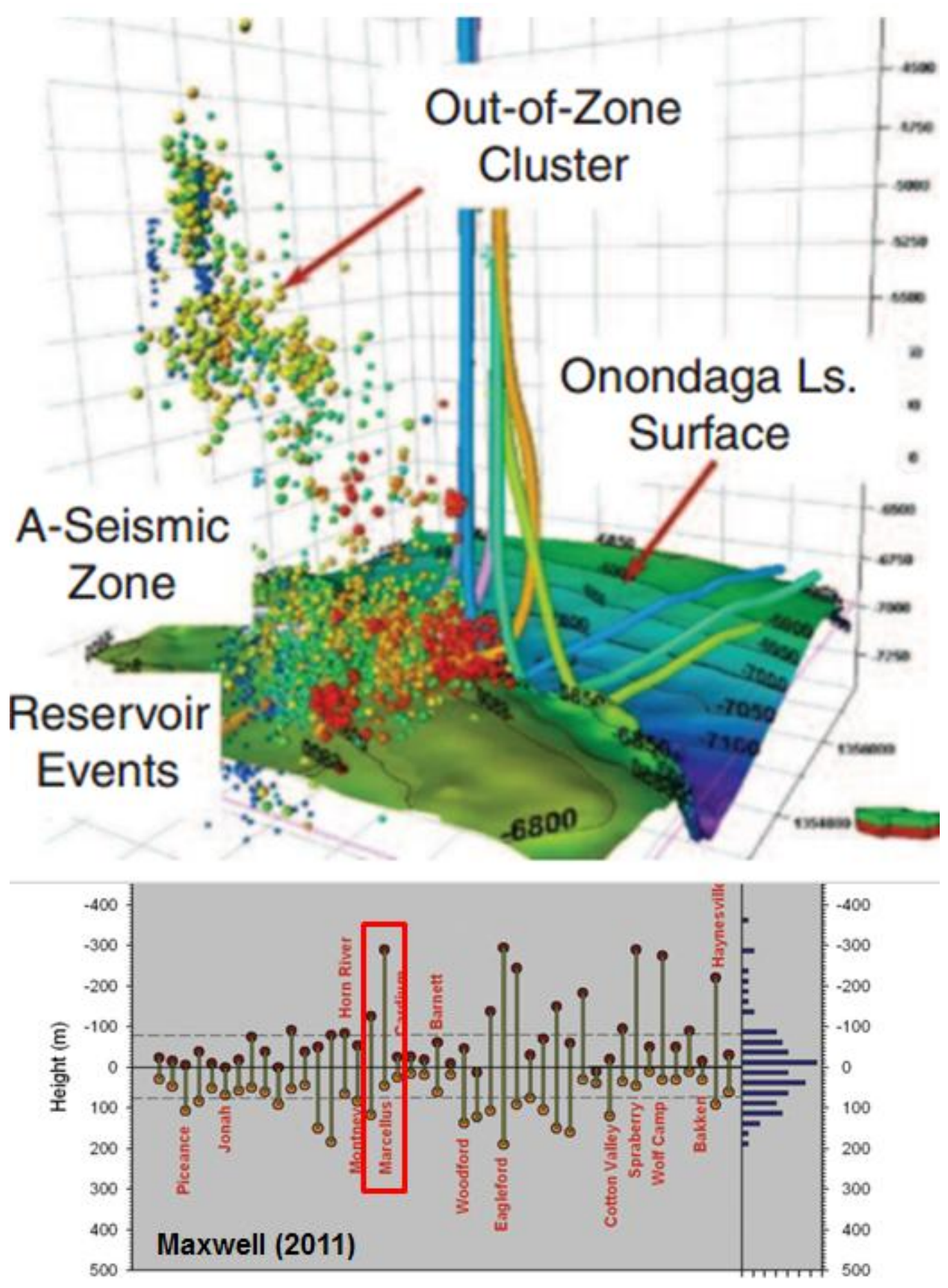

Figure 25: Microseismic events shown for all hangingwall wells (Wilson et al., 2014c). Note the extensive upward vertical propagation. Inset are results compiled from other research; microseismic activity in the Marcellus tends to propagate upward quite extensively. $300 \mathrm{~m}=>984.25 \mathrm{ft}$. 
reliable listening radius and their location could be imprecisely known (Figure 26). Microseismic events swarms were also compared with $t^{\star}$ attenuation-based seismic discontinuity workflow maps generated for the study. Results from Wilson et al. (2014a) show that seismic discontinuity mapping integrated with microseismic data can be a useful tool for inferring where zones of increased fracture intensity may be present (Figure 27). The TVTAS seismic volume also shows complex faulting exists throughout the area (Figure 28). Vertically-oriented discontinuities are present throughout the Upper Devonian section; this is also where there was a large vertically-oriented out-of-zone concentration of microseismic activity.

One question that was posed was whether there was a fluid connection between the out-of-zone microseismic activity and the reservoir events. It is not likely there is a direct fluid connection between reservoir events and out-of-zone events. Out-of-zone events are positioned $\sim 1,100$ ' above the reservoir with very few events in between the main reservoir event cloud and the out-of-zone events (Figure 29); this evidence suggests that there is not a direct hydraulic connection between the out-of-zone events and reservoir events. The presence of numerous proximal cross well events also supports the lack of a direct fluid connection; Wilson et al., (2014b) describes proximal cross well events as those occurring close to events produced during the treatments of nearby wells (in the case of this research, within $\left.75^{\prime}\right)$. This occurrence implies repeated rupture in the same or nearly the same area in response to treatment stages separated by 3,300 to 5,000 feet (Wilson et al., 2014c). 


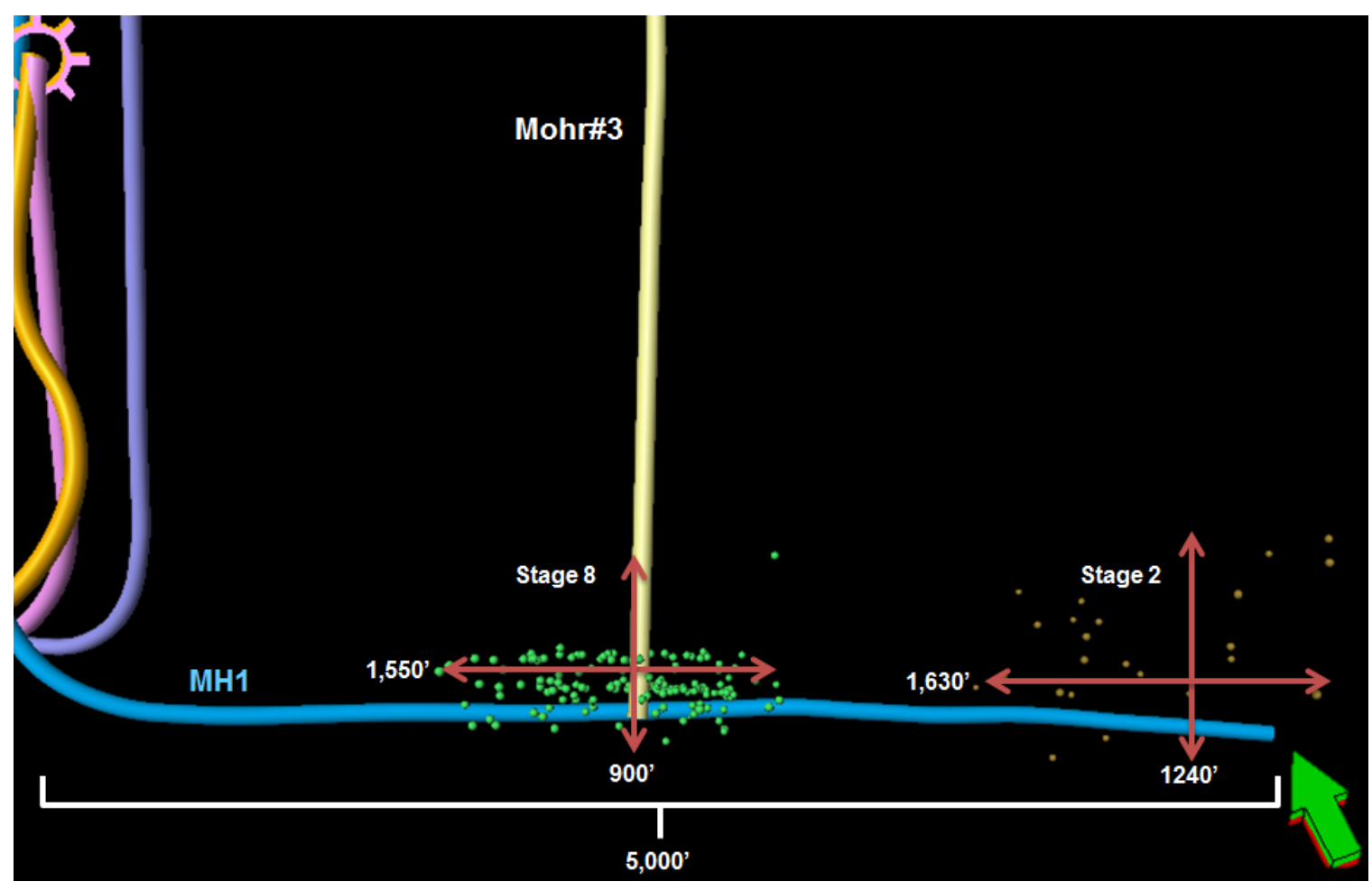

Figure 26: Microseismic events for stages 8 and 2 from the MH1 well. Note event scatter occurring towards the toe of the well. 


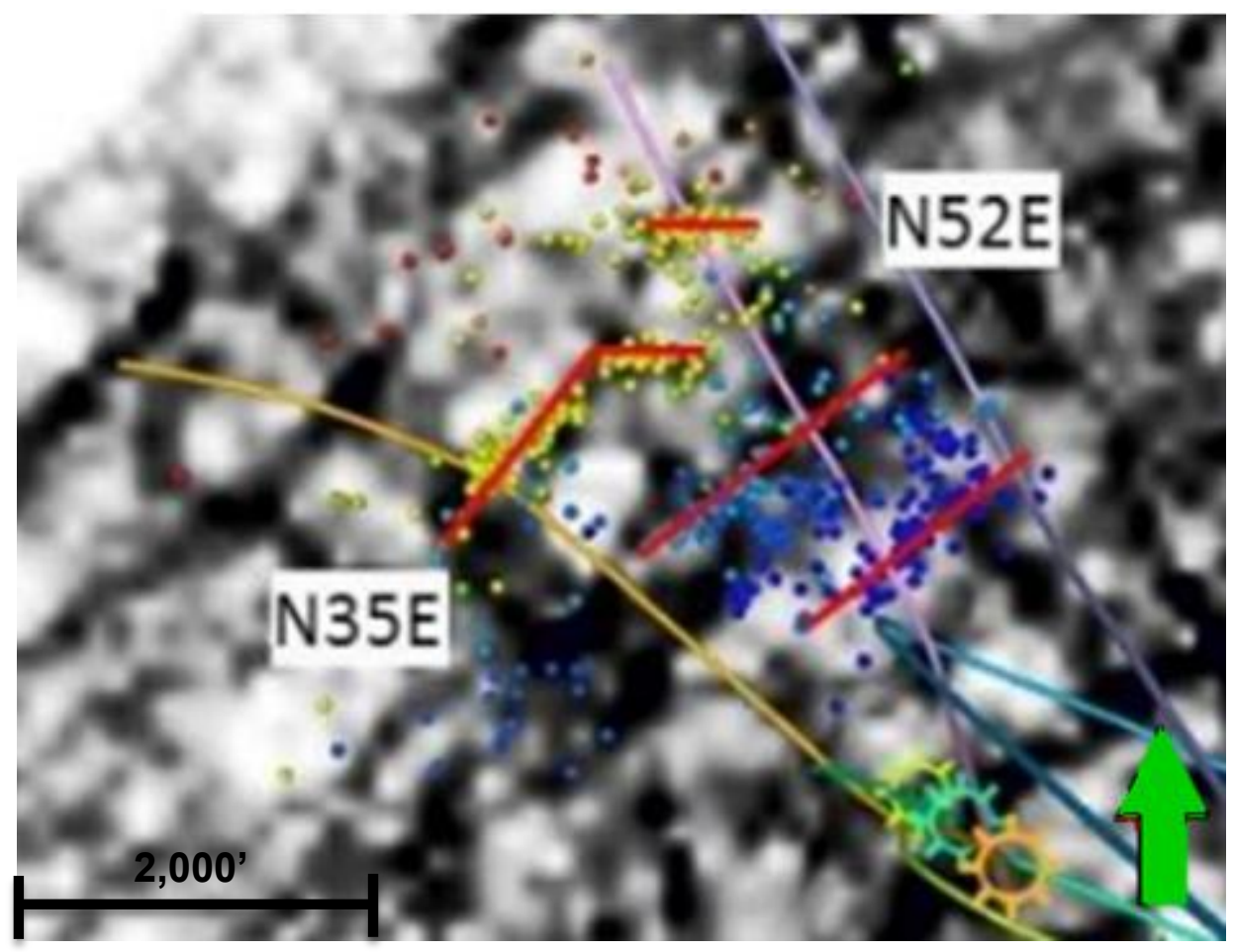

Figure 27: Microseismic events produced for the MH5 well displayed on extracted seismic discontinuities. Modified from Wilson et al., (2014a). 


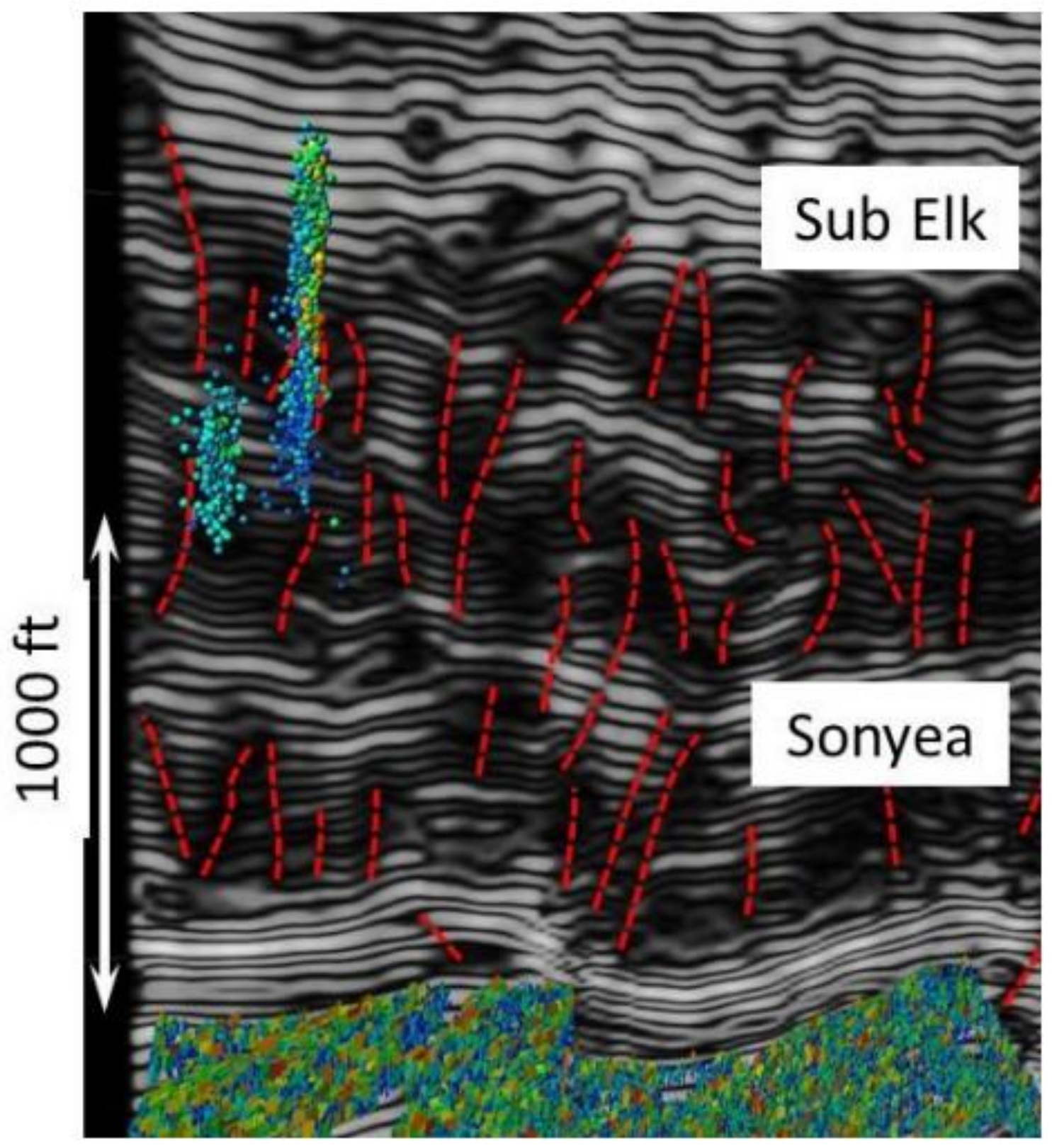

Figure 28: Figure taken from Wilson et al., (2014a). The TVTAS volume shows complex faulting exists throughout the area of out-of-zone microseismic activity. 


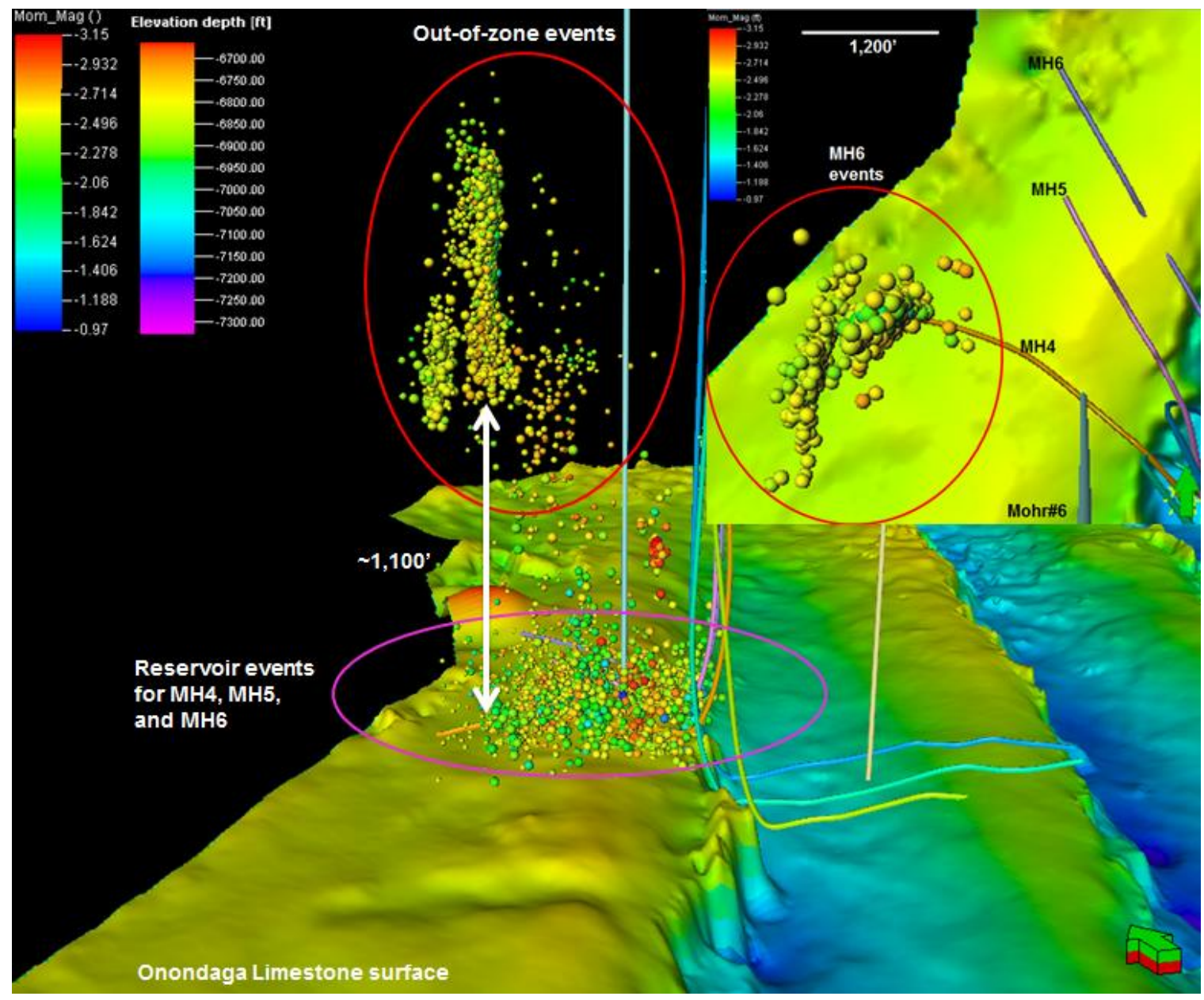

Figure 29: Notice the lack of microseismic activity between the main reservoir events and the out-of-zone events. There is also an absence of microseismic events extending from stage 1 of the MH6 well over to the MH4 well. 


\subsection{Energy Release Analysis}

Injection energy, fracture energy, and radiated seismic energy were calculated on a stage-by-stage basis for all wells in this study using Boroumand and Eaton's method (2012); tabulated results and equations can be seen in Table 2. Injection energies were calculated to ascertain how much energy input was available for the hydraulic fracturing process, fracture energies were estimated to see how much energy was needed to create a tensile fracture (Figure 30) (value used for fracture width in Table 2), and radiated seismic energies were calculated to determine how much energy was released by the frac in the form of microseismicity (Boroumand and Eaton, 2012).

These results show that footwall wells ( $\mathrm{MH} 1,2$, and 3$)$ released 3 times the radiated seismic energy that hangingwall wells $(\mathrm{MH} 4,5$, and 6) did (Figure 31). Injection energy for footwall wells was 1.2 times greater than the energy put into hangingwall wells, and footwall wells also generated 2 times more fracture energy than hangingwall wells (Figures 32-33). Footwall wells did have overall higher injection, fracture, and radiated seismic energies associated with them, but we only have microseismic data for one stage of the MH6 well (on the hangingwall). This lack of data for an entire well is going to bias results. In order to offset some of this bias injection, fracture, and radiated seismic energies were normalized by average per stage (Table 3 ).

Hangingwall injection, fracture, and radiated seismic energies are on average lower than those of the footwall wells (refer to Figures 31-33); however, the $\mathrm{MH} 6$ well, a hangingwall well, did generate in one stage more microseismic 
Table 2: Energy analysis results

\begin{tabular}{|c|c|c|c|c|c|c|}
\hline Well & Average Eı per Stage & Total EI & Average EF per Stage & Total EF & Average Es per Stage & Total Es \\
\hline MH1 & $1.28 \mathrm{E}+11$ & $1.79 E+12$ & $1.16 \mathrm{E}+10$ & $1.62 \mathrm{E}+11$ & $1.15 E+04$ & $1.61 \mathrm{E}+05$ \\
\hline MH2 & $6.87 E+10$ & $9.62 E+11$ & $8.29 E+09$ & $1.16 \mathrm{E}+11$ & $7.59 \mathrm{E}+03$ & $1.06 \mathrm{E}+05$ \\
\hline MH3 & $7.10 E+10$ & $7.10 E+11$ & $8.20 E+09$ & $8.20 E+10$ & $7.84 \mathrm{E}+03$ & $7.84 \mathrm{E}+04$ \\
\hline MH4 & $6.70 E+10$ & $6.70 E+11$ & $7.96 \mathrm{E}+09$ & $7.96 \mathrm{E}+10$ & $1.12 \mathrm{E}+03$ & $6.64 \mathrm{E}+04$ \\
\hline MH5 & $7.45 E+10$ & $5.21 E+11$ & $5.49 \mathrm{E}+09$ & $3.30 E+10$ & $1.26 \mathrm{E}+03$ & $2.86 \mathrm{E}+04$ \\
\hline MH6 & $7.77 E+10$ & $7.77 E+10$ & $6.10 \mathrm{E}+08$ & $6.10 E+08$ & $2.28 \mathrm{E}+04$ & $2.28 \mathrm{E}+04$ \\
\hline \multicolumn{3}{|c|}{$E_{I}=$ Injection energy } & \multicolumn{3}{|c|}{$P(t)=$ Surface treatment pressure } & \\
\hline \multicolumn{3}{|c|}{$E_{F}=$ Fracture energy } & \multicolumn{2}{|c|}{$Q(t)=$ Injection rate } & & \\
\hline \multicolumn{3}{|c|}{$E_{s}=$ Radiated seismic energy } & $P_{d}=$ Dow & \multicolumn{2}{|c|}{$P_{d}=$ Downhole pressure } & \\
\hline \multicolumn{3}{|c|}{$E_{I}=\langle P(t)\rangle\langle Q(t)\rangle \Delta t$} & \multicolumn{4}{|c|}{$\begin{array}{l}A_{F}=\text { Fracture area }=(\mu \text { seismic event swarm length } \\
\mu \text { seismic event swarm height })\end{array}$} \\
\hline \multicolumn{3}{|c|}{$\begin{array}{l}E_{F}=\left\langle P_{d}\right\rangle A_{F} w \\
\log _{10} E_{S}=1.5 M_{0}+4.8\end{array}$} & \multicolumn{4}{|c|}{$\begin{array}{l}w=\text { Fracture width }=5 \mathrm{~mm} \\
M_{0}=\text { Moment magnitude }\end{array}$} \\
\hline
\end{tabular}

${ }^{* *}$ Equations highlighted in red box. All energies are measured in Joules 


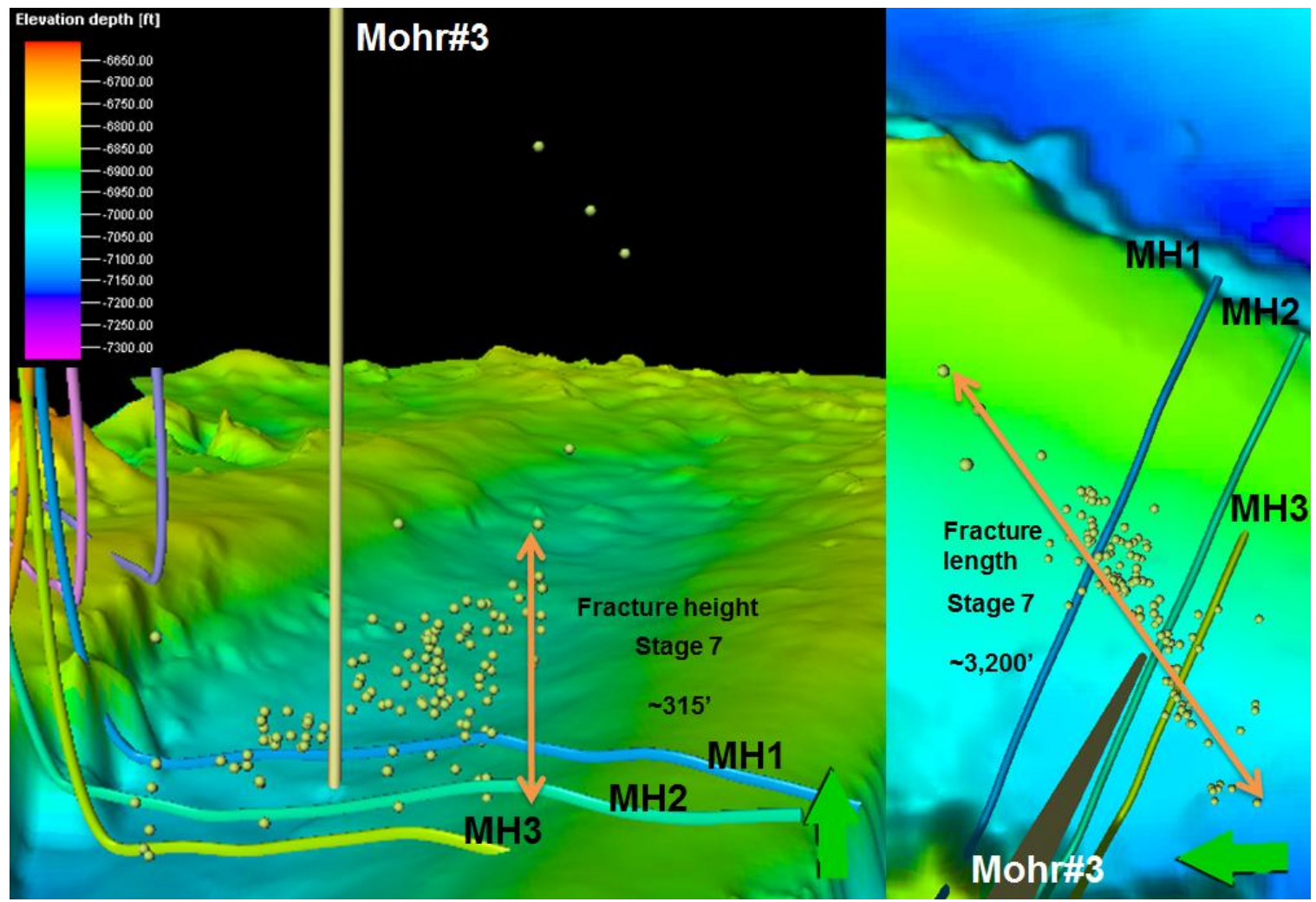

Figure 30: Fracture area determination example for stage 7 of the MH1.Microseismic event cloud height (left) and length (right) values were used to determine fracture energy for this stage. Greater height and length are usually associated with a more complex fracture network. Fracture width estimation was taken from the literature and was estimated to be $5 \mathrm{~mm}$ - this value was used for each stage of each well. 

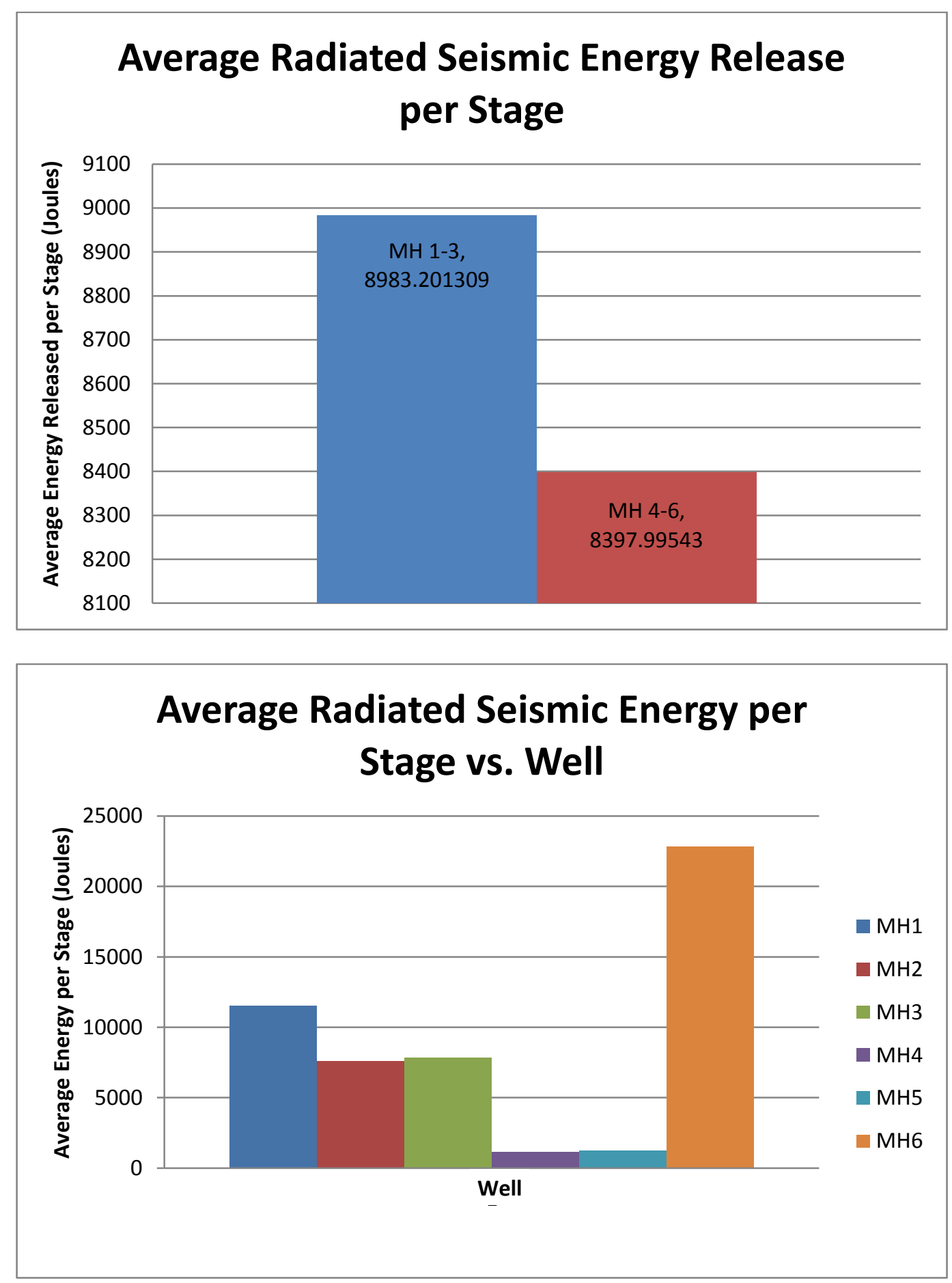

Figure 31: footwall wells (MH1, 2, and 3) released 3 times the radiated seismic energy that hangingwall wells (MH4, 5, and 6) did; however, the MH6 well accounts for $90 \%$ of the radiated seismic energy release for Hangingwall wells. 

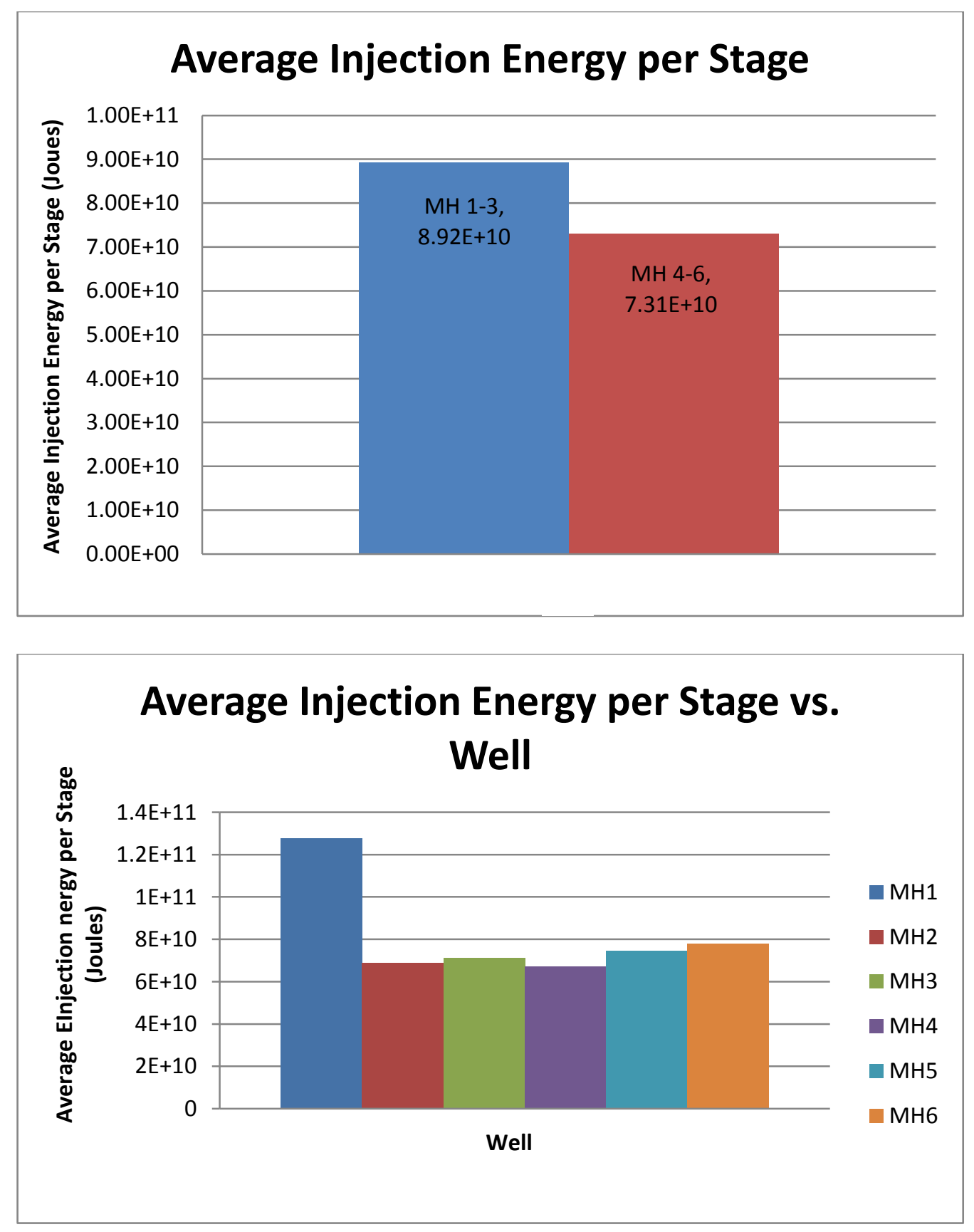

Figure 32: Injection energy for footwall wells was 1.2 times greater than the energy put into hangingwall wells. Other than the MH1 well, there wasn't much of a difference in injection energies on a per stage basis. 

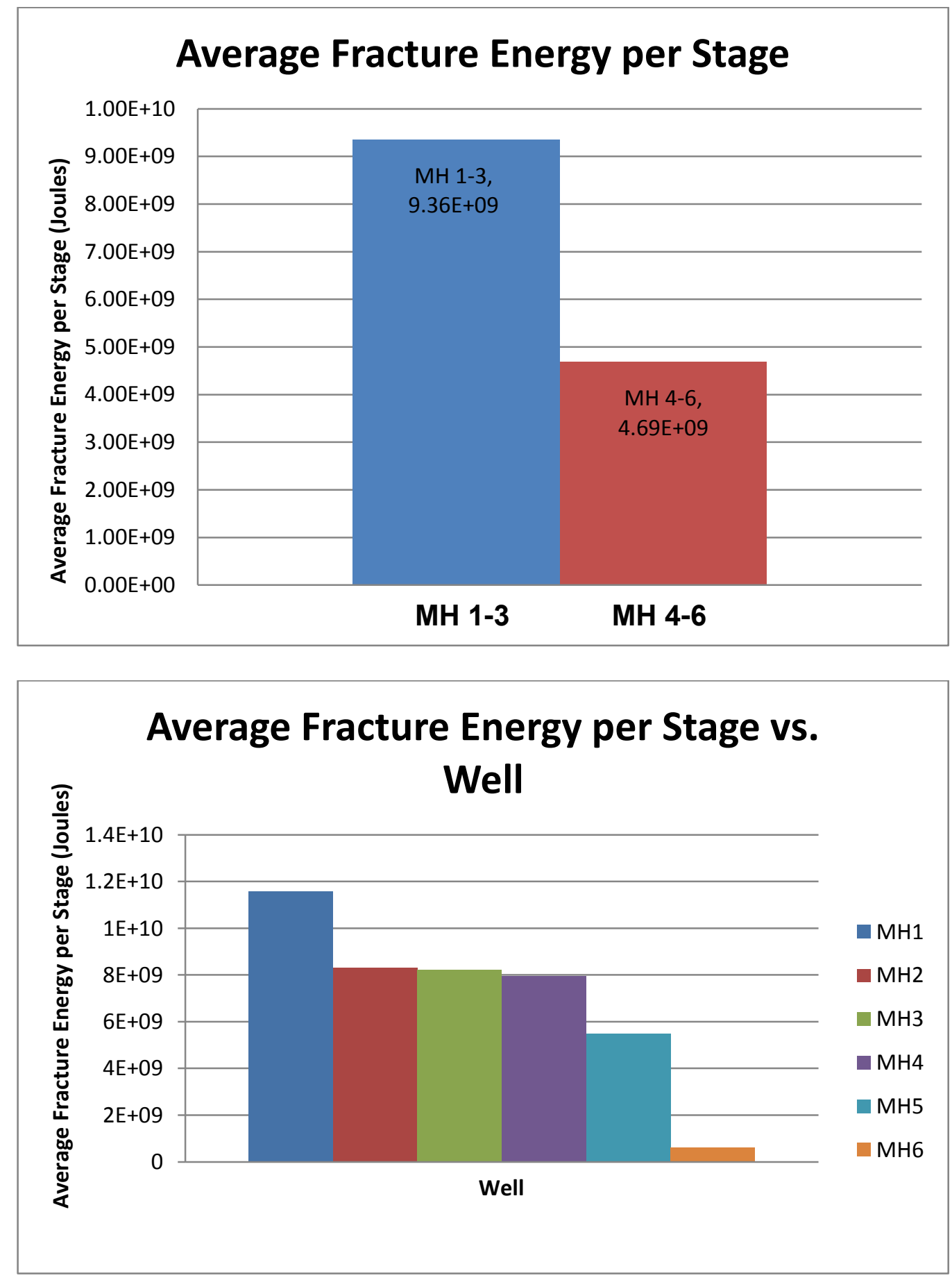

Figure 33: Footwall wells generated 2 times more fracture energy than hangingwall wells on a per stage basis. The frac was much more effective for footwall wells. 
Table 3: Average Fracture, Injection, and Radiated Seismic Energies per Stage

\begin{tabular}{|c|c|c|c|c|c|c|}
\hline & $\mathrm{EF}$ & $\begin{array}{l}\text { Avg. EF per } \\
\text { stage }\end{array}$ & EI & Avg. El per stage & ES & Avg. ES per stage \\
\hline MH1 & $7.8 \mathrm{E}+08$ & & $1.1 \mathrm{E}+11$ & & $8.2 \mathrm{E}+02$ & \\
\hline \multirow[t]{13}{*}{1} & $1.5 \mathrm{E}+10$ & & $1.3 \mathrm{E}+11$ & & $2.9 E+03$ & \\
\hline & $2.4 \mathrm{E}+10$ & & $1.4 \mathrm{E}+11$ & & $1.2 \mathrm{E}+04$ & \\
\hline & $1.0 \mathrm{E}+10$ & & $1.4 \mathrm{E}+11$ & & $5.4 \mathrm{E}+03$ & \\
\hline & $4.8 \mathrm{E}+09$ & & $1.6 \mathrm{E}+11$ & & 2.7E+03 & \\
\hline & $1.2 \mathrm{E}+10$ & & $1.2 \mathrm{E}+11$ & & $1.5 \mathrm{E}+04$ & \\
\hline & $1.4 \mathrm{E}+10$ & & $1.4 \mathrm{E}+11$ & & $6.1 \mathrm{E}+03$ & \\
\hline & $8.9 E+09$ & & $1.2 \mathrm{E}+11$ & & $1.0 \mathrm{E}+04$ & \\
\hline & $1.2 \mathrm{E}+10$ & & $1.1 \mathrm{E}+11$ & & $1.1 \mathrm{E}+04$ & \\
\hline & $1.1 \mathrm{E}+10$ & & $1.2 \mathrm{E}+11$ & & $3.5 E+04$ & \\
\hline & $1.3 \mathrm{E}+10$ & & $1.1 \mathrm{E}+11$ & & $2.2 \mathrm{E}+04$ & \\
\hline & $1.4 \mathrm{E}+10$ & & $1.2 \mathrm{E}+11$ & & $1.4 \mathrm{E}+04$ & \\
\hline & $1.1 \mathrm{E}+10$ & & $1.2 \mathrm{E}+11$ & & $1.3 \mathrm{E}+04$ & \\
\hline & $1.1 \mathrm{E}+10$ & $1.2 \mathrm{E}+10$ & $1.4 \mathrm{E}+11$ & $1.3 \mathrm{E}+11$ & $1.1 \mathrm{E}+04$ & $1.2 \mathrm{E}+04$ \\
\hline MH2 & $1.8 \mathrm{E}+09$ & & $9.0 E+10$ & & $2.1 \mathrm{E}+03$ & \\
\hline \multirow[t]{13}{*}{2} & $5.5 \mathrm{E}+09$ & & $6.5 E+10$ & & $4.6 \mathrm{E}+03$ & \\
\hline & $1.3 \mathrm{E}+10$ & & $7.8 \mathrm{E}+10$ & & $7.8 \mathrm{E}+03$ & \\
\hline & $7.4 \mathrm{E}+09$ & & $8.0 E+10$ & & $4.5 \mathrm{E}+03$ & \\
\hline & $6.9 E+09$ & & $6.8 \mathrm{E}+10$ & & $4.3 \mathrm{E}+03$ & \\
\hline & $4.4 \mathrm{E}+09$ & & $7.4 \mathrm{E}+10$ & & $6.4 \mathrm{E}+03$ & \\
\hline & $4.7 \mathrm{E}+09$ & & $6.6 \mathrm{E}+10$ & & $4.6 \mathrm{E}+03$ & \\
\hline & $3.8 \mathrm{E}+09$ & & $7.2 E+10$ & & $1.1 \mathrm{E}+04$ & \\
\hline & $3.9 E+09$ & & $6.8 \mathrm{E}+10$ & & $2.4 \mathrm{E}+04$ & \\
\hline & $1.7 \mathrm{E}+10$ & & $6.4 \mathrm{E}+10$ & & $9.3 \mathrm{E}+03$ & \\
\hline & $1.5 \mathrm{E}+10$ & & $3.7 E+10$ & & $1.1 \mathrm{E}+04$ & \\
\hline & $2.0 E+10$ & & $5.2 E+10$ & & $6.2 \mathrm{E}+03$ & \\
\hline & $1.2 \mathrm{E}+09$ & & $8.3 E+10$ & & $3.0 \mathrm{E}+03$ & \\
\hline & $1.2 \mathrm{E}+10$ & $8.3 E+09$ & $6.7 \mathrm{E}+10$ & $6.9 \mathrm{E}+10$ & $8.4 \mathrm{E}+03$ & $7.6 \mathrm{E}+03$ \\
\hline МH3 & $1.3 E+09$ & & $7.6 \mathrm{E}+10$ & & $1.7 \mathrm{E}+03$ & \\
\hline \multirow[t]{7}{*}{3} & $5.0 E+09$ & & $8.1 E+10$ & & $5.4 \mathrm{E}+03$ & \\
\hline & $8.6 E+09$ & & $8.1 E+10$ & & $5.8 \mathrm{E}+03$ & \\
\hline & $1.0 \mathrm{E}+10$ & & $6.5 E+10$ & & $2.0 \mathrm{E}+04$ & \\
\hline & $1.0 \mathrm{E}+10$ & & $6.5 \mathrm{E}+10$ & & $1.3 \mathrm{E}+04$ & \\
\hline & $7.3 E+09$ & & $8.3 E+10$ & & $6.4 \mathrm{E}+03$ & \\
\hline & $1.3 \mathrm{E}+10$ & & $7.4 \mathrm{E}+10$ & & $1.0 \mathrm{E}+04$ & \\
\hline & $3.5 E+09$ & & $6.3 E+10$ & & $3.3 E+03$ & \\
\hline
\end{tabular}




\begin{tabular}{|c|c|c|c|c|c|c|}
\hline & $1.5 \mathrm{E}+10$ & & $6.2 E+10$ & & $7.2 \mathrm{E}+03$ & \\
\hline & $8.5 E+09$ & $8.2 E+09$ & $6.0 \mathrm{E}+10$ & $7.1 \mathrm{E}+10$ & $5.4 \mathrm{E}+03$ & $7.8 \mathrm{E}+03$ \\
\hline MH4 & $4.0 \mathrm{E}+08$ & & $6.6 \mathrm{E}+10$ & & $2.3 \mathrm{E}+02$ & \\
\hline 4 & $1.8 \mathrm{E}+10$ & & $7.2 \mathrm{E}+10$ & & $1.6 \mathrm{E}+03$ & \\
\hline & $9.2 \mathrm{E}+09$ & & $7.2 E+10$ & & $4.2 \mathrm{E}+02$ & \\
\hline & $9.6 \mathrm{E}+09$ & & $8.0 E+10$ & & $8.4 \mathrm{E}+02$ & \\
\hline & $9.1 \mathrm{E}+09$ & & $7.4 \mathrm{E}+10$ & & $1.3 \mathrm{E}+03$ & \\
\hline & $7.4 \mathrm{E}+09$ & & $6.8 \mathrm{E}+10$ & & $1.7 \mathrm{E}+03$ & \\
\hline & $1.1 \mathrm{E}+10$ & & $7.0 \mathrm{E}+10$ & & $1.2 \mathrm{E}+03$ & \\
\hline & $7.4 \mathrm{E}+09$ & & $5.9 E+10$ & & $7.2 E+02$ & \\
\hline & 4.7E+09 & & $4.2 E+10$ & & $2.0 \mathrm{E}+03$ & \\
\hline & $2.8 \mathrm{E}+09$ & $8.0 E+09$ & $6.6 \mathrm{E}+10$ & $6.7 E+10$ & $1.2 \mathrm{E}+03$ & $1.1 \mathrm{E}+03$ \\
\hline MH5 & $7.3 \mathrm{E}+08$ & & $8.4 \mathrm{E}+10$ & & $1.8 \mathrm{E}+03$ & \\
\hline 5 & $9.4 \mathrm{E}+09$ & & $6.7 \mathrm{E}+10$ & & $5.6 \mathrm{E}+02$ & \\
\hline & $9.0 \mathrm{E}+09$ & & $7.9 E+10$ & & $2.1 \mathrm{E}+03$ & \\
\hline & $3.0 \mathrm{E}+09$ & & $4.6 \mathrm{E}+10$ & & 1.7E+02 & \\
\hline & & & $1.0 \mathrm{E}+11$ & & $8.9 E+02$ & \\
\hline & $8.4 E+09$ & & $7.5 E+10$ & & $4.0 \mathrm{E}+02$ & \\
\hline & $2.4 \mathrm{E}+09$ & $5.5 \mathrm{E}+09$ & $6.5 E+10$ & $7.4 \mathrm{E}+10$ & $2.9 E+03$ & $1.3 \mathrm{E}+03$ \\
\hline MH6 & $6.1 E+08$ & $6.1 E+08$ & $7.8 \mathrm{E}+10$ & $7.8 \mathrm{E}+10$ & $2.3 E+04$ & $2.3 \mathrm{E}+04$ \\
\hline
\end{tabular}


events (1048 events) than all stages of the MH3 well (936 events). The MH6 averaged the most radiated seismic energy on a per stage basis (see Figure 31). Also surprisingly, the MH4 well generated the most events (2622 events) with significantly fewer stages and lower injection, radiated seismic, and fracture energies than those of the footwall wells (Figures 34-36). The MH3 well had the fewest events at 936 - the number of events per well can be seen in Figures 3436. More microseismic events generated during a frac can be tied to favorable production (Patel et al., 2013); however, in this case all of the events associated with stage 1 for the MH6 were out-of-zone. $77 \%$ of events for the MH4 and $68 \%$ of events for the MH5 wells were out-of-zone as well. Out-of-zone events for hangingwall wells account for $69 \%$ of the energy released (Table 4 ) (Wilson et al., 2014b).

Energy released decreases from the $\mathrm{MH} 1$ to the $\mathrm{MH} 3$ and from the $\mathrm{MH} 4$ to the MH6. A linear relationship between radiated seismic energy and the number of microseismic events has been established for both hangingwall and footwall wells; high $\mathrm{R}^{2}$ values (.96 for footwall wells and .99 for hangingwall wells) for both sets of wells indicate the number of microseismic events heavily controls how much radiated seismic energy is output. The MH1-3 wells (footwall wells) have a lower correlation coefficient, but display a more consistent relationship (data points are spaced more evenly apart). The MH 4-6 wells (hangingwall wells) have a very high correlation coefficient, but it should be noted that data points are not evenly spaced and the slope of the trendline is shallower; the shallower slope of the $\mathrm{MH}$ 4-6 wells' trendline indicates that a greater \# of events 


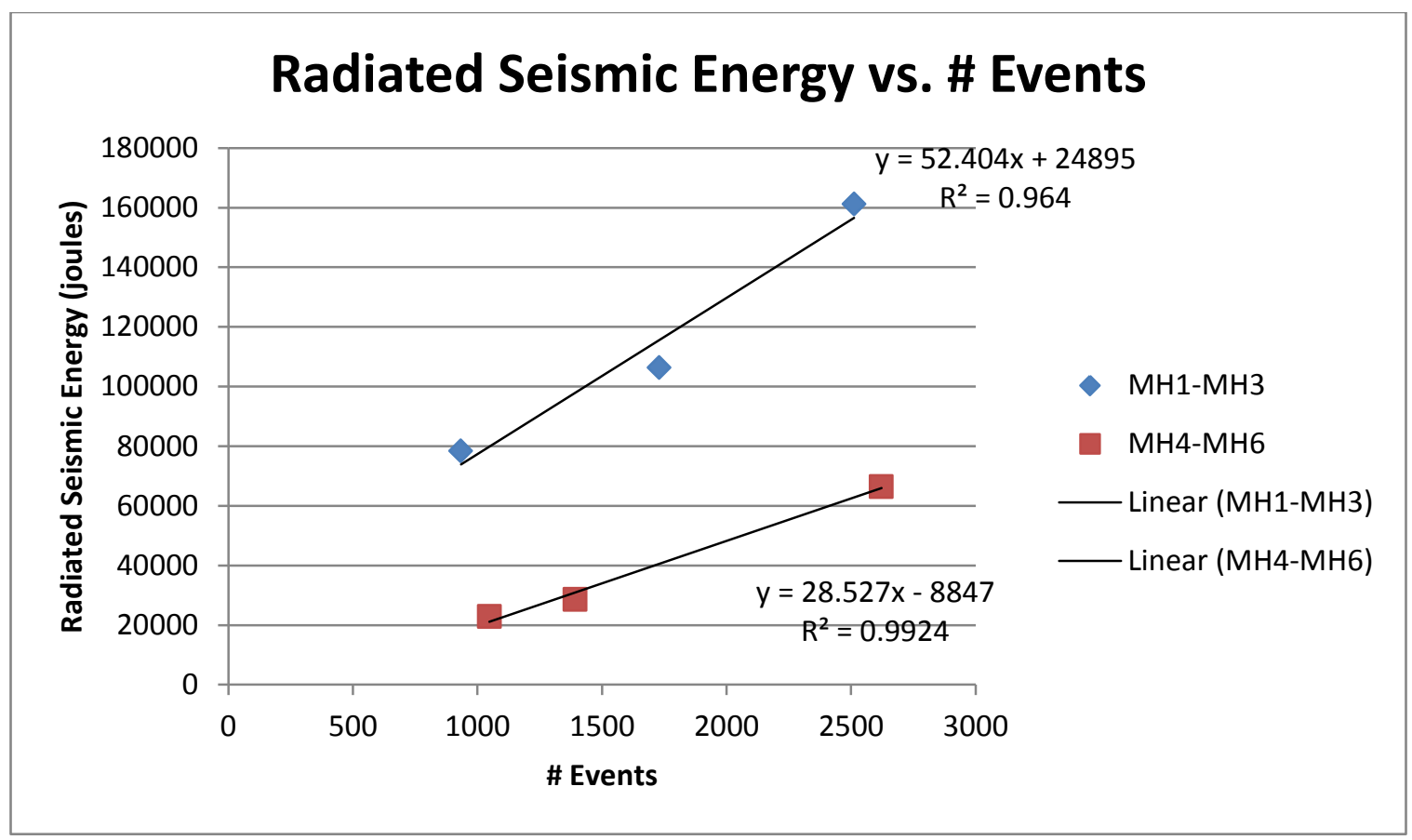

Figure 34: Average radiated seismic energy on a per stage basis vs. number of events. Number of events increases linearly with radiated seismic energy. 


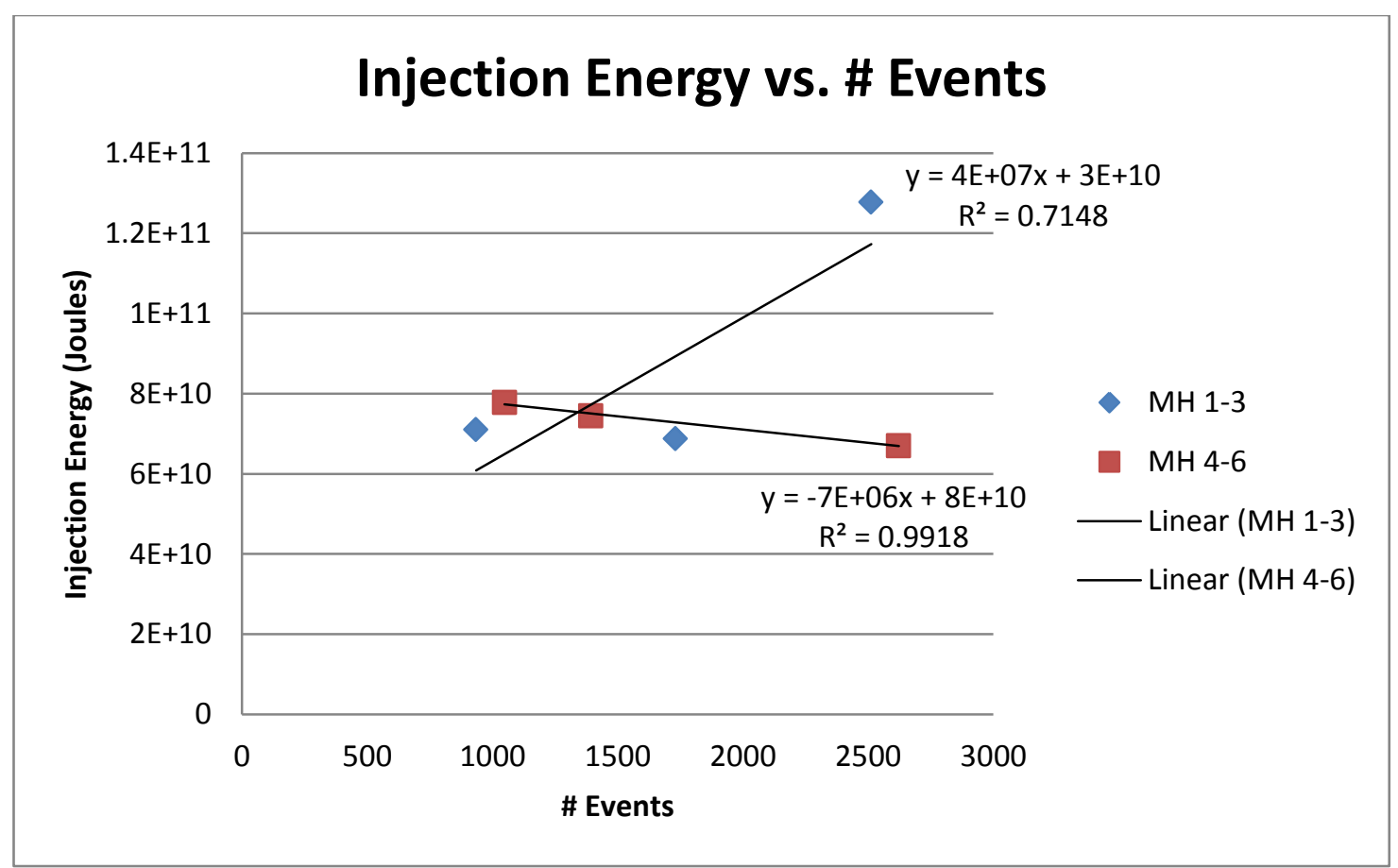

Figure 35: Average injection energy on a per stage basis for each well vs. number of events. The MHI well had the highest injection energy and the second to greatest amount of events. The MH4 had injection energy 1.9 times lower than that of the MH1 and had the most events. 


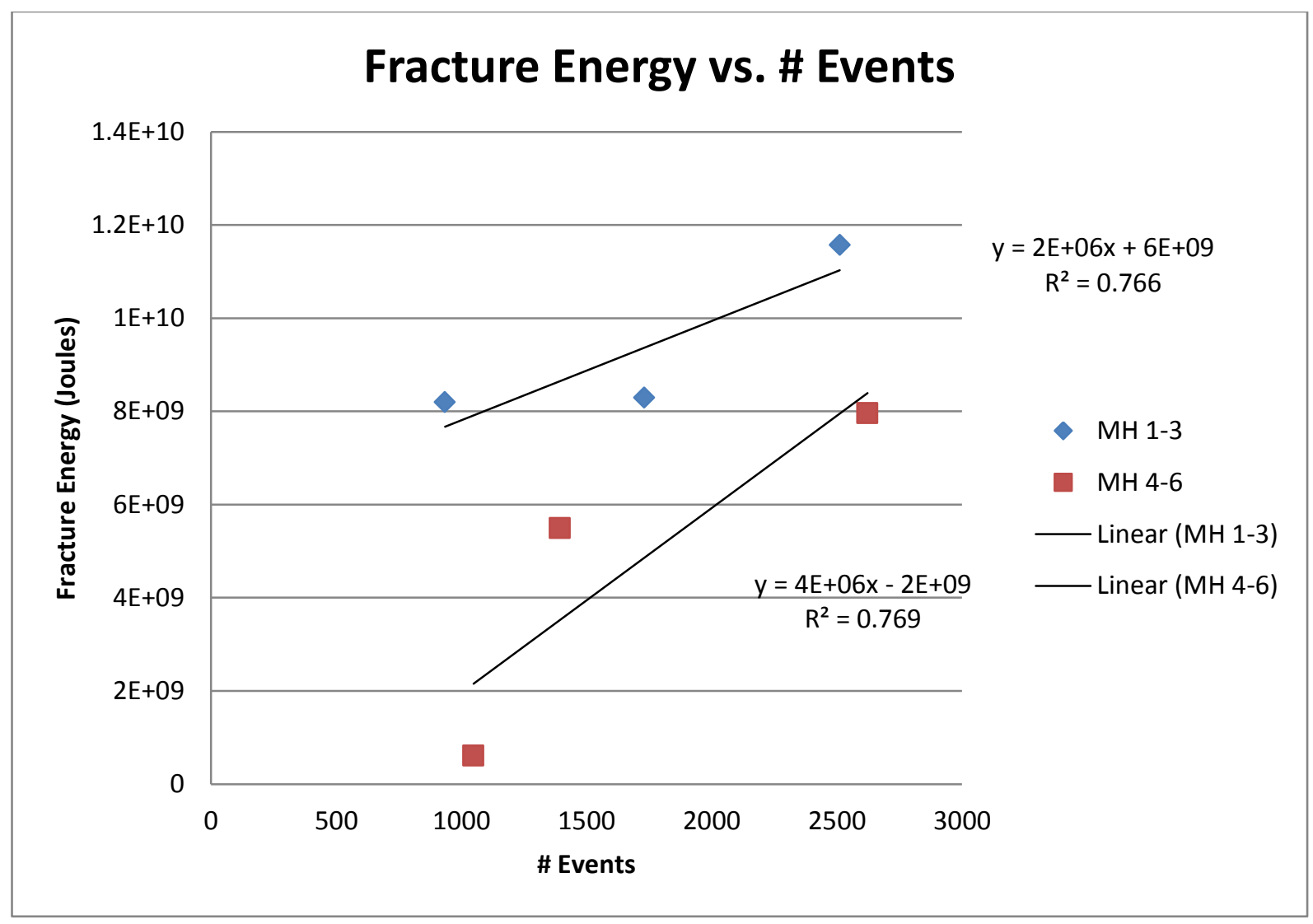

Figure 36: Average fracture energy on a per stage basis vs. number of events. The MH1 well had the highest fracture energy and the second to greatest amount of events. The MH4 had fracture energy 1.45 times lower than that of the MHI and had the most events. Trendlines for this graph have similar slopes and indicate a relationship probably exists between fracture energy and the \# of events. 
Table 4: Out-of-zone Energy Release for Hangingwall Well

$\begin{array}{crcc}\text { Well } & \text { Total Energy }(\mathrm{J}) & \text { OOZ Energy }(\mathrm{J}) & \text { \% OOZ Energy } \\ \mathbf{4} & 6.64 \mathrm{E}+04 & 4.21 \mathrm{E}+04 \\ \mathbf{5} & 2.86 \mathrm{E}+04 & 1.67 \mathrm{E}+04 \\ \mathbf{6} & 2.28 \mathrm{E}+04 & 2.28 \mathrm{E}+04 \\ \text { ALL } & 1.18 \mathrm{E}+05 & 8.16 \mathrm{E}+04\end{array}$

$69 \%$ 
leads to a lesser increase in production (compared to the MH 1-3 wells).

Strong relationships between injection and fracture energies and number of events also exist (see Figures 34-36). One thing to notice is that in Figure 35, hangingwall wells and footwall wells have opposing slopes. Trendlines display promising correlation coefficients, but the opposing slopes between hangingwall and footwall wells indicates a complex and not well understood relationship between injection energy and \# of events. The MH 4-6 trendline slope is negative, whereas the MH 1-3 trendline slope is positive. The lack of data points has made extracting a relationship between injection energy and \# of events difficult. It appears as though the fracture zone activated during the completion of hangingwall wells has further complicated the relationship between energy put into the rock during the frac and the amount of generated microseismicity. This graph displays how complex and unusual relationships can arise from changes in the stress state of the reservoir.

A few interesting occurrences to note would be that the $\mathrm{MH} 4$ well had a greater number of microseismic events per stage than the $\mathrm{MH} 1$ well, and the MH6 well had a greater number of microseismic events per stage than all wells (also once again it is worth noting that the MH6 well only recorded one stage) (Figure 37). Table 5 displays how much more radiated seismic energy the MH6 well released than all the other wells on a per stage basis. The linear nature of energy released vs. the number of events that occur for each well indicates that an increase in microseismic events generated leads to an increase in radiated seismic energy release; however, the same cannot necessarily be said for 


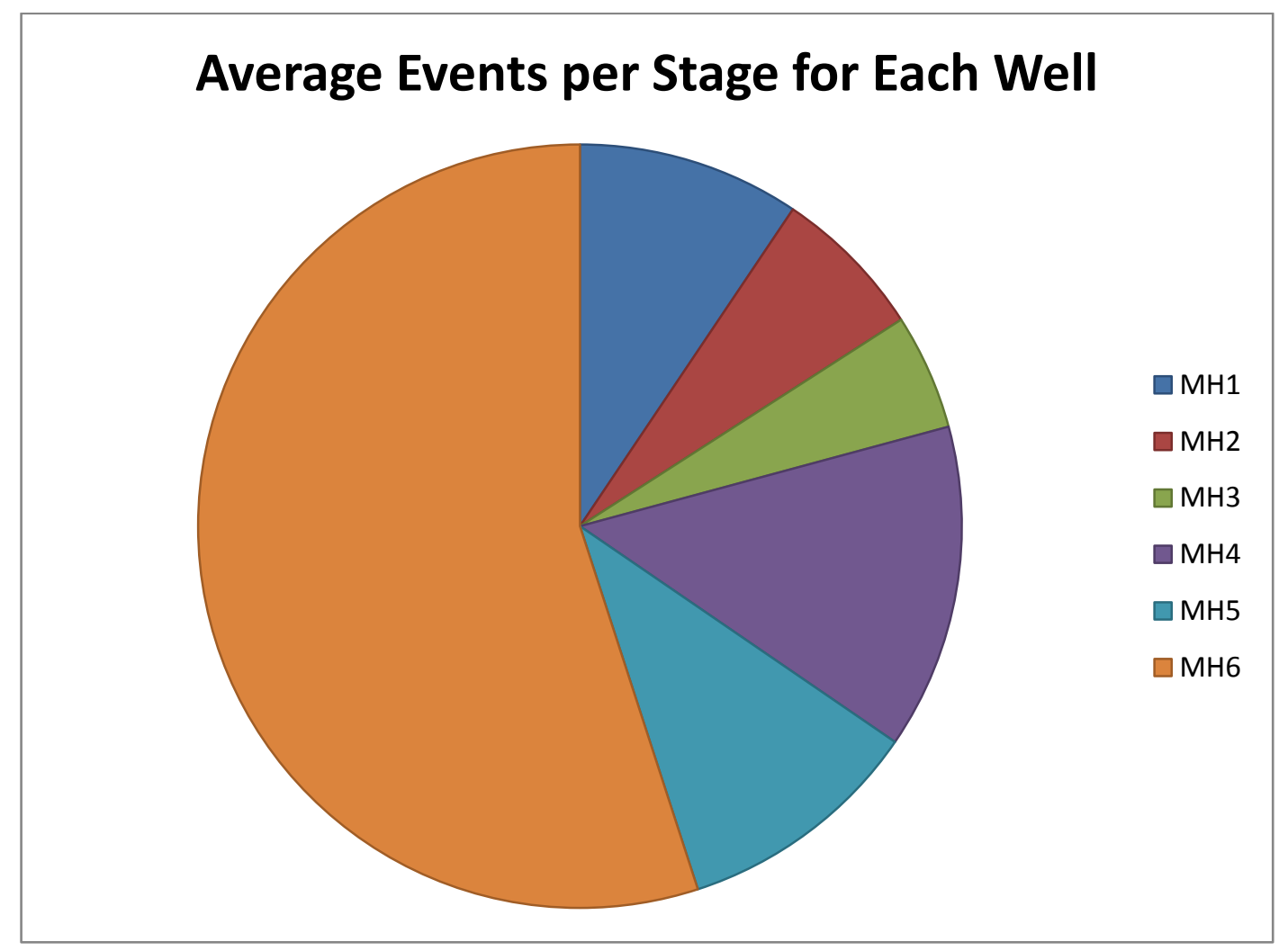

Figure 37: The MH6 well accounted for 55\% of all events generated on a per stage basis. 


\section{Table 5: Difference in Radiated Seismic Energy Release on a per Stage Basis Between MH6 and Other Wells}

\begin{tabular}{|cc|}
\hline Well & Energy difference \\
\hline MH6/MH1 & 1.98 \\
MH6/MH2 & 3.00 \\
MH6/MH3 & 2.90 \\
MH6/MH4 & 20.37 \\
MH6/MH5 & 18.16 \\
\hline
\end{tabular}

injection energy vs. radiated seismic energy (Figure 38). Footwall wells seem to display a linear relationship (with an $\mathrm{R}^{2}$ value of .98 ) between injection energy and radiated seismic energy - overall the greater the injection energy, the greater the radiated seismic energy. Hangingwall wells display a weaker linear relationship $\left(R^{2}=.60\right)$ and show that greater injection energy does not have as much control over radiated seismic energy release. The MH6 well had the lowest injection energy and just one stage, but it put out almost as much radiated seismic energy as the MH5 well which had 7 stages.

Another finding was significant variation in radiated seismic energy released by neighboring stages (Figure 39). These large differences in energy released by neighboring stages are interesting. Microseismic events associated with large stage-to-stage differences in energy release tend to follow NE-SW injection energy vs. radiated seismic energy (Figure 38). Footwall wells seem to display a linear relationship (with an $R^{2}$ value of .98) between injection energy and radiated seismic energy - overall the greater the injection energy, the greater the radiated seismic energy. Hangingwall wells display a weaker linear relationship $\left(R^{2}=.60\right)$ and show that greater injection energy does not have as 
much control over radiated seismic energy release. The MH6 well had the lowest injection energy and just one stage, but it put out almost as much radiated seismic energy as the MH5 well which had 7 stages.

Another finding was significant variation in radiated seismic energy released by neighboring stages (Figure 39). These large differences in energy released by neighboring stages are interesting. Microseismic events associated with large stage-to-stage differences in energy release tend to follow NE-SW trending discontinuities that cross-cut multiple wells. Based on a visual comparison, there appears to be some association with the seismic discontinuity maps (Figures 40 and 41); however, examination of such relationships is left for future studies to explore. Correlation of variations in radiated seismic energy released by neighboring stages and seismic discontinuity maps generated for this study is inconclusive. 

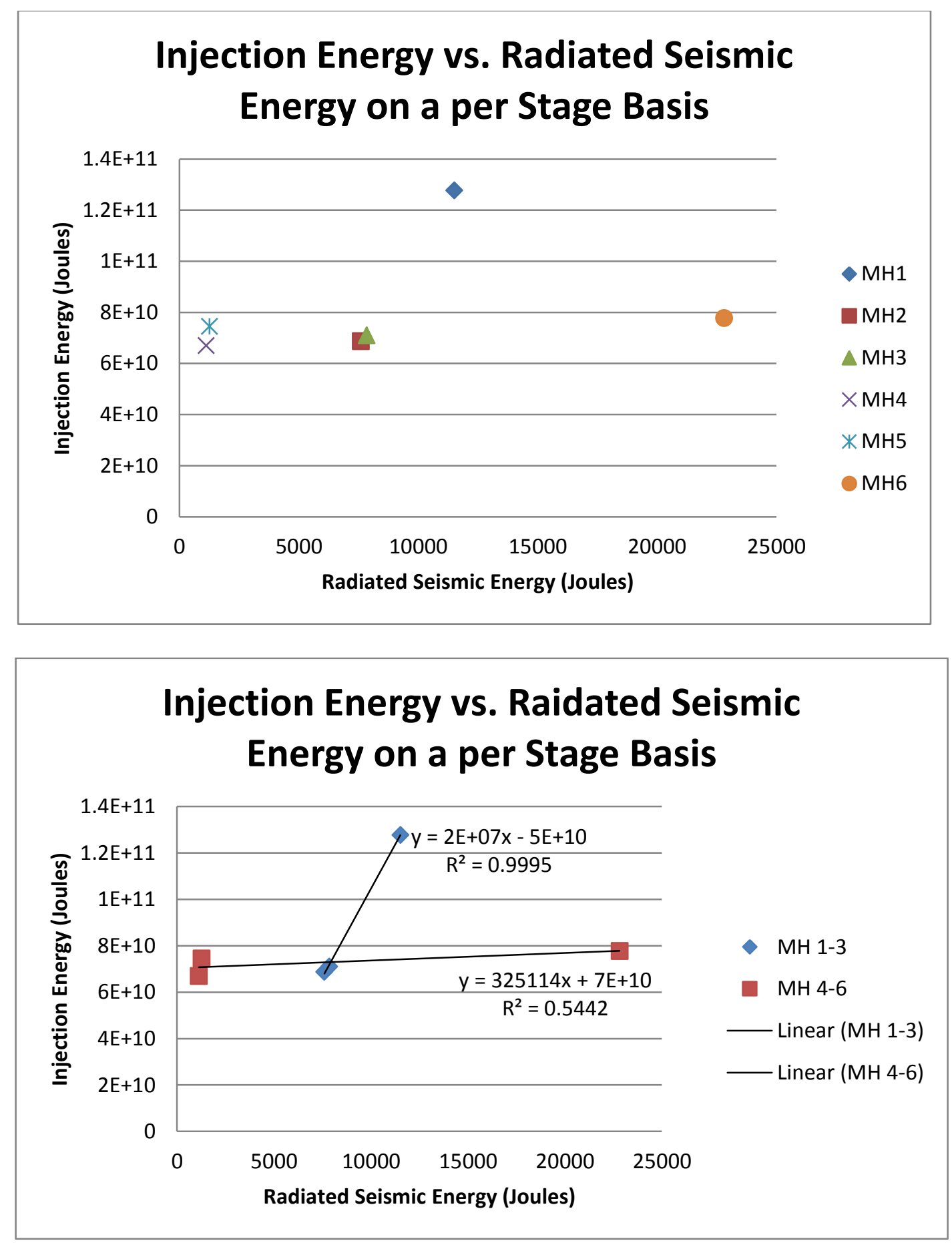

Figure 38: Injection energy vs. radiated seismic energy. There appears to be a strong linear rtrend for MH1-MH3 wells, but the MH4-6 wells display no real pattern. A lack of data points makes establishing relationships difficult. 

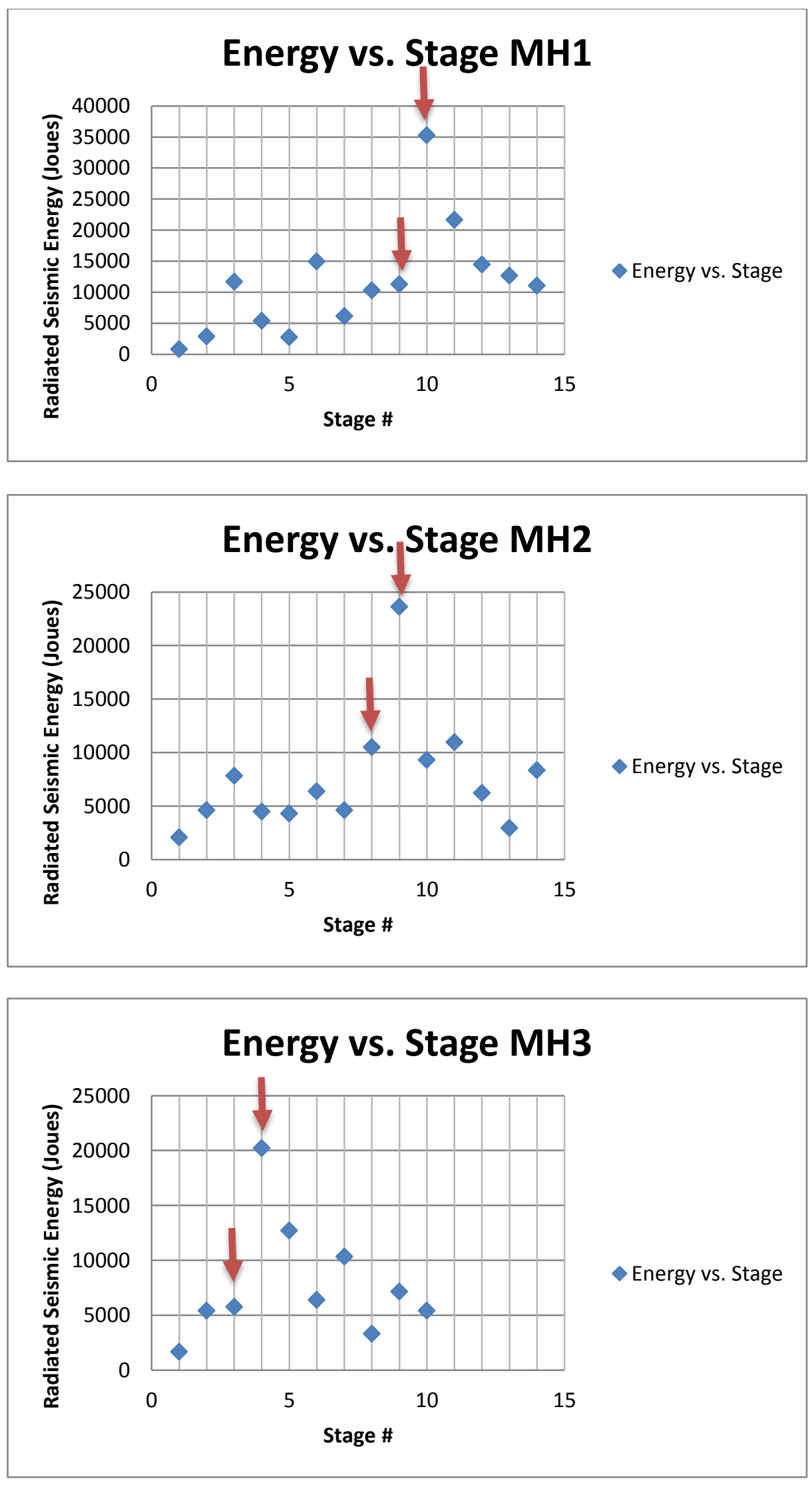

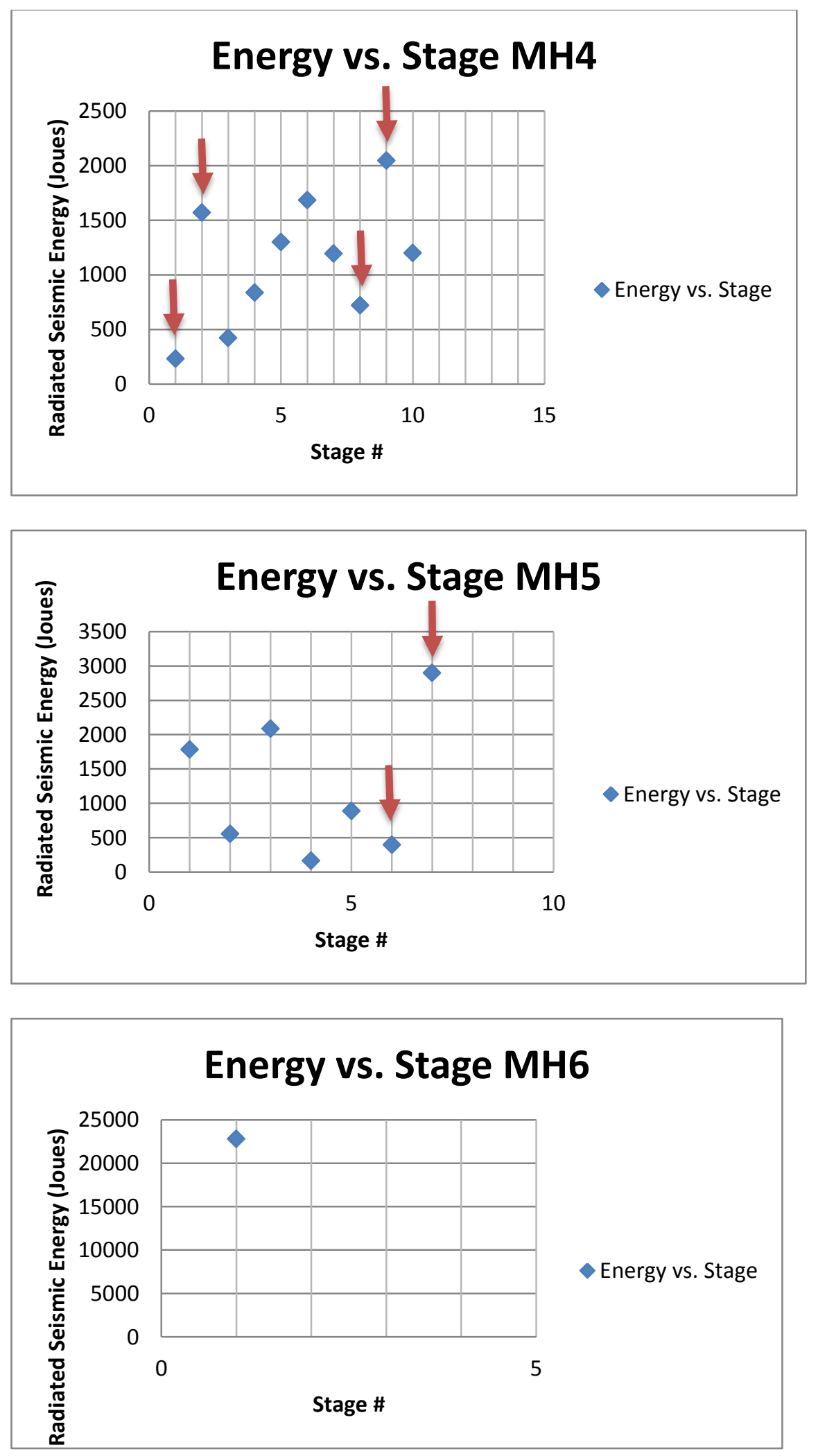

Figure 39: Energy vs. stage presented well-by-well. Note the large discrepancies in energy release between some neighboring stages (red arrows). 

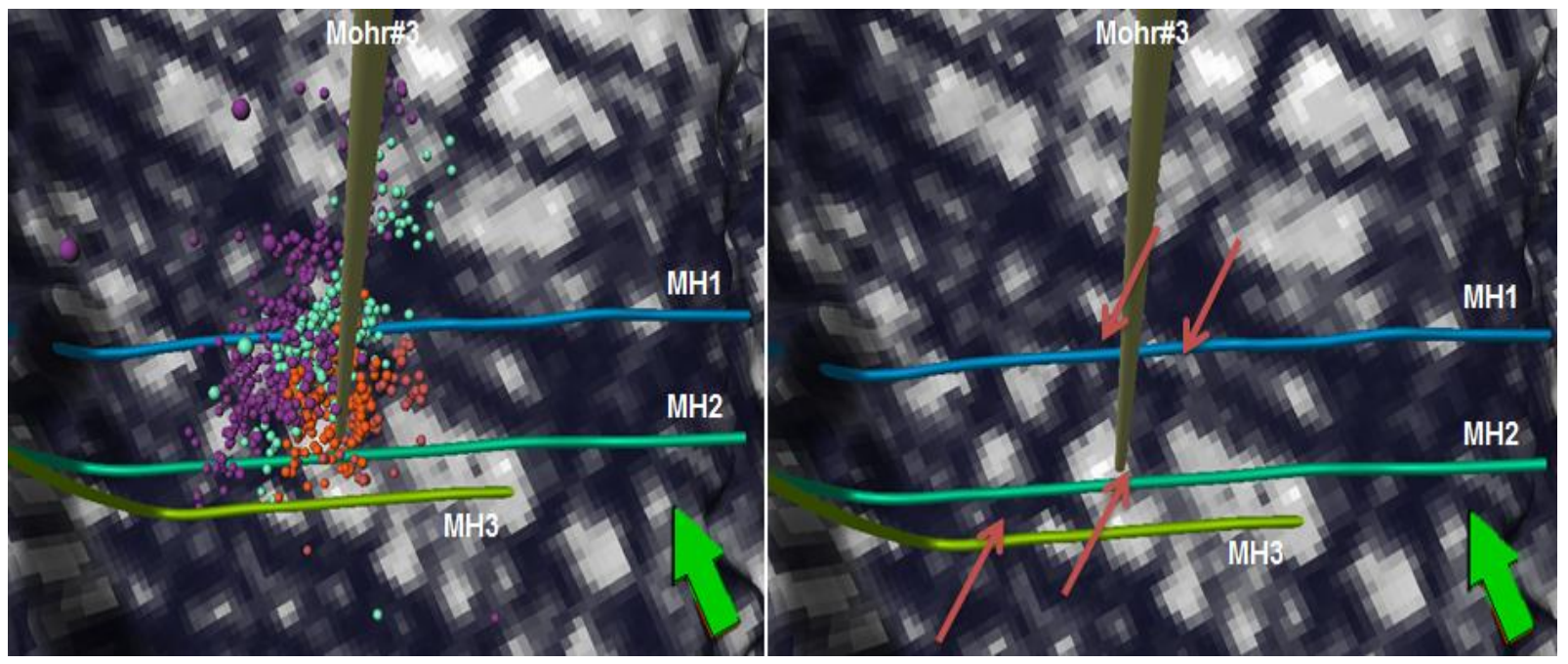

Figure 40: Stages 9 and 10 of the MH1 well and Stages 8 and 9 of the MH2 well displayed on seismic discontinuities extracted along the Onondaga Limestone surface. Slight visual correlation can be seen between the microseismic event swarm orientations and extracted discontinuity orientations. Stages shown have significant differences in radiated seismic energy release between them. 


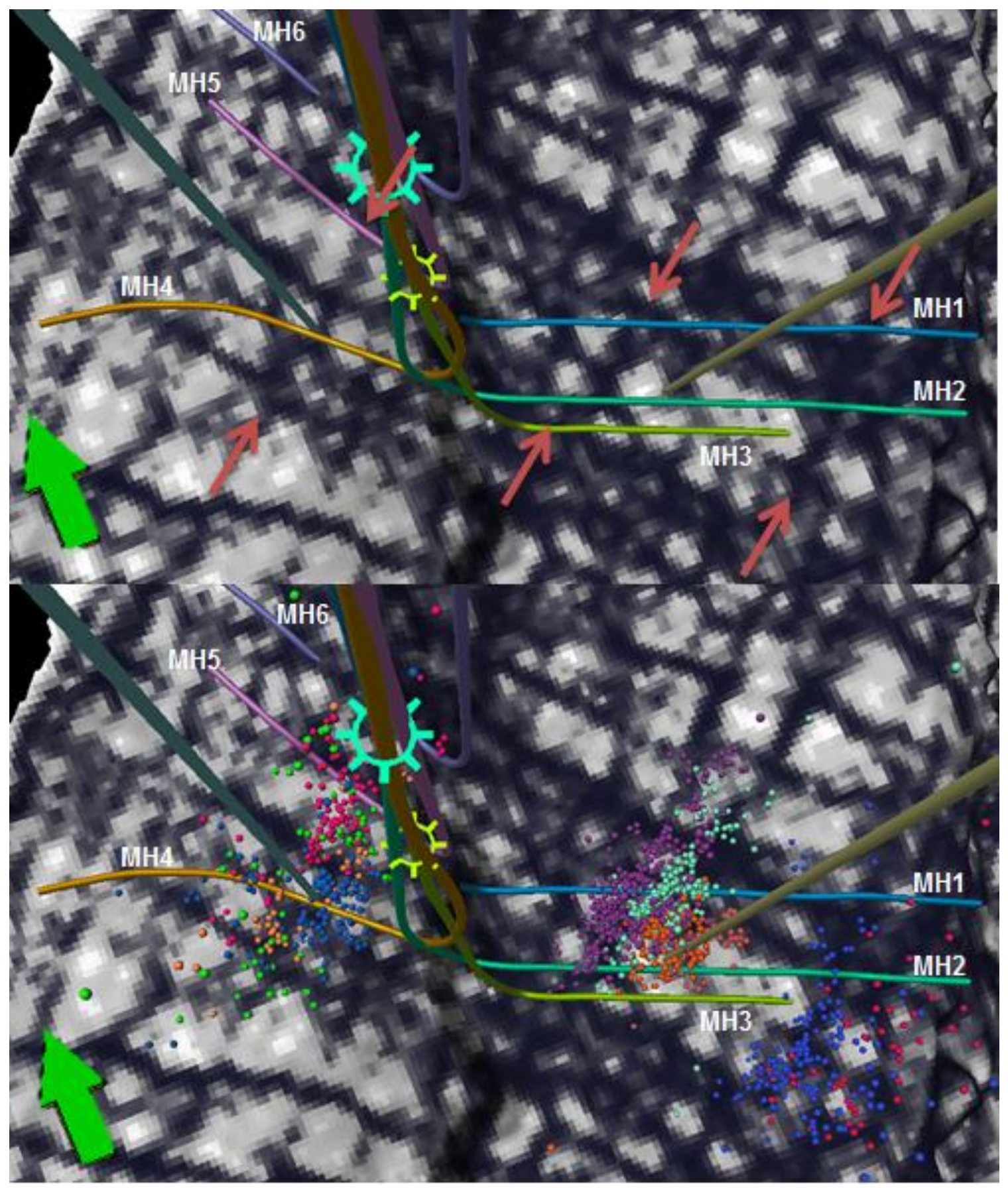

Figure 41: Neighboring stages with large discrepancies in radiated seismic energy shown on seismic discontinuities extracted onto Onondaga Limestone surface. Note how the microseismic event swarms follow some large NE-trending seismic discontinuities. 


\subsection{Summary}

The evidence presented in this chapter supports that out-of-zone microseismic behavior may be associated with reactivation of critically stressed fractures in the complexly deformed Upper Devonian section (Figure 42). Hydraulic fracture treatment in one stage of the MH4 appears to have weakened a preexisting fault; as a result this fault was brought closer to its frictional limit. Following stages of the $\mathrm{MH} 4, \mathrm{MH} 5$, and $\mathrm{MH} 6$ precipitated continued rupture of the fault. The less aggressive hydraulic fracturing strategy applied to hangingwall wells could also support this interpretation. These observations also suggest that it is unlikely there was a hydraulic connection between reservoir events and outof-zone events. Stage-to-stage radiated seismic energy release differences between neighboring stages may result from local structural variations, some of which may be seen in seismic discontinuity maps; however, correlation of variations in radiated seismic energy released by neighboring stages and seismic discontinuity maps generated for this study is inconclusive.

Wilson et al., (2014a) and this study show that integrating seismic discontinuity mapping and microseismic is useful for locating potential zones of increased fracture intensity. The TVTAS seismic volume was also shown to be useful for determining where complex faulting exists within the 3D seismic survey (Wilson et al., 2014a). $\mathrm{S}_{\mathrm{Hmax}}$ near the area, as noted on the world stress map and derived from hydraulic fracture treatment data, is oriented $\sim$ N96E. Microseismic event swarms form roughly at acute angles to $\mathrm{S}_{\mathrm{Hmax}}$ in the $\sim \mathrm{N} 56 \mathrm{E}$ direction as a potential result of shearing along pre-existing fracture planes (Figure 43). The 


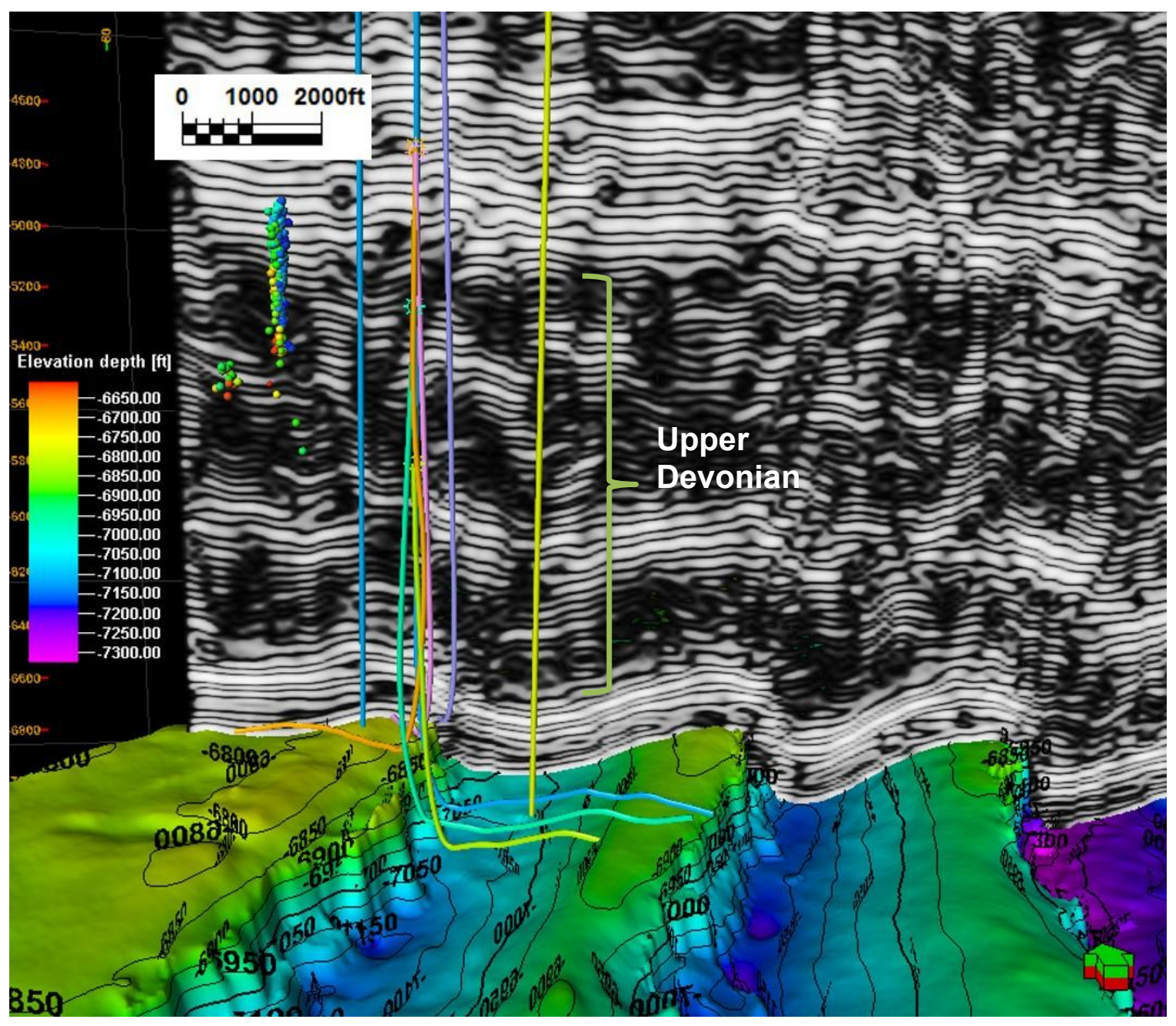

Figure 42: The TVTAS seismic volume shows complex deformation in the Upper Devonian section 


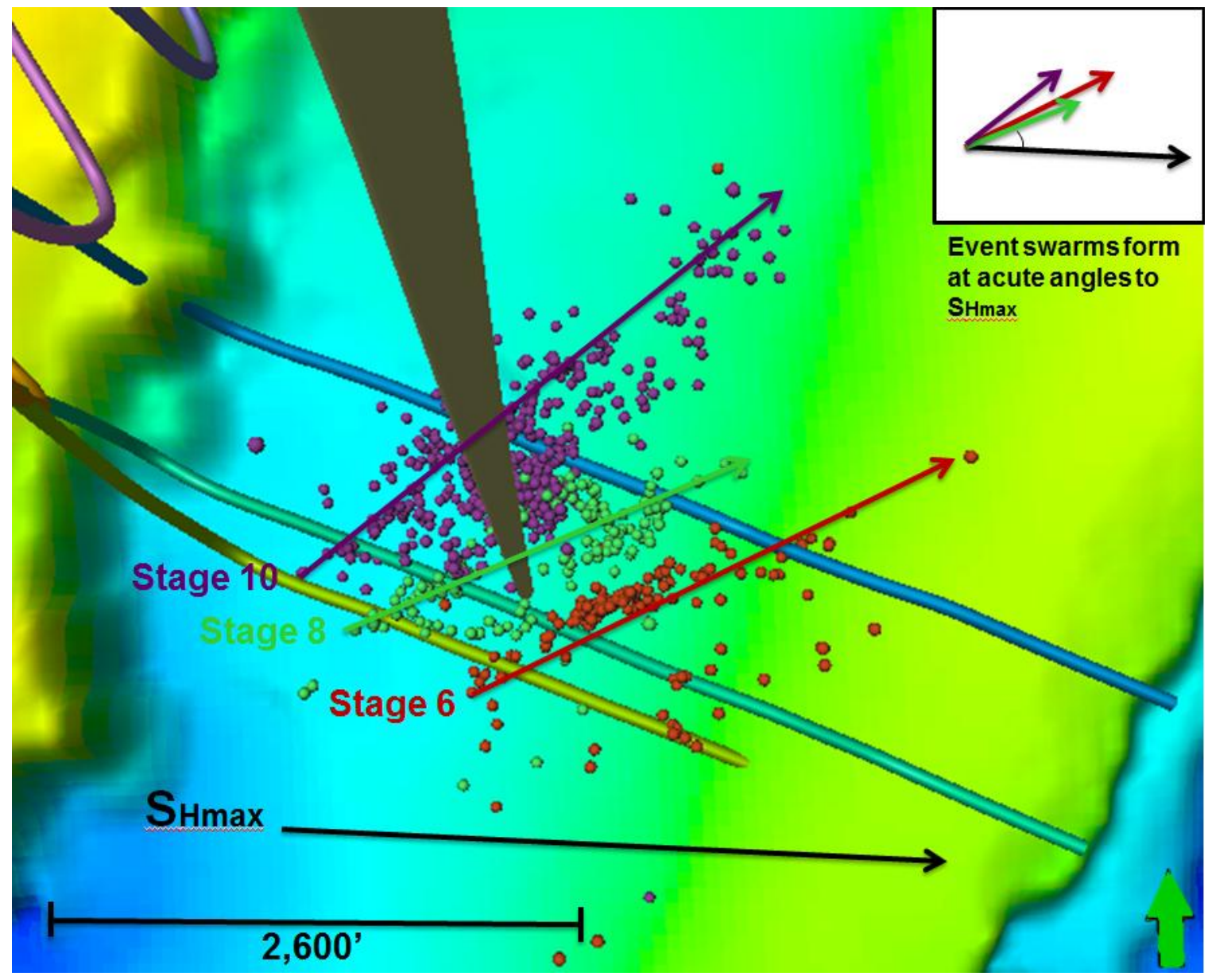

Figure 43: Microseismic event swarms have formed at acute angles to $S_{\text {Hmax }}$ as a potential result of shearing along pre-existing fracture planes 
author recommends drilling future laterals in the N50W and the N65W directions. 


\section{Chapter 5: Interpretations}

Understanding the local structure is important for drilling successful wells in the Appalachian Basin, as targeted shale intervals in the region are not very permeable and require successful stimulation to produce economic quantities of hydrocarbons. Previous studies conducted in the region have focused on gaining a better understanding of structural features, such as where zones of increased fracture intensity exist. These zones are associated with increased fracture permeability in the reservoir (Donahoe, 2011); (Wilson et al., 2014a).

Donahoe (2011) used a WMR (Waveform Model Regression) version of the 3D seismic volume (which was designed to enhance resolution of the structure) and conducted a seismic attribute analysis in the same study area. That study found that the three major NE-trending thrust faults are likely surrounded by areas of increased faulting and concluded that detachment has occurred in multiple intervals throughout the Devonian, including within the Marcellus Shale. Wilson et al., (2014a) also used 3D seismic processing workflows designed to enhance resolution as well as reveal the presence of discontinuities in the seismic response. Seismic discontinuities were interpreted to be areas of increased fracture intensity.

Location and characterization of these zones helps us better understand their potential relationship to production from these unconventional naturally fractured reservoirs. These studies are also important from a risk analysis perspective; they identify fault systems that could minimize the effectiveness of hydraulic fracture treatment. 
Unusual behavior on the hangingwall - out-of-zone microseismic activity in particular - was of interest in this study. Production from the $\mathrm{MH} 1, \mathrm{MH} 2$, and $\mathrm{MH} 3$ wells was noted as being better than that from the $\mathrm{MH} 4, \mathrm{MH} 5$, and $\mathrm{MH} 6$ wells which are located on the westernmost fault block (Table 4 and Figure 44). The lack of similar levels of production in the hangingwall wells may be due to increased levels of out-of-zone activity. Total production from the MH4-6 wells was only $\sim 56 \%$ of production from the $\mathrm{MH} 1-3$ wells. Poorer production in $\mathrm{MH} 4$, $\mathrm{MH} 5$, and $\mathrm{MH} 6$ may be due to frac energy being lost to other formations higher up in the stratigraphic column (Sullivan, oral communication 2013). Log analyses revealed little variation in the petrophysical properties of the two fault blocks. This is not unusual, since the reservoir intervals formed in a quiescent, anoxic, deep marine setting (Boyce and Carr, 2010). This study will explore variations in local structure and their potential relationship to out-of-zone microseismic behavior.

\subsection{Structural Interpretations}

\subsubsection{Fault Interpretations}

Previous interpretation of the area (Donahoe, 2011) identified three southwest to northeast-trending thrust faults that strike $\sim$ N25E through the area. The three major thrust faults have steep dips associated with them. Closer inspection of a seismic profile across the area also suggests numerous smaller faults exist. The structure in this area is quite complex, and indicates the environment has been subjected to numerous styles of deformation; low and high angle faulting, folding, and detachment faulting are present within the study area (Figure 45). 


\section{Table 4: MH wells production data}

\begin{tabular}{|c|c|c|c|c|c|}
\hline Well & API\# & Cumulative Gas (Mcf) & Cumulative per well & 2012-2013 Production & \\
\hline \multirow[t]{3}{*}{ МH1 } & $37-059-25718$ & $670,761.00$ & & & \\
\hline & $37-059-25718$ & $45,089.00$ & & & \\
\hline & $37-059-25718$ & $439,192.00$ & $1,155,042.00$ & & \\
\hline \multirow[t]{3}{*}{ MH2 } & $37-059-25719$ & $504,376.00$ & & & \\
\hline & $37-059-25719$ & $37,265.00$ & & & \\
\hline & $37-059-25719$ & $316,274.00$ & $857,915.00$ & & \\
\hline \multirow[t]{3}{*}{ МH3 } & $37-059-25720$ & $413,655.00$ & & & \\
\hline & $37-059-25720$ & $38,800.00$ & & & \\
\hline & $37-059-25720$ & $251,968.00$ & $704,423.00$ & Cumulative MH1-3 & $2,717,380.00$ \\
\hline \multirow[t]{3}{*}{ MH4 } & $37-059-25721$ & $395,350.00$ & & & \\
\hline & $37-059-25721$ & $100,492.00$ & & & \\
\hline & $37-059-25721$ & $204,314.00$ & $700,156.00$ & & \\
\hline \multirow[t]{3}{*}{ MH5 } & $37-059-25722$ & $224,209.00$ & & & \\
\hline & $37-059-25722$ & $56,344.00$ & & & \\
\hline & $37-059-25722$ & $111,939.00$ & $392,492.00$ & & \\
\hline \multirow[t]{3}{*}{ МH6 } & $37-059-25723$ & $230,787.00$ & & & \\
\hline & $37-059-25723$ & $40,300.00$ & & & \\
\hline & $37-059-25723$ & $153,653.00$ & $424,740.00$ & Cumulative MH4-6 & $1,517,388.00$ \\
\hline
\end{tabular}




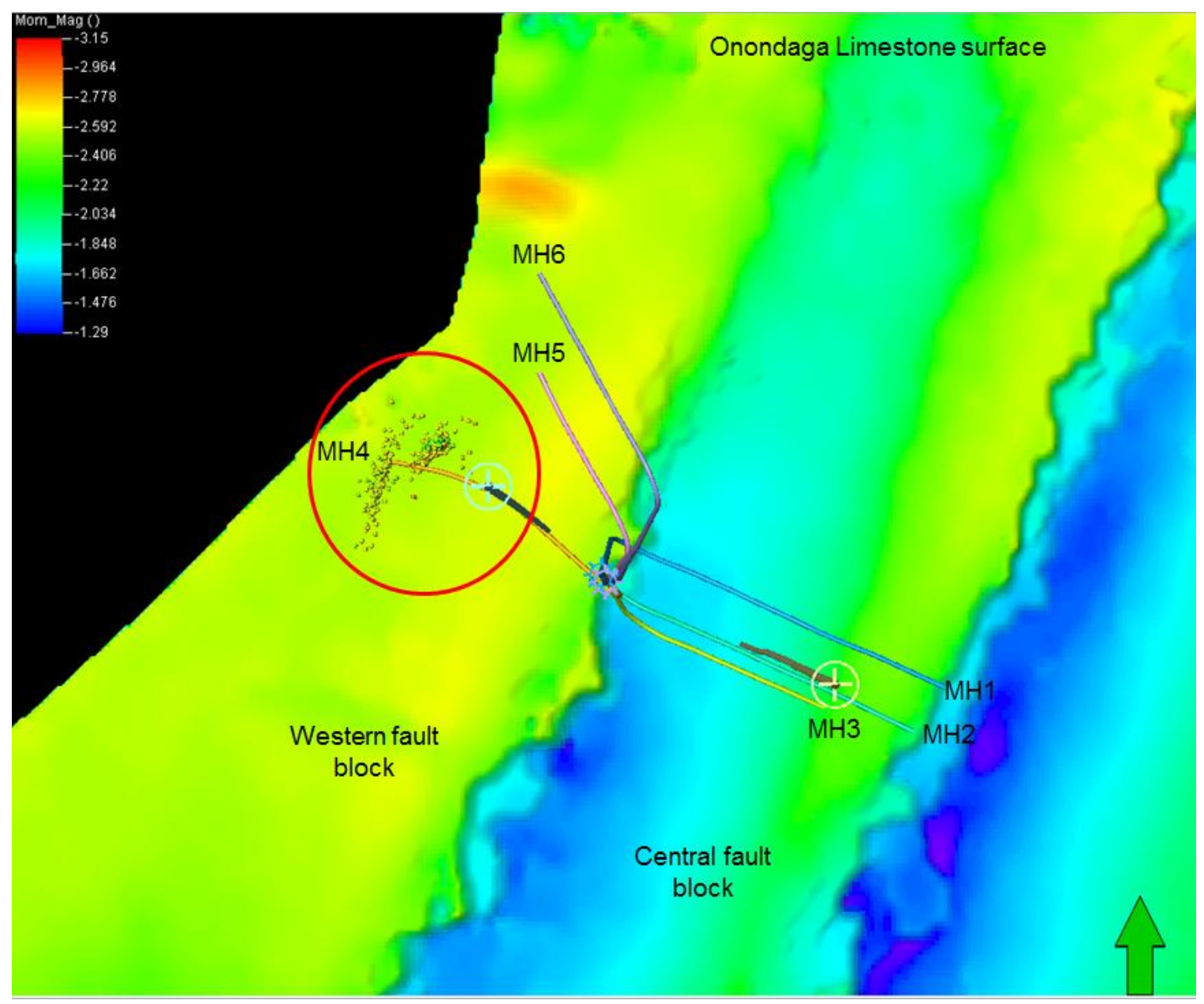

Figure 44: The MH4, MH5, and MH6 wells are located on the westernmost fault block where out-of-zone activity and poor production exist. 


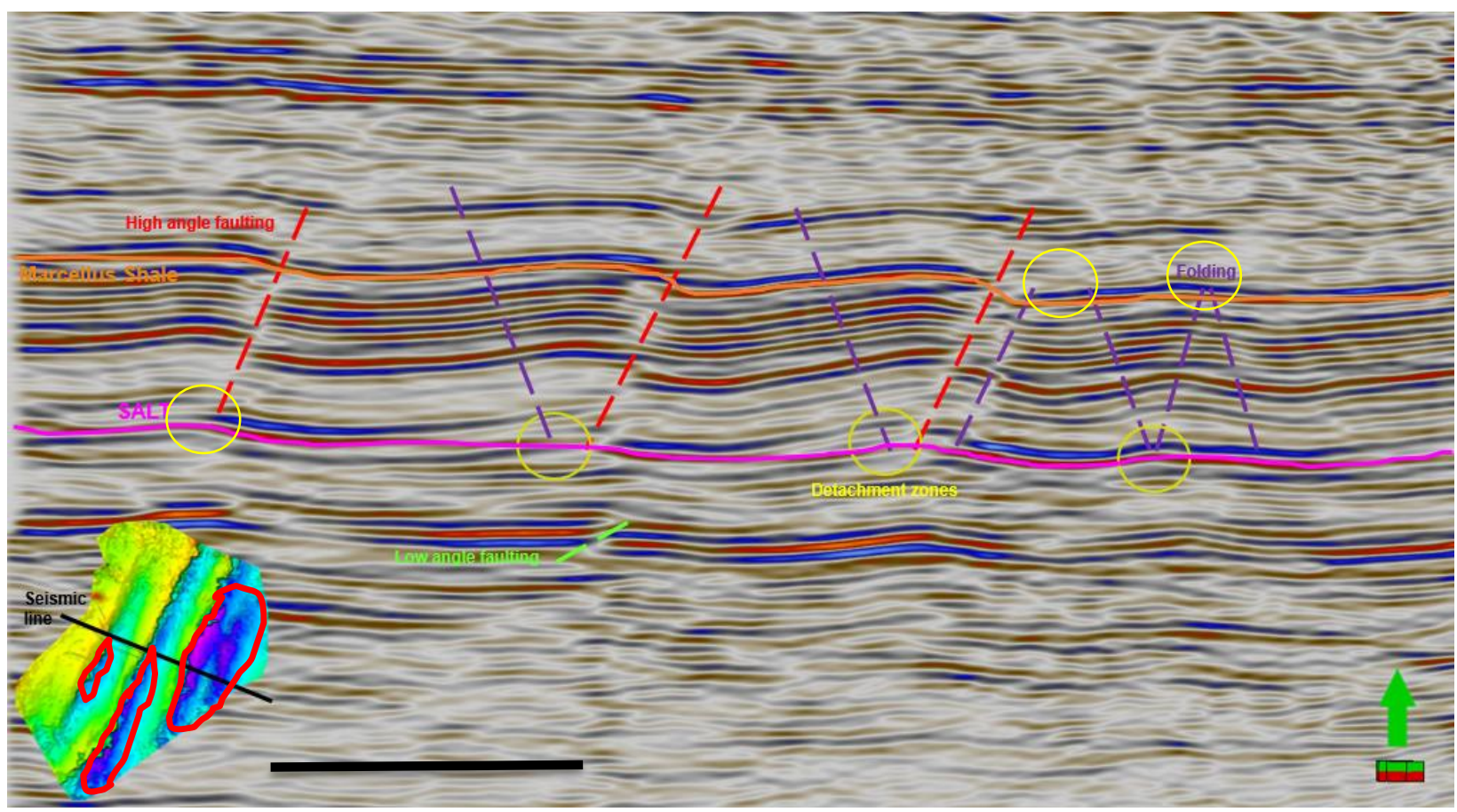

Figure 45: Examples of faulting, folding, and detachment within the study area. Zones of detachment are denoted on the 2D map by red circles. 
The Middle Devonian section in particular displays significant detachment in multiple intervals - in the top of the Hamilton Group, within the Marcellus, and within salt beds of the Salina Group (Figure 46). Detachment locations were determined based on where kink lines converged within the seismic section. Salt bed locations were picked based off of low gamma ray signature and rapid accelerations in the ROP (rate of penetration); the salt picks correlate well with a high acoustic impedance reflection event where numerous kink lines appear to merge (Figure 47). Salt is mechanically very weak (which makes it a great detachment surface), but its seismic velocity is usually much higher than the rock surrounding it.

The westernmost fault and fault block are of great interest to this study since the out-of-zone microseismic activity associated with poor production originated on that fault block. This large fault is roughly 22,000 ' long and terminates within the 3D seismic coverage (Figure 48), but the other two faults to the east maintain offset throughout the 3D seismic survey area. The out-of-zone microseismicity on the western fault block may result from complex faulting and high residual stress areas associated with complex faulting (Figure 49).

Estimated shortening for each stratigraphic marker at each seismic line location can be seen in Table 6 and the calculation process can be seen in Figure 50. Stratigraphic marker beds were traced in 3D Move and anchored to both an unfolding pin and a line marking the edge of the seismic line studied. After beds were traced, 2D Unfolding was used to unfold the beds and measure the difference between the original extent of the seismic (frame length) and how 


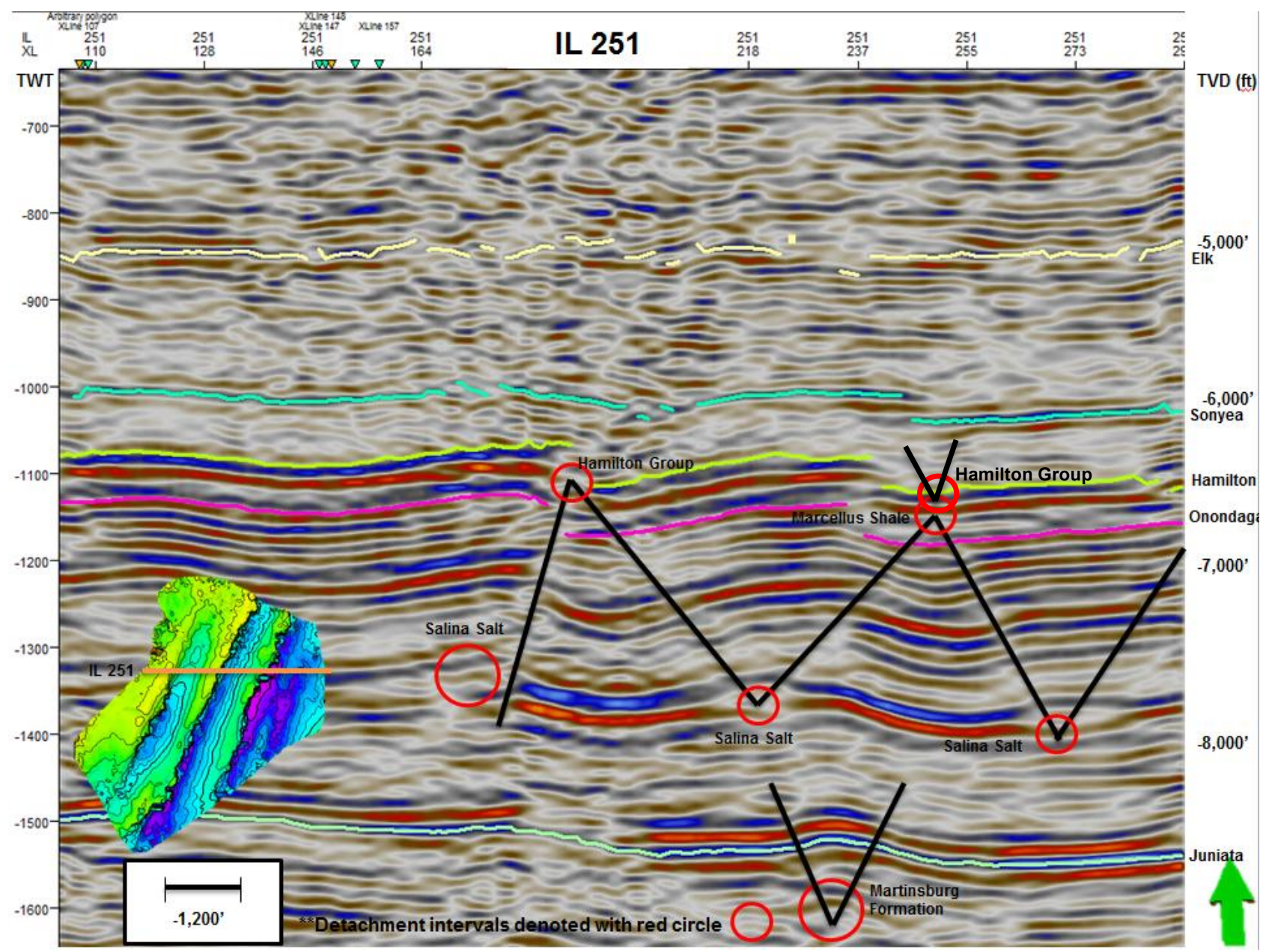

Figure 46: Examples of zones of detachment within the study area. Black lines represent kink lines, and red circles denote where kink lines disappear into a detachment surface. 


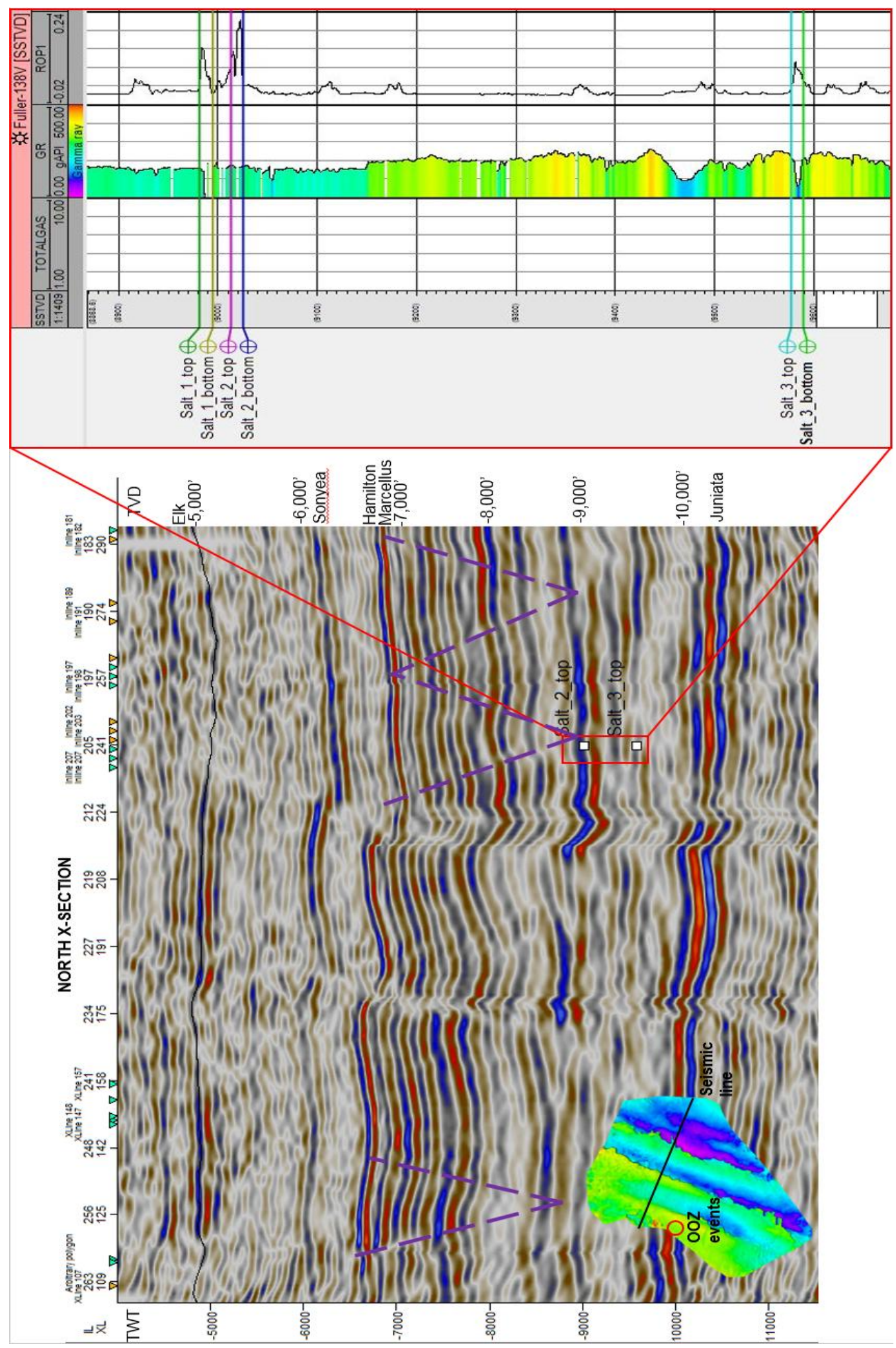

Figure 47: Salt layers were picked using mainly ROP (rate of penetration) as the gamma log cuts out in a few important places. When a drillbit hits salt the rate of penetration will usually greatly increase. Salt picks from logs also correlate well with high acoustic impedance reflection events. 


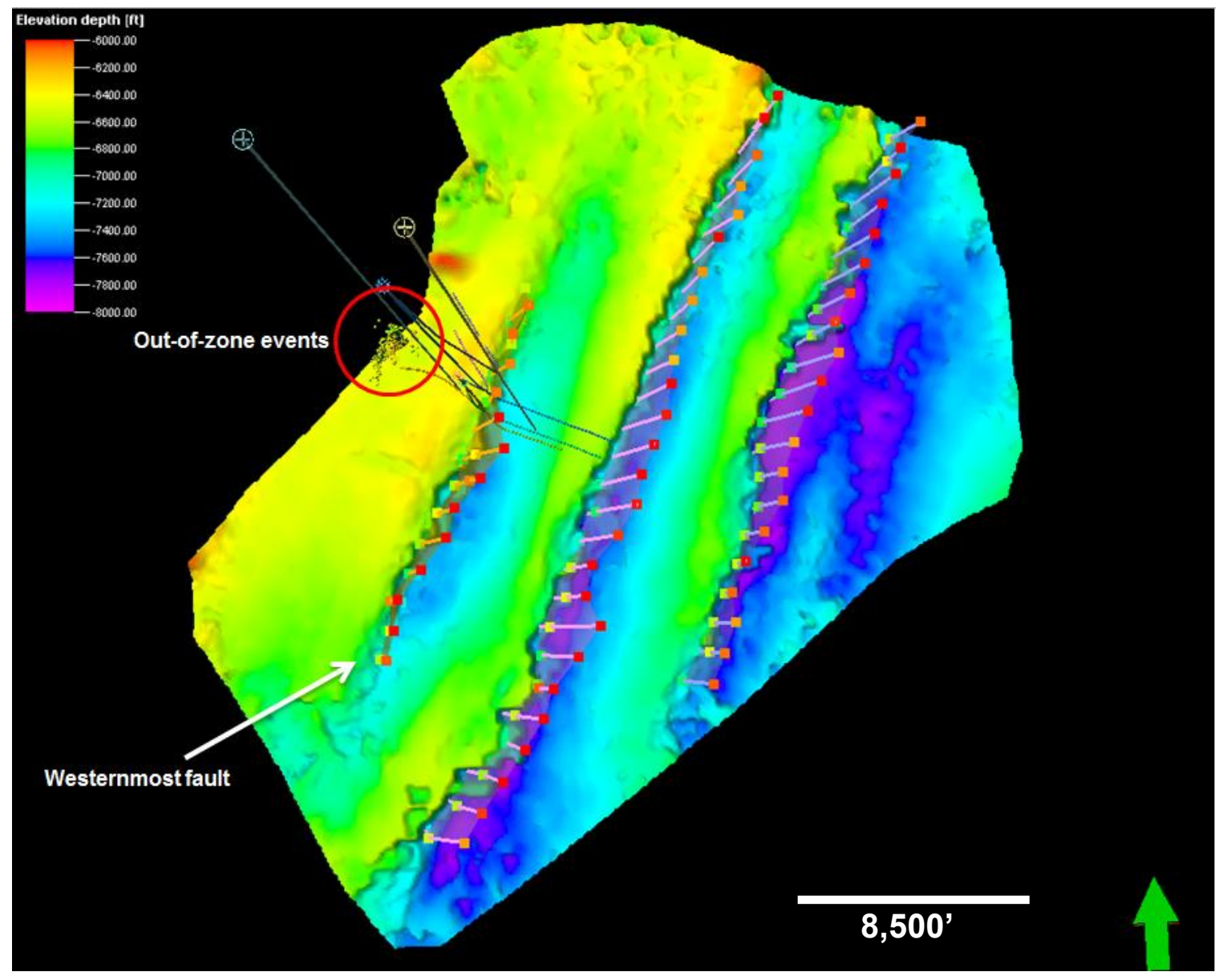

Figure 48: Out-of-zone events shown on the Onondaga Limestone surface along with westernmost fault location 


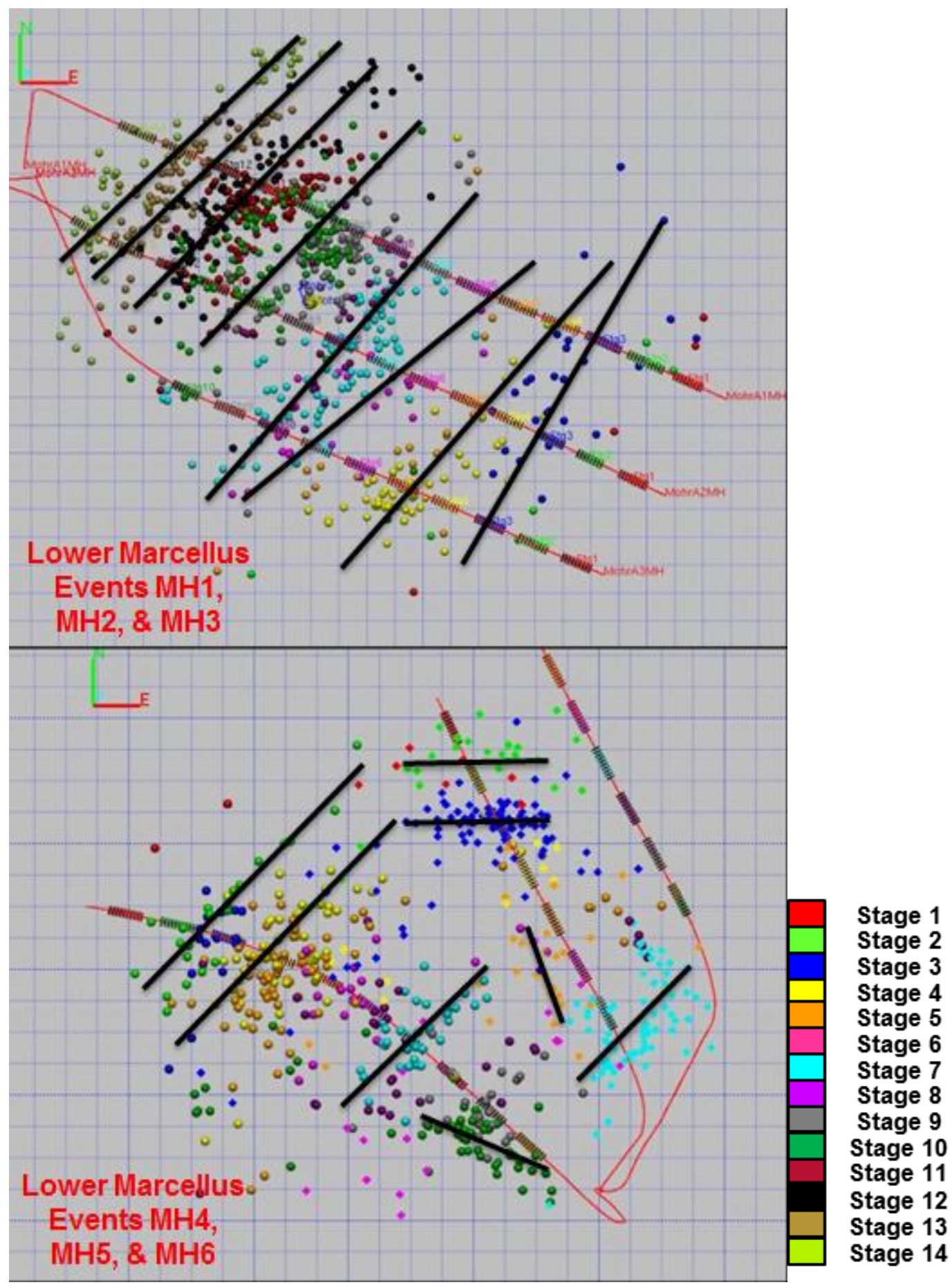

Figure 49: Microseismic event swarm patterns differ for hangingwall wells (MH4-6) and footwall wells (MH1-3). Events are colored by stage. Image courtesy of Weatherford. Grid blocks are 200'by 200'. 


\section{Table 6: Average \% Shortening for Each Stratigraphic Marker Measured}

ELK GRP

X-Section Name Frame Length [cm] Amt. Shortening [cm] \% Shortening Total Avg. \% Shortening Northernmost North MHEX-Section Microseismic South

Southernmost

SDNYEA GRP

X-Section Name Frame Length [cm] Amt. Shortening [cm] \% Shortening Northernmost North MH6 X-Section Microseismic South

Southernmost

\section{HAMILTON GRP}

$X$-Section Name Northernmost North

MHE X-Section Microseismic South Southernmost 21.55 19.55

22.50

19.45

19.85

15.21

0.12
0.25
0.80
0.10
0.15
0.12 0.56

1.28

3.56

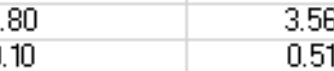

0.76

0.79

1.24

ARCELLUS SHALE

X-Section Name Frame Length [cm] Amt. Shortening [cm] \% Shortening

Northernmost North

MHE X-Section

Microseismic South

Southernmost

Southernmost
JUNIATA FM

21.55

19.55

22.50

19.45

19.85

15.21
19.55

22.50

19.45

19.85

15.21
0.31

0.40

1.30

0.40

0.32

0.40
1.44

2.05

5.78

2.06

1.61

2.63

Frame Length [cm] Amt. Shortening [cm] \% Shortening

21.55

19.55

22.50

19.45

19.85

15.21

0.59

0.56

0.70

0.65

0.50

0.30

0.52

0.65

0.59

0.58

0.53

0.30

2.74

2.86

3.11

3.34

2.52

1.97

2.76
2.41

3.32

2.62

2.98

2.67

1.97
2.66
Northernmost North

MH6 X-Section

Microseismic South

Southernmost

TRENTON LS

$X$-Section Name Northernmost North

MH6 X-Section

Microseismic

South

Southernmost

Frame Length [cm] Amt. Shortening [cm]

21.55

19.55

22.50

19.45

19.85

15.21

Frame Length [cm] Amt. Shortening [cm]

\subsection{5}

19.55

22.50

19.45

19.85

15.21
0.17

0.20

0.20

0.15

0.11

0.005

0.11

0.10

0.10

0.10

0.10

0.10

\% Shortening

0.79

1.02

0.89

0.77

0.55

0.03

0.68

\% Shortening

0.51

0.51

0.44

0.51

0.50

0.66

0.52 


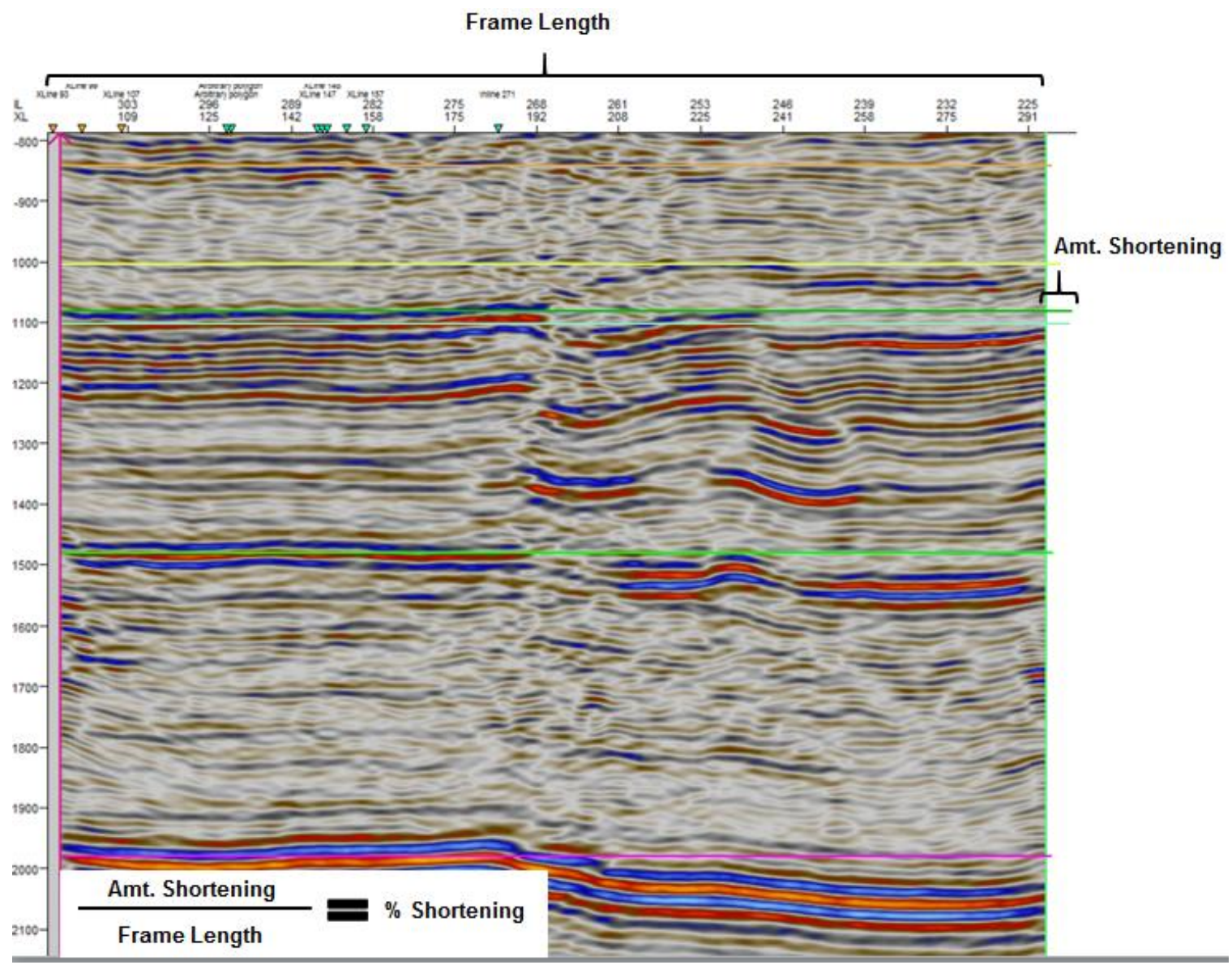

Figure 50: \% Shortening was calculated by dividing how much a stratigraphic marker's length increased after unfolding by seismic frame length. 
much unfolded beds stretched beyond the seismic (amount shortening).

However, there are limitations to this method; variations in shortening may not be real, as shortening could be accommodated along structures not resolved in the seismic.

Of all the cross-sections generated, the cross-section intersecting the outof-zone microseismic activity shows that the sum of fault offsets are greatest around this location; this cross-section also displayed the second highest amount of shortening of all the cross-sections created (Figure 51). The North crosssection experienced the most shortening of all cross-sections generated (Figure 52). This is interesting considering the sum of the fault throws in this region is not the greatest - fault offsets in this region rank $4^{\text {th }}$ out of 6 cross-sections created. It is likely that much of the shortening in this area is accommodated by higher amplitude folding and detachment farther east (Figure 53).

The Hamilton and the Marcellus have experienced the most shortening on average, $2.76 \%$ and $2.66 \%$ respectively (refer to Table 6 ). Shortening appears to have been accommodated by large thrust faults that verge towards the southeast (with average offset of 237 feet), detachment, intense folding, and smaller-scale vertical faulting present throughout the Devonian. Degrees of faulting and folding vary from northeast to southwest, with the most intense faulting occurring in the heart of the survey; the most intense folding and detachment occurs towards the eastern portion of the survey (Figure 54).

Isochron maps display the variation in time between two seismic events; for this study isochron maps were made to look at time differences between 
Fault Throws \& \% Shortening at Each Location

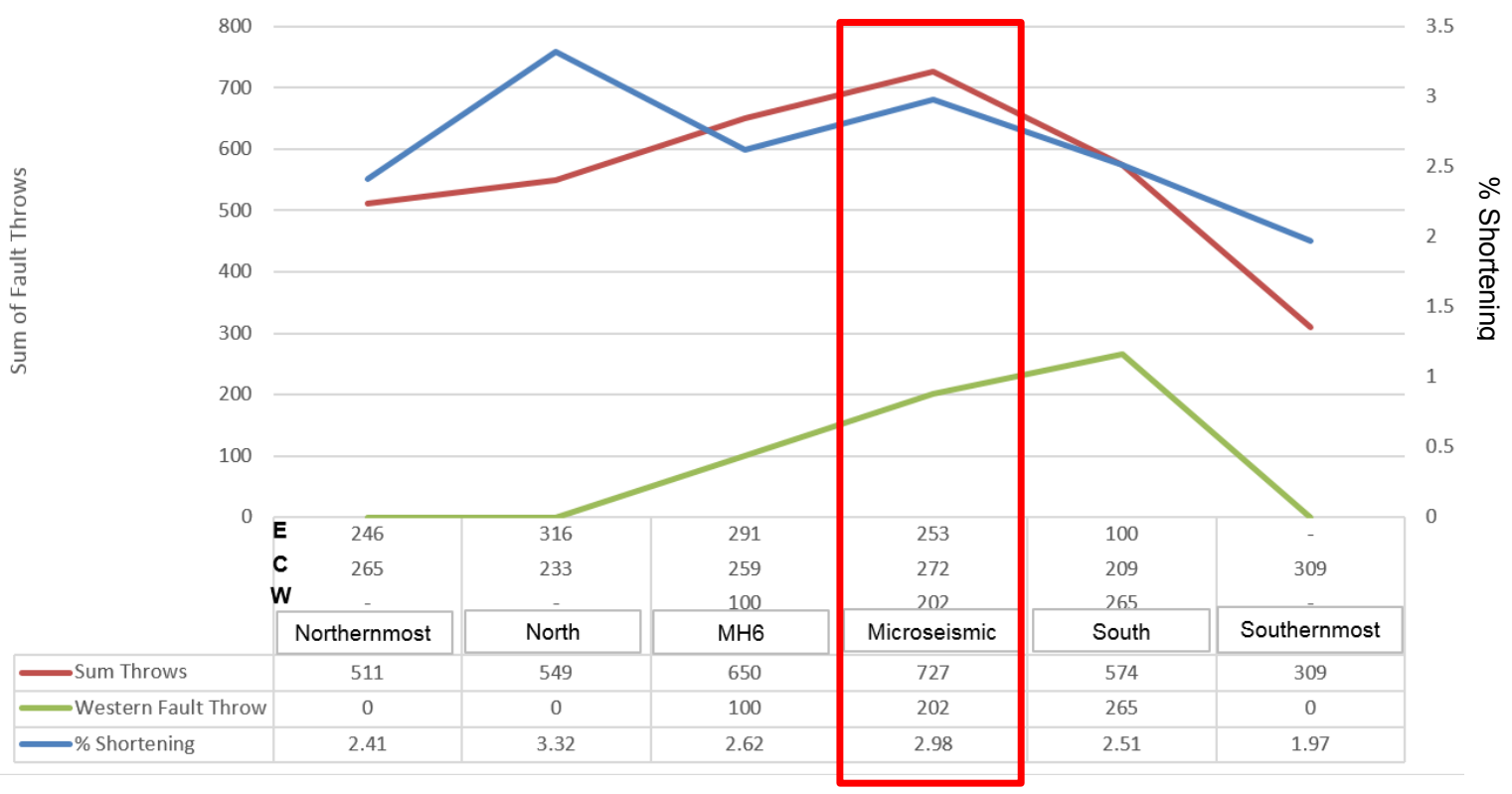

Figure 51: sum of fault offsets are greatest on cross-section intersecting area of out-ofzone microseismic activity. This cross-section also displayed the second highest amount of shortening.

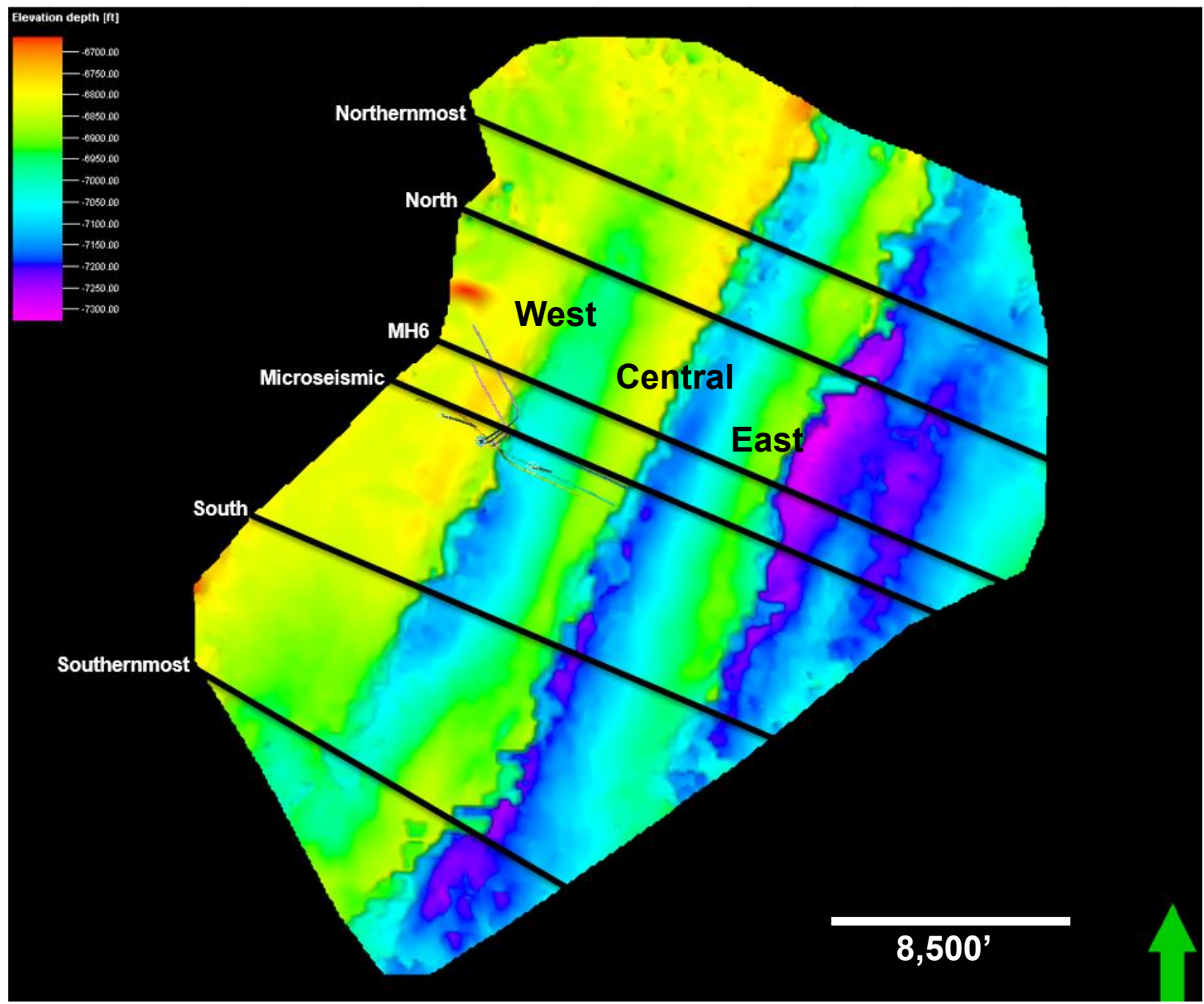


Fault Throw vs. Location

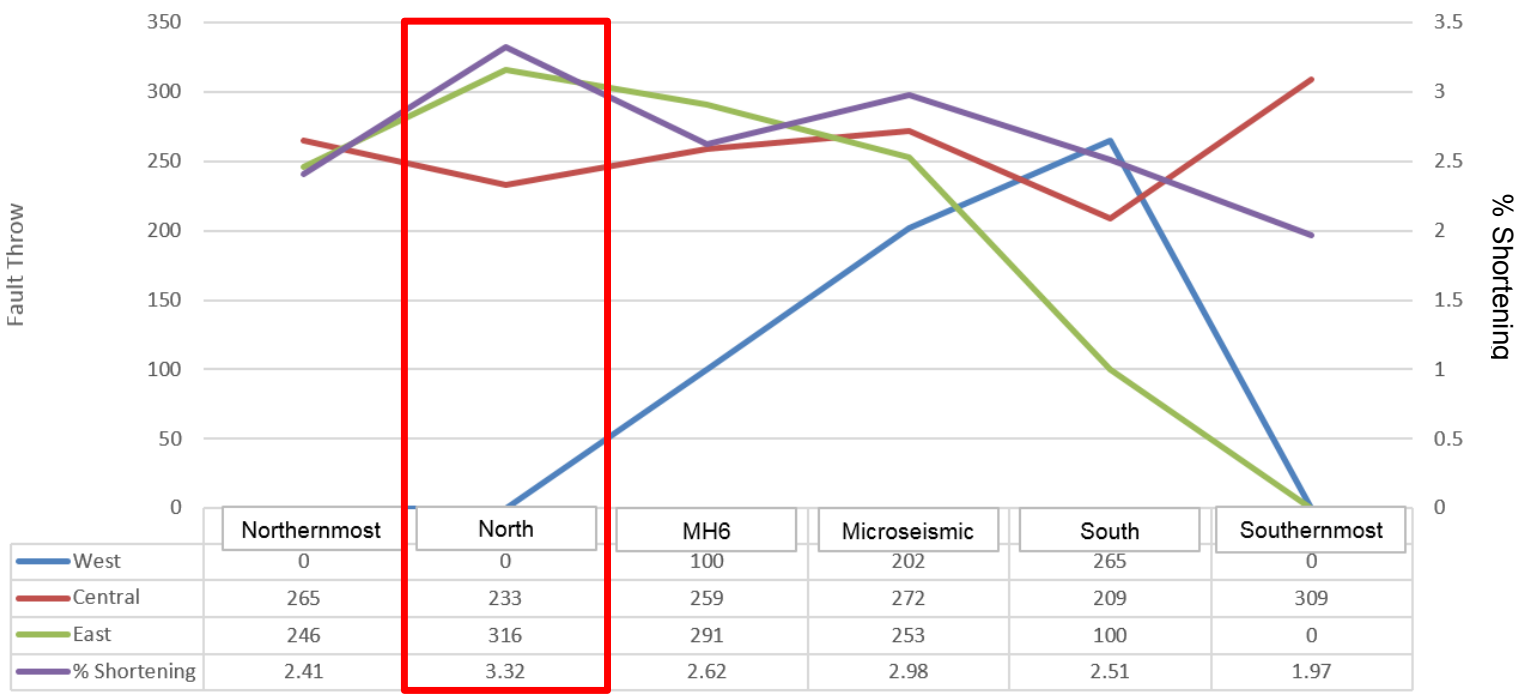

Figure 52: The sum of the fault throws in the North cross-section is not the greatestfault offsets in this region rank $4^{\text {th }}$ out of 6 cross-sections created; however, shortening in this region is the greatest. This is probably due to high amplitude folding in the east.

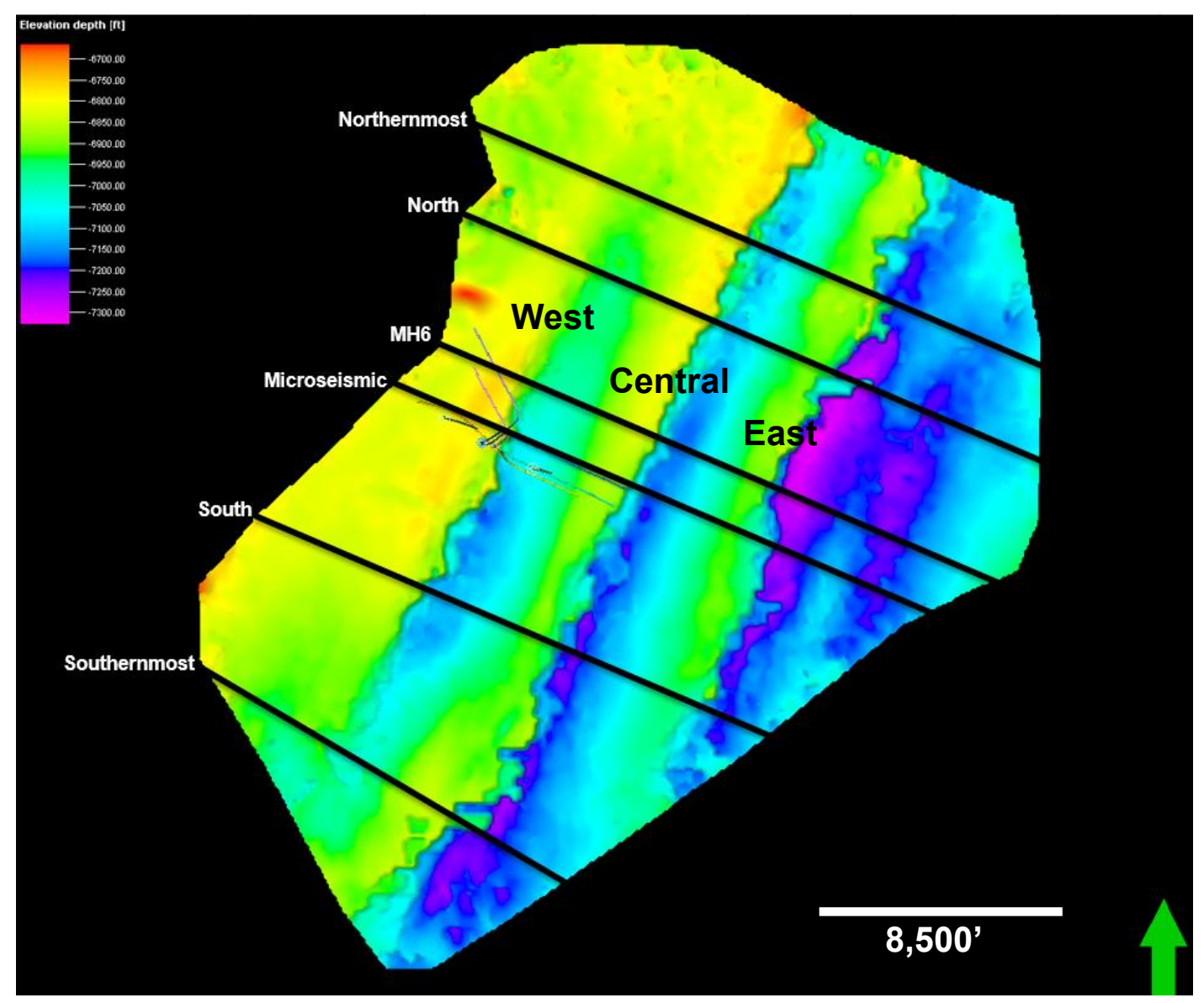




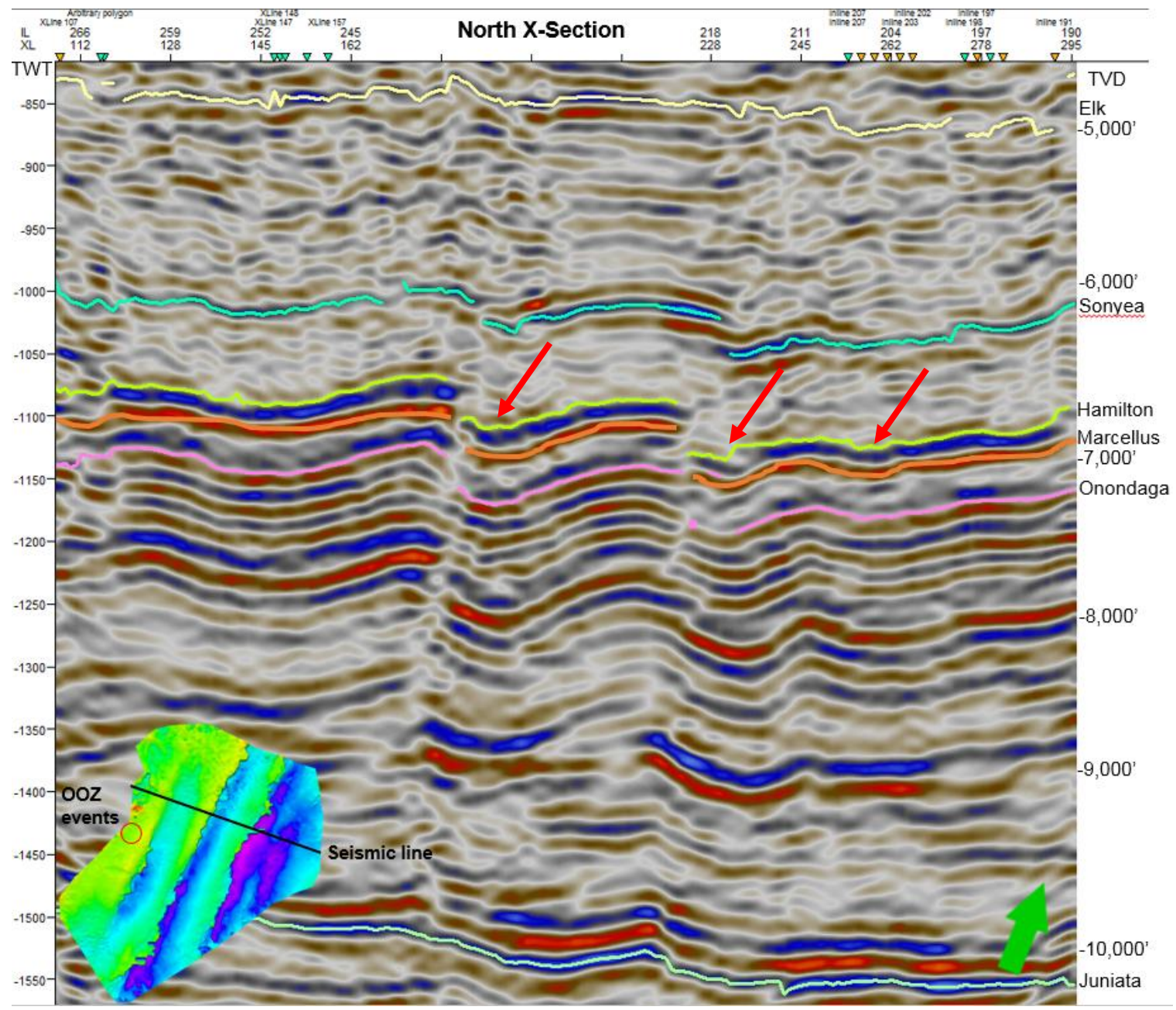

Figure 53: The north cross-section displays high amplitude folding. Detachment (red arrows) in this region is very pronounced 

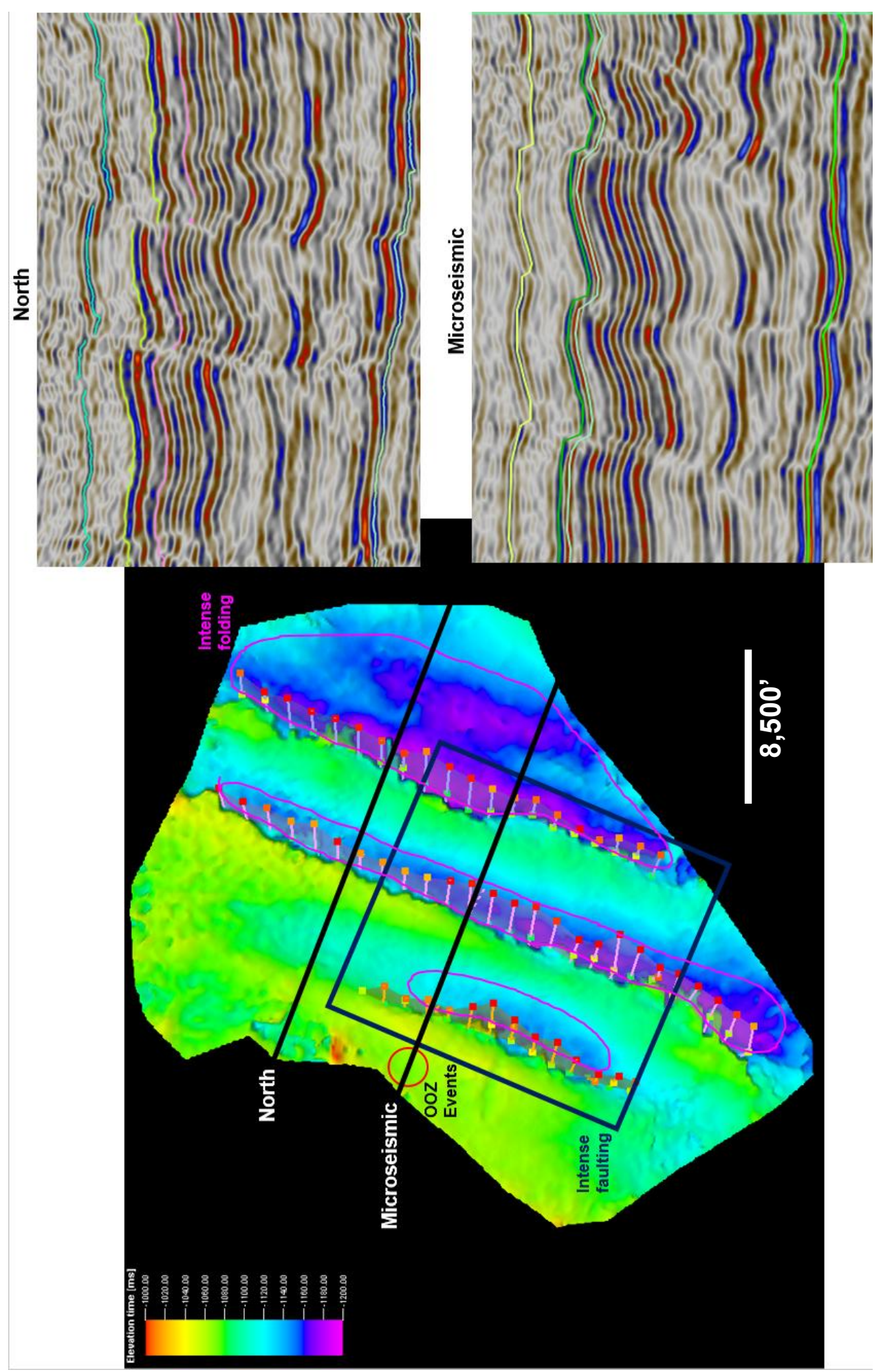

Figure 54: Faulting is most prominent in the area outlined by the box, and folding is most intense towards the eastern portion of the survey. North of where the westernmost fault terminates shortening is accommodated through increased intra-block folding and folding towards the east. 
multiple stratigraphic boundary markers. Isochron mapping of the Rose Run to Trenton intervals (late Cambrian - early Ordovician) reveals a large structure oriented at $\sim \mathrm{N} 45 \mathrm{E}$ and smaller structures formed during this time to be oriented at $\sim$ N30E (Figure 55). Time structure maps of the Trenton to Juniata interval (early Ordovician to late Ordovician) depict the formation of structures oriented $\sim$ N25E; these structures are interpreted to be a result of continental collision during the Alleghenian Orogeny (Figure 56). Thickening is interpreted to be a result of detachment in incompetent units of the Martinsburg Formation and Utica shale which lie inbetween the Juniata Formation and Trenton Limestone. Figure 57 shows a comparison of the deeper Cambro-Ordovician structural trends codisplayed with the shallower Ordovician structural trends. Cambro-Ordovician structure differs in orientation from the shallower structure, but those deeper structural influences appear to have affected completions in the area. Generated microseismicity and extracted seismic discontinuities more closely follow the deeper N45E orientation (Figure 58). Isochron maps generated for the Juniata to Onondaga interval (late Ordovician to Devonian) (Figure 59), Onondaga to Hamilton interval (early to middle Devonian) (Figure 60), and Onondaga to Tully interval (early to middle Devonian) (Figure 61) show significant increases in travel times around each fault. This thickening is related to detachment along the salts of the Salina Group (for the Juniata to Onondaga interval) and within incompetent shales of the Hamilton Group (Onondaga and above) during the Acadian and Alleghenian Orogenies; thickening deeper in the Cambrian Ordovician section (see Figure 55) is related to formation of the Rome Trough 


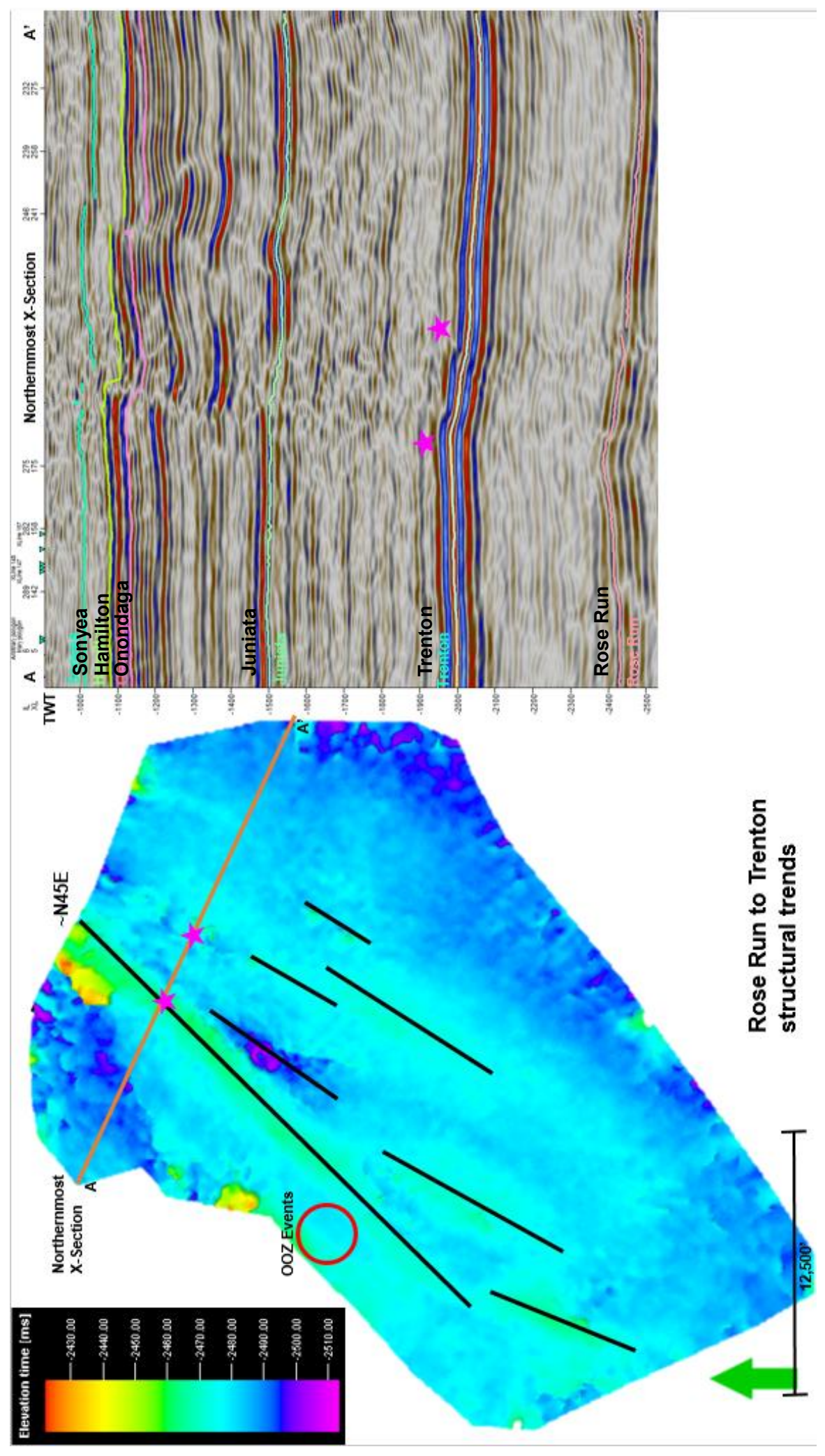

Figure 55: Rose Run to Trenton isochron map. The large structure within the late Cambrian to early Ordovician exhibits a N45E trend, and smaller structures exhibit a N30E trend. 

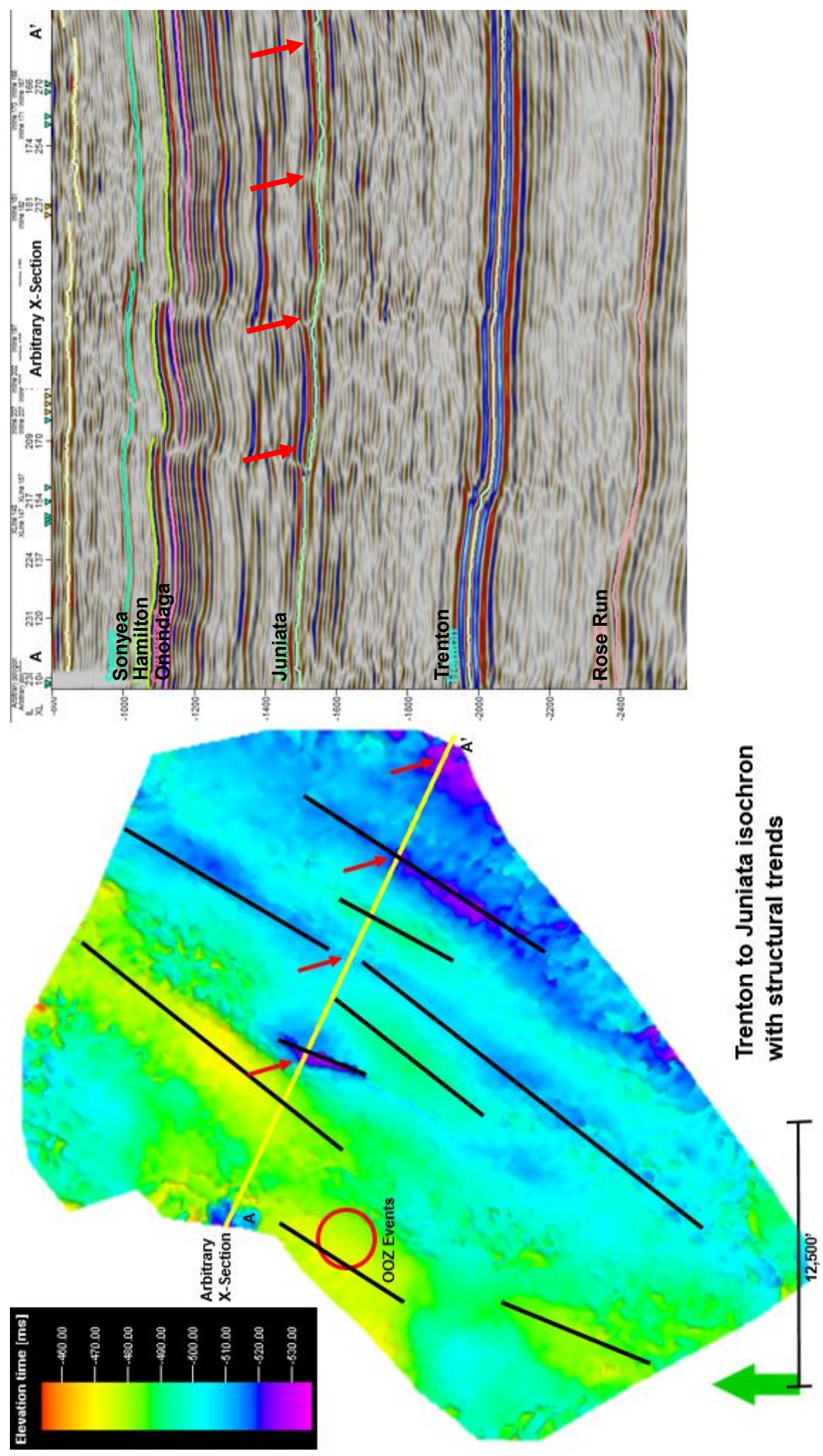

Figure 56: structures through the Ordovician are oriented $\sim N 25 E$; these structures are interpreted to be a result of the Taconic Orogeny. Red arrows correspond to thickening locations identified in the isochron map. 


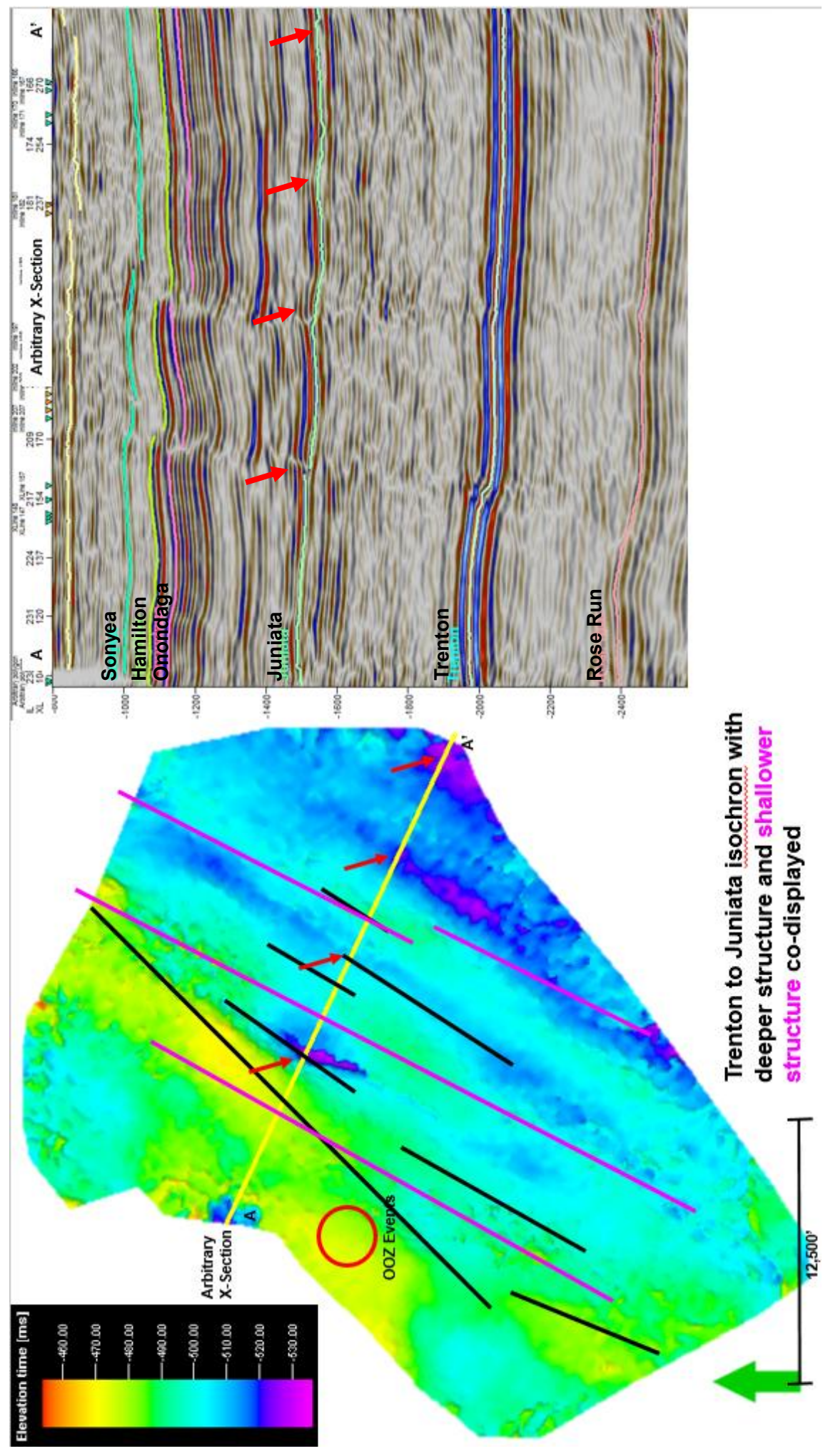

Figure 57: Deeper Cambro-Ordovician structural trends ( N45E and $\sim N 30 E)$ codisplayed with the shallower Ordovician structural trends ( N25E). Cambro-Ordovician structure differs in orientation from the shallower structure on average about 20 degrees. 


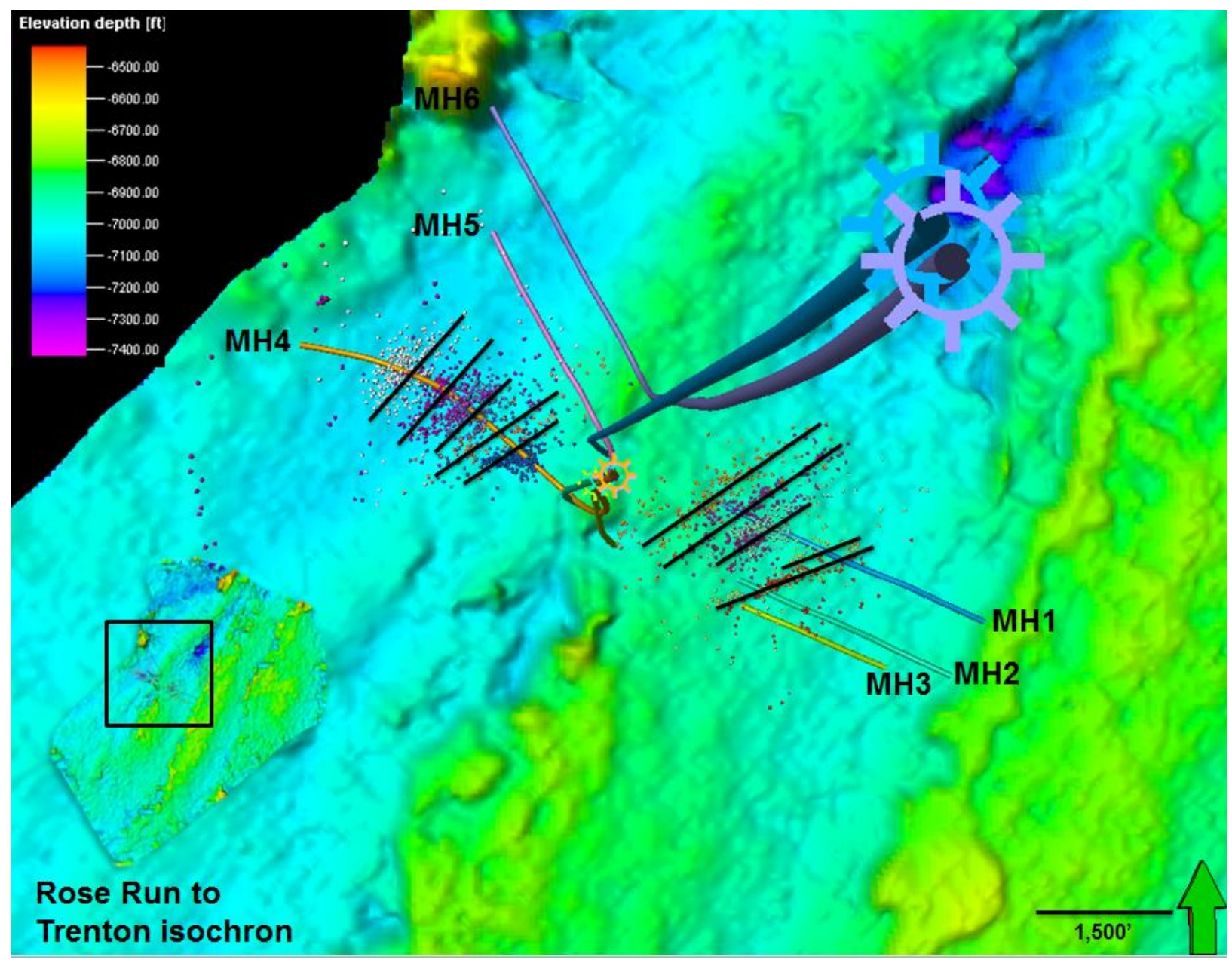

Figure 58: Stages 4, 6-9 from the MH4 well and stages 6-7, 9-10, 12 for the MH1 well illustrate that microseismic events more closely follow the trends of the deeper structures. 


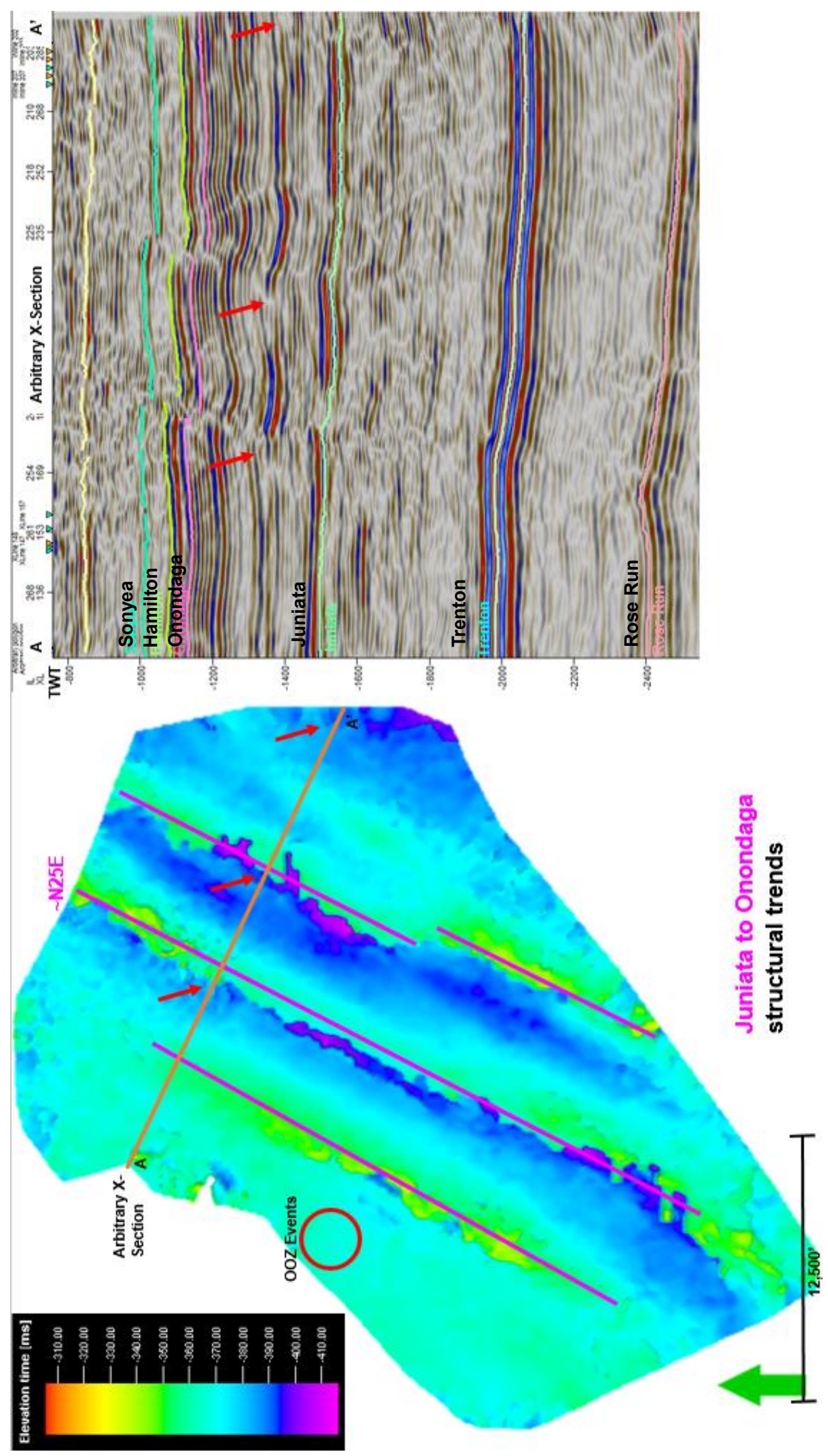

Figure 59: Isochron map displaying areas of salt thickening as a result of detachment 


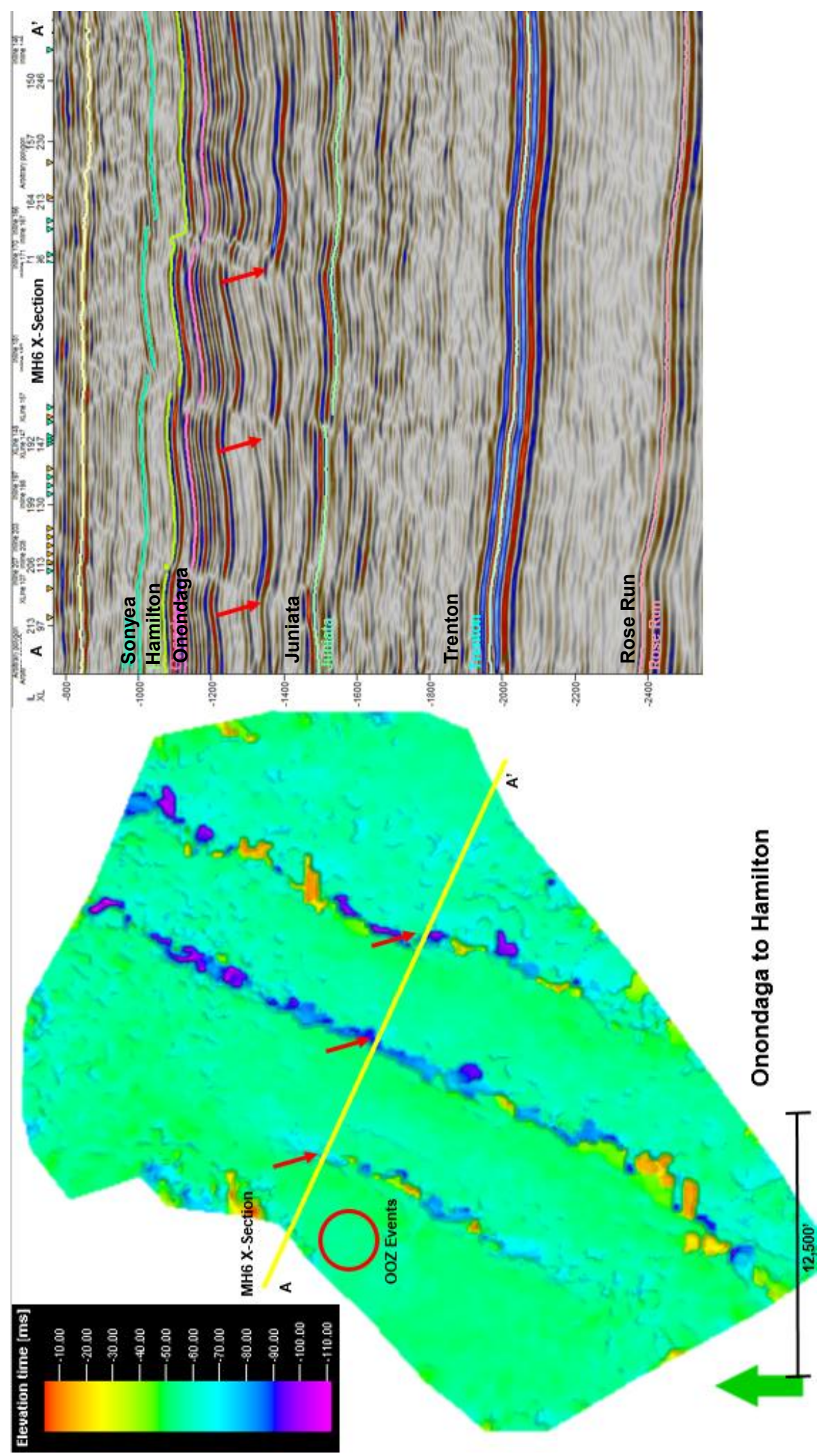

Figure 60: Isochron map showing thickening as a result of detachment within the Marcellus Shale 


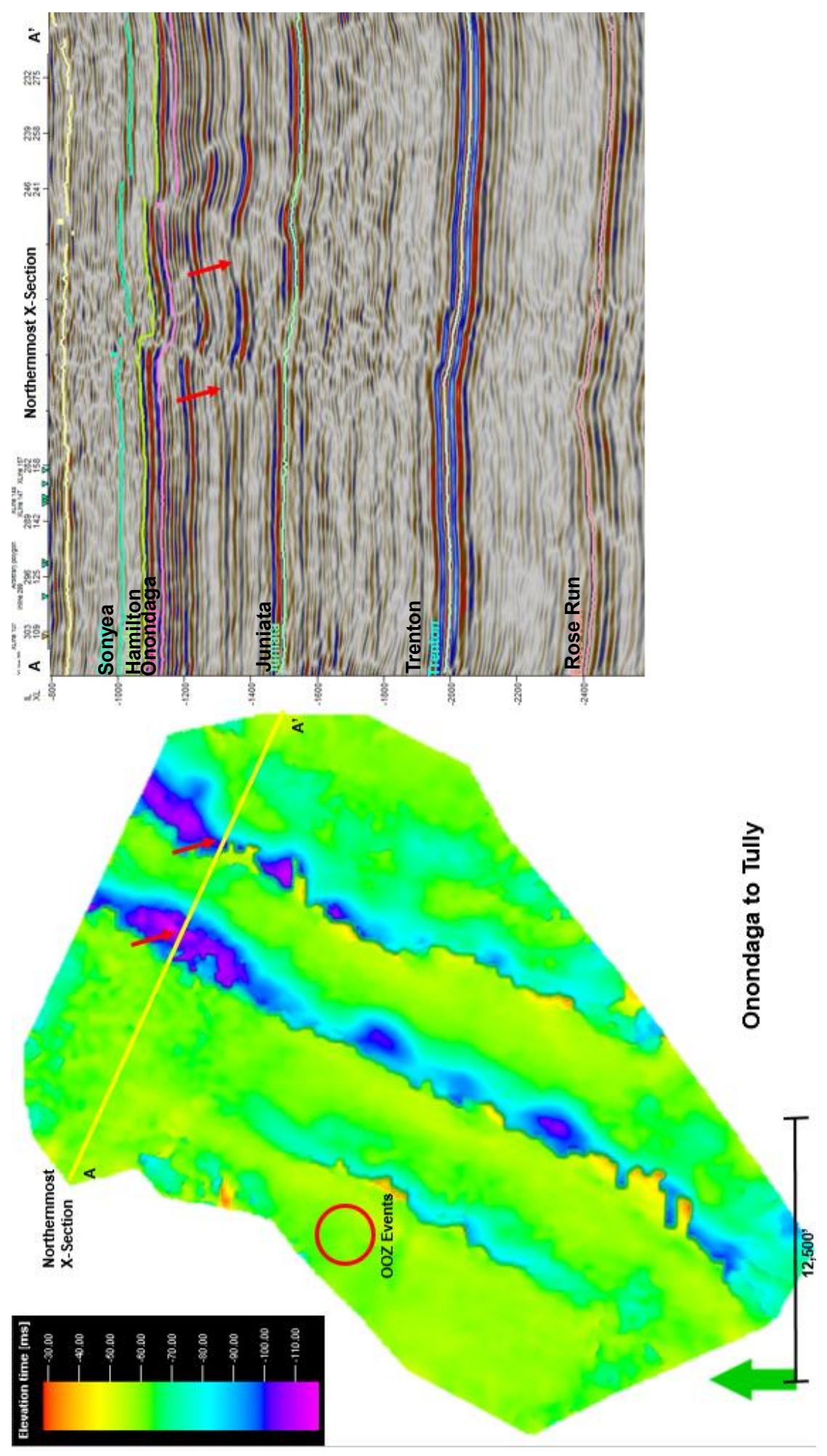

Figure 61: Isochron map showing thickening as a result of detachment within the Hamilton Group. 
rather than detachment as a result of the Acadian and Alleghenian Orogenies.

Early Cambrian rifting spawned extensional faults rooted in the PreCambrian basement, and these faults were re-activated throughout the Paleozoic - during the Taconic, Acadian, and Alleghenian orogenies (Wilson, 2000).

Cratonic loading during these collisional events produced reverse displacements in some of these earlier formed normal faults (Wilson, 2000). These deeper faults appear to have also aided in creating seed points for faulting further upsection, as seen in Figure 62.

The southeast-vergent thrust faults in the study area are anomalous with respect to the overall direction of tectonic transport in the Appalachians. Central Appalachian folds are northwest vergent and generally develop along southeast dipping reverse faults. Southeast vergent structures, while anomalous, are not uncommon. Gwinn (1964) and Shumaker (2002) note the presence of numerous fault blocks displaced to the southeast. These southeast-vergent thrusts are interpreted to be a result of underthrusting related to the Chestnut Ridge Anticline triangle zone described in Shumaker (2002) (Figure 63). The Chestnut Ridge anticline exists east of the study area and was formed as a result of continental collision and subsequent detachment during the Alleghenian orogeny. The triangle zone transferred tectonic transport from detachment surfaces of the Martinsburg Formation and Utica Shale upward to younger incompetent units such as the Salina Group and Middle and Upper Devonian shales (Shumaker, 2002). This model is supported by the presence of multiple detachment horizons in the study area, as well as the presence of southeast-vergent thrusts (the 

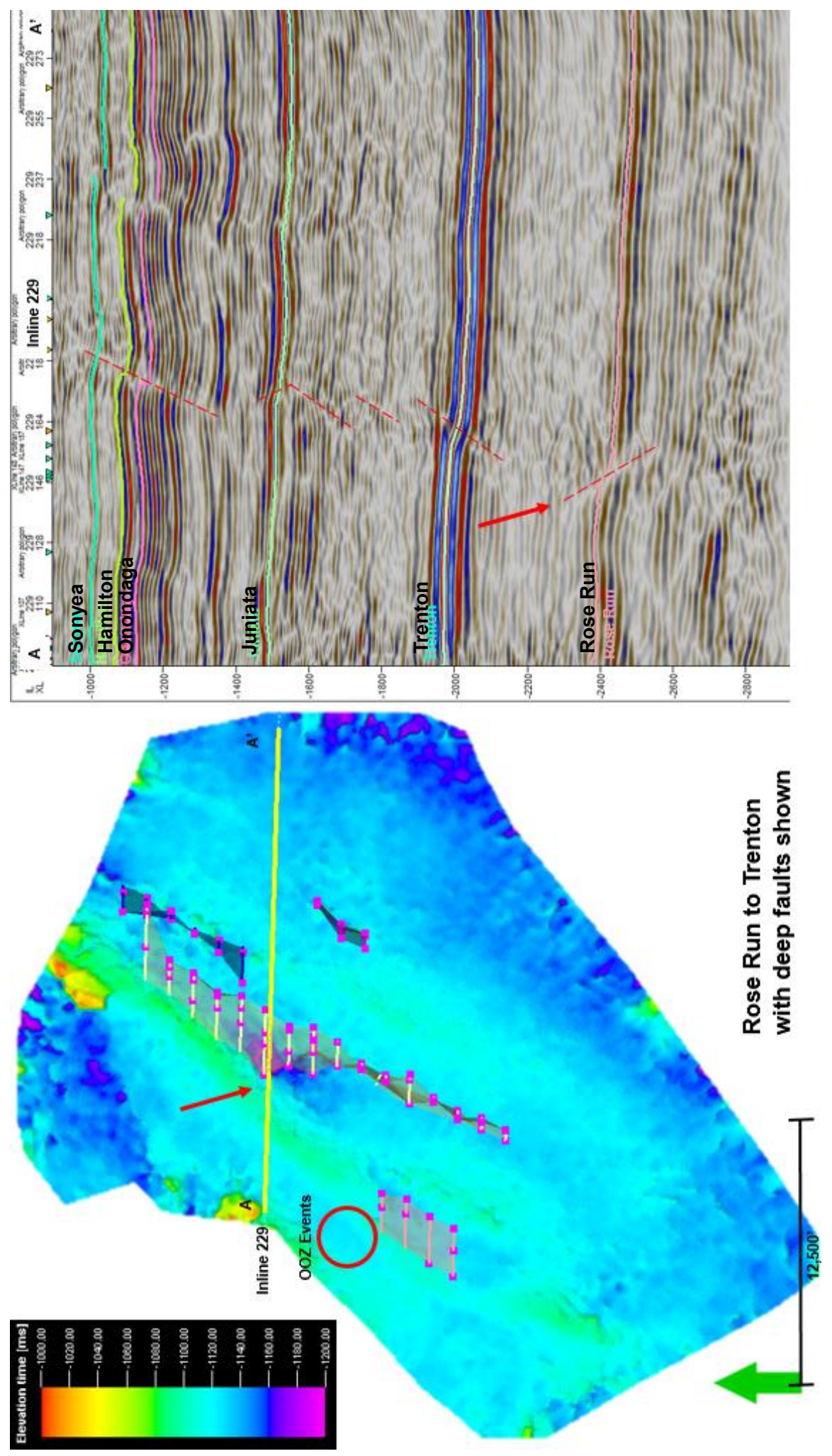

Figure 62: Isochron map showing where thickening has occurred. A normal deeper fault that cuts the Rose Run formation appears to have seeded thrust faults higher up in the section. 


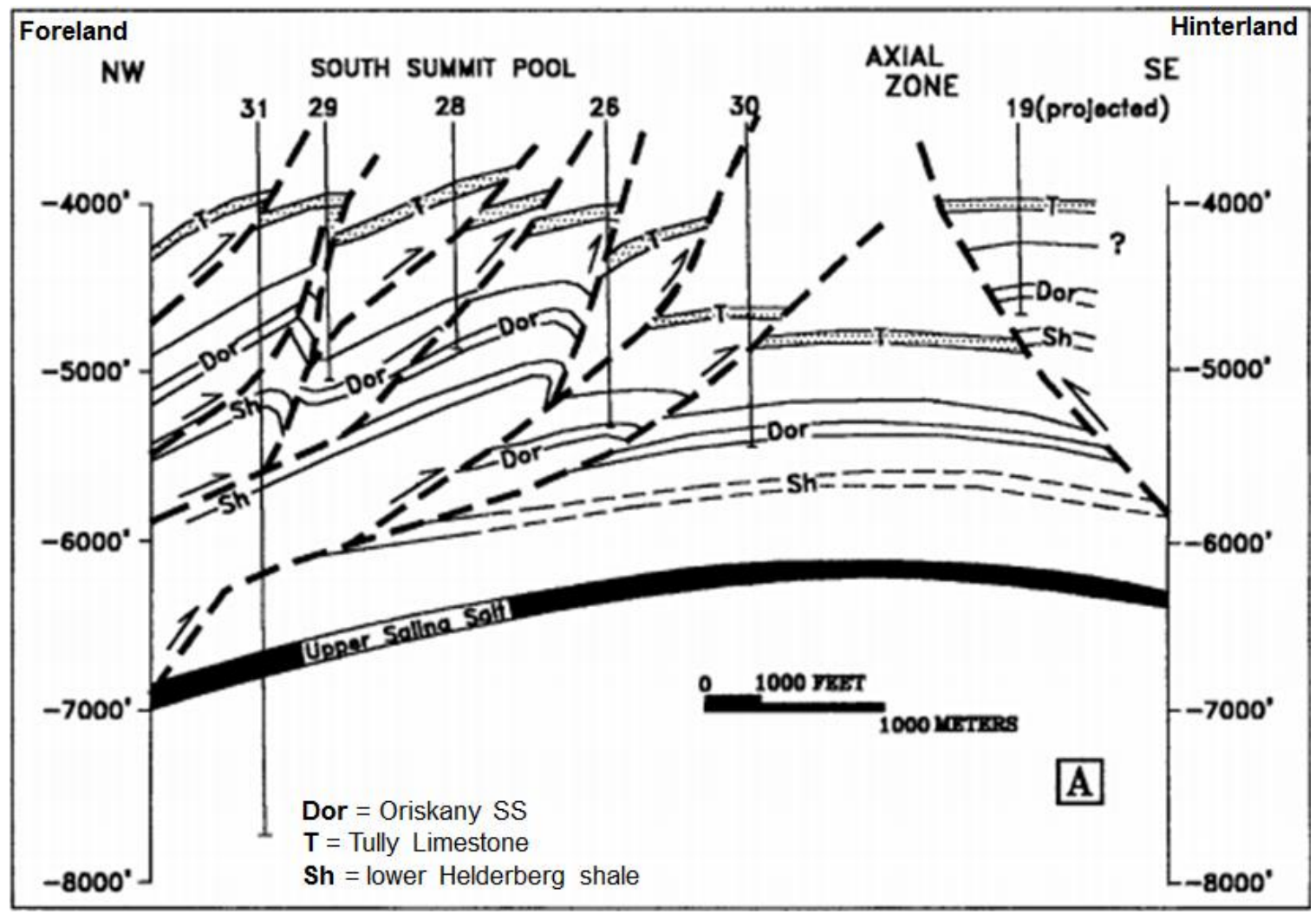

Figure 63: Figure modified from Gwinn (1964). Geologic cross-section of the South Summit field showing imbricate thrust faulting (verging towards the hinterland) and detachment. The study area displays a similar faulting style and is nearby. 
thrusts verge towards the hinterland). Donahoe (2011) suggested these structures arose as a result of a strain resistant rock volume either opposing or moving against colliding plates during orogenesis.

\subsubsection{Discontinuity Mapping Interpretations}

The Ant Tracking attribute was used on multiple volumes to extract discontinuities in the seismic reflection response; this attribute is helpful for fault extraction as well as identifying where areas of increased fracture intensity may exist. Chaos, variance, and $t^{*}$ attenuation-based workflows were analyzed for this study. Both passive and aggressive Ant Tracking parameters were used for each attribute tested in order to compare how maps differ with alternate parameterization.

Ant Tracking applied to the variance seismic volume was useful for determining where significant structural features (such as larger faults and areas of intense folding) existed (Figures 64-65). Two discontinuities that cross-cut hangingwall and footwall wells were of particular interest. Their relationships with anomalies in radiated seismic energy output by neighboring stages were tested. However, no clear association between discontinuities seen in Ant Tracking maps and differences in radiated seismic energy output by neighboring frac stages was observed.

Chaos-based ant tracking did not yield results that were as useful as those generated by the variance-based and $t^{\star}$ attenuation-based workflows. There were relatively few differences between passive and aggressive parameterizations of the ant-tracking attribute, and it seems that the only large difference is an 

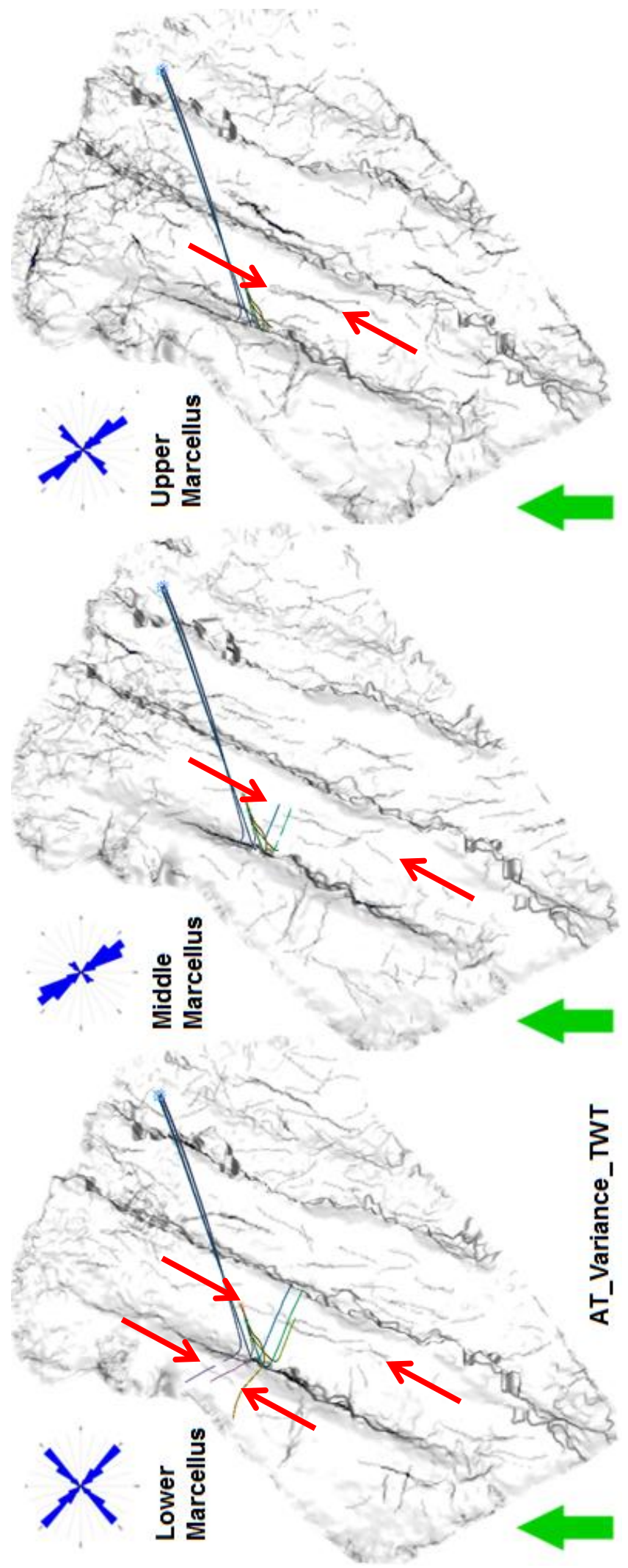

Figure 64: Passive ant tracks on the variance attribute. Red arrows note locations of discontinuities that cross-cut multiple wellbores. 

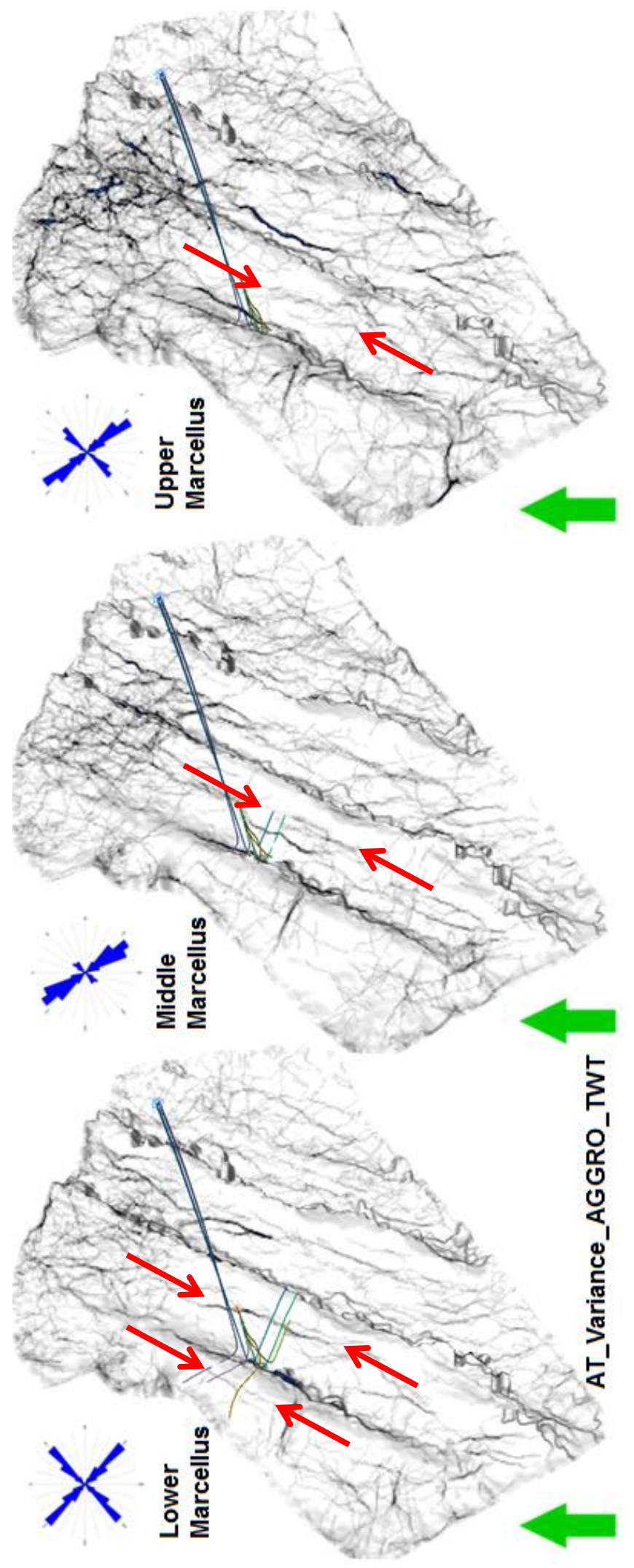

Figure 65: Aggressive ant tracks on the variance attribute. Red arrows note locations of discontinuities that cross-cut multiple wellbores. 
increase in discontinuities extracted in the far north portion of the survey in the Upper Marcellus around the central fault (Figures 66-67).

3D seismic data conditioned using a t*attenuation based workflow outlined in Wilson et al., (2014a) were analyzed; the seismic data were enhanced for optimal 3D visualization of folding and faulting as well as for preconditioning for seismic discontinuity extraction. Both the TVTAS and $t^{*}$ attenuation workflows helped to enhance fault and fracture zones that are not visible in the 3D seismic data alone, and ant tracking was used to extract discontinuities in the $t^{\star}$ attenuation-based seismic. Discontinuities observed in the seismic data have been interpreted as fracture zones and small faults (Wilson et al., 2014a). These methods are used to help assess possible structural controls on the distribution of out-of-zone microseismic activity.

Figure 68 displays discontinuity mapping results from the Lower Marcellus Shale. The t*attenuation-based workflow described in Wilson et al., (2014a) was used to generate these maps. Two prominent modes of discontinuities were identified $-\mathrm{a} \sim \mathrm{N} 41 \mathrm{~W}$ mode and $\mathrm{a} \sim \mathrm{N} 52 \mathrm{E}$ mode. One can see that discontinuity orientations are very similar for each interval tested throughout the Marcellus Shale, but the number of occurrences of northeastern-oriented discontinuities decrease in the Middle and Upper Marcellus Shale (Figure 69).

These dominant discontinuity modes do not coincide with Engelder's $J_{1}$ and $\mathrm{J}_{2}$ joint sets which have orientations of roughly N80E and N45W. The N52E discontinuity set most closely follows Engelder's $J_{1}$ joint set which has an orientation of $\mathrm{N} 80 \mathrm{E}$, and the $\mathrm{N} 41 \mathrm{~W}$ discontinuity set most closely follows 

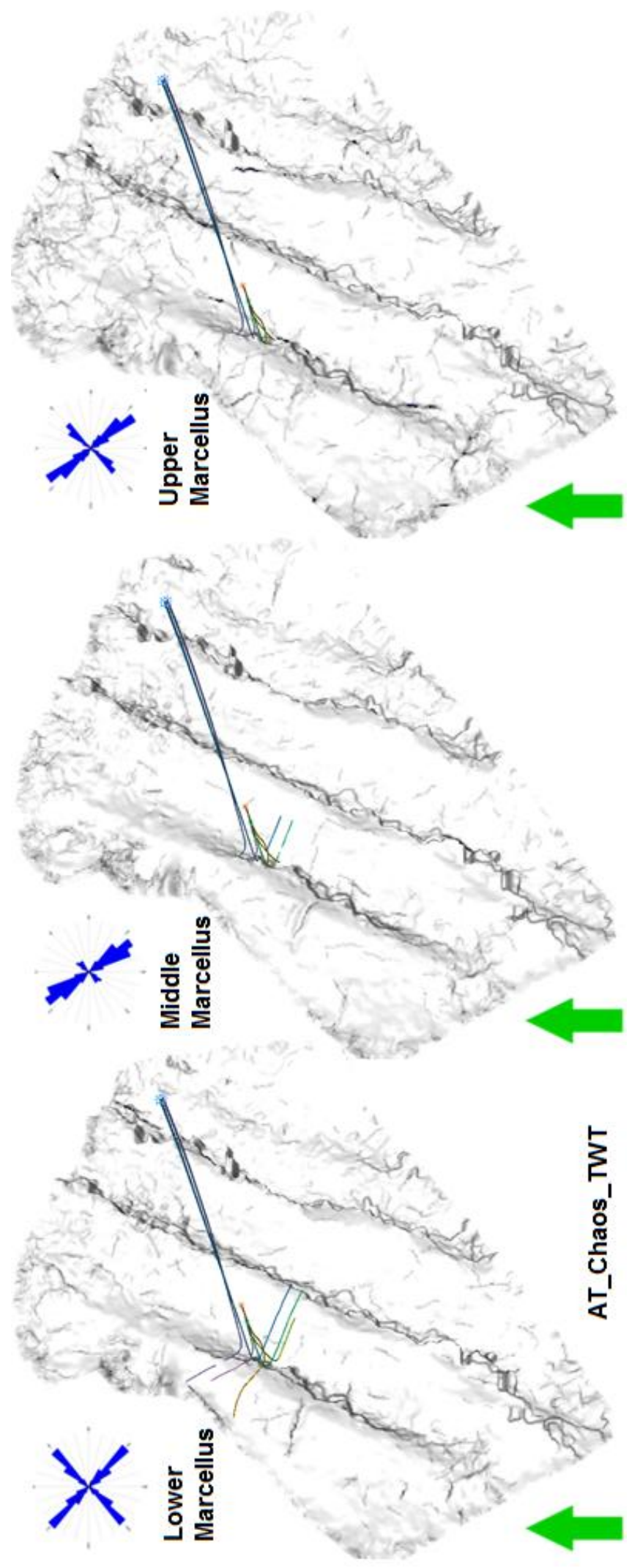

Figure 66: Passive ant tracks on the chaos attribute. 

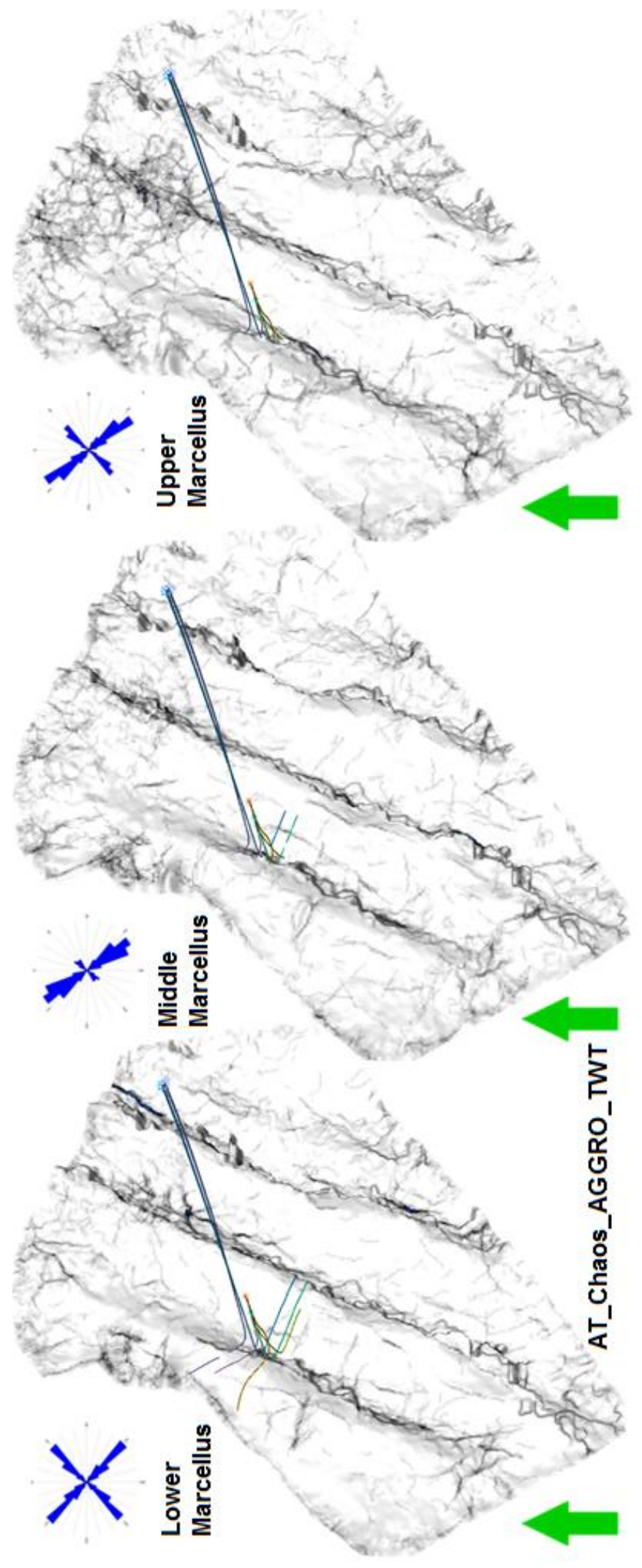

Figure 67: Aggressive ant tracks on the chaos attribute. 


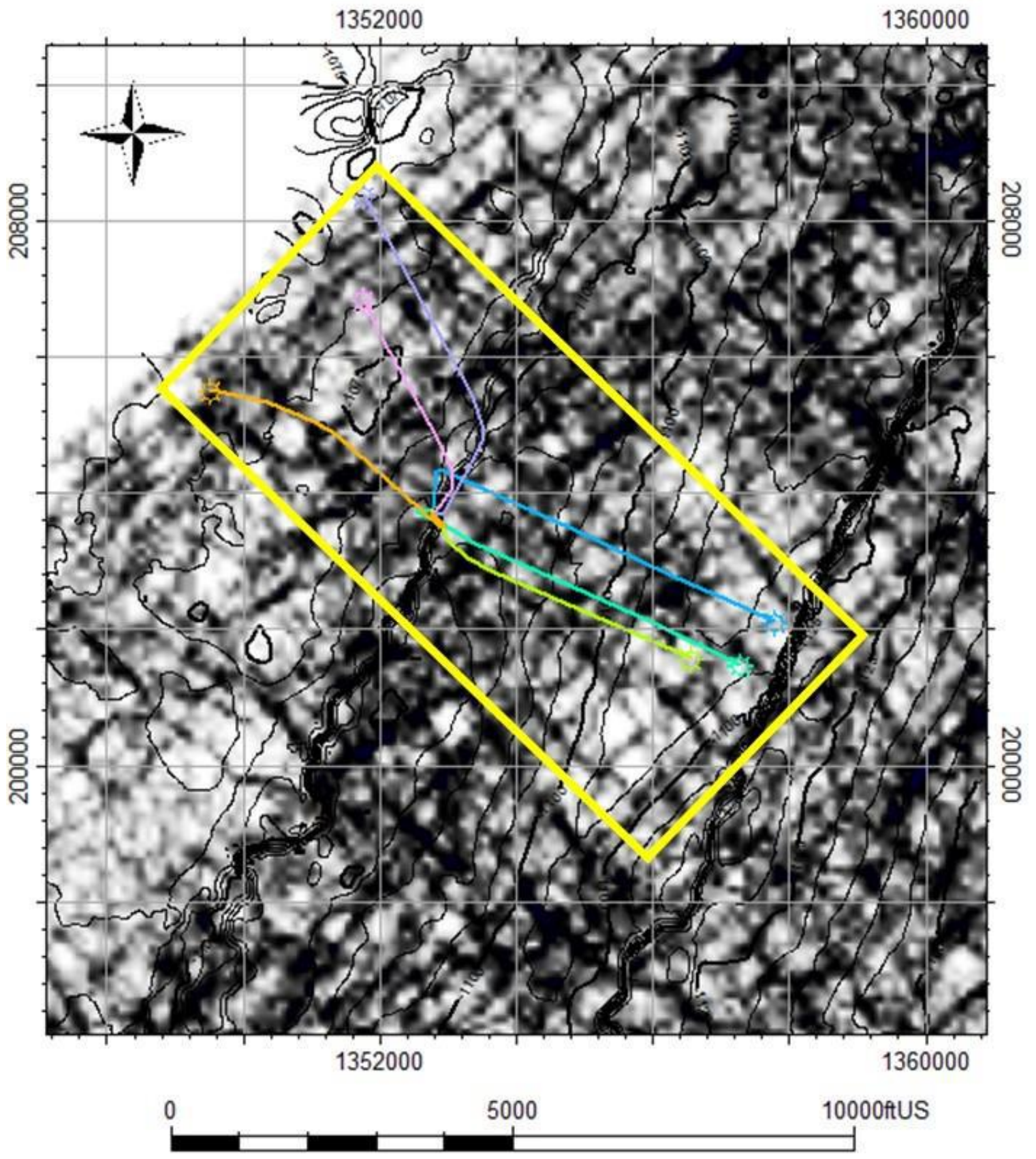

Figure 68: Discontinuity mapping results for the lower Marcellus 


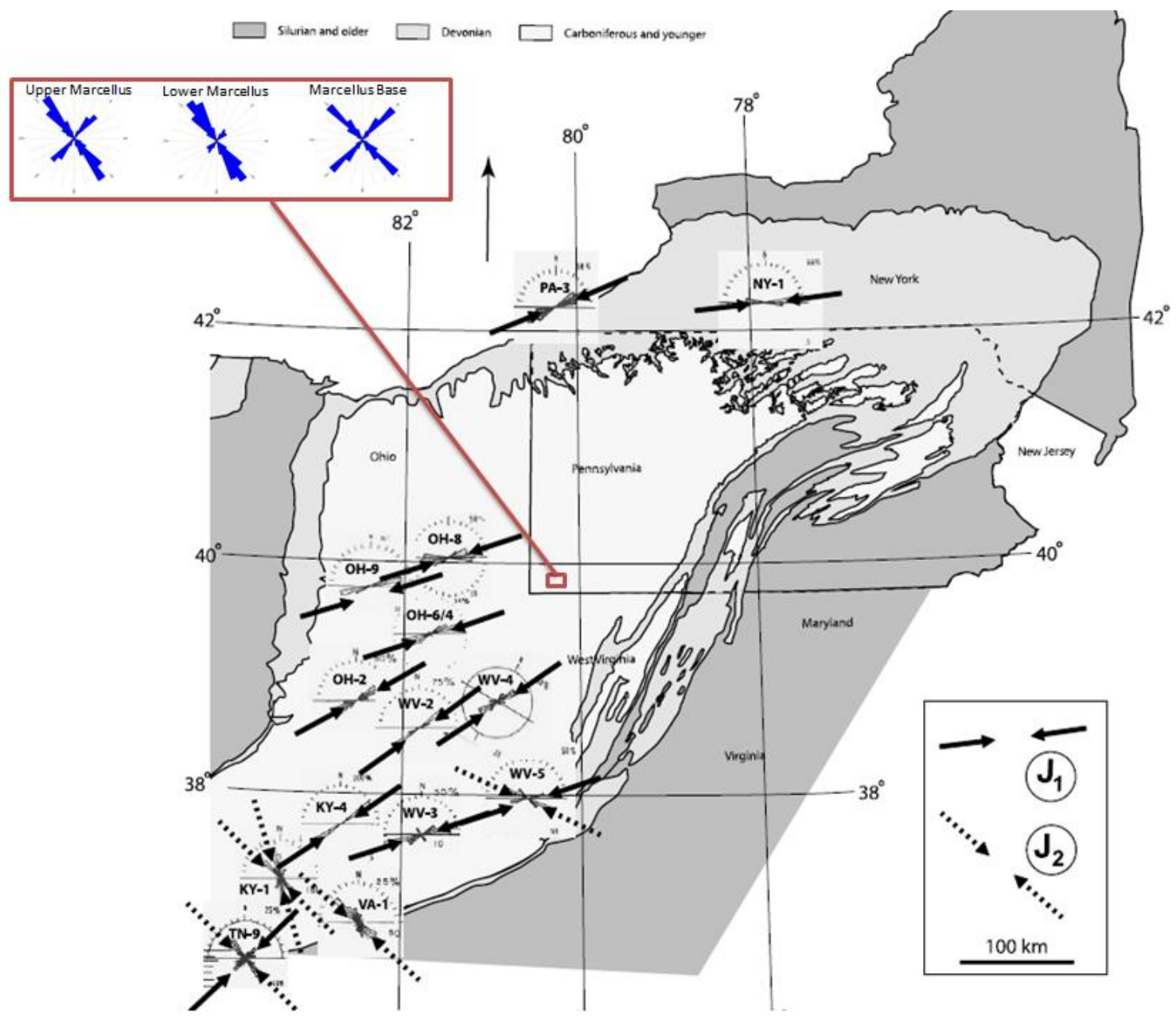

Figure 69: Interpreted discontinuity results for Greene County, PA displayed with Engelder et al., (2009) $J_{1}$ and $J_{2}$ interpretations 
Engelder's $\mathrm{J}_{2}$ joint set which has an orientation of roughly $\mathrm{N} 45 \mathrm{~W}$.

The discontinuity maps suggest the presence of zones of increased fracture intensity, large faults, and smaller faults, but features such as joints or very small-scale faults will not be individually visible in the seismic. The minimum resolvable thickness in the Marcellus Shale is $\sim 61$ feet assuming an average velocity of 11,000 feet per second (Wilson, written communication, 2014). The post-migration Fresnel zone diameter is $\sim 80$ feet (assuming $V_{\text {avg }}=14,000 \mathrm{ft} / \mathrm{s}$ and pulse frequency $=45 \mathrm{~Hz}$ ), so this is the minimum distance that we can tell two features apart in the seismic data. If two seismic discontinuities are seen in the seismic data at a distance closer than $\sim 80$ feet, they cannot be reliably imaged.

The Upper and Middle Marcellus display more occurrences of the N41W discontinuities than N52E discontinuities (Figure 70). Upon further analysis, this is a result of $\mathrm{N} 52 \mathrm{E}$ oriented discontinuities having greater length than $\mathrm{N} 41 \mathrm{~W}$ discontinuities. Ant tracking preferentially made more elongated connections in the N52E direction, whereas N41W discontinuities are shorter and their paths are more truncated. These differences in discontinuity length could be related to structural trends; the longer N52E discontinuity set is possibly related to activation of deeper faults related to continued movement across Pre-Cambrian basement faults in response to tectonic stresses - primarily those during the Alleghenian Orogeny (Wilson, 2000); (Wilson et al, 2014a).

\subsection{Stratigraphic Interpretations}

Throughout most of the Devonian, the study area was in the distal region 

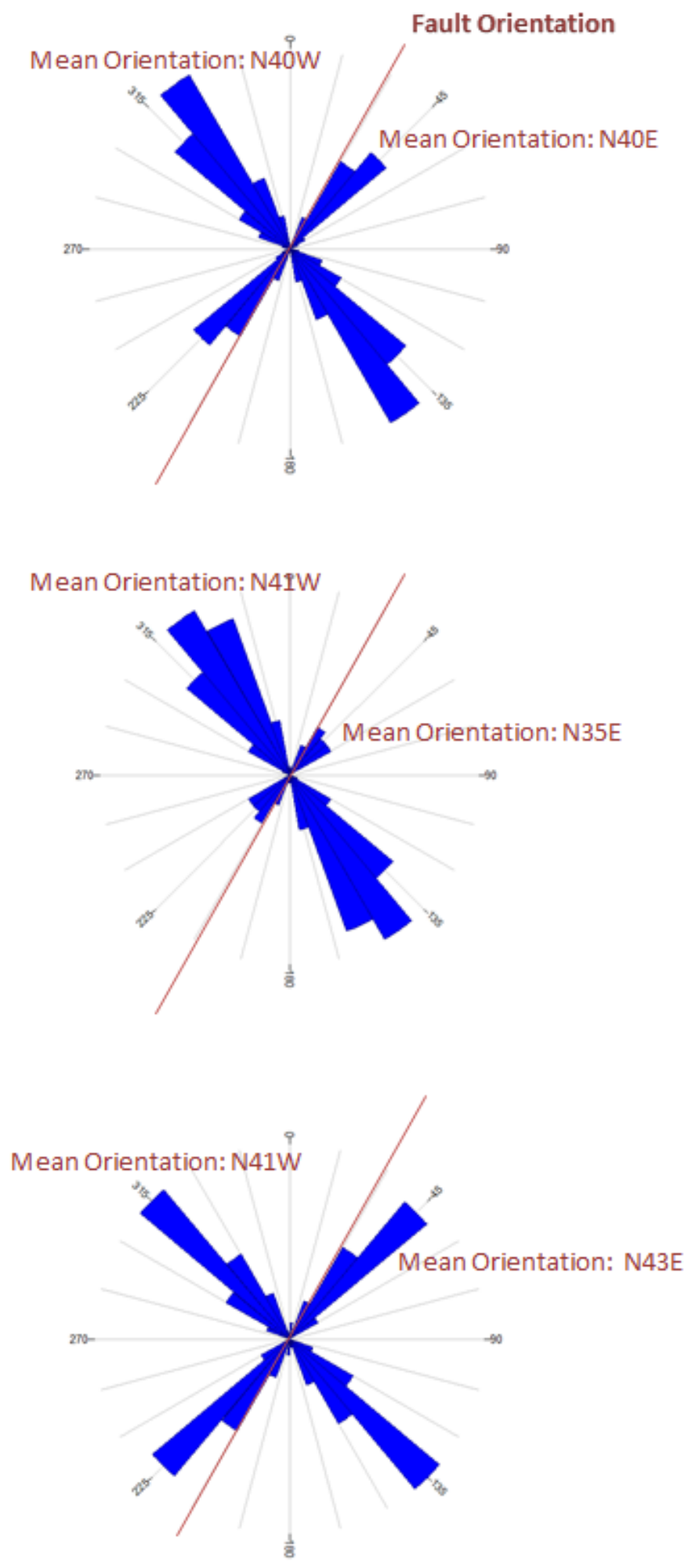

Figure 70: Note there are more occurrences of the N45W discontinuities than N51E discontinuities 
of the basin plain (Boyce and Carr, 2010); thus, most of the stratigraphy is comprised of marine shales with occasional limestone interbedded. This can be confirmed by core and well logs run in this region. This lack of lithologic variation in so much of the Upper Devonian strata (Figure 71) could have also helped facilitate out-of-zone microseismic activity, as lithology changes such as horizontal laminations and planes of weakness along bedding planes can inhibit vertical fracture growth (Maxwell, 2011; Maxwell, 2014). 


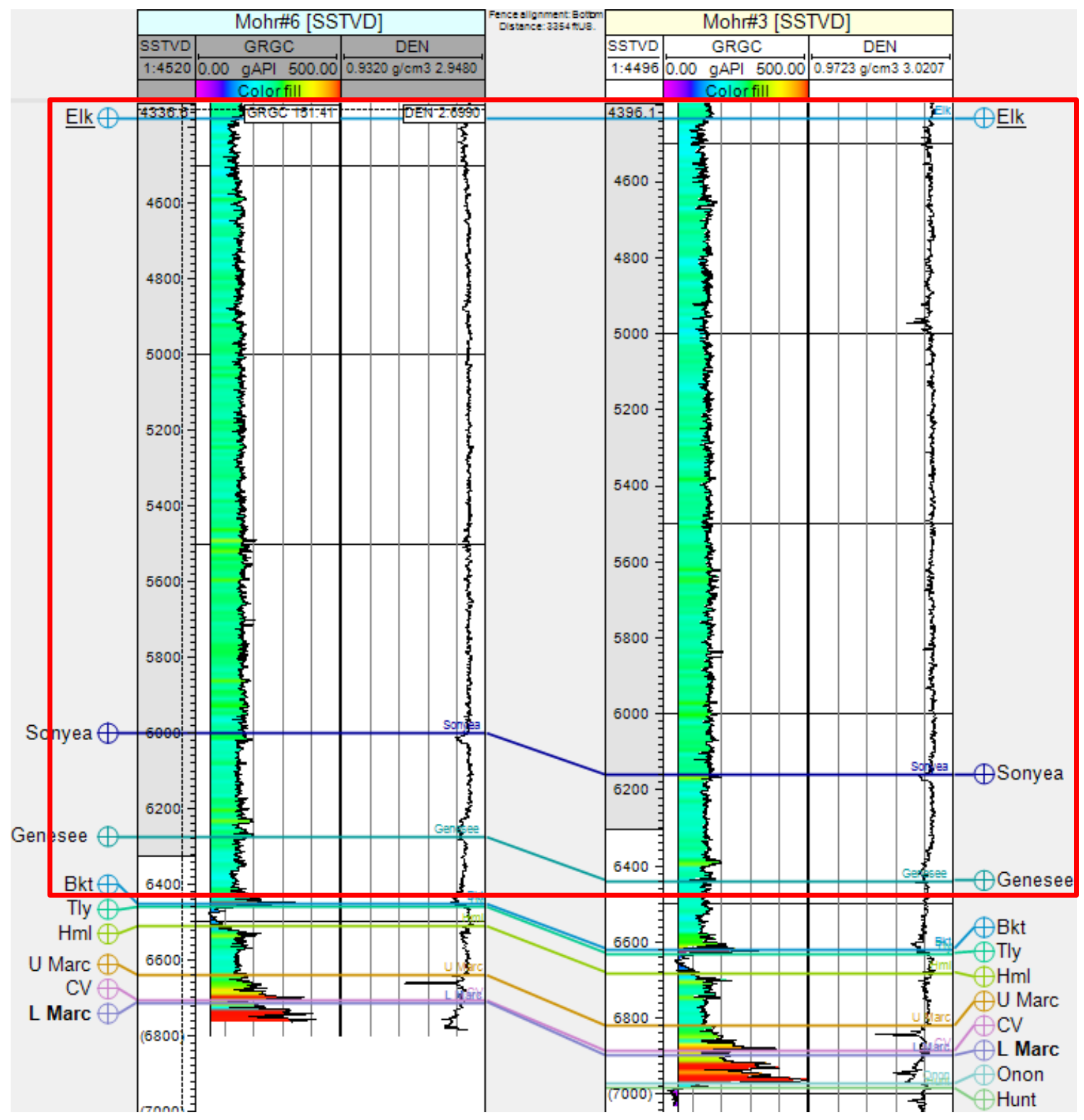

Figure 71: There is relatively very little variation in the gamma ray and density of Upper Devonian strata (red box) as examined at the Hangingwall (Mohr\#6) and footwall (Mohr\#3) monitoring wells. 


\section{Chapter 6: Conclusions \& Future Work}

\subsection{Conclusions}

An analysis of 3D seismic and microseismic data suggests that variations in local structure could be the cause of the out-of-zone microseismic activity, rather than variations in pumping parameters. However, the evidence is inconclusive and further study is needed in the area.

An analysis of pumping parameters actually shows that 1.22 times less injection energy was used for hangingwall wells where the out-of-zone microseismicity appeared (Figure 72). Injection energy did not exert a significant influence on radiated seismic energy; however, based on limited data (Figure 73), injection energy appears to be positively correlated with radiated seismic energy in the footwall wells. The correlation on the hanging wall wells, although high, suggests that very small changes of injected energy result in larger difference in radiated energy. It should be noted, however, that a greater volume of proppant was linked to greater production (Figure 74). Although a greater number of microseismic events is associated with increased radiated seismic energy release, the number of events were weakly correlated with natural gas production (Figure 75). Figures 76 and 77 show fracture energy $\left(R^{2}=.74\right)$ and number of stages $\left(R^{2}=.75\right)$ had a strong control on production; these showed the strongest relationships to production of all the criteria tested (Table 7).

These study results show that in order to optimize production, the reservoir must be sufficiently stimulated with large diffuse "fracture areas" per stage. That is not necessarily accomplished with greater injection energies or 


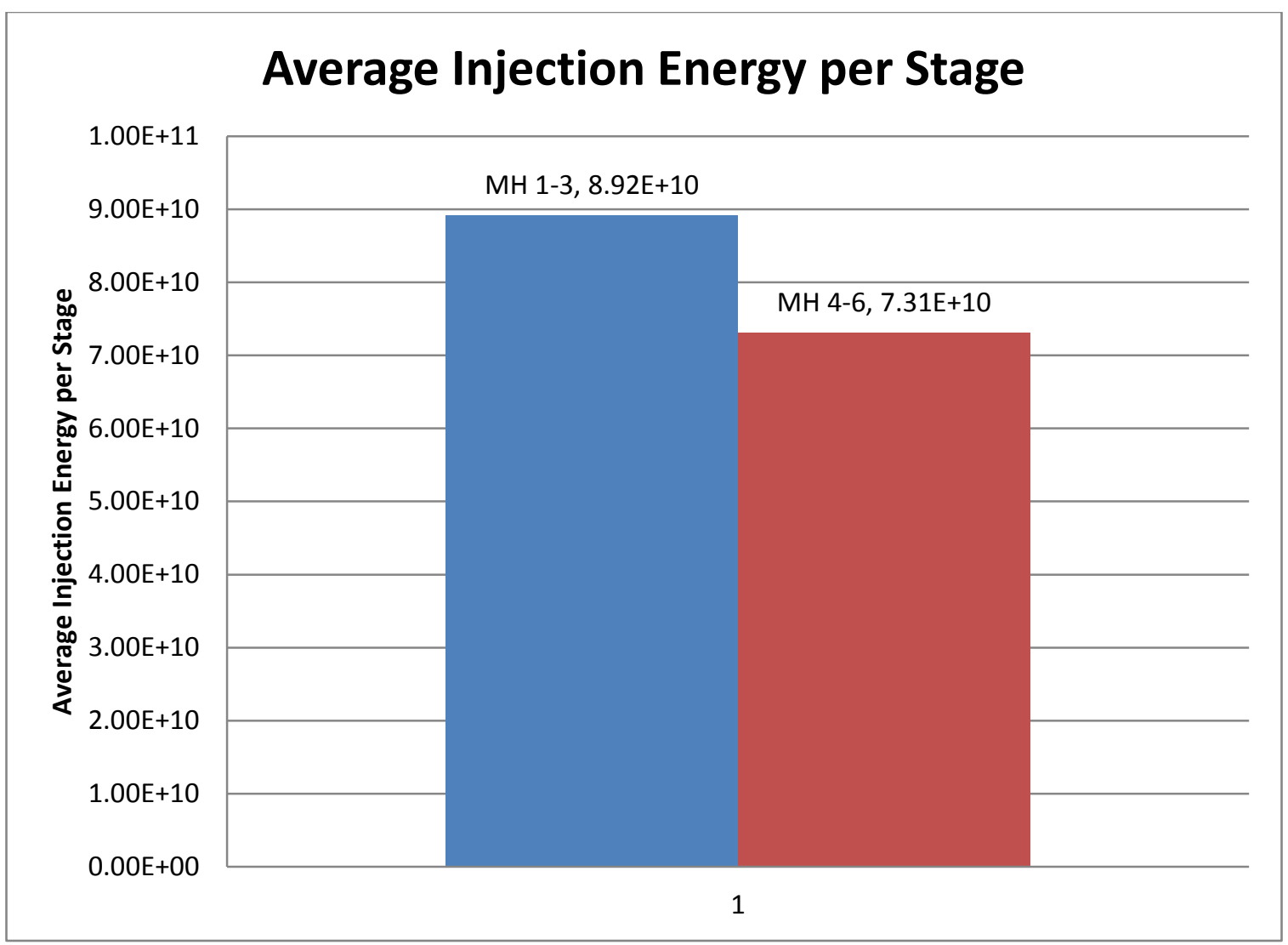

Figure 72: 1.22 times less injection energy was used for hangingwall wells where the outof-zone microseismicity appeared 


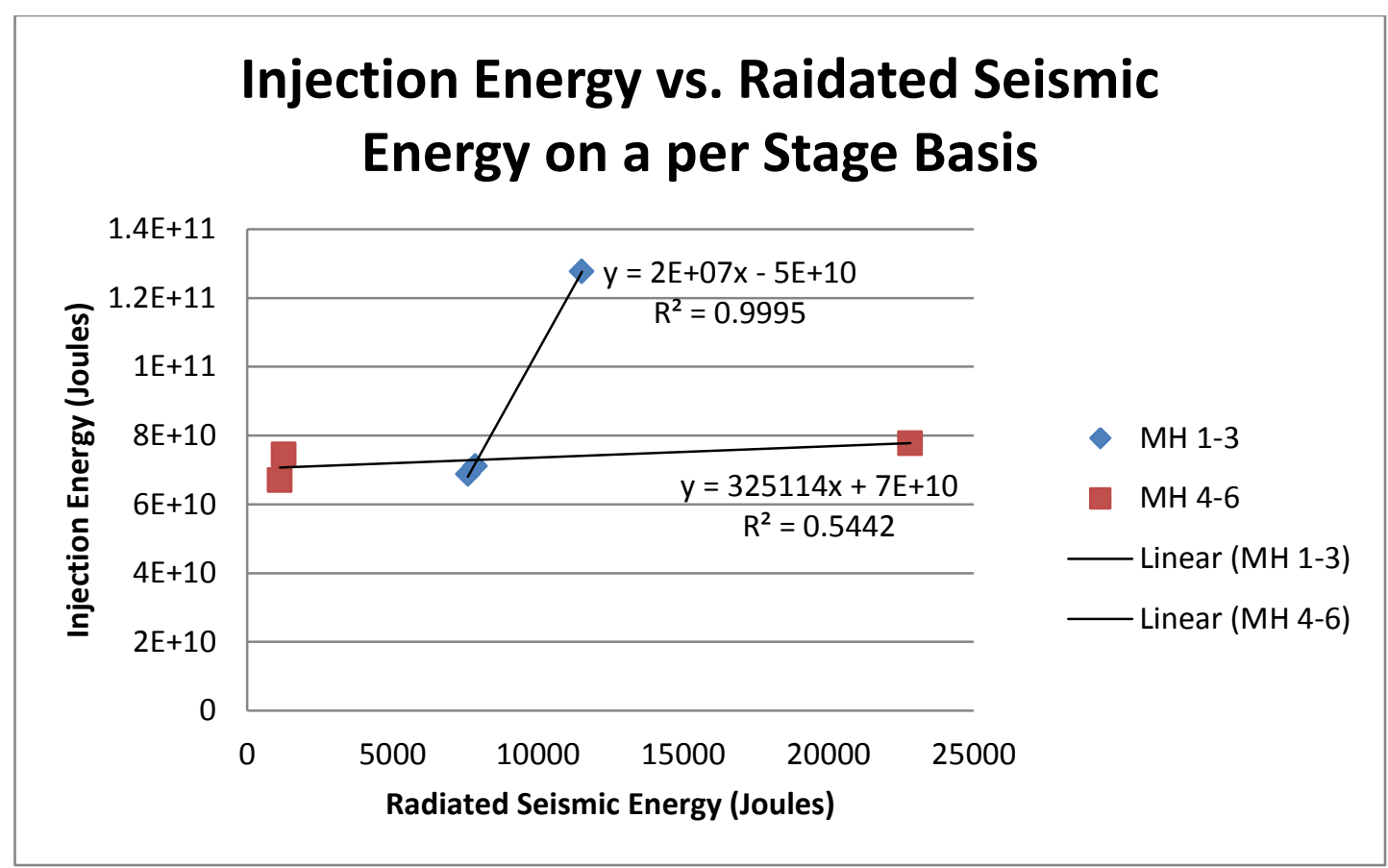

Figure 73: Injection energy displayed a very strong relationship with radiated seismic energy for footwall wells and a weaker relationship for hangingwall wells. There is some possibility of positive correlation. 


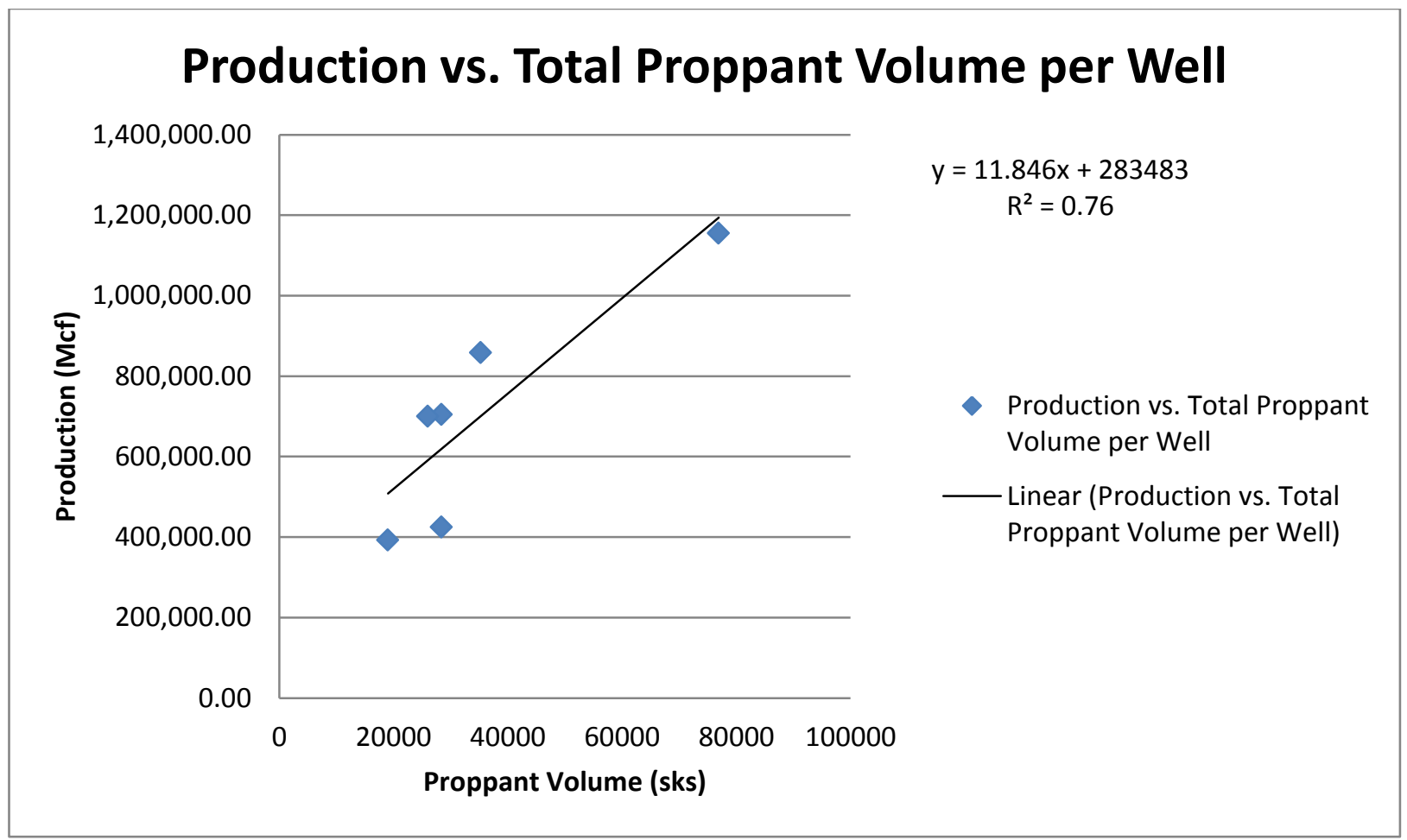

Figure 74: Greater overall proppant volume can be linked with better production. 


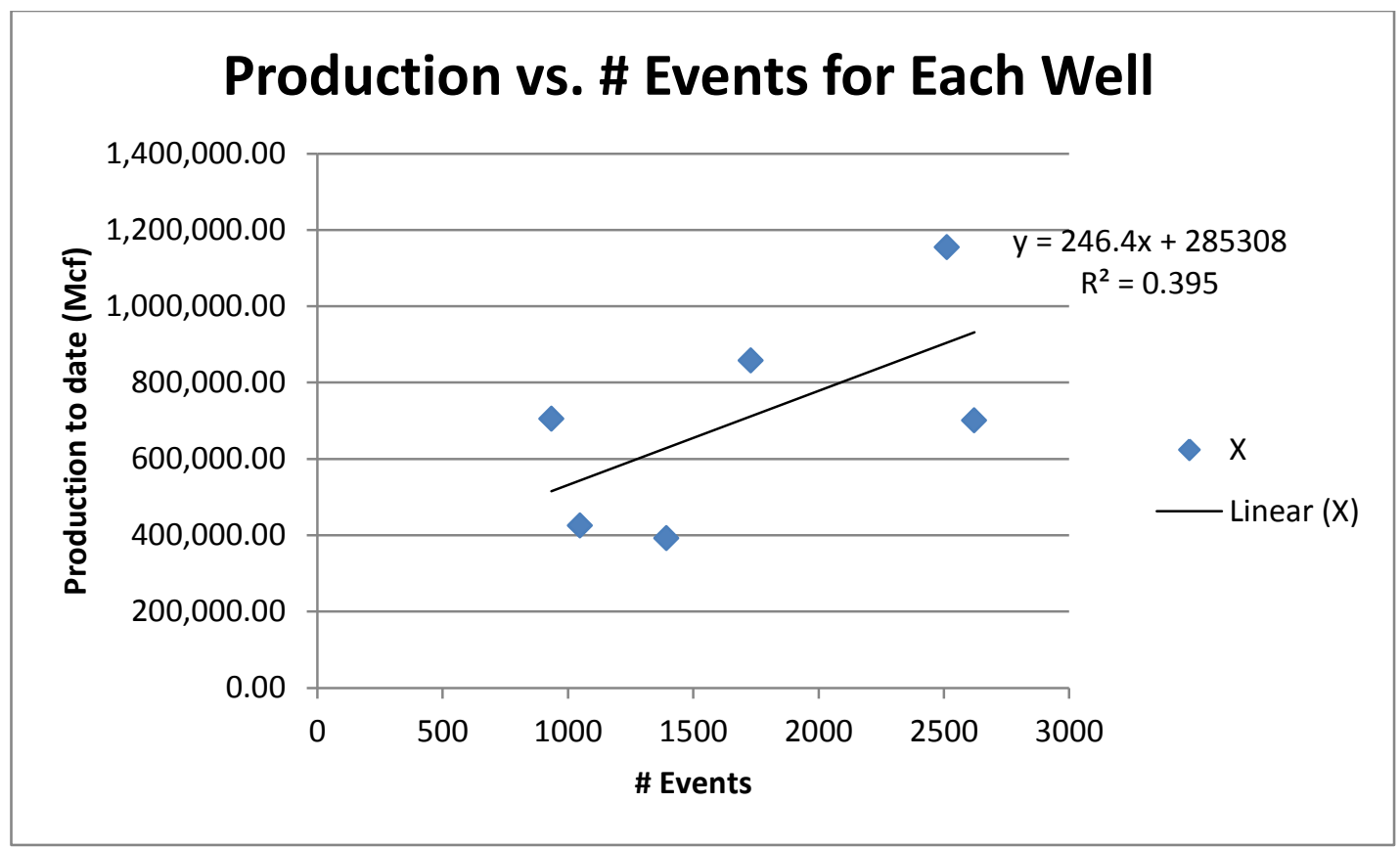

Figure 75: A positive but weak correlation is observed between production versus number of microseismic events. 


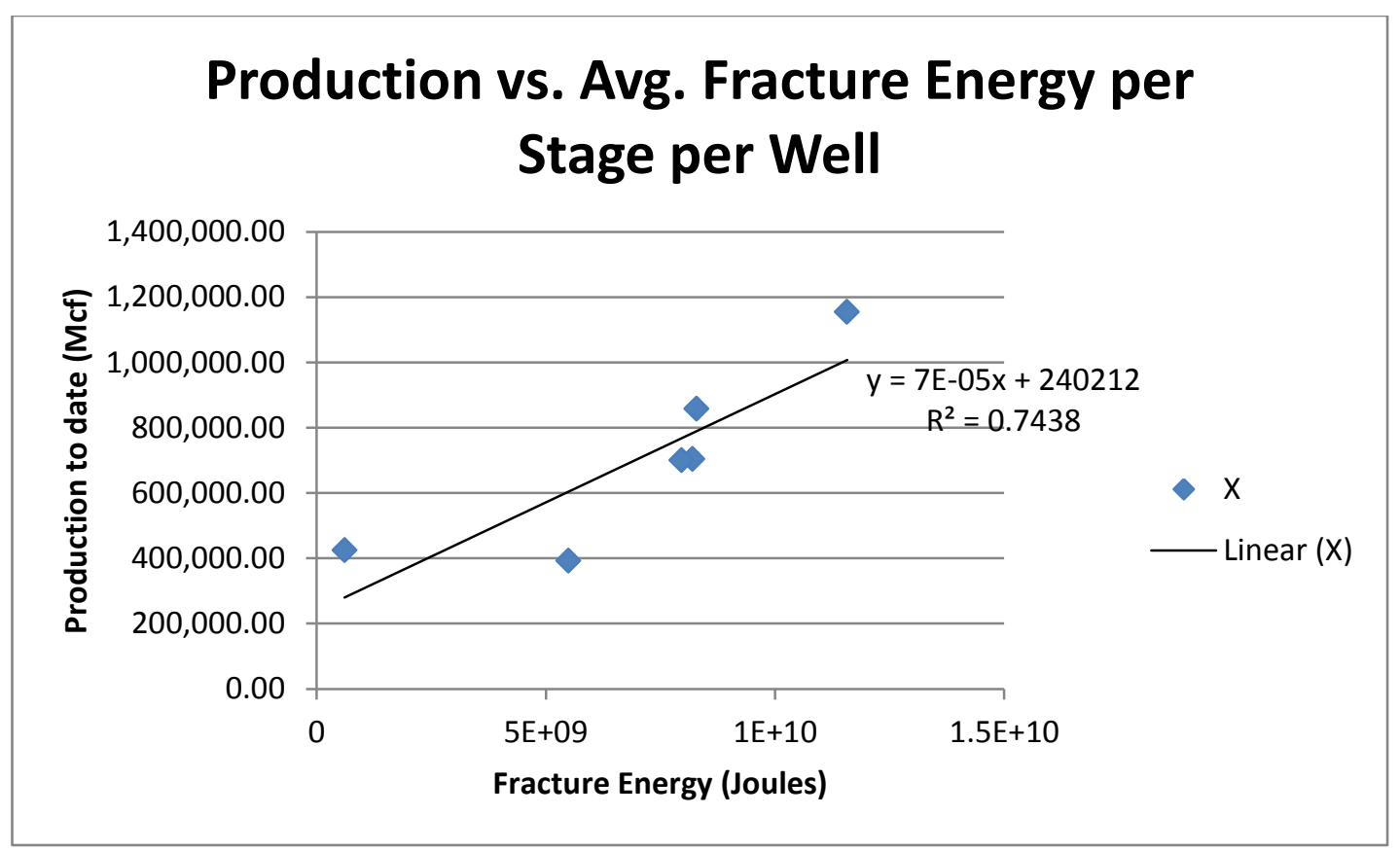

Figure 76: A fairly strong relationship exists for fracture energy and production. Microseismic event swarm lengths and heights are incorporated into the fracture energy estimate, so larger and more complex event clouds (such as those seen in footwall wells)are going to increase the fracture energy value. Greater event cloud extent means better reservoir stimulation which improves production. 


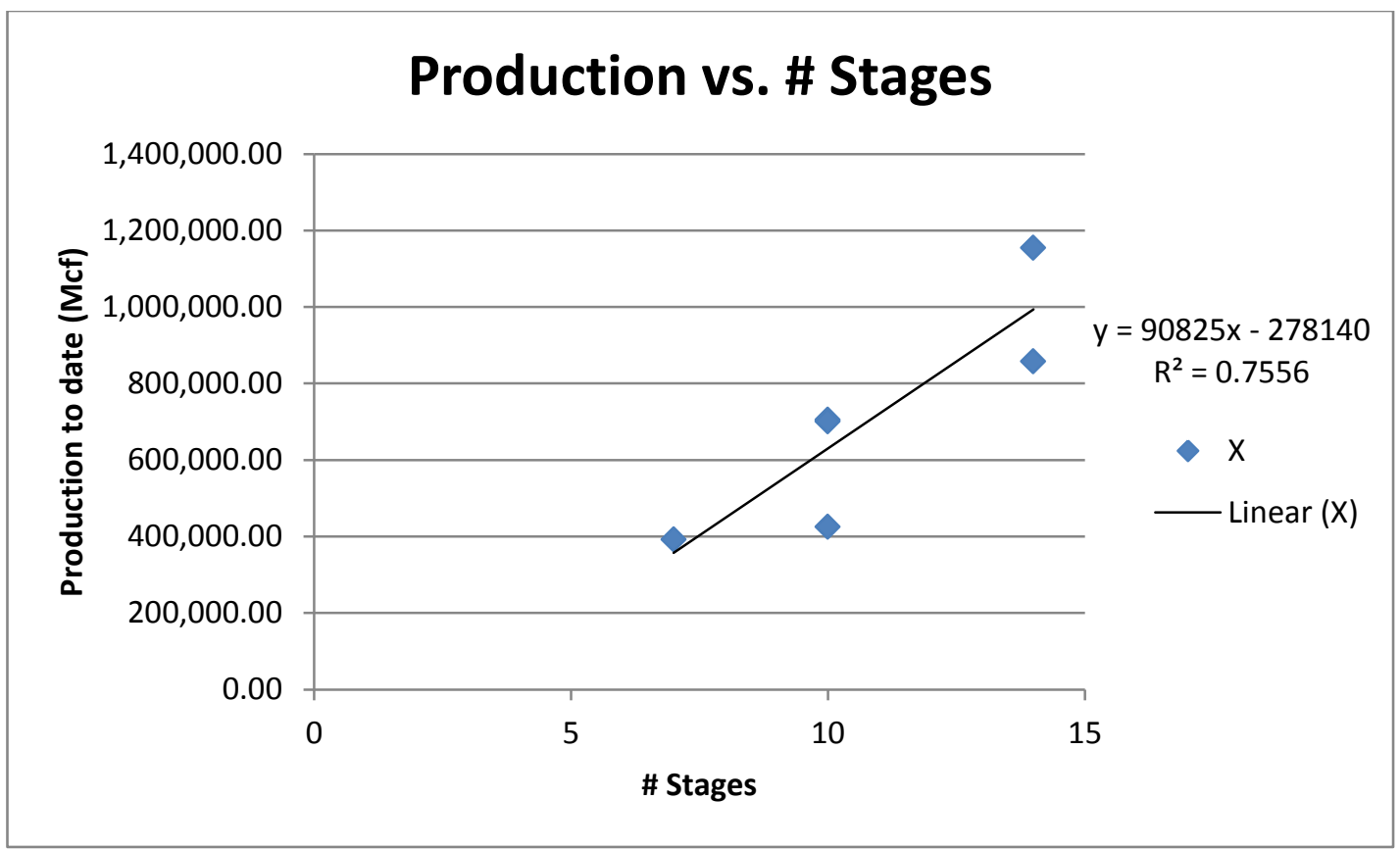

Figure 77: Increasing the number of stages appeared to have a beneficial effect on production. 


\section{Table 7: Criteria Tested and Corresponding $\mathbf{R}^{2}$ Values}

$\begin{array}{cc}\text { CRITERIA } & \text { R2 } \\ \text { Production vs. Injection Energy } & 0.45 \\ \text { Production vs. Fracture Energy } & 0.74 \\ \text { Production vs. Radiated Seismic Energy } & 0.55 \\ \text { Production vs. Avg. Magnitude } & 0.38 \\ \text { Production vs. \# Events } & 0.39 \\ \text { Production vs. \# Stages } & 0.75 \\ \text { Production vs. \% Lateral in Onondaga } & 0.22 \\ \text { Production vs. Total Proppant Volume per } & \\ \text { Well } & 0.76 \\ \text { Production vs. Avg. Vol. 80/100 per Stage } & 0.53 \\ \text { Production vs. Avg. Vol. 40/70 per Stage } & 0.52\end{array}$


greater amounts of radiated seismic energy, but rather is more likely to occur with an increased number of stages. Unfortunately we do not have microseismic data for stages 2-10 of the MH6 well, and are thus missing fracture energies for this well. Rich and Ammerman (2010) proposed that more diffuse microseismicity suggests complex fracturing due to greater interaction with pre-existing fractures, and this study has generated evidence that seems to support their conclusions.

The author recommends that wells be oriented roughly between N50W and N65W in the Lower Marcellus since microseismic events swarms followed a roughly N56E trend. Existing well orientations can be seen in Figure 78 - the average orientation of hangingwall wells is $\sim \mathrm{N} 37 \mathrm{~W}$ and the average for footwall wells is N65W. The MH5 and MH6 wells were oriented at $\sim \mathrm{N} 29 \mathrm{~W}$ and produced poorly; stages 3 and 6 of the MH5 also generated events that propagated along the wellbore - this could have affected production and can compromise wellbore stability. The MH1 and MH2 wells produced very well and were spaced $\sim 800$ feet apart; the author recommends maintaining a well spacing close to this value and stage spacing at $\sim 330$ feet as to sufficiently stimulate and drain the reservoir.

Microseismic events swarms appeared to follow structural grain seen in $t^{\star}$ attenuation-based seismic discontinuity maps (Wilson et al., 2014a); which suggests discontinuity mapping could provide useful insights as to where zones of increased fracture intensity may be and in which orientations future horizontal wells should be positioned. The TVTAS (time-variant trace amplitude slice) seismic volume (Wilson et al., 2014a) showed complex faulting around the area 


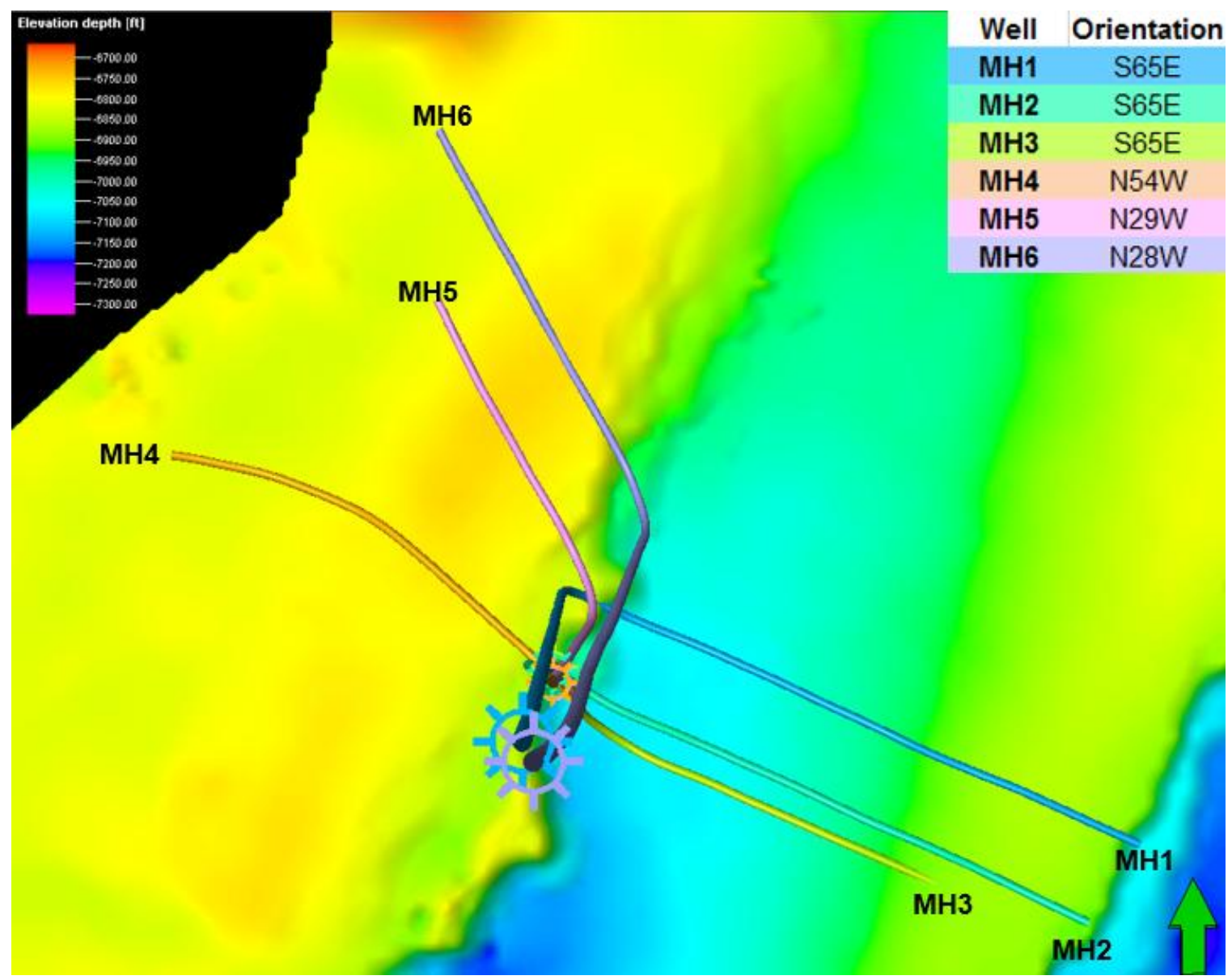

Figure 78: Wells in study area shown with orientations (upper right hand corner). 
of out-of-zone microseismic activity. The lack of connecting events from all stages in treated wells suggests these events may not be indicative of a fluid connection between reservoir and out-of-zone events. While the events may not be indicative of a fluid connection, other aseismic processes (creep, smallmagnitude events, seismicity the instrumentation is not tuned to detect) could be occurring and thus a fluid connection cannot be completely ruled out.

Significant changes in radiated seismic energy released by neighboring stages are also interpreted to be a result of local structural variations. The author was not able to make a correlation between discontinuities seen in the 3D seismic data and sudden large increases or drops in radiated seismic energy. More work should be done in this area to see what other factors may play a part in these discrepancies in radiated seismic energy release between neighboring stages, since injection energy did not seem to be a factor on a per stage basis. There was, however, a correlation between injection energy vs. radiated seismic energy for footwall wells (see Figure 38); greater injection energy yielded greater radiated seismic energy.

One can see in the TVTAS seismic volume that more vertical faulting is present throughout the Upper Devonian while detachment and low angle thrust faults chiefly accommodate shortening in the Middle Devonian and Salina section. Shumaker (2002) also mentions that shortening is accommodated differently by rocks above the Tully Limestone vs. below the Tully Limestone. The pattern of out-of-zone microseismicity present in the Upper Devonian is suggestive of rupture along extensive vertical fracture zones and small faults. 
Faults seeded by Early Cambrian rifting were re-activated during subsequent orogenic events (Wilson, 2000). Deeper faults which initially displayed a normal sense of motion experienced slight reverse movement brought by shelf loading throughout the Paleozoic combined with compression generated by the Taconic Orogeny. Isochron maps generated for this study show where thickening occurred as a result of shelf loading as well as how deeper faults acted as seed points for shallow faults (see Figure 62).

Mountains built throughout the Taconic Orogeny eroded during the Silurian and probably to a greater degree during the Devonian Acadian Orogeny (the Marcellus Shale was deposited throughout the Acadian). Compressive stress as a result of Avalonian terranes colliding with Laurasia caused deformation and detachment to occur in incompetent units of the Martinsburg Formation and Utica Shale and salts of the Salina Group. The N25E oriented thrusts that cut the Upper Silurian and most of the Devonian section in the area are interpreted to be a result of underthrusting and subsequent detachment related to the Alleghenian Orogeny. The triangle zone associated with the Chestnut Ridge anticline transferred tectonic transport from older incompetent units (such as the Martinsburg Formation and Utica Shale) up into younger incompetent units such as salts of the Salina Group and Upper Devonian shales (Shumaker, 2002). This is why we see more shortening in the Upper Silurian and Devonian sections (Figure 79). Identifying where detachment zones exist is important for future well planning, as detachment zones can act as zones of increased porosity and permeability in an otherwise low permeability reservoir. 
$\%$ Shortening of Various Stratigraphic Markers

Elk Group

- Sonyea Group

- Top of Hamilton Group

- Marcellus Shale

- Juniata Formation

- Trenton Limestone
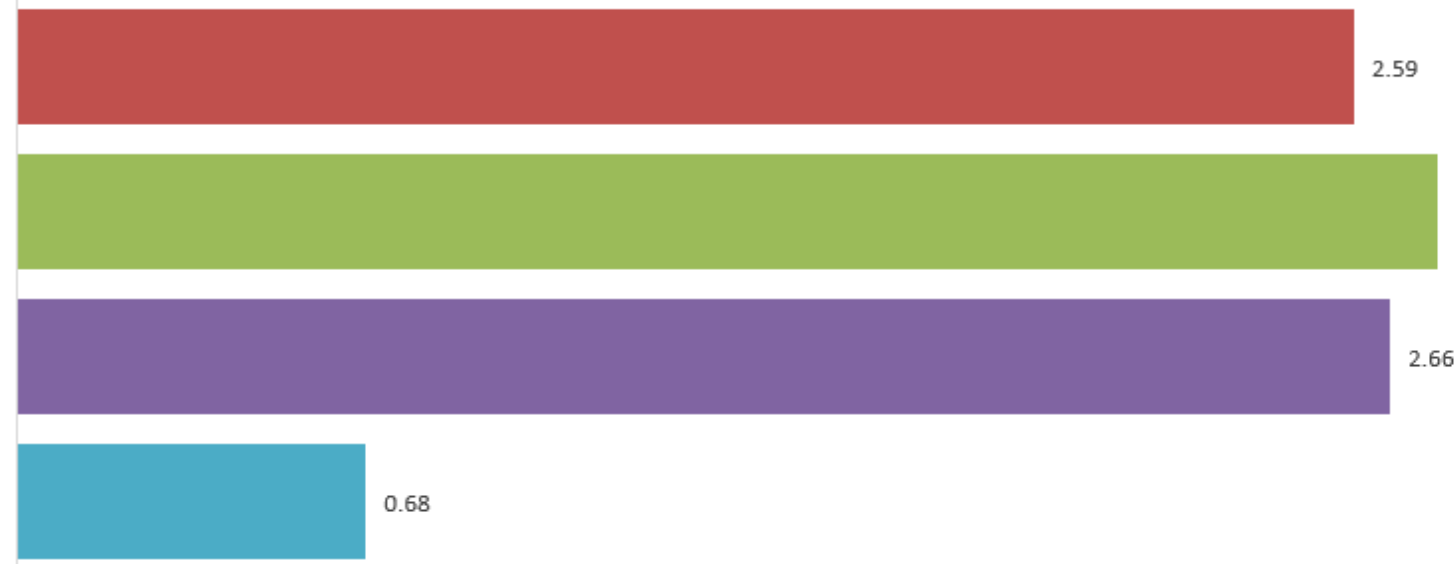

0.52

Figure 79: Shortening is chiefly accommodated by Middle and Upper Devonian strata. 


\subsection{Future Work}

\subsubsection{Structural and Stratigraphic Analyses}

This region's varied structural history greatly complicates how the reservoir may react to drilling and hydraulic fracturing, so it is essential to explore how variations in local stress fields affect completions - especially in zones of severe detachment such as those identified towards the eastern portion of the survey. The company $(\mathrm{ECA})$ has drilled wells into detachment zones within the Marcellus identified earlier in the study (Figure 80). Gathering microseismic data for wells in this region would help determine how detachment zones react to a hydraulic fracturing treatment. Shumaker (2002) states that detachment zones, especially those associated with Devonian shales, are important gas-producing horizons due to the enhanced fracture porosity.

A pre-stack inversion of the 3D seismic data could aid in creating a model which could help determine elastic properties of the reservoir. Being familiar with the elastic properties of the reservoir (such as Poisson's ratio, Young's modulus, shear modulus...) could reduce drilling risk and allow engineers to adjust completions strategies as needed based on model results. This knowledge may help identify which stratigraphic zones are more or less likely to rupture, ascertain where better hydraulic fracturing targets may lie, and determine how engineers may improve upon existing completions strategies. To the author's knowledge the seismic survey used has not been preconditioned with 5D interpolation (interpolation in 5 dimensions: inline, crossline, offset, azimuth, frequency); this preprocessing step would be highly beneficial if one were to 


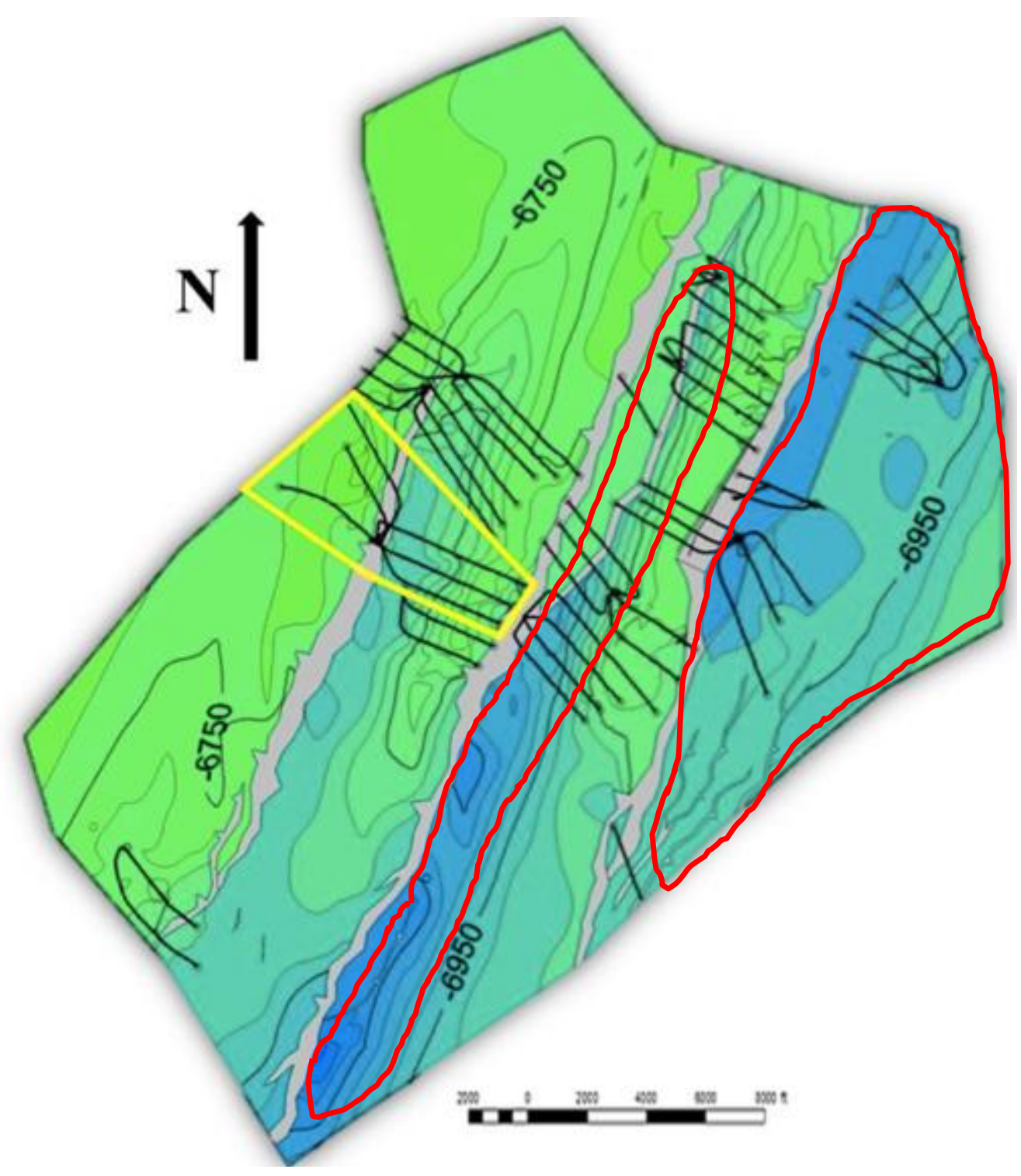

Figure 80: Wells have been drilled in detachment zones (red outline) in the study area. 
conduct a pre-stack inversion on this data set or conduct AVO analyses, as 5D interpolation honors amplitude variations with offset and azimuth, decreases bin size, improves resolution, and improves imaging results (Chopra and Marfurt, 2013). Enhancing resolution of the seismic data and eliminating processing artifacts is a must if one plans to build an inversion model - a model is only as good as the information it is fed.

\subsubsection{Seismic Attributes}

One of the setbacks the author experienced involves an issue with the depth-converted seismic, possibly caused by a glitch in Petrel (Figure 81). This is something that needs to be addressed and fixed if possible, as these lines are obscuring major faults in the region and the damage zones surrounding them. The seismic discontinuities generated by the depth conversion skew most attribute results (Figure 82). However it should be noted that the conversion to depth was accurate in the vicinity of the Mohr wells and allowed for accurate placement of the microseismic events in the context of subsurface stratigraphy and structure in the area (Wilson, written communication).

\subsubsection{Microseismic Events}

Additional analysis of microseismic events is recommended. Some waveforms from picked events were very erratic (Figure 83), so it would definitely be beneficial to future interpretations to re-process event hypocenters that were determined in the field. The author will not be re-processing events, but plans on using higher signal-to-noise ratio events in part of the interpretation. The author had traveled to Blacksburg, VA to discuss revisions made to the velocity model 


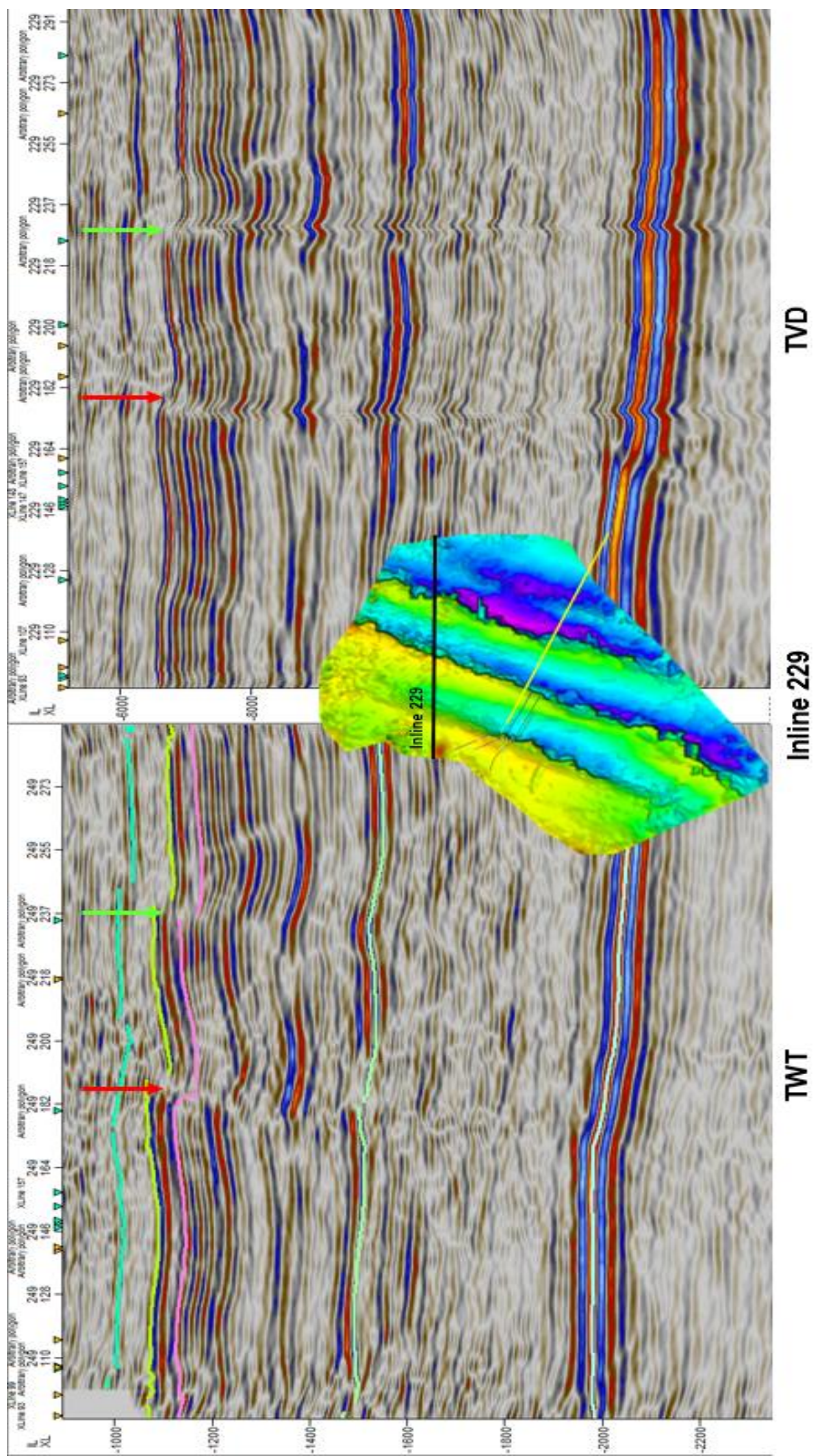

Figure 81: Depth-converted seismic skews features along 3 large thrusts in the region 


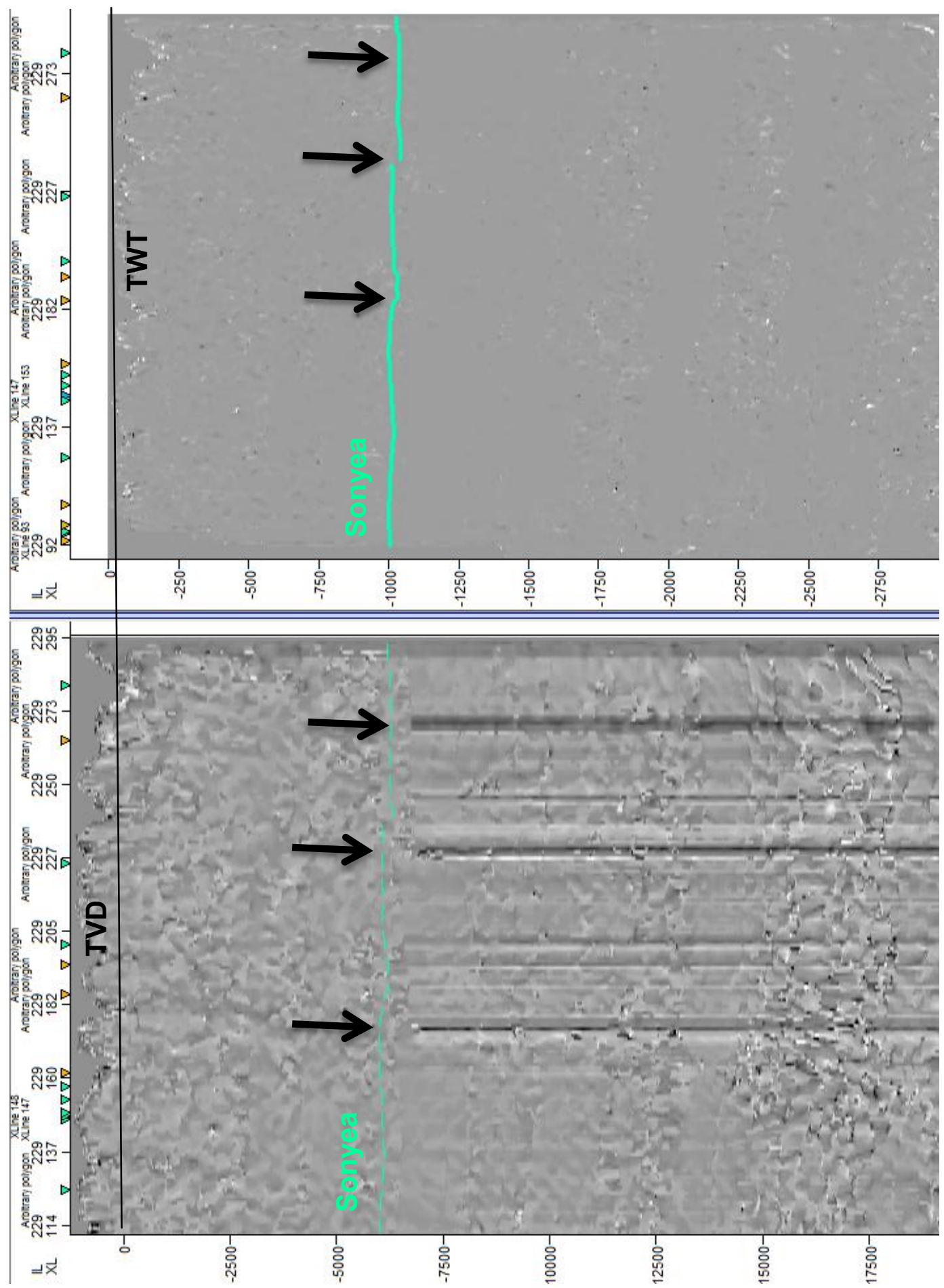

Figure 82: Large lines obscure fault locations on the depth-converted volume. 3D Curvature shown for both volumes on Inline 229 


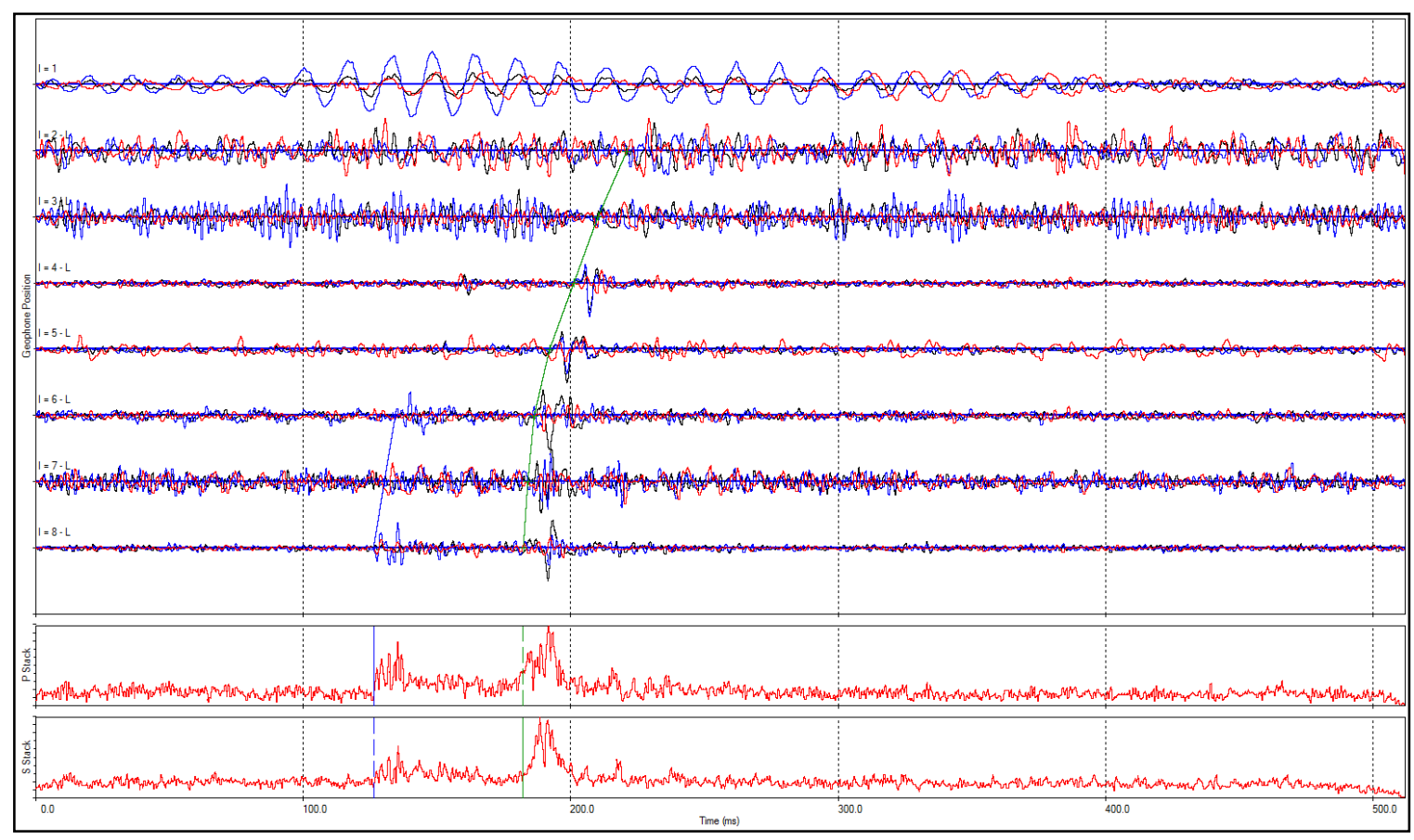

Figure 83: A poor signal-to-noise ratio event (MH1 Stage 10). The uppermost geophone appears to be resonating, and $P$ and $S$ wave arrival times were not able to be constrained for each geophone. 
with Dr. Erik Westman (Virginia Tech). No revisions were made to the velocity model and the geometry of the monitoring set up did not allow for double difference tomographic modeling. 


\section{References:}

Alfaro, Jose Camara et al. "Reducing Exploration Risk." Oilfield Review (2007): Web. 18 July 2013

Ardoso, J Oaquín C, and Geophysical Consultant. "Geomechanical and Geometric Seismic Attributes in an Interpretation Workflow for Characterization of Unconventional Reservoirs." The Leading Edge April (2013): Print.

Baig, A M, Ted Urbancic, and Gisela Viegas. "Do Hydraulic Fractures Induce Events Large Enough to Be Felt on Surface?” CSEG Recorder October (2012): p. 40-44. Web. 8 May 2013.

Blakey, R.C., 2008, Gondwana paleogeography from assembly to breakup-A 500 m. y. odyssey, in Fielding, C.R., Frank, T.D., and Isbell, J.L., eds., Resolving the Late Paleozoic Ice Age in Time and Space: Geological Society of America Special Paper 441, p. 1-28, doi: 10.1130/2008.2441(01).

Boswell, Ray. "Play UDs: Upper Devonian Black Shales." The Atlas of Major Appalachian Gas Plays (1996): p. 93-99. Print.

Boyce, Matt and Carr, Timothy, "Stratigraphy and Petrophysics of the Middle Devonian Black Shale Interval in West Virginia and Southwest Pennsylvania." AAPG Convention, New Orleans, Louisiana, April 11$14,2010$.

CGG Veritas. http://www.cgg.com/default.aspx?cid=1363

Chopra, Satinder, and K. J. Marfurt. Pre-conditioning seismic data with 5D interpolation for computing geometric attributes. Houston, TX: Society of Exploration Geophysicists Annual Meeting, 2013.

Chopra, Satinder, and K. J. Marfurt. Seismic Attributes for Prospect Identification and Reservoir Characterization. Tulsa, OK: Society of Exploration Geophysicists, 2007. Print.

Das and Zoback, Long-period, long-duration seismic events during hydraulic stimulation of shale and tightgas reservoirs - Part 1: Waveform characteristics." Geophysics, 2013, v. 78

deWitt, Wallace, Jr., Roen, J.B., and Wallace, L. G., 1993, Stratigraphy of Devonian black shales and associated rocks in the Appalachian basin, in Roen, J.B., and Kepferle, R.C., 1993, Petroleum geology of the Devonian and Mississippian black shale of eastern North America: U.S. Geological Survey Bulletin 1909B, p. B1-B57.

Donahoe, Thomas Bradley. "3D Seismic , Attribute-Assisted, Structural Interpretation for Hydrocarbon Exploration and Production : Southwest Pennsylvania , Central Appalachian Basin ." (2011): Print.

Fisher, Kevin, and Norm Warpinski. "SPE 145949 Hydraulic Fracture-Height Growth : Real Data." Society of Petroleum Engineers November (2011): Print.

Gao, D. (2004). Texture model regression for effective feature discrimination: Application to seismic facies visualization and interpretation. Geophysics, 69. 958-967

Halliburton. "A Case Study: Improving horizontal completion efficiency and production." (2012)

Hatcher Jr., Robert D. "The Appalachian orogen: A brief summary." Geological Society of America Memoirs, 2010, 206, p. 1-19.

Heidbach, O., Tingay, M., Barth, A., Reinecker, J., Kurfeß, D. and Müller, B., 2008, The World Stress Map database release. doi:10.1594/GFZ.WSM.Rel2008

Hulsey, B.J; Cornette, Brian; Pratt, David. "Surface Microseismic Mapping Reveals Details of the Marcellus Shale." SPE International (2010).

Jacobi, Robert; Starr, Joel; Jackson, David; Warner, Travis; Eckert, Craig "Acadian Sliding: Anatomy of Styles for Gravitational Fault Development and Hydrocarbon Migration in the Western Appalachian Foreland Basin of Pennsylvania and West Virginia." Search and Discovery (2013).

Pascal Klein, Loic Richard, and Huw James. "3D Curvature Attributes: A New Approach for Seismic Interpretation." first break April (2008) v. 26.

Landmark. "Learning PostStack and PAL." (2009): v. 2, rev. K, p. 6-20 - 6-21. Print.

Maxwell, Shawn C. "Hydraulic Fracture Height Growth." CSEG Recorder November (2011): p. 18-21. Print.

Maxwell, Shawn. "Microseismic Imaging of Hydraulic Fractures : Improved Engineering of Unconventional Shale Reservoirs" 2014 Distinguished Instructor Short Course: p. 116. Print. 
Maxwell, Shawn. "Microseismic Imaging of Hydraulic Fractures : Snap , Crackle and Pops of Shale." CSEG Recorder March (2012): p. 9-11. Print.

Maxwell, Shawn and Norton, Mark. "The Impact of Reservoir Heterogeneity on Hydraulic Fracture Geometry: Integration of Microseismic and Seismic Reservoir Characterization." Search and Discovery (2012).

"Definition of pheromone". MedicineNet Inc. 19 March 2012.

May, Paul R. "Pattern of Triassic-Jurassic Dlabase Dikes around the North Atlantic in the Context of Predrift Position of the Continents." (1971).

Milici, R. C. "Stratigraphic History of the Appalachian Basin." The Atlas of Major Appalachian Gas Plays (1996): p. 4-7. Print.

Miller, Cameron. "Horizontal Well Planning Within the Woodford and Other Gas Shales Within the MidContinent, USA." PowerPoint presentation. Retrieved from http://www.ogs.ou.edu/pdf/GSMillerS.pdf (2013)

Patel, Hemali; Johanning, John; Fry, Michael. 2013, Borehole microseismic, completion and production data analysis to determine future wellbore placement, spacing and vertical connectivity, Eagle Ford Shale, South Texas: Unconventional Resources Technology Conference, URTeC, Proceedings.

Stein Inge Pedersen, Trygve Randen, Lars Sonneland, and Oyvind Steen. "Automatic Fault Extraction Using Artificial Ants." Mathematics in Industry v. 7, 2005, pp 107-116.

Rich, J.P., and M. Ammerman, 2010, Unconventional geophysics for unconventional plays: Unconventional Gas Conference, SPE 131779.

Schlumberger Petrel 2012.3 User Manual

Shumaker, R.C., and T.H. Wilson, 1996, Basement structure of the Appalachian foreland in West Virginia: its style and effect on sedimentation, in B.A. van der Pluijm and P.A. Catacosinos, eds., Basement and basins of eastern North America: Geological Society of America Special Paper 308, p. 141-155.

Shumaker, R.C., 2002, "Reinterpreted Oriskany Structure at the North Summit Field, Chestnut Ridge Anticline, Pennsylvania." AAPG Bulletin

Thachaparambil, MV, R Wu, and D Wang. "Automated Extraction of Fracture Network from 3D Poststack Seismic Data for Fracture and Fault Characterization and Modeling." The Leading Edge April (2013): p. 380-384. Web. 8 May 2013.

Trygve Randen, Erik Monsen, Claude Signer, Arve Abrahamsen, Jan Ove Hansen, Toril Sæter, and Jürgen Schlaf (2000) Three-dimensional texture attributes for seismic data analysis. SEG Technical Program Expanded Abstracts 2000: pp. 668-671.

Warpinski, Norm. "Microseismic Monitoring: Inside and Out." Journal of Petroleum Technology November (2009): p. 80-85. Web. 8 May 2013.

Wheeler, H.E., 1963, Post-Sauk and pre-Absaroka Paleozoic stratigraphic patterns in North America: AAPG Bulletin, v. 47, no. 8, p. 1497-1526.

Wilson, Thomas H.; Hart, Ariel K.; Sullivan, Peter A. "Characterization of Marcellus shale fracture systems for fracture model development using 3D seismic and microseismic data." SEG Annual Meeting and International Exposition (2014a)

Wilson, Thomas H.; Hart, Ariel K.; Sullivan, Peter A. "Proximal cross-well microseismicity as a possible indicator of drainage efficiency and critically stressed strata." SEG Annual Meeting and International Exposition (2014b)

Wilson, Thomas H.; Hart, Ariel K.; Sullivan, Peter A. "3D Seismic Observations of Out-of-Zone Microseismic Behavior in the Marcellus Shale." The American Oil and Gas Reporter (2014c)

Wrightstone, Gregory. "Marcellus Shale - Geologic Controls on Production." Search and Discovery September (2009): p. 1-10. Web. 18 July 2013.

Zagorski , W; Bowman, D.; Emery, M.; Wrightstone, G. "An Overview of Some Key Factors Controlling Well Productivity in Core Areas of the Appalachian Basin Marcellus Shale Play." AAPG Search and Discovery (2011): Web. 16 July 2013 


\section{APPENDIX A:}

\section{MOHR A 6MH (MH6) Treatment Curves}

\section{Stage 1}

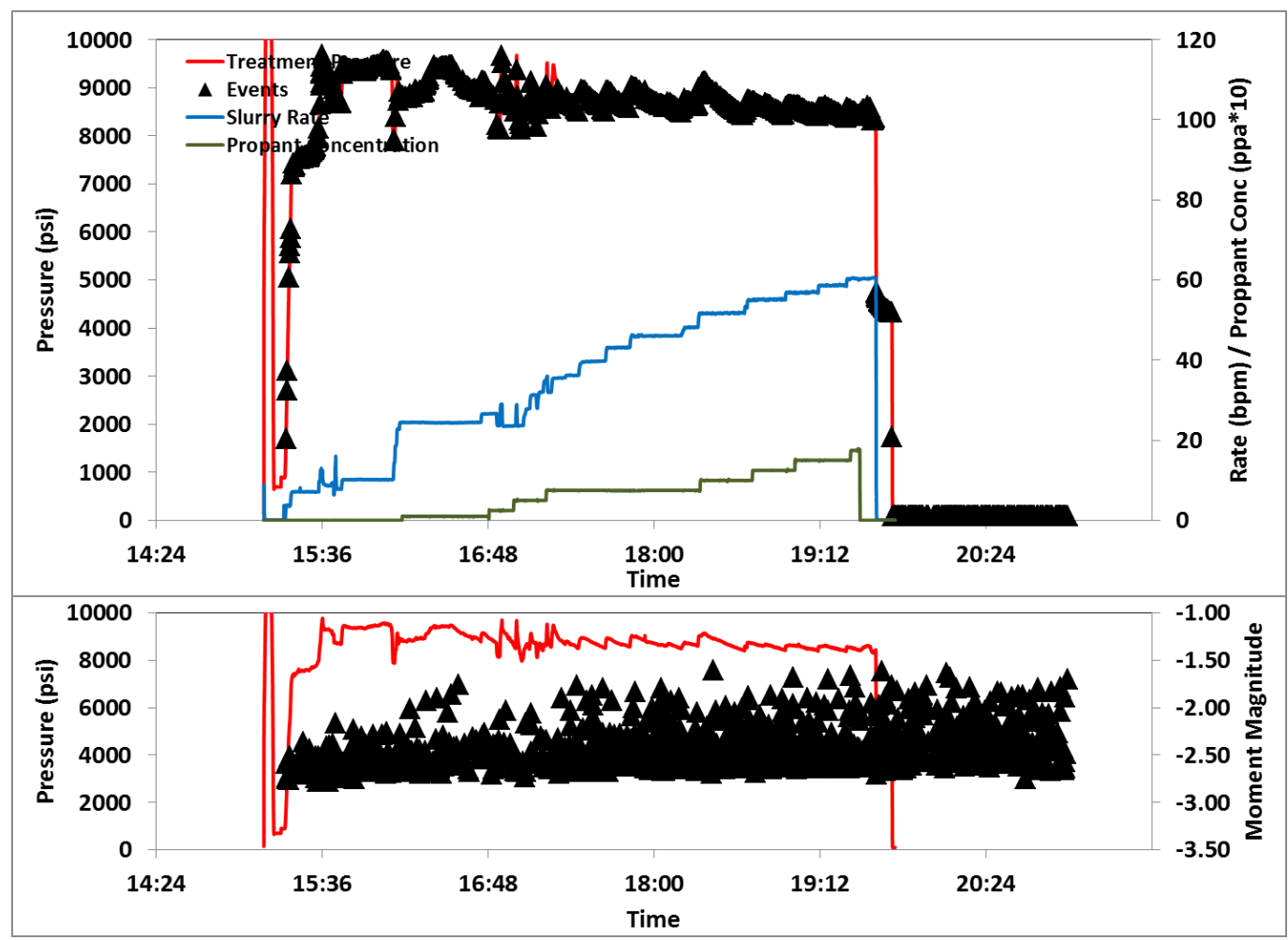


TVD vs. Microseismic Event Count (Images courtesy Weathertord)

\section{MOHR A 6MH (MH6)}

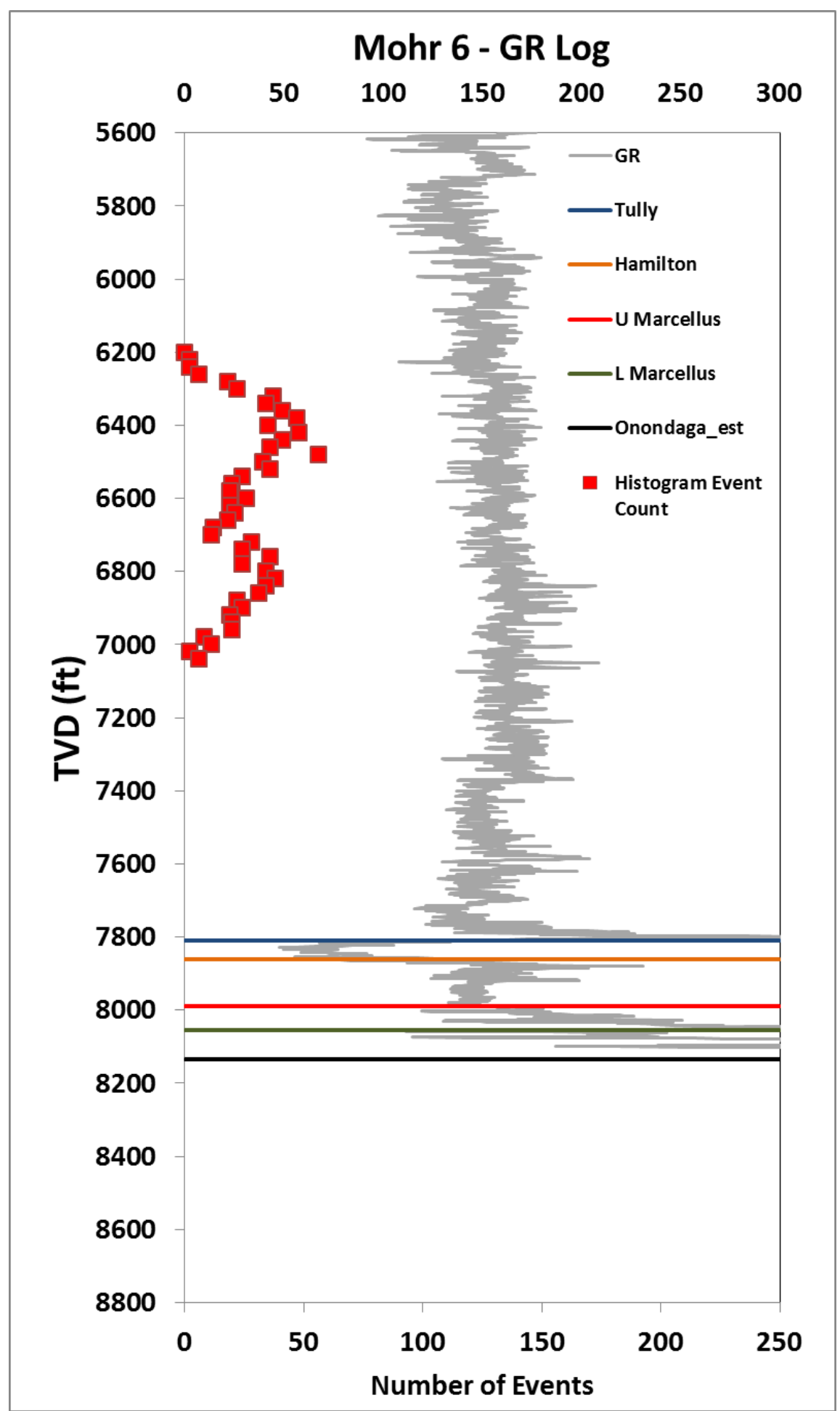


Microseismic Events Colored by Stage $\mathbf{e}_{\text {(mages courtesy Weatherford) }}$

\section{MOHR A 6MH (MH6)}

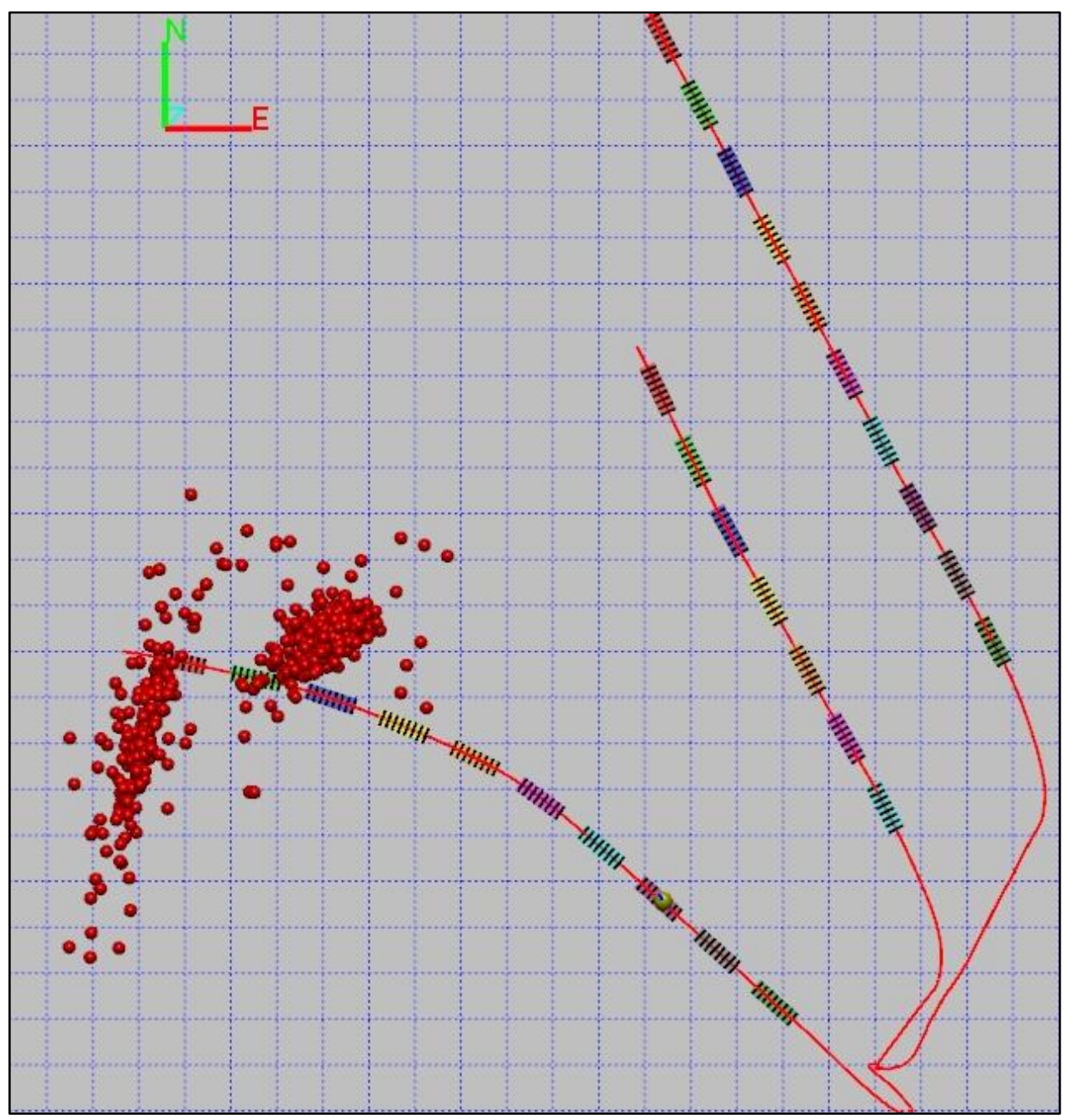

Stage 1

Stage 2

Stage 3

Stage 4

Stage 5

Stage 6

Stage 7

Stage 8

Stage 9

Stage 10

Stage 11

Stage 12

Stage 13

Stage 14 